
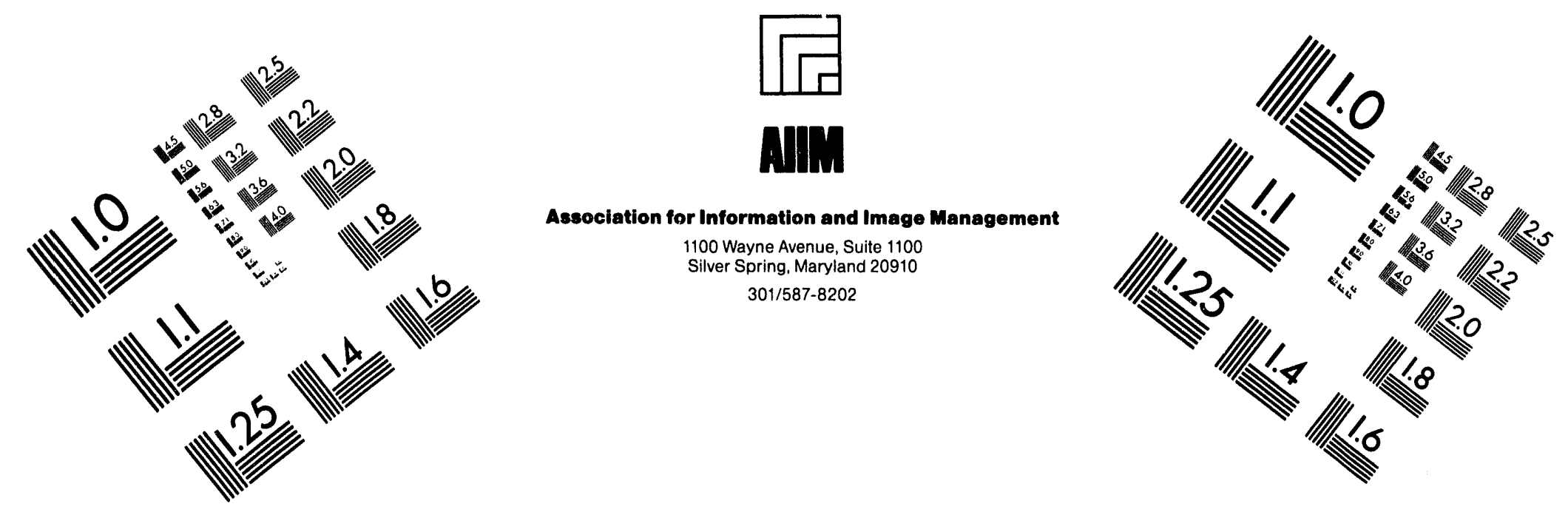

\title{
Centimeter
}

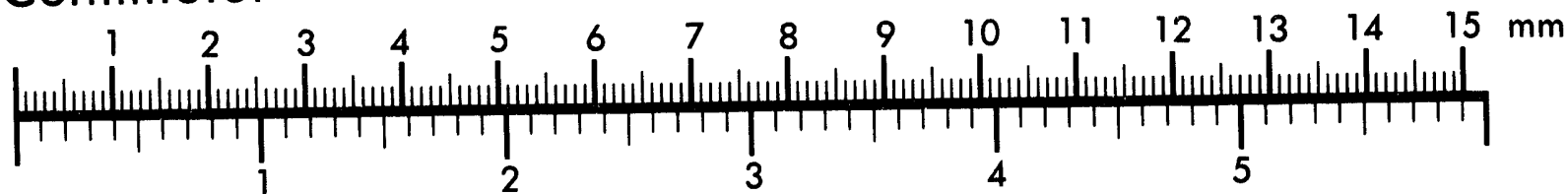
Inches
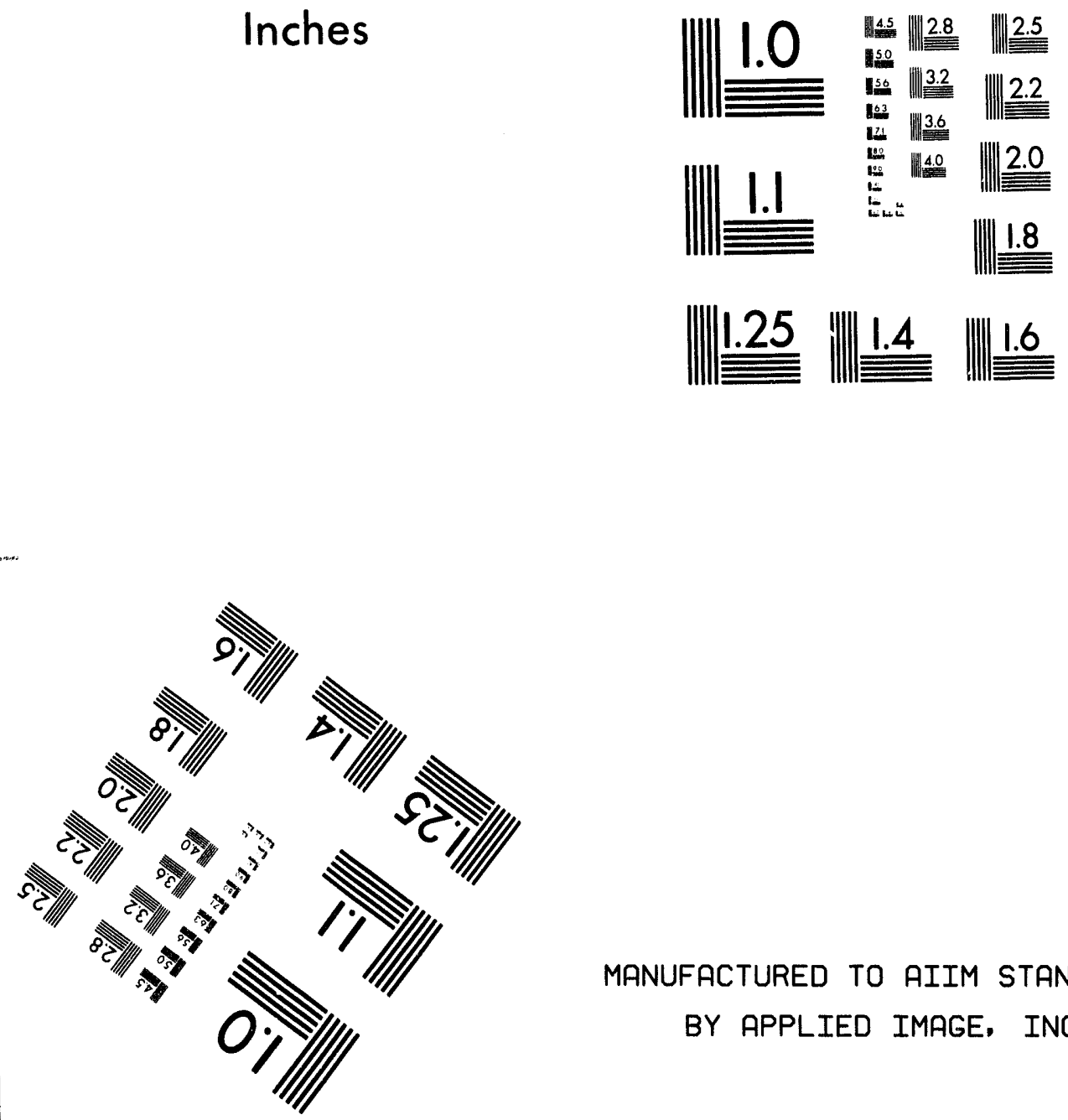

MANUFACTURED TO AIIM STANDARDS BY APPLIED IMAGE, INC.

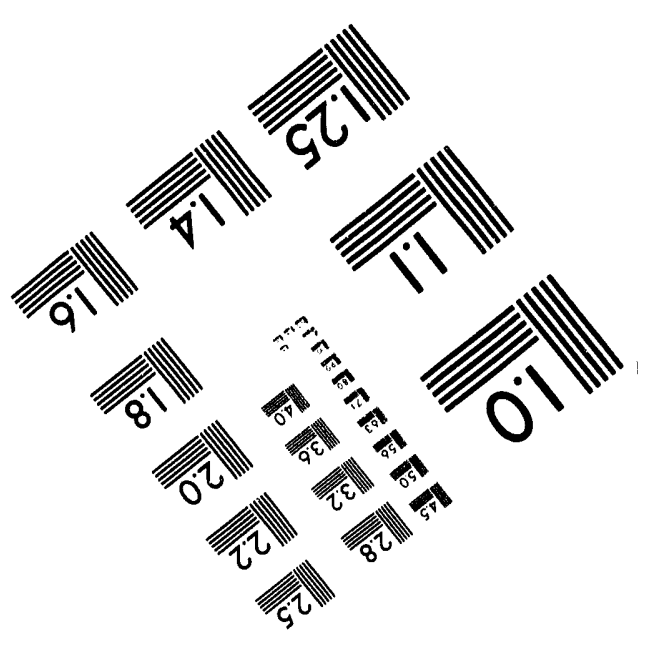



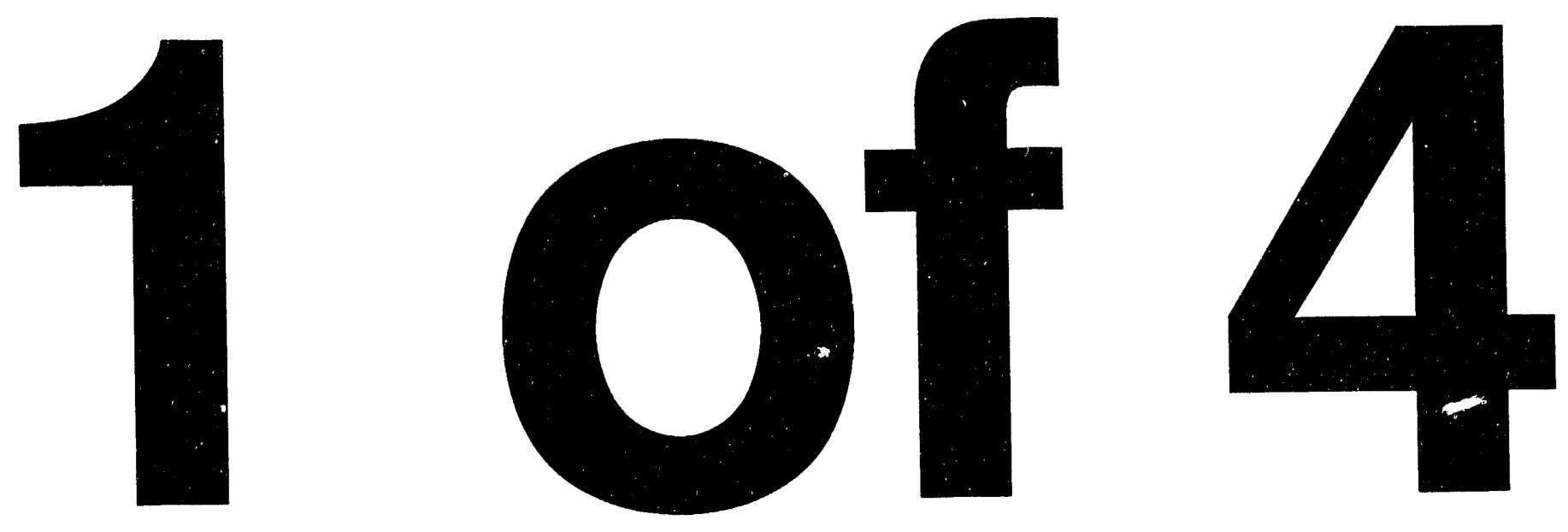
Civilian Radioactive Waste Management System Management and Operating Contractor

\section{REVIEW AND SELECTION OF UNSATURATED FLOW MODELS}

Document No. B00000000-01425-2200-00001 Rev. 00

April 4, 1994

Prepared for:

U.S. Department of Energy Yucca Mountain Site Characterization Project Office

P.O. Box 98608

Las Vegas, Nevada 89193-8608

Prepared by:

Mark Reeves, Noreen A. Baker and James O. Duguid INTERA Inc. 101 Convention Center Drive Las Vegas, Nevada 89109




WBS: 1.2 .5 .4 .6

Civilian Radioactive Waste Management System

Management \& Operating Contractor

\section{REVIEW AND SELECTION OF UNSATURATED FLOW MODELS}

B00000000-01425-2200-00001-Rev. 00

April 4, 1994

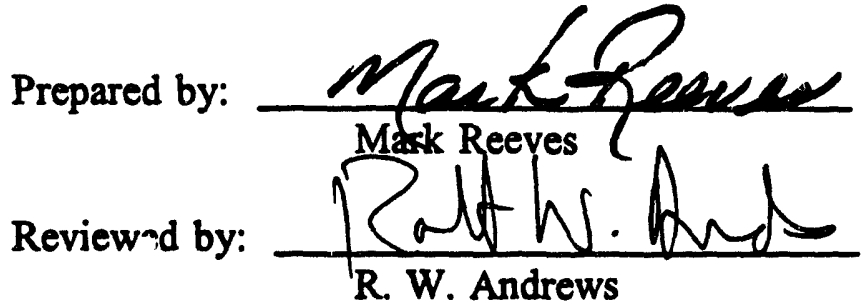

Date: $4 / 7 / 94$

Date: $4 / 7 / 94$

Approved by: $\frac{Q \text { R Yrunhs }}{\text { J. L. Younker, Manager }}$

Date: $4-7-44$

Regulatory and Technical Evaluation 


\section{ACKNOWLEDGEMENTS}

Several members of the CRWMS M\&O team contributed to this work. Mark Reeves, James O. Duguid, and Noreen A. Baker conducted the model reviews and prepared the draft documentation, while R.W. Andrews developed helpful review comments. S. Sareen provided management support and personal encouragement throughout the effort.

The authors wish to thank the developers of the major models that are reviewed in this document for their review and comments on the draft document. Their comments contributed greatly to the completion of this review and were greatly appreciated. 


\section{TABLE OF CONTENTS}

Page

1. INTRODUCTION $\ldots \ldots \ldots \ldots \ldots \ldots \ldots \ldots \ldots \ldots \ldots \ldots \ldots \ldots \ldots \ldots \ldots$

2. APPROACH TO MODEL SELECTION $\ldots \ldots \ldots \ldots \ldots \ldots \ldots \ldots \ldots \ldots$

3. MODEL-SELECTION REQUIREMENTS $\ldots \ldots \ldots \ldots \ldots \ldots \ldots \ldots \ldots$

4. TECHNICAL REVIEW $\ldots \ldots \ldots \ldots \ldots \ldots \ldots \ldots \ldots \ldots \ldots \ldots$

4.1 MODEL DENTIFICATION $\ldots \ldots \ldots \ldots \ldots \ldots \ldots \ldots \ldots \ldots, 8$

4.2 MODEL CHARACTERIZATION $\ldots \ldots \ldots \ldots \ldots \ldots \ldots \ldots \ldots, 8$

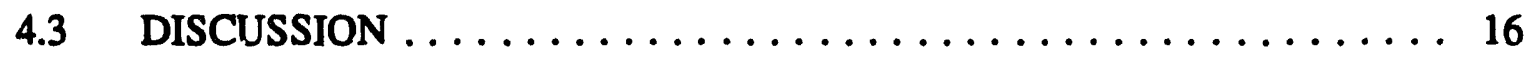

5. SELECTION OF MODELS FOR TESTING $\ldots \ldots \ldots \ldots \ldots \ldots \ldots \ldots \ldots$

5.1 COMPARISON OF MODEL CHARACTERISTICS AND MODEL

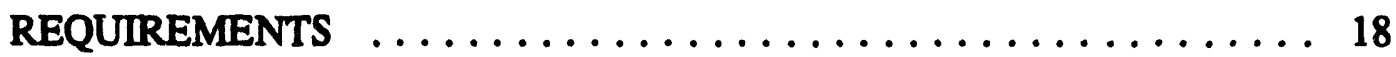

5.2 CROSS-COMPARISON OF MODEL CHARACTERISTICS . . . . . 19

5.3 MODEL SELECTION $\ldots \ldots \ldots \ldots \ldots \ldots \ldots \ldots \ldots \ldots \ldots \ldots$

6. MODEL VERIFICATION AND TESTING $\ldots \ldots \ldots \ldots \ldots \ldots \ldots \ldots \ldots \ldots 24$

$6.1 \quad$ TEST PLAN $\ldots \ldots \ldots \ldots \ldots \ldots \ldots \ldots \ldots \ldots \ldots \ldots \ldots \ldots \ldots \ldots \ldots \ldots \ldots, 24$

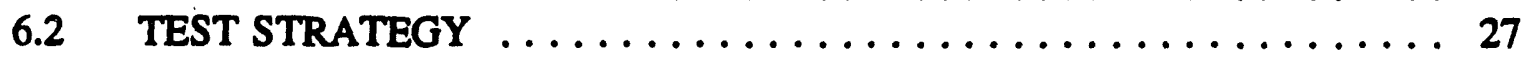

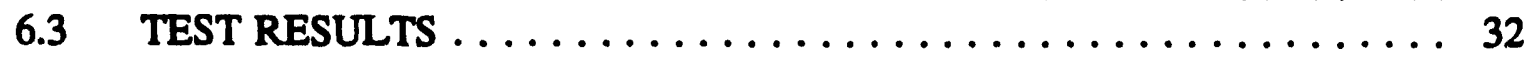

7. CONCLUSIONS ............................ 53

7.1 GENERAL CONCLUSIONS $\ldots \ldots \ldots \ldots \ldots \ldots \ldots \ldots \ldots \ldots \ldots \ldots \ldots$

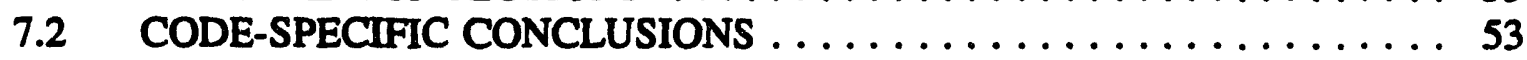

8. RECOMMENDATIONS ........................ 56

8.1 GENERAL RECOMMENDATIONS $\ldots \ldots \ldots \ldots \ldots \ldots \ldots \ldots \ldots$

8.2 CODE-SPECIFIC RECOMMENDATIONS $\ldots \ldots \ldots \ldots \ldots \ldots \ldots, 56$

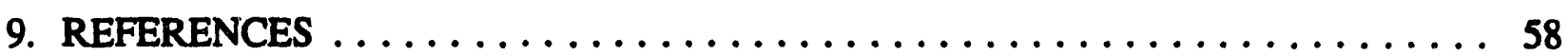
APPENDIX A

A.1 DCM3D $\ldots \ldots \ldots \ldots \ldots \ldots \ldots \ldots \ldots \ldots \ldots \ldots \ldots \ldots \ldots \ldots \ldots \ldots \ldots \ldots \ldots, 1$

A.2 FEHM $\ldots \ldots \ldots \ldots \ldots \ldots \ldots \ldots \ldots \ldots \ldots \ldots \ldots \ldots \ldots \ldots \ldots \ldots \ldots \ldots \ldots \ldots, 1$

A.3 FEMTRAN $\ldots \ldots \ldots \ldots \ldots \ldots \ldots \ldots \ldots \ldots \ldots \ldots \ldots \ldots \ldots \ldots \ldots \ldots \ldots \ldots \ldots$ A.3-1

A.4 FEMWASTE $\ldots \ldots \ldots \ldots \ldots \ldots \ldots \ldots \ldots \ldots \ldots \ldots \ldots \ldots \ldots \ldots \ldots \ldots \ldots \ldots$ A.4-1

A.5 FEMWATER $\ldots \ldots \ldots \ldots \ldots \ldots \ldots \ldots \ldots \ldots \ldots \ldots \ldots \ldots \ldots \ldots \ldots$ A.5-1

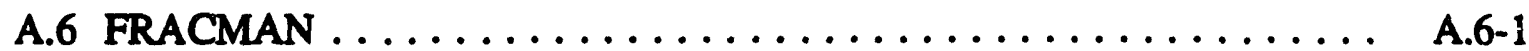

A.7 LLUVIA AND LLUVIA-II $\ldots \ldots \ldots \ldots \ldots \ldots \ldots \ldots \ldots \ldots \ldots \ldots$ A.7-1

A.8 MAFIC $\ldots \ldots \ldots \ldots \ldots \ldots \ldots \ldots \ldots \ldots \ldots \ldots \ldots \ldots \ldots \ldots \ldots \ldots \ldots \ldots \ldots \ldots, 1$

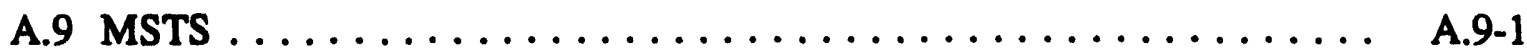




\section{TABLE OF CONTENTS}

Page

A.10 NORIA AND NORIA-SP $\ldots \ldots \ldots \ldots \ldots \ldots \ldots \ldots \ldots$ A.10-1

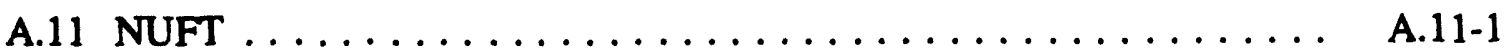

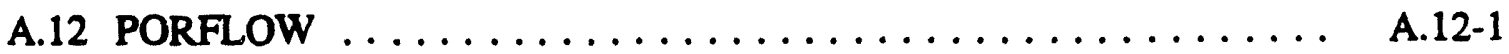

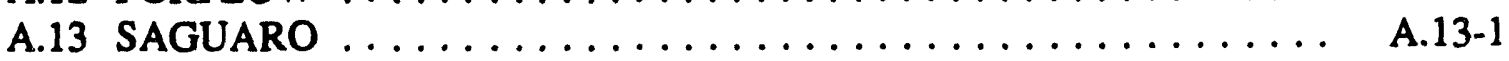

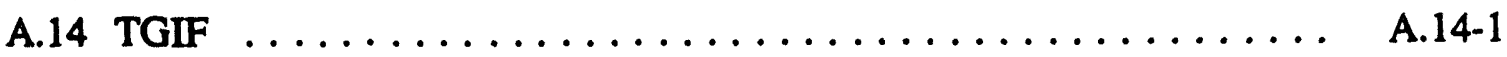

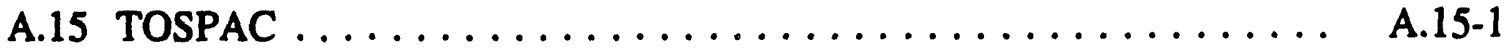

A.16 TOUGH, V-TOUGH, AND TOUGH2 $\ldots \ldots \ldots \ldots \ldots \ldots$ A.16-1

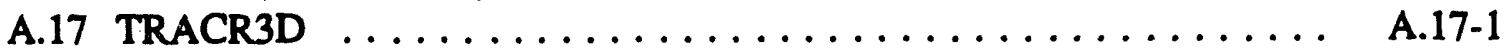

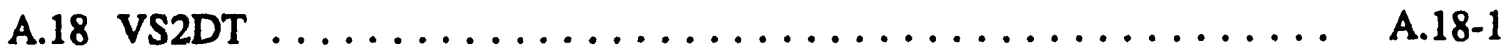

APPENDIX B

B.1 Jornada Trench $\ldots \ldots \ldots \ldots \ldots \ldots \ldots \ldots \ldots \ldots \ldots \ldots \ldots \ldots \ldots \ldots \ldots$, B-1

B.2 COVE2a $\ldots \ldots \ldots \ldots \ldots \ldots \ldots \ldots \ldots \ldots \ldots \ldots \ldots \ldots \ldots \ldots \ldots \ldots \ldots \ldots$, B-4

B.3 Pre-Emplacement Vapor Diffusion $\ldots \ldots \ldots \ldots \ldots \ldots \ldots \ldots \ldots$ B-4

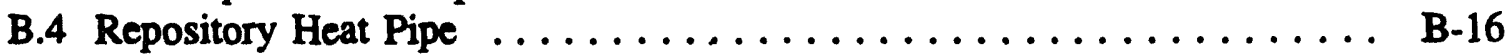




\section{LIST OF FIGURES}

Page

1. Calculated Saturation Profiles at $\mathbf{3 0}$ days for the Jornada-Trench Problem, Case $\mathbf{A}_{2}$. 33

2. Calculated Saturation Profiles at $\mathbf{3 0}$ days for the Jornada-Trench Problem, Case $\mathbf{B}_{2}$. 35

3. Calculated Saturation Profiles at $\mathbf{3 0}$ days for the Jornada-Trench Problem, Case $A_{3}$. 37

4. Calculated Saturation Profiles at 30 days for the Jornada-Trench Problem, Case $\mathbf{B}_{3}$. 37

5. Calculated Capillary-Pressure Profiles at Steady State for the COVE2a Problem . . 40

6. Calculated Saturation Profiles at Steady State for the COVE2a Problem . . . . . . 42

7. Conductivity Curves for the Paintbrush Unit ................. 44

8. Calculated Capillary-Pressure Profiles for the COVE2a Problem . . . . . . . . . 45

9. Calculated Saturation Profiles for the COVE2a Problem . . . . . . . . . . . 47

10. Calculated Saturation and Flux Profiles at Steady State for the Pre-Emplacement

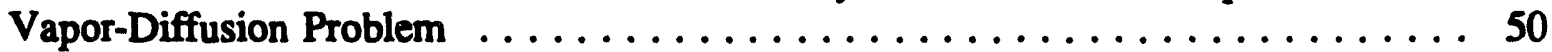

B-1. Two-Dimensional Cross-Sectional View for the Jomada-Trench Problem . . . . . . B-2

B-2. Three-Dimensional View for the Jomada-Trench Problem, with Discretization ... B-5

B-3. Stratigraphy for the COVE2a Problem $\ldots \ldots \ldots \ldots \ldots \ldots \ldots \ldots \ldots \ldots$

B-4. Stratigraphy for the Pre-Emplacement Vapor-Diffusion Problem . . . . . . . . B-11

B-5. Boundary Conditions for the Pre-Emplacement Vapor-Diffusion Problem . . . . . B B-12

B-6. Stratigraphy for the Repository Heat-Pipe Problem . . . . . . . . . . . B-17

B-7. Heat Source for the Repository Heat-Pipe Problem $\ldots \ldots \ldots \ldots \ldots \ldots \ldots$. . . . B-20

B-8. Steady-State, Pre-Emplacement Profiles - Initial-Boundary Conditions for the Repository Heat-Pipe Problem . . . . . . . . . . . . . . . . . B-21 


\section{LIST OF TABLES}

Page

1. Models Considered by the Technical Review $\ldots \ldots \ldots \ldots \ldots \ldots$

2. Summary of Model Requirements for Ground-Water Travel-Time

Calculations in the Unsaturated Zone . . . . . . . . . . . . . . 6

3. Summary of Model Requirements for Calculation of Unsaturated

Flow Under Repository Conditions $\ldots \ldots \ldots \ldots \ldots \ldots \ldots \ldots$

4. General Characterization of Multiphase Models . . . . . . . . . . . . 9

5. General Characterization of Single-Phase Models $\ldots \ldots \ldots \ldots \ldots \ldots$

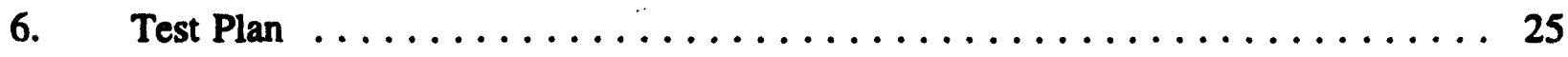

7. Detailed Code Characterization $\ldots \ldots \ldots \ldots \ldots \ldots \ldots \ldots \ldots \ldots \ldots \ldots$

8. Computational Parameters for the Jornada-Trench Problems . . . . . . . . . . 38

9. Computational Parameters for the COVE2a Problem . . . . . . . . . . . . 49

B-1. Hydraulic Properties for the Jornada-Trench Problem . . . . . . . . . . . . B-3

B-2. Discretization of the Jornada-Trench Problem $\ldots \ldots \ldots \ldots \ldots \ldots \ldots \ldots$

B-3. Hydraulic Properties for the COVE2a Problem $\ldots \ldots \ldots \ldots \ldots \ldots \ldots \ldots$

B-4. Discretization of the COVE2a Problem $\ldots \ldots \ldots \ldots \ldots \ldots \ldots \ldots \ldots \ldots$

B-5. Material Properties for the Pre-Emplacement Vapor-Diffusion Problem . . . . . B-13

B-6. Hydraulic Properties for the Pre-Emplacement Vapor-Diffusion Problem . . . . B-14

B-7. Discretization of the Pre-Emplacement Vapor-Diffusion Problem . . . . . . . B-15

B-8. Hydraulic Properties for the Repository Heat-Pipe Problem . . . . . . . . . B-18

B-9. Thermal Properties for the Repository Heat-Pipe Problem . . . . . . . . . . . B-19

B-10. Discretization of the Repository Heat-Pipe Problem . . . . . . . . . . B-22 


\section{INTRODUCTION}

Since the 1960's, ground-water flow models have been used for analysis of water resources problems. In the 1970's, emphasis began to shift to analysis of waste management problems. This shift in emphasis was largely brought about by site selection activities for geologic repositories for disposal of high-level radioactive wastes. Model development during the 1970's and well into the 1980's focused primarily on saturated ground-water flow because geologic repositories in salt, basalt, granite, shale, and tuff were envisioned to be below the water table. Selection of the unsaturated zone at Yucca Mountain, Nevada, for potential disposal of waste began to shift model development toward unsaturated flow models. This emphasis was greatly increased by the Nuclear Waste Policy Act Amendment in 1987 which named Yucca Mountain as the only site under investigation for potential disposal of high-level radioactive waste. Since the mid-1980's, pre-existing unsaturated flow models have been used, and many new unsaturated flow models have been developed. These models, which incorporate various flow submodels, have been developed on a somewhat independent basis by universities, national laboratories, and private companies. Interactions among developers, however, stimulated the development so that there is a considerable amount of similarity among the existing models. Also, during the development, as the significance of fractures was realized, models progressed from porous-media flow toward fractured flow through porous media.

Under the U.S. Department of Energy (DOE), the Civilian Radioactive Waste Management System Management and Operating Contractor (CRWMS M\&O) has the responsibility to review, evaluate, and document existing computer models; to conduct performance assessments; and to develop performance assessment models, where necessary. In the area of scientific modeling, the M\&O CRWMS has the following responsibilities:

- To provide overall management and integration of modeling activities

- To provide a framework for focusing modeling and model development

- To identify areas that require increased or decreased emphasis

- To ensure that the tools necessary to conduct performance assessment are available.

These responsibilities are being initiated through a three-step process. It consists of a thorough review of existing models, testing of models which best fit the established requirements, and making recommendations for future development that should be conducted. Future model enhancement will then focus on the models selected during this activity. Furthermore, in order to manage future model development, particularly in those areas requiring substantial enhancement, the three-step process will be updated and reported periodically in the future.

This document describes the CRWMS M\&O approach to model review and evaluation (Chapter 2), and the requirements for unsaturated flow models which are the bases for selection from among the current models (Chapter 3). Chapter 4 identifies existing models and their characteristics. Through a detailed examination of characteristics, Chapter 5 presents the selection of models for testing. Chapter 6 discusses the testing and verification of selected models. Chapters 7 and 8 give conclusions and make recommendations, respectively. Chapter 9 records the major references for each of the models reviewed. Appendix A, a collection of technical reviews for each model, contains a more complete list of references. Finally, Appendix B characterizes the problems used for model testing. 


\section{APPROACH TO MODEL SELECTION}

The approach used in this evaluation was to compile a list of existing models from those currently used in the DOE waste management programs and those used in the recent past. This list included appropriate models from the Basalt Waste Isolation Project, the Office of Nuclear Waste Isolation, and the Waste Isolation Pilot Plant, as well as those currently being used by the Yucca Mountain Site Characterization Project Office (YMPO). The models were then divided into categories such as subsystem models, subsurface natural processes, waste and repository induced processes, biosphere processes, and uncertainty/sensitivity analyses. Unsaturated flow models, the subject of this report, appeared in two categories: subsystem models and subsurface natural processes.

Because of the importance of unsaturated flow to waste isolation at Yucca Mountain, and because of the amount of model development being conducted in this area, unsaturated flow models were selected for a thorough evaluation. Waste isolation at Yucca Mountain is a function of fluid flow through fractured and porous media. The fluids, which are composed of liquid water, water vapor and air, flow through fractured and porous rocks which can be modeled by the concepts of porous media and fractured rock. For this reason, multiphase, single-phase liquid, single-phase gas, and discrete-fracture models were selected for evaluation. Table 1 presents a list of the unsaturated flow models that were evaluated.

The model evaluation was carried out by completing the following three steps:

- Technical Review

- Model Testing

- Programmatic Review.

The technical review of each model was based on documentation, publications, and discussions with the developers, where necessary. Appendix A presents the individual technical reviews, which serve as the basis of Chapters 4 through 6. These technical reviews form the basis for comparison of individual models with the requirements in Chapter 3 and for the selection of specific models for testing in Chapter 5.

Models selected for testing were installed on CRWMS M\&O computers for component and site representative testing. Component tests consisted of comparison of simulated results with analytical solutions of simplified model equations. This comparison demonstrates that the coding of a specific mathematical model is correct (i.e., code verification). Site representative testing (Chapter 6) consisted of simulations which are more representative of the Yucca Mountain site to gain more familiarity with the models. Also, based on the review and testing of the models, recommendations for further enhancement of selected models are made in Chapter 8 of this report.

Because of the importance of model selection to performance assessment, and to the licensing of the repository, a program-wide review of the selection process, the results, and the recommendations for further development or enhancement was conducted. A draft of this document provided the basis for that review, and comments from the model developers aided greatly in making this evaluation more complete. 
TABLE 1. Models Considered by the Technical Review

\begin{tabular}{|c|c|c|c|}
\hline & $\begin{array}{l}\text { DEVELOPING } \\
\text { AGENCY }\end{array}$ & REFERENCE & $\begin{array}{c}\text { SELECTED } \\
\text { FOR } \\
\text { TESTING }\end{array}$ \\
\hline MULTI-PHASE & 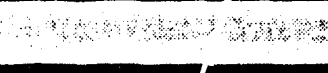 & 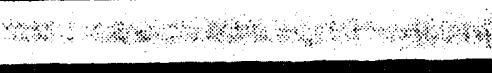 & xamentaras \\
\hline FEHM & LAN:- & Zyvoloski et al. (1991) & $x$ \\
\hline MSTS & PN'L & $\begin{array}{l}\text { White and Nichols (1992) } \\
\text { Nichols and White (1992) }\end{array}$ & $x$ \\
\hline NORIA & SNL & Bixler (1985) & \\
\hline NUFT & LLNL & Nitao (1992) & $\underline{x}$ \\
\hline TOUGH2 & LBL. & Pruess (1991) & $\underline{x}$ \\
\hline V-TOUGH & LLNL, LBL & Nitao (1989) & \\
\hline SINGLE-PHASE-LIQUID & $+4 \times 2+3$ & 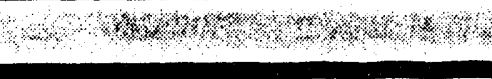 & $18+5,4 x$ \\
\hline DCM3D & GRAM, SNL, NRC & Updegraff et al. (1991) & \\
\hline FEMTRAN & SNL & Martinez (1985) & \\
\hline FEMWATER/FEMWASTE & ORNL & $\begin{array}{c}\text { Yeh (1987) } \\
\text { Yeh and Ward (1981) } \\
\end{array}$ & \\
\hline LLUVIA-II & SNL & Eaton and Hopkins (1992) & $\underline{x}$ \\
\hline NORIA-SP & SNL & Hopkins et al. (1991) & \\
\hline SAGUARO & SNL & Eaton et al. (1983) & \\
\hline TOSPAC & SPECTRA, SNL & $\begin{array}{l}\text { Gauthier et al. (1992) } \\
\text { Dudley et al. (1988) }\end{array}$ & $x$ \\
\hline TRACR3D & LANL & Birdsell and Travis (1991a) & $x$ \\
\hline VS2DT & USGS & Lappala et al. (1987) & $x$ \\
\hline SINGLE-PHASE-GAS & 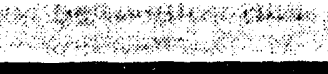 & 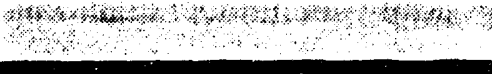 & 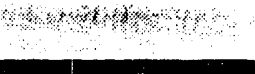 \\
\hline TGIF & $\begin{array}{l}\text { DISPOSAL } \\
\text { SAFETY, SNL }\end{array}$ & Ross et al. (1992) & \\
\hline DISCRETE-FRACTURE & 8 & 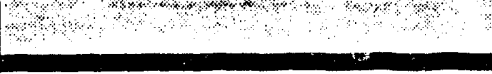 & \\
\hline FRACMAN/MAFIC & GOLDER & $\begin{array}{l}\text { Dershowitz et al. (1991), } \\
\text { Miller (1990) }\end{array}$ & \\
\hline
\end{tabular}




\section{MODEL-SELECTION REQUIREMENTS}

The requirements for selection of flow models in the unsaturated zone are based on two regulatory requirements: one for calculating the pre-emplacement ground-water travel time (10 CFR 60), and one for calculating the release of radionuclides to the accessible environment over 10,000 years (40 CFR 191). The latter requires a detailed analysis of unsaturated flow under repository conditions which includes a significant input of thermal energy from the decaying waste. Also, the ground-water flow models will be used for analyses during site characterization, analyses of repository and waste package designs, and interpretation of the effects of natural events and processes which are expected to occur over the 10,000-year period. In addition to the regulations, the model requirements stem from the geologic characteristics of the Yucca Mountain site and from the theory of unsaturated flow itself.

The requirement of providing reasonable assurance that the pre-emplacement ground-water travel time from the disturbed zone of the repository to the accessible environment is greater than 1,000 years (10 CFR 60) combined with the geologic nature of Yucca Mountain produces the following model requirements:

- Water vapor and gas flowing through the mountain will affect the ground-water travel time. Changes in temperature and pressure due to topography and differences in rock-gas and atmospheric humidity levels cause gas to circulate within the mountain. This effect is degraded by the relatively high saturation levels of nonwelded tuff units and enhanced by the fractured nature of welded tuff units.

- Tuff layers having low hydraulic conductivity (nonwelded units) can cause perching of liquid water which produces a dominant lateral flow component. On this basis flow models must be capable of simulating both saturated and unsaturated water flow.

- Both requirements above lead to at least two-dimensional models (e.g., models which can solve ground-water flow problems in the space domain of a cross-section through the mountain). Here it is possible that heterogeneity in flow properties along the axis of Yucca Mountain may require a three-dimensional approach, or at least three-dimensional codes will need to be used to demonstrate the viability of the two-dimensional approach.

- The tuff units at Yucca Mountain contain both matrix and fracture porosities. Flow models must take both porosities into account.

- In underground openings in tuff and other rock types, dripping fractures have been observed within the unsaturated zone. These observations lead to the realization that disequilibrium conditions may exist between liquid in the fractures and liquid in the matrix. 
Table 2 summarizes the requirements for the models needed to calculate ground-water travel time in the unsaturated zone. These requirements should be met or the models used should be shown to be conservative when compared to models that meet the requirements presented in Table 2 .

Three factors suggest that the saturated zone at Yucca Mountain may be a significant consideration in the calculation of pre-emplacement ground-water travel time. These factors are summarized i s follows: (1) 10 CFR 60 requires that the outer extremity of the disturbed zone be used as the starting point for the travel-time calculation. Depending upon how it is defined, the thermally disturbed zone, at higher thermal loads, may go below the water table; (2) it appears unlikely that any pre-emplacement, fracture-dominated flow channels connect the ground surface to the water table, and pass through the repository horizon. Nevertheless, establishing the non-existence of such flow channels may prove to be difficult and expensive; and (3) most likely, recent conceptualizations of the saturated zone will yield travel times that are substantially greater than 1,000 years. If this is true, it may be desirable to use only the saturated-zone travel time to demonstrate compliance with 10 CFR 60 . However, because flow modeling in the saturated zone is better understood and accepted by the scientific community, and because performance assessment will require detailed modeling of flow in the unsaturated zone under repository conditions, the decision was made to limit this review to unsaturated flow models.

For the second regulatory requirement, the calculation of release of radionuclides to the accessible environment over 10,000 years, the input of thermal energy to Yucca Mountain must be considered. The input of thermal energy requires that the models include the capability of considering a heat pipe and an enhanced flow of gas through the mountain. In a heat pipe, water vaporizes near the heat source causing pressurization of the gas phase and flow of gas away from the heat source. The vapor is carried away from the heat source to cooler regions, where it condenses and deposits its heat. The water saturation profile, which increases with distance from the heat source, drives liquid water toward the heat source where it is vaporized. Near the Yucca Mountain repository, anisotropy in the fracture connectivity pattern will influence both the return flow of condensate and the outward flow of water vapor and latent heat.

In a heat pipe, heat transfer is primarily through convection. However, the model should be capable of handling convective, radiative, and conductive heat transfer. Outside the heat pipe, and perhaps near the waste as well, heat transfer is primarily by conduction. Near the waste, radiation may also contribute to the heat transfer. The conceptual design for thermal loading has not yet been developed, and the relative merits of a "hot" versus a "cold" repository are still being considered. Because of this, the capability to consider heat transfer caused by all three heat-transfer mechanisms must be maintained. Table 3 summarizes the requirements for calculation of unsaturated flow under repository conditions. 


\section{TABLE 2. Summary of Model Requirements for Ground-Water Travel-Time Calculations in the Unsaturated Zone}

\begin{tabular}{|c|l|}
\hline NUMBER & \multicolumn{1}{|c|}{ MODEL REQUIREMENT } \\
\hline 1 & $\begin{array}{l}\text { Capability of considering mountain-scale water-vapor and gas flow } \\
\text { under ambient conditions as affected by pressure and temperature } \\
\text { changes due to topography }\end{array}$ \\
\hline 2 & Capability of handling both saturated and unsaturated water flow \\
\hline 3 & Capability of two- and three-dimensional flow \\
\hline 4 & $\begin{array}{l}\text { Capability of considering both disequilibrium and equilibrium } \\
\text { conditions between fractures and matrix }\end{array}$ \\
\hline
\end{tabular}




\section{TABLE 3. Summary of Model Requirements for \\ Calculation of Unsaturated Flow Under Repository Conditions}

\begin{tabular}{|c|l|}
\hline NUMBER & \multicolumn{1}{|c|}{ MODEL REQUIREMENT } \\
\hline 1 & $\begin{array}{l}\text { Capability of considering mountain-scale water-vapor and gas flow } \\
\text { under ambient conditions as affected by pressure and temperature } \\
\text { changes due to topography and barometric pressure changes }\end{array}$ \\
\hline 2 & Capability of handling both saturated and unsaturated water flow \\
\hline 3 & Capability of two- and three-dimensional flow \\
\hline 4 & $\begin{array}{l}\text { Capability of considering both disequilibrium and equilibrium } \\
\text { conditions between fractures and matrix }\end{array}$ \\
\hline 5 & $\begin{array}{l}\text { Capability of considering mountain-scale water vapor and gas flow } \\
\text { due to repository heat }\end{array}$ \\
\hline 6 & $\begin{array}{l}\text { Capability of considering a decaying heat source at temperatures } \\
\text { that begin above boiling }\end{array}$ \\
\hline 7 & $\begin{array}{l}\text { Capability of considering the heat-pipe problem with heat transfer } \\
\text { occurring by both convection and condiction }\end{array}$ \\
\hline
\end{tabular}




\section{TECHNICAL REVIEW}

\subsection{MODEL IDENTIFICATION}

The first step in the technical review process was to compile a list of those models which had either been used by or developed by the Yucca Mountain Site Characterization Project (YMP). For each such model, Table 1 gives model names, developing agencies, and major references. It also divides the flow models into four categories. Those designated as "multiphase, nonisothermal" consider flow processes for both liquid and gas phases. One two-phase model, TRACR3D, is not included in this ca.egory since it does not consider the nonisothermal processes of vaporization and condensation, which are crucially important for multiphase analyses of Yucca Mountain. However, TRACR3D has an excellent single-phase option, and Table 1 lists it as a single-phase liquid-flow model.

Models designated as "single-phase-liquid" use the Richards approximation to ground-water flow. This approximation assumes the gas phase to be infinitely mobile. On. model, designated as "single-phase-gas," assumes 100 percent humidity levels in the rock gas. Disposal Safety's TGIF thus avoids a solution of the liquid phase and focuses on nonisothermal gas flow. Presently, a related pair of models have been designated as "discrete-fracture" models. Using borehole and outcrop data, FracMan develops statistical fracture properties and, from them, develops geometrical realizations of the fractured rock. FracMan is linked to a companion model MAFIC, but, because it can simulate only saturated flow, the companion model will be used only sparingly within the YMP. However, some of the algorithms which link it to FracMan may be directly transferable to a more general flow model.

\subsection{MODEL CHARACTERIZATION}

The second step in the technical review process was to identify model characteristics. This part of the technical review derived from documentation, publications, discussions with developers where necessary, and code listings, in some cases. Here, the primary goal was to identify internal algorithms, particularly those related to the code's performance and to its flow-process capabilities. Appendix A presents the model summaries developed during this review. To facilitate model comparisons, Table 4 characterizes multiphase models, and Table 5 characterizes single-phase liquid-flow models using the uniform set of characteristics described below.

\subsubsection{Dimensions}

Several geohydrologic factors indicate that multidimensional effects may be significant. These factors include gas flow through the mountain, lateral flow due to perched water, energy transfer through heat-pipe zones, and lateral flow between fractures and matrix, particularly in nonwelded units. As a concession to the computational difficulties, many Yucca Mountain calculations now assume oute-dimensional flow. Such calculations may prove satisfactory, but they require extensive justification. To fully comply with Requirement 3 of Tables 2 and 3, the YMP will have to overcome the hardware and software limitations which now restrict problem dimensionality. 
TABLE 4. General Characterization of Multiphase Models

\begin{tabular}{|c|c|c|c|}
\hline & FEHM & MSTS & NOAIA \\
\hline DIMENSIONS & 2,3 & $1,2,3$ & 2 \\
\hline $\begin{array}{l}\text { FRACTURED-FLOW } \\
\text { CONCEPTUALIZATION }\end{array}$ & $\begin{array}{l}\text { Equivalent continuum } \\
\text { Dual porosity } \\
\text { Dual permeability } \\
\end{array}$ & Equivalent continuum & Equivalent continuum \\
\hline PHASES & 2 & 1,2 & 2 \\
\hline HEAT & Yes & Yes & Yes \\
\hline SPATIAL DISCRETIZATION & Finite element & Finite difference & Finite element \\
\hline LNEARIZATION & Newton-Raphson & Newton-Raphson & Newton-Raphson \\
\hline FLOW SOLVER & Conjugate gradient/gmres & $\begin{array}{l}\text { Conjugate gradient/gmres } \\
\text { Direct }\end{array}$ & Direct \\
\hline MISCIBLE COMPONENTS & $\begin{array}{c}\text { Liquid? yes } \\
\text { Gas? no } \\
\end{array}$ & $\begin{array}{c}\text { Liquid? yes } \\
\text { Gas? no }\end{array}$ & No \\
\hline CHAINING & Decay & Decay & None \\
\hline $\begin{array}{l}\text { GEOCHEMICAL } \\
\text { REACTIONS } \\
\end{array}$ & Linear sorption & Linear sorption & None \\
\hline TRANSPORT SOLVER & $\begin{array}{c}\text { Explicit } \\
\text { Conjugate gradientgmres }\end{array}$ & $\begin{array}{c}\text { Conjugate gradient/gmres } \\
\text { Direct }\end{array}$ & Direct \\
\hline
\end{tabular}

(a) Not yet available 
TABLE 4. General Characterization of Multiphase Models (Continued)

\begin{tabular}{|c|c|c|c|}
\hline & NUFT & PROTLOW & TOUGH2 \\
\hline DIMENSIONS & $1,2,3$ & $1,2,3$ & $1,2,3$ \\
\hline $\begin{array}{l}\text { FRACTURED-FLOW } \\
\text { CONCEPTUALIZATION }\end{array}$ & Equivalent continuum & $\begin{array}{l}\text { Equivalent continuum } \\
\text { Embedded planes }\end{array}$ & $\begin{array}{l}\text { Equivalent continuum } \\
\text { Multiple continuum }\end{array}$ \\
\hline PHASES & $1,2, \ldots N^{(a)}$ & 3 & 2 \\
\hline HEAT & Yes & Yes & Yes \\
\hline SPATIAL DISCRETIZATION & Integrated finite difference & Finite difference & Integrated finite difference \\
\hline LINEARIZATION & Newton-Raphson & Picard & Newton-Raphson \\
\hline FLOW SOLVER & $\begin{array}{c}\text { Conjugate gradient/gmres } \\
\text { Direct }\end{array}$ & $\begin{array}{c}\text { Conjugate gradient/gmres } \\
\text { Direct } \\
\text { Successive overrelaxation } \\
\text { Alternating directions }\end{array}$ & $\begin{array}{c}\text { Conjugate gradient/gmres }{ }^{(0)} \\
\text { Direct }\end{array}$ \\
\hline MISCIBLE COMPONENTS & $\begin{array}{c}\text { Liquid? Yes } \\
\text { Gas? No } \\
\end{array}$ & $\begin{array}{c}\text { Liquid? Yes } \\
\text { Gas? No } \\
\end{array}$ & $\begin{array}{c}\text { Liquid? Yes } \\
\text { Gas? No } \\
\end{array}$ \\
\hline CHAINING & Decay & $\begin{array}{c}\text { Decay } \\
\text { Production }\end{array}$ & None \\
\hline $\begin{array}{l}\text { GEOCHEMICAL } \\
\text { REACTIONS }\end{array}$ & Linear sorption & Linear sorption & None \\
\hline TRANSPORT SOLVER & $\begin{array}{c}\text { Conjugate gradient/gmres } \\
\text { Direct }\end{array}$ & $\begin{array}{l}\text { Conjugate gradient/gmres } \\
\text { Direct } \\
\text { Successive overrelaxation } \\
\text { Alternating directions }\end{array}$ & Direct \\
\hline
\end{tabular}

(a) $\mathbf{N}$ is arbitrarily large

(b) Not yet available 
TABLE 5. General Characterization of Single-Phase Models

\begin{tabular}{|c|c|c|c|c|c|}
\hline & DCM3D & FEMTRAN & FEMWATER/FEMWASTE & LLUVIA-II & NORIA-SP \\
\hline DIMENSIONS & $1,2,3$ & 2 & 2 & 2 & 2 \\
\hline $\begin{array}{l}\text { FRACTURED-FLOW } \\
\text { CONCEPTUALIZATION }\end{array}$ & Dual permeability & None & Equivalent continuum & $\begin{array}{l}\text { Equivalent } \\
\text { continuum }\end{array}$ & $\begin{array}{l}\text { Equivalent } \\
\text { continuum }\end{array}$ \\
\hline PHASES & 1 & None & 1 & 1 & 1 \\
\hline STEADY INITAL CONDITIONS & No & None & Yes & Yes & No \\
\hline HEAT & No & None & No: & No & No \\
\hline SPATIAL DISCRETIZATION & Finite difference & None & Finite element & Finite difference & Finite element \\
\hline LINEAPIZATION & Newton-Raphson & None & Picard & Newton-Raphson & Newton-Raphson \\
\hline FLOW SOLVER & Method of lines & None & $\begin{array}{l}\text { Successive overrelaxation } \\
\text { Conjugate gradient/GMRES }\end{array}$ & Method of lines & Direct \\
\hline $\begin{array}{l}\text { FRACTURED-TRANSPORT } \\
\text { CONCEPTUALIZATION }\end{array}$ & Dual permeability & Equivalent continuum & Equivalent continuum & $\begin{array}{l}\text { Equivalent } \\
\text { continuum }\end{array}$ & None \\
\hline MISCIBLE COMPONENTS & Yes & Yes & Yes & No & No \\
\hline CHAINING & $\begin{array}{c}\text { Decay } \\
\text { Production }\end{array}$ & $\begin{array}{c}\text { Decay } \\
\text { Production }\end{array}$ & Decay & None & None \\
\hline GEOCHEMICAL REACTIONS & Linear sorption & Linear sorption & $\begin{array}{l}\text { Linear sorption } \\
\text { lon exchange } \\
\end{array}$ & None & None \\
\hline TRANSPORT SOLVER & Method of lines & Direct & $\begin{array}{c}\text { Successive overrelaxation } \\
\text { Conjugate gradientGMRES } \\
\text { Direct }\end{array}$ & None & None \\
\hline
\end{tabular}


TABLE 5. General Characterization of Single-Phase Models (Continued)

\begin{tabular}{|c|c|c|c|c|}
\hline & SAGUARO & TOSPAC & TRACR3D & VS2DT \\
\hline DIMENSIONS & 2 & 1 & $1,2,3$ & 1,2 \\
\hline $\begin{array}{l}\text { FRACTURED-FLOW } \\
\text { CONCEPTUALIZATION }\end{array}$ & Equivalent continuum & Equivalent continuum & $\begin{array}{l}\text { Equivalent continuum } \\
\text { Embedded planes }\end{array}$ & Equivalent continuum \\
\hline PHASES & 1 & 1 & 1,2 & 1 \\
\hline STEADY INITIAL CONDITONS & Yes & Yes & No & No \\
\hline HEAT & Yes & No & No & No \\
\hline SPATIAL DISCRETIZATION & Finite element & Finite difference & Finite difference & Finite difference \\
\hline LINEARIZATION & Picand & Newton-Raphson & Newton-Raphson & Hybrid \\
\hline FLOW SOLVER & Direct . & Direct & $\begin{array}{c}\text { Conjugate } \\
\text { gradient/GRMES }\end{array}$ & Strongly implicit \\
\hline $\begin{array}{l}\text { FRACTURED-TRANSPORT } \\
\text { CONCEPTUAUZATION }\end{array}$ & Equivalent continuum & Dual permeability & Equivalent continuum & Equivalent continuum \\
\hline MISCIBLE COMPONENTS & No & Yes & Yes & Yes \\
\hline CHAINING & None & $\begin{array}{c}\text { Decay } \\
\text { Production }\end{array}$ & $\begin{array}{c}\text { Decay } \\
\text { Production }\end{array}$ & Decay \\
\hline GEOCHEMICAL REACTIONS & None & Linear sorption & $\begin{array}{c}\text { Linear sorption } \\
\text { Nonlinear sorption } \\
\text { Precipitation } \\
\text { Nonequilibrium sorption } \\
\end{array}$ & $\begin{array}{l}\text { Linear sorption } \\
\text { Nonlinear sorption } \\
\text { Precipitation }\end{array}$ \\
\hline TRANSPORT SOLVER & None & Direct & Explicit & $\begin{array}{l}\text { Conjugate } \\
\text { gradient/GMRES } \\
\text { Strongly implicit }\end{array}$ \\
\hline
\end{tabular}




\subsubsection{Fracture-now Conceptualization}

Unsaturated-flow models offer a variety of options for simulating fracture-flow conceptualizations:

- Equivalent Continuum. Assuming equilibrium, hydraulic property curves composite the effects of fractures and rock matrix. The approximation breaks down for rapid transients, a very tight rock matrix, and/or large fracture spacings.

- Dual Permeability. One continuum characterizes the fractures; the other, the rock matrix. This implementation permits fracture-to-matrix, fracture-to-fracture, and matrix-to-matrix fluid movements. Typically, it employs a pseudo-steady coupling of fracture and rock matrix. With current hardware and software, a fully transient coupling yields excessive computer execution times, so that only relatively smallscale simulations can be performed. The YMP must overcome this deficiency to satisfy Requirement 4 of Tables 2 and 3.

To obtain a fully transient coupling, one defines a sufficiently large number of grid blocks within the rock matrix to accurately characterize the pressure gradients. Such an approach accurately characterizes the time behavior at times which are small compared with the time required to saturate the rock matrix. Alternatively, to obtain a pseudo-steady coupling, one uses a relatively small number of grid blocks within the rock matrix, generally separating neighbcring fractures with only a single block thickness. The pseudo-steady approach becomes accurate only as the rock matrix nears saturation, when gradients are relatively small.

- Dual Porosity. As in the dual-permeability conceptualization, one continuum characterizes the fracture, and the other, the rock matrix. Unlike the dual-continuum approach, however, the dual-porosity approach assumes that the rock matrix acts predominantly as a storage mechanism, with large-scale flows occurring only within the fractures. Here, a fully transient coupling of fracture and matrix may be simulated efficiently.

- Multiple Continuum. This method is quite flexible. It will reduce to either dualcontinuum or dual-porosity implementations with either pseudo-steady or fullytransient coupling of fractures and rock matrix. In addition, several porosity levels may be characterized (e.g., fractures, vugs, and rock matrix).

- Embedded Planes. Embedded fracture planes provide alternate flow pathways to the rock matrix. Fracture-matrix exchanges of fluid and contaminants are permitted only at grid-block interfaces. In analogy to an electric circuit, the fracture plane across a given grid block serves as a resistor in parallel to the rock matrix within that block. 


\subsubsection{Phases}

In partially saturated rocks, two fluids, or phases, move simultaneously within the porous rock. Under pre-emplacement conditions, gas-phase pressure gradients are expected to be small, and a single-phase Richards-equation approximation should be adequate. Under repository conditions, repository heat will induce non-negligible gas-phase pressure gradients, thus requiring that two phases be considered.

\subsubsection{Heat}

Under repository conditions, repository heat will vaporize water, increase gas pressures, and thereby induce a heat-pipe-type transfer of energy. To consider this effect, the model must include heat transport, as well as liquid- and gas-phase flows.

\subsubsection{Spatial Discretization}

The efficiency of the matrix solver may depend sensitively upon the spatial-discretization method. The procedure used for assigning a number to each node yields an incidence matrix (a pattern of zeros and ones), and the incidence matrix influences solver design. The finite-element and integrated finite-difference methods , rield a problem-dependent incidence matrix. In contrast, the finite-difference method yields a problem-independent incidence matrix, thereby facilitating the development of efficient direct solvers. For direct solvers, the relationship is relatively sensitive and, consequently, the finite-element and integrated finite-difference methods typically require substantially longer solution times when applied to two- and three-dimensional problems. However, because of their efficiency for large problems, iterative solvers are most appropriate for many Yucca Mountain analyses. For iterative solvers, the relationship between discretization method and solver appears to be much less sensitive, and, here finite-element and integrated finite-difference discretization methods yield computer execution times which are competitive with those arising from finite-difference discretization.

\subsubsection{Linearization}

Via their dependence on saturation levels, hydraulic-property functions cause multiphasu systems to be highly nonlinear. This occurs even in the single-phase Richards approximation. Via their dependence on pressure, temperature, and composition, phase properties such as density, viscosity, and specific enthalpy also introduce non-linearities into multiphase systems. In the conservation equations characterizing flow and transport processes in porous media, this non-linearity appears in the coefficients of otherwise linear operators since the coefficients themselves become functions of the dependent variables. Assuming that the coefficients are relatively weak functions of the dependent variable, the Picard method evaluates these coefficients using dependent-variable values obtained from prior iterations. Starting from a residual expression of the conservation equations, the Newton-Raphson method expands this residual in a Taylor series. In contrast to the Picard method, this approach considers all firstorder variations with respect to the dependent variables. 


\subsubsection{Flow Solver}

For each nonlinear iterate, the solver evaluates the dependent variables. Both the numerical treatment of the time domain and the size of contemplated simulations dictate the type of solver to be used. Discretization of only the spatial derivatives of the transport terms yields a set of coupled 0 .dinary equations, which may be solved by the method of lines. Discretization of the time derivatives of the accumulation terms as well, leads to either implicit or explicit types of solutions. For solution of the flow equation, stability considerations generally dictate the use of implicit solutions, and matrix-solution methods are required. For relatively small applications of one, perhaps two, dimensions, available computer memory and speed will allow the investigation to employ a direct matrix-solution method. Relatively large Yucca Mountain applications of two or three dimensions necessitate the use of iterative solution methods such as the successive-over-relaxation, alternating-direction implicit, conjugate-gradient/gmres, and strongly implicil methods.

\subsubsection{Fracture-Transport Conceptualization}

Most models use the same fracture conceptualization for both flow and transport. However, one model (TOSPAC) recognizes that the flow and transport mechanisms may require different conceptualizations for the fractured media.

\subsubsection{Miscible Components}

For Yucca Mountain, radionuclides are the miscible components of interest. In contrast to immiscible components (phases), miscible components have no capillarity and may be dissolved in either liquid or gas phases, or both.

\subsubsection{Chaining}

Decay and production processes combine various nuclides into radioactive chains, or families. For the parent radionuclide, a single equation may be employed to characterize the combined effect of transport and decay. For daughter products, however, the radioactive production process must also be characterized. In this case, transport equations must be solved simultaneously to characterize the decay, production, and transport processes of each progenitor.

\subsubsection{Geochemical Reactions}

Four different algorithms are currently being used within the YMP to characterize geochemical reactions. They are:

- Linear Sorption. A constant ratio $k_{d}$ of sorbed and dissolved concentrations is maintained.

- Nonlinear Sorption. The variable ratio $\mathbf{k}_{\mathbf{d}}$ depends on the concentration level.

- Non-equilibrium Sorption. The variable ratio $k_{d}$ depends on the time of exposure of rock to the dissolved concentration. 
- Saturation Limits. Solubilities and catio-exchange capacities limit the amounts which may be dissolved and sorbed.

\subsubsection{Transport Solver}

The relative importance of advection to disprrsion and diffusion (i.e., the Peclet number) determines the most desirable transport solver. If the effects of advection dominate (i.e., Peclet number greater than approximately two) then computer-performance considerations may dictate the use of an explicit solution. If the effects of dispersion and diffusion dominate (i.e., Peclet number less than approximately two) then stability consideratio. is generally dictate the use of an implicit solution. For relatively small implicit solutions for one and two dimensions, available computer memory and speed will allow the investigator to employ a direct matrix-solution method. Relatively large Yucca Mountain applications of two or three dimensions necessitate the use of iterative solution methods such as the successive-over-relaxation, alternating-direction implicit, and conjugate gradient/gmres methods.

\subsection{DISCUSSION}

Tables 4 and 5 permit the reviewer to speculate on relative code performance. Linearization, for example, affects both computer time and robustness. In calculating single-phase flow, the Picard method used in PORFLOW, FEMWATER, and SAGUARO and the hybrid method used in VS2DT yield symmetric coefficient matrices, whereas the Newton-Raphson method used in all other codes yields an asymmetric coefficient matrix. For problems that are only moderately nonlinear, this reduces computer time by as much as a factor of four. However, for problems that are highly nonlinear, the Picard and hybrid methods converge poorly, and their computational advantage during each iteration is more than offset by the increased number of iterations required for convergence. Mixed results would be anticipated with models using the Newton-Raphson method yielding reduced computer times for highly nonlinear problems, and models using the Picard and hybrid techniques yielding reduced computer times for moderately nonlinear problems. The issue here is the viability of the Picard and hybrid methods for the levels of non-linearity to be encountered in Yucca Mountain analyses.

Some multiphase models (e.g., MSTS, NUFT, and TRACR3D) have a single-phase option. Some multiphase models (e.g., TOUGH2 and FEHM) do not have such an option. Because of design limitations, other models can perform only single-phase analyses. The use of two phases rather than one increases the order of the coefficient matrix by a factor of two. For a single iteration, this increases CPU time by a factor ranging from slightly less than $2^{2}$ to $2^{3}$, depending on the type of solver. Nevertheless, one cannot immediately conclude that, for a single-phase problem, the single-phase implementation will require the least CPU time. For multidimensional nonlinear problems, the added robustness of the two-phase approach can reduce the total number of iterations sufficiently to offset the CPU-time increase per iteration. Thus, as the dimensionality and level of non-linearity increase, one should expect the efficiency of two-phase simulations to approach and perhaps exceed that of single-phase simulations.

Tables 4 and 5 reveal that transport capabilities vary significantly. Some multiphase models (NORIA and TOUGH2) offer no transport capability at all. However, most multiphase models offer a minimal capability which includes radioactive decay, linear sorption, and an implicit 
solver. Only one (PORFLOW) offers radioactive production and decay. Models classified as single-phase liquid-flow models generally offer more transport options. Four models (DCM3D, FEMTRAN, TOSPAC, and TRACR3D) provide radioactive production and decay algorithms, and two models (TRACR3D and VS2DT) offer rather lengthy menus of geochemical-reaction options. One model (TRACR3D) offers both explicit and implicit solvers.

Tables 4 and 5 also indicate differing strategies for solution of the transport equation. Most models simultaneously simulate flow and transport using a single model. Some strategies, however, match a stand-alone flow model with a stand-alone transport model. FEMWASTE, for example, simulates transport using Darcy velocities generated by FEMWATER. Similarly, FEMTRAN simulates transport using Darcy velocities generated by FEMWATER, NORIA, NORIA-SP, or SAGUARO. For multidimensional analyses of Yucca Mountain, it may be inconvenient to store the relatively large files of Darcy velocities which are required by the transport analysis. 


\section{SELECTION OF MODELS FOR TESTING}

The third step in the technical review process consisted of two activities, with the objective being to select models for testing. Section 5.1 compares model characteristics and model-selection requirements and describes general deficiencies. Section 5.2 then cross-compares model characteristics. With the understanding that final selection will follow testing, the objective here is to identify models which would be most suitable for further development in view of the general deficiencies that are identified in Section 5.1.

\subsection{COMPARISON OF MODEL CHARACTERISTICS AND MODEL REQUIREMENTS}

Assuming that discrete-fracture effects may be neglected, most analyses employ continuum conceptualizations. Tables 4 and 5 indicate that two models (PORFLOW and TRACR3D) offer the embedded-planes conceptualization for discrete-fracture analysis. However, this option has not been used in Yucca Mountain analyses, most likely due to its unrealistic treatment of fracture-matrix fluid exchanges. Tables 4 and 5 also indicate that many models offer equivalentcontinuum, dual-porosity, and dual-permeability conceptualizations. One model (TOUGH2) offers a multiple-continuum conceptualization. In theory, the equivalent-continuum, dualporosity, dual-permeability, and multiple-continuum conceptualizations may be employed in discrete-fracture implementations. However, except for small-scale implementations, that is not a practical reality. Thus, technologies for modeling discrete-fracture features of Yucca Mountain, such as an anisotropic fracture connectivity pattern, are not currently available within the project. The YMP will have to overcome this deficiency to completely satisfy Requirement 1 of Table 2 and Requirements 1,5, and 7 of Table 3.

A fully transient characterization of non-equilibrium flow in fractured rocks can be characterized by a refined gridding near the fracture-matrix interface which is gradually graded into a coarse grid within the rock-matrix interior. In addition, a pseudo-analytic characterization of fracturematrix coupling may prove sufficiently accurate and general that it too may be used to characterize non-equilibrium fracture flow. One-dimensional Yucca Mountain simulations can use the refined-gridding approach. Multidimensional simulations using this approach, while theoretically possible with the multiple-continuum implementation, are significantly limited by software inefficiency and excessive execution times. The equivalent-continuum conceptualization offered by most codes and the pseudo-steady, dual-permeability conceptualization offered by the a few flow models are unable to accurately characterize non-equilibrium flow in fractured rock. Thus, except at small spatial scales, Yucca Mountain models are unable to characterize the effects of non-equilibrium fracture-matrix flow. Requirement 4 of Tables 2 and 3 indicates that this capability is inadequate.

Private communications with code developers indicate that multiphase analyses are limited to a few thousand grid cells and that single-phase analyses based on a solution of Richards equation are generally limited to a few tens of thousands of grid cells. Here the efficiency of the flow solver is a primary consideration. A facility for performing transient, mountain-scale simulations of 100,000 grid cells or more, in computer processing times of 24 hours or less, would facilitate the resolution of many site-characterization and design issues. Such is not available at the 
present time. With such a facility, some realistic discrete-fracture and non-equilibrium fractureflow calculations would be possible.

The discussion above points out three deficiencies which are generally present in all multiphase and single-phase liquid-flow models. Section 5.2 seeks to identify models which would provide the most suitable starting points for remedying these deficiencies.

\subsection{CROSS-COMPARISON OF MODEL CHARACTERISTICS}

Two ultimate objectives of the final selection process have influenced the selection of models for testing. These may be identified as follows:

- To provide code-to-code verification, both finite-difference and finite-element models should be selected.

- Both to provide code-to-code verification and to provide an efficient analysis capability for pre-emplacement problems, single-phase as well as multiphase flow mode's should be selected.

In addition, a desire to examine the efficiency of certain algorithms has also influenced the selection of models for testing.

\subsubsection{Multiphase Models}

FEHM. FEHM offers the most advanced finite-element capability within the YMP. As shown in Table 4, it has a three-dimensional capability, offers an irerative conjugategradient/gmres solver, and provides a selection of fractured flow and transport conceptualizations. As a finite-element model, it appears to offer a good host structure for developing a multiphase discrete-fracture capability. In addition, developing a single-phase, liquid-flow option for FEHM should be more cost effective than upgrading one of the existing single-phase, finite-element models. FEHM was selected for testing.

MSTS. MSTS is user friendly. It has an excellent graphics-based preprocessor. For complex multidimensional simulations of Yucca Mountain, data setup will be a timeconsuming process, and such a capability will be useful. MSTS also implements boundary conditions in a flexible manner. It permits different types of conditions to be applied at the same boundary. This means, for example, that at the ground surface one could specify a Dirichlet condition with gas pressure equal to, say, atmospheric pressure, and one could also specify a Neumann condition with liquid flux equal to, say, the average annual recharge. This feature greatly facilitates code application and should be standardized on all multiphase codes used by the YMP. In order to examine these user-friendly features more carefully, MSTS was selected for testing.

Nevertheless, MSTS suffers from the fact that its internal algorithms closely resemble those of the older and more widely accepted TOUGH line of codes. Both MSTS and TOUGH2 use finite-difference, Newton-Raphson, and direct-solution algorithms. Furthermore, a conjugate-gradient/gmres solver is now being implemented in both. 
NORIA. NORIA has one unique capability when compared to other multiphase flow codes, namely a non-equilibrium rate of vaporization. An appropriate choice for the value of an empirical constant of proportionality causes the vaporization rate to fall smoothly to zero with decreasing moisture content. However, non-equilibrium vaporization should not be an important effect at Yucca Mountain, given the large time scale of interest.

However, in choosing a multiphase finite-element model for the project, FEHM is the better choice. Table 4 indicates that NORIA is restricted to two dimensions, while FEHM offers a three-dimensional capability. NORIA offers only a direct solver. Though quite suitable for multiphase problems involving less than a few thousand elements, such a solver is inefficient for larger problems. FEHM's conjugategradient/gmres solver is more appropriate although it, too, will require upgrading for problems larger than a few tens of thousands of elements. Finally, NORIA offers only an equivalent-continuum conceptualization of fracture flow, while FEHM offers dualpermeability and dual-porosity conceptualizations, as well. For these reasons, NORIA was not selected for testing.

NUFT. NUFT represents a shell of executive and utility routines which support one of several flow and transport modules. It offers both direct and conjugategradient/orthomin solvers. With five different preconditioners, the latter represents a serious attack on the problem of software inefficiency. Liberal use of the " $\mathrm{C}$ " language is intended to make the maintenance of NUFT as easy as possible.

The general USNT module considers fully coupled flow and transport processes for $\mathbf{N}$ phases and $\mathrm{N}_{c}$ components where $\mathrm{N}_{\text {and }} \mathrm{N}_{\mathrm{c}}$ are arbitrary. The more specialized US1P and US1C modules consider two-phase, Richards-equation flow with sequentially calculated transport of a single dilute species. In order to assess its computer efficiency relative to that of other Yucca Mountain codes, NUFT was selected for testing.

PORFLOW. PORFLOW has several positive characteristics. Its transport module offers a variety of features. Even so, its capability with respect to geochemical reactions is substantially less than that offered by VS2DT and by TRACR3D, as shown in Table 4. For both flow and transport modules, PORFLOW provides a large selection of solvers. However, PORFLOW omits one rather important option which TRACR3D includes, and, for relatively coarse-gridded transport problems resulting in relatively high Peclet numbers, the explicit option can be extremely important.

PORFLOW uses the Picard linearization method. Anticipating that the level of nonlinearity in Yucca Mountain problems might rule out the use of this method, only one code employing the Picard method (VS2DT) was selected for testing. PORFLOW was not selected for testing.

TOUGH2. TOUGH2 derives from an old and well-established line of codes dating back to MULKOM. It is widely accepted, and its clean coding and clear organization have prompted improvements from scientists outside Lawrence Berkeley Laboratory (LBL). For example, starting from TOUGH, Lawrence Livermore National Laboratory 
(LLNL) has optimized the coding for Cray computers, resulting in a version of the model called V-TOUGH. Others have added iterative solvers to improve computer efficiency. LBL itself is now including an iterative solver in their TOUGH2.

Like other models, TOUGH2 is capable of discrete-fracture and fracture-matrix disequilibrium simulations, but, because of efficiency considerations, this capability is restricted to relatively small problems. Nevertheless, as a finite-difference model, it offer an excellent host structure for further development. TOUGH2 was selected for testing.

V-TOUGH. In the future, LLNL plans to replace V-TOUGH with NUFT. In addition, one may note that LBL's TOUGH2 now incorporates some V-TOUGH features (e.g., vapor-pressure lowering) and that a forthcoming release of TOUGH 2 employing a variant of the conjugate-gradient algorithm will supersede V-TOUGH's use of efficient direct solvers. Other superior V-TOUGH features include an upgraded time-stepping algorithm, an efficient steam-table evaluation procedure, and a detailed output-control algorithm. One may reasonably assume that future TOUGH2 development will also incorporate or supersede these features. Given then that both NUFT and TOUGH 2 have been selected, V-TOUGH was not selected for testing.

\subsubsection{Single-Phase Liquid-Flow Models}

DCM3D. Like LLUVIA-II, DCM3D uses a method-of-lines solver. Because it is rarely used in hydrogeological investigations, this solver represents a natural choice. Consequently, one code using a method-of-lines solver (LLUVIA-II) was selected for model testing. DCM3D was not selected for testing.

FEMTRAN. Two different transport-solution strategies have been pursued in the development of models for the YMP. Many models simultaneously simulate flow and transport using a single model. Some strategies, however, match a stand-alone flow model with a stand-alone transport model. FEMTRAN results from the latter strategy. It simulates transport using Darcy velocities generated by FEMWATER, NORIA, NORIA-SP, or SAGUARO. Its ability to consider radionuclides upgrades the capability of FEMWASTE. However, none of its companion flow models were selected for testing. Furthermore, in comparison to TRACR3D and PORFLOW, its ability to simulate high-Peclet flow is limited, and, in comparison to TRACR3D and VS2DT, its options for characterizing geochemical reactions are limited. For these reasons, FEMTRAN was not selected for testing.

FEMWATER/FEMWASTE. Of the models considered by this review, only FEMWATER, NORIA-SP, and SAGUARO offer a single-phase, liquid-flow capability based on finite-element discretization. FEMWATER derives from a model published by Reeves and Duguid (1975) and FEMWASTE, from a model published by Duguid and Reeves (1976). The original Reeves-Duguid version of FEMWATER has three characteristics which make it inappropriate for Yucca Mountain analyses: Picard linearization, a direct solver, and two dimensions. Since 1975, FEMWATER development has removed one by adding two iterative solver options, but two 
limitations still remain. As noted in the discussion below, NORIA-SP development has also removed only one of the limitations found in the original Reeves-Duguid version of FEMWATER. FEMWATER/FEMWASTE was not selected for testing.

LLUVIA II. The uniqueness of the LLUVIA-II model derives from its use of an old and well-developed solver designed for "stiff" ordinary differential equations (ODEs). Differencing only the spatial-derivative terms in the flow equation yields a set of coupled ODEs in the time variable, which are solved by the ODE package (Shampine and Watts, 1980) which derives from the work of Hindmarsh (1981). This approach, known as the method of lines, is rarely used in hydrogeological investigations.

Some researchers contend that, for highly nonlinear unsaturated flow, this method provides a more efficient solution than more conventional methods. In addition, the benefit to be gained from parallelization is unknown. To further evaluate the method of lines, LLUVIA-II was selected for testing.

NORIA-SP. NORIA-SP is a single-phase, isothermal version of NORIA. In specializing NORIA, the object was to gain efficiency for single-phase implementations. In contrast to the TRACR3D development, which added a single-phase option, the NORIA-SP development elected to create a new version of the base model.

In comparison to other single-phase, finite-element models, NORIA-SP's use of Newton-Raphson linearization makes it relatively robust for highly nonlinear problems. However, for Yucca Mountain-scale problems, it is limited by its two dimensionality and by the poor efficiency of its direct solver. For these reasons, NORIA-SP was not selected for testing.

SAGUARO. As noted in Table 4, SAGUARO has a heat-transport capability. However, since the effects of vaporization and condensation are not included, it is not useful for Yucca Mountain analyses. Except for the heat-transport capability, SAGUARO's flow model is very close to that of the 1975 Reeves-Duguid version of FEMWATER. It therefore has three characteristics which make it inappropriate for Yucca Mountain analyses: Picard linearization, a direct solver, and two dimensions. For these reasons, SAGUARO was not selected for testing.

TOSPAC. TOSPAC was designed to be used as the flow module of the total system analyzer TSA. Nevertheless, it is of interest in the present review of detailed process models because of the emphasis of its design on efficiency. Although its steady-state model is used in the total-system studies, the efficiency of its transient solutions provides a benchmark for comparison with other models. TOSPAC was selected for testing.

TRACR3D. TRACR3D is a well-known and well-respected finite-difference model, which has been continually upgraded for more than a decade. Although it supports a two-phase capability, the lack of a thermal capability has led this review to consider only its single-phase flow capability for application to Yucca Mountain. In addition, TRACR3D offers one of the most advanced transport capabilities within the project. 
As shown in Table 5, its facility for geochemical reactions is challenged only by VS2DT, and it is the only model to offer an explicit solution for high-Peclet transport. For these reasons, TRACR3D was selected for testing.

VS2DT. The uniqueness of the VS2DT model derives from two aspects of its implementation. First, its hybrid linearization is carefully designed to gain as much robustness as possible from the Newton-Raphson method while maintaining the symmetric coefficient matrix which is characteristic of the Picard method. (Theoretically, in obtaining a direct solution for a set of linear equations of order $n$, the solution time for a symmetric matrix is one fourth of that for an asymmetric matrix.) Second, rather than to use separate linearization and iterative solution loops like most codes do, VS2DT uses a single loop. This keeps the accuracy of the matrix solution in line with the accuracy of the linearization and further improves efficiency. Though it uses separate loops, TRACR3D accomplishes the same function by refining the tolerance of the matrix solution in accord with the accuracy of the linearization. Tests by both McCord (1991) and by Eaton (1992) showed VS2DT to be relatively fast in comparison to other single-phase liquid-flow models. However, these tests did not adequately test VS2DT's efficiency and robustness with hydraulic properties appropriate for Yucca Mountain. For these reasons, VS2DT was selected for testing.

\subsection{MODEL SELECTION}

As described above, a comparison with selection requirements and a cross-comparison of characteristics resulted in the selection of both multiphase and single-phase liquid-flow models for testing. The multiphase models are: FEHM, MSTS, NUFT, and TOUGH2. The single-phase liquid-flow models selected for testing are: LLUVIA-II, TOSPAC, TRACR3D, and VS2DT. 


\section{MODEL VERIFICATION AND TESTING}

The codes selected for testing were first modified, if necessary, to run on a $486 / 33$ personal computer with a Salford Fortran compiler. Documented test cases were then executed to show that the modifications had been done correctly and to become familiar with the codes. Once this phase (the verification phase) was completed, additional tests were performed to make code-tocode comparisons. To control these comparisons as carefully as possible and to understand differing results (Section 6.3), a test plan (Section 6.1) and a test strategy (Section 6.2) were developed.

\subsection{TEST PLAN}

Table 6 presents the plan developed to guide model testing. It identifies the models selected for testing and the problems to be executed by each. Footnoting indicates the extent to which this plan can been implemented at the present time. Appendix B discusses in detail the four problems, and the following paragraphs briefly characterize their relevance to the test plan.

\subsubsection{Test Problems}

The transient Jomada-Trench Problems consider the multidimensional, isothermal flow of unsaturated water in a dry heterogeneous soil. As shown in the table, they consist of Cases $A_{2}$, $B_{2}, A_{3}$, and $B_{3}$. Setting initial head values to $-734 \mathrm{~cm}$ makes Cases $A_{2}$ and $A_{3}$ relatively easy to solve. Decreasing these values to $-10,000 \mathrm{~cm}$ substantially increases the level of difficulty for Cases $B_{2}$ and $B_{3}$. At such dry moisture conditions, numerical oscillations to less-than-residual saturation levels introduce discontinuities in the moisture accumulation term. By considering such an effect, which occurs frequently in the aralysis of dry soils, Cases $B_{2}$ and $B_{3}$ test the code's ability to minimize such oscillations. By introducing three-dimensionality, Cases $A_{3}$ and $B_{3}$ show the effect which an order-of-magnitude increase in the number of grid cells has on the efficiency of the code's solver.

Assuming steady initial conditions, the transient COVE2a Problem considers the one-dimensional, isothermal, unsaturated flow of water in a layered column of Yucca Mountain tuff. For this problem, the Paintbrush-tuff capillary-pressure and relative-permeability curves contain sharp variations. Rather than occurring at near-residual levels, such non-linearities occur at somewhat larger saturations. Had this problem assumed infiltrations greater than the levels of 0.1 and $0.2 \mathrm{~mm} / \mathrm{y}$ used for steady and transient analyses, respectively, it would have more significantly engaged the rather severe non-linearities associated with fracture flow. However, the chosen problem definition is quite adequate to test the ability of a code's linearization algorithm to weat the type of non-linearity caused by continuous, yet rapidly varying, hydraulic properties.

In addition to non-linearities, the next two problems introduce complications related to the simulation of nonisothermal multiphase flow. The steady Pre-emplacement, VaporDiffusion Problem considers the one-dimensional, nonisothermal movement of water, vapor, and air in an undisturbed column of Yucca Mountain tuff. For a near-geothermal temperature gradient, it tests a code's ability to simulate the vastly different mobilities of gas and liquid phases and to simulate the counter-current flow fields of vapor and liquid which are present in 


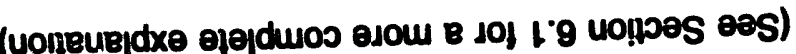

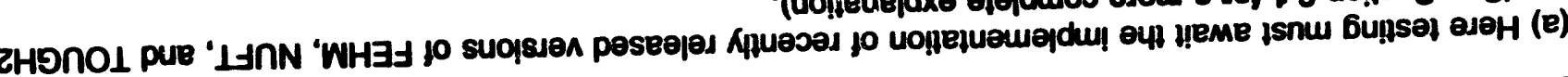

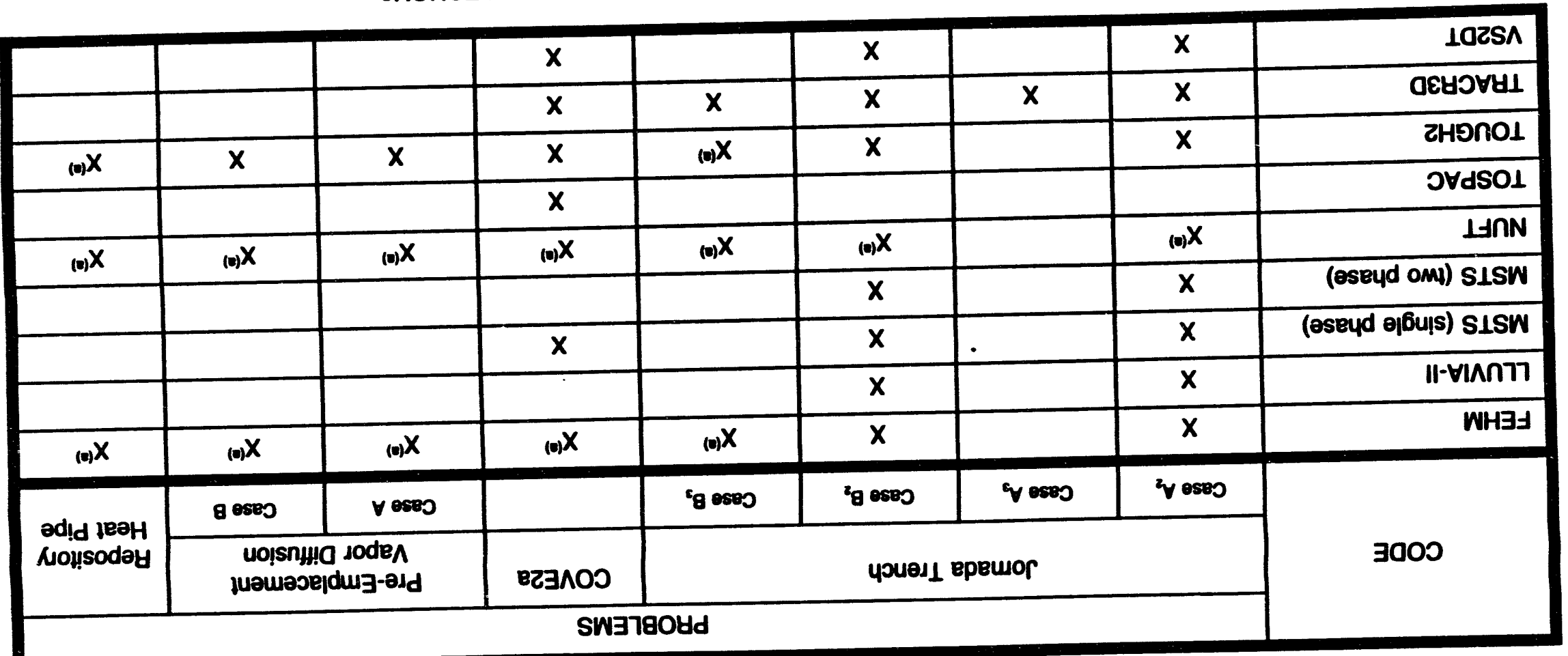

ueld $1801 \cdot 9$ a79 1 
unsaturated rock. With a relative humidity of 50 percent prescribed at the top boundary, the problem also tests a code's algorithm for vapor-pressure lowering.

The transient Repository Heat-Pipe Problem considers the nonisothermal movement of water, vapor, and air, as influenced by the presence of repository heat. In contrast to the steady Pre-emplacement, Vapor-Diffusion Problem, the Repository Heat-Pipe Problem increases problem dimensionality from one to two dimensions, and it includes both saturated and unsaturated zones. Since the applied heat load causes repository temperatures to rise above boiling, this problem tests a code's ability to simulate the convective transport of latent heat. It also tests a code's ability to simulate, in a transient fashion, the cycle of vaporization and condensation which occurs.

\subsubsection{Discussion}

The test plan of Table 6 reflects code limitations. For example, an assumption of isothermal flow restricts TRACR3D to the Jomada-Trench and COVE2a Problems. An assumption of singlephase flow in the Richards approximation restricts LLUVIA-II and VS2DT to the same two problems. An additional assumption of one spatial dimension restricts TOSPAC to the COVE2a Problem only.

Except for rather minor considerations, the nonisothermal, multiphase codes FEHM, MSTS, NUFT, and TOUGH2 are capable of solving all four test problems. For these codes, the test plan reflects a strategy. As stated in Section 5.2, one objective of the final model selection process is to select both finite-difference and finite-element models. This means that FEHM, the only viable representative of the finite-element class, should be thoroughly tested to justify its selection. Broad acceptance by the scientific community conveys an advantage to the finitedifference model TOUGH2. It means that other finite-difference models need to evidence significant advantages over TOUGH2 in order to justify final selection. The technical review suggested that MSTS would not possess such advantages. To confirm this conclusion, MSTS was applied only to the Jornada-Trench and COVE2a Problems.

Implementation of the test plan of Table 6 is only partially complete. LANL's recent release of a new version of FEHM containing the vapor-diffusion algorithm did not permit execution of the Pre-Emplacement Vapor-Diffusion and Repository Heat-Pipe Problems prior to the scheduled release of this report. Similarly, LLNL's recent release of NUFT did not permit us to perform the indicated testing. In addition, time constraints did not permit us to report either the testing of FEHM with the Jornada-Trench Case $B_{3}$. Nevertheless, only in one case could additional testing affect the conclusions and recommendations of Chapters 7 and 8 . A consideration of the relative merits of NUFT and TOUGH2 would necessitate a comparative testing of NUFT and a new version of TOUGH 2 containing a conjugate-gradient/gmres solver.

\section{$6.2 \quad$ TEST STRATEGY}

The testing strategy consists of identifying essential c xde differences and understanding their effects. To facilitate this activity, Table 7 provides a detailed code characterization. 
TABLE 7. Detailed Code Characterization ${ }^{(1)}$

\begin{tabular}{|c|c|c|c|c|c|c|c|}
\hline \multirow{3}{*}{ CODE } & \multicolumn{3}{|c|}{ TIME INTEGRATION } & \multicolumn{4}{|c|}{ SPACE INTEGRATION } \\
\hline & \multirow{2}{*}{ Time Step Controls } & \multirow{2}{*}{ Technique } & \multirow{2}{*}{ Options } & \multirow{2}{*}{ Technique } & \multicolumn{3}{|c|}{ Permeability Weighting } \\
\hline & & & & & Absolute & Saturated & Relative \\
\hline FEHM & $\begin{array}{l}\text { Minimum and maximum step sizes } \\
\text { Coupling to nonlinear teration } \\
\text { Recalculation/chopping controls }\end{array}$ & Finite difference & $\begin{array}{l}\text { Backward } \\
\text { Centered } \\
\text { Variable } \\
\end{array}$ & Finite element & $\begin{array}{l}\text { Upstream } \\
\text { None }\end{array}$ & NA & NA \\
\hline LLUVIA-II & $\begin{array}{l}\text { Step sizes adjusted via accuracy } \\
\text { requirements }\end{array}$ & Method of lines & NA & $\begin{array}{l}\text { Finite difference } \\
\text { Point distributed(o) }\end{array}$ & $\begin{array}{l}\text { Upstream } \\
\text { Centered }\end{array}$ & NA & NA \\
\hline MSTS & $\begin{array}{l}\text { Accieleration factor } \\
\text { Maximum step size } \\
\text { Recalculation/chopping control }\end{array}$ & Finite difference & Backward & Finite difference & $\begin{array}{l}\text { Harmonic } \\
\text { Upstream } \\
\text { Centered } \\
\text { Geometric } \\
\text { Linear } \\
\end{array}$ & NA & NA \\
\hline NUFT & $\begin{array}{l}\text { Desired solution-vector changes } \\
\text { Minimum and maximum step sizes } \\
\text { Recalculation/choppirg control } \\
\end{array}$ & Finite difference & Backward & $\begin{array}{l}\text { Finite difference } \\
\text { Block centered }\end{array}$ & NA & $\begin{array}{l}\text { Harmonic } \\
\text { Upstream }\end{array}$ & $\begin{array}{l}\text { Harmonic } \\
\text { Upstream } \\
\text { Centered } \\
\end{array}$ \\
\hline TOSPAC & $\begin{array}{l}\text { Desired change in permeablility or } \\
\text { capillary pressure } \\
\text { Block throughput time } \\
\text { Maximum step-size change } \\
\text { Recalculation/chopping control } \\
\end{array}$ & Finite difierence & $\begin{array}{l}\text { Backward } \\
\text { Centered } \\
\text { Variable }\end{array}$ & $\begin{array}{l}\text { Finite difference } \\
\text { Block centered }\end{array}$ & Centered & NA & NA \\
\hline TOUGH2 & $\begin{array}{l}\text { Maximum step size } \\
\text { Coupling to nonlinear iteration } \\
\text { Recalculation/chopping controls } \\
\end{array}$ & Finite difference & Backward & $\begin{array}{l}\text { Finite difference } \\
\text { Block centered }\end{array}$ & NA & $\begin{array}{l}\text { Harmonic } \\
\text { Upstream }\end{array}$ & $\begin{array}{l}\text { Harmonic } \\
\text { Upstream } \\
\text { Centered }\end{array}$ \\
\hline TRACR3D & $\begin{array}{l}\text { Minimum and maximum step sizes } \\
\text { Coupling to nonlinear iteration } \\
\text { Recalculation/chopping controls } \\
\end{array}$ & Finite difference & Backward & $\begin{array}{l}\text { Finite difference } \\
\text { Block centered }\end{array}$ & NA & Harmonic & Upstream \\
\hline VS2DT & $\begin{array}{l}\text { Minimum and maximum step sizes } \\
\text { Coupling to nonlinear iterations } \\
\text { Recalculation/chopping control }\end{array}$ & Finite difference & Backward & $\begin{array}{l}\text { Finite difference } \\
\text { Block centered }\end{array}$ & NA & Harmonic & $\begin{array}{l}\text { Geometric } \\
\text { Upstream } \\
\text { Centered } \\
\text { Variable }\end{array}$ \\
\hline
\end{tabular}

(a) NA - not applicable

(b) Aziz and Setter (1979), p. 75

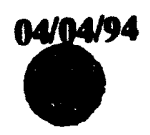


TABLE 7. Detalled Code Characterization (Continued) (2,b)

\begin{tabular}{|c|c|c|c|c|c|}
\hline \multirow[b]{2}{*}{ CODE } & \multirow[b]{2}{*}{ PHASES } & \multicolumn{2}{|c|}{ NONLINEAR ITERATION } & \multicolumn{2}{|c|}{ MATRIX SOLUTION } \\
\hline & & $\begin{array}{l}\text { Linearization } \\
\text { Technique }\end{array}$ & $\begin{array}{l}\text { Convergence-Control } \\
\text { Variables }\end{array}$ & Technique & $\begin{array}{c}\text { Convergence-Control } \\
\text { Variable }\end{array}$ \\
\hline FEHM & 2 & $\begin{array}{l}\text { Newton-Raphson } \\
\text { with reduced } \\
\text { degrees of freedom }\end{array}$ & Residual w.r.t. zero-th iterate & Conjugate gradient-GMRES & Residual w.r.t. zero-th iterate \\
\hline LLUVIA-II & 1 & Newton-Raphson & $\begin{array}{l}\text { Absolute change and relative } \\
\text { change in capillary pressure }\end{array}$ & NA & NA \\
\hline MSTS & 1,2 & Newton-Raphson & $\begin{array}{l}\text { Residual w.r.t. mass or heat } \\
\text { accumulation }\end{array}$ & $\begin{array}{l}\text { Direct } \\
\text { Conjugate gradient-GaMres }{ }^{(e)}\end{array}$ & $\begin{array}{l}\text { NA } \\
\text { Residual w.r.t. mass or heat } \\
\text { accumulation }\end{array}$ \\
\hline NUFT & $1,2, \ldots N^{(s)}$ & Newton-Raphson & Change in solution vector & $\begin{array}{l}\text { Direct } \\
\text { Conjugate gradient/orthomin }\end{array}$ & Residual w.r.t. zero-th iterate \\
\hline TOSPAC & 1 & Newton-Raphson & $\begin{array}{l}\text { Relative change in capillary } \\
\text { pressure }\end{array}$ & Direct & NA \\
\hline TOUGH2 & 2 & Newton-Raphson & $\begin{array}{l}\text { Residual w.r.t. mass or heat } \\
\text { accumulation and absolute } \\
\text { value of residual }\end{array}$ & $\begin{array}{l}\text { Direct } \\
\text { Conjugate gradient-GMREs }\end{array}$ & $\begin{array}{l}\text { NA } \\
\text { Residual w.r.t. mass or heat } \\
\text { accumulation and absolute } \\
\text { value of residual }\end{array}$ \\
\hline TRACR3D & 1,2 & Newton-Raphson & Residual w.r.t. zero-th iterate & Conjugate gradient-GMrRES & Residual w.r.t. zero-th iterate \\
\hline VS2DT & 1 & $\begin{array}{l}\text { Hybrid: Picard and } \\
\text { Newton-Raphson }\end{array}$ & Change in total pressure & Strongly implicit & Change in total pressure \\
\hline
\end{tabular}
(a) ivA - not applicable
(b) w.r.t. - with respect to
(c) Not yet available
(d) $\mathrm{N}$ is arbitrarily large 


\subsubsection{Time Integration}

The column labeled "Options" lists the time-differencing methods offered by each code. Using the backward differencing option gave a high degree of similarity among the codes. However, one code, LLUVIA-II, uses a high-ordered time differencing scheme with a time-stepping algorithm based on accuracy requirements. LLUVIA's treatment of the time domain represents an essential code difference.

Other essential code differences are present. The column labeled "Time-Step Controls" identifies the types of parameters used by the automatic-time-stepping algorithms. Here, similar values were used for the minimum (initial) and maximum step sizes and for the magnification factor. Nevertheless, in relation to the single-phase codes, the two-phase codes can achieve specified error tolerances with larger values for the minimum and maximum step sizes and for the magnification factor. Most, but not all, codes control application of the magnification factor based on the ease of convergence, as measured by the number of iterations. One code, NUFT, also controls the magnitude of the magnirication factor according to a desired change in the solution vector.

\subsubsection{Space Integration}

The column labeled "Space Integration - Permeability Weighting" lists the permeability-weighting methods which may be used by each code. Local similarity was achieved among the codes TOUGH2, TRACR3D, and VS2DT by using harmonic weighting of the saturated permeabilities and upstream weighting of the relative permeabilities. FEHM offers either no weighting at all or upstream weighting according to the prescription of Dalen (1979) for finite-element models. Here, upstream weighting was selected. For TOSPAC, only centered differencing was available. Although steps were taken to unify the analyses, differences persisted. Nevertheless, results suggest that these are nonessential differences. Only in one-dimensional applications does an essential code difference appear in the space-integration algorithms. Since the finite-element technique (FEHM) and the point-distributed finite-difference technique (LLUVIA-II) place nodes at cell boundaries, they cannot be specialized to one dimension.

\subsubsection{Phases}

Table 7 notes that all codes but FEHM and TOUGH2 can be executed in a single-phase mode. Thus, on the Jornada-Trench and COVE2a Problems, which can be executed with a single phase, the computer times required by FEHM and TOUGH 2 might be expected to be significantly larger. One may understand this by considering the effect which a two-phase solution has on the solver, which is generally a dominant consumer of computer time. Using two phases where one would suffice means that the order of the coefficient matrix must be increased by a factor of two.

For a direct solver, computer time varies approximately as the cube of the order. Thus, for a single iteration, the two-phase solution would require a computer time which exceeds that of the single-phase solution by a factor of $2^{3}$. For a conjugate-gradient type solver, the facto: of $2^{3}$ is replaced by a smaller, but still significant, factor. As noted above, however, the results below indicate that, for some problems, the improved stability of a two-phase solution reduces the total number of time steps and iterations sufficiently to offset the increased solution tine of a 
conjugate-gradient solver. The number of phases must be identified as an essential code difference.

\subsubsection{Nonlinear Iteration}

Specification of an acceptable tolerance controls the number of iterations and, in some cases, the number of time-step reductions necessary to achieve nonlinear convergence. Computer execution times thus depend sensitively on the value specified for this parameter and on the performance variable to which it is applied. The column labeled "Convergence-Control Variable" identifies five different control variables and hence five different methods for applying convergence criteria.

To cope with such differences, the study arbitrarily adopted the absolute change in total head as the standard control variable. For the Jornada-Trench Case $A_{2}$, an absolute change of $1 \mathrm{~cm}$ of total head was specified for the final simulation time (30 days). For all but one of the codes (c.f., discussion of LLUVIA-II in Section 6.3) such a criterion appeared to establish a reasonable basis for code-to-code comparisons.

To achieve a uniform absolute change of $1 \mathrm{~cm}$, the following procedure was implemented. By repeatedly running the problem, each time with a tighter tolerance, a reference run was defined. For the reference run, run-to-run changes, as determined by a post-processing step, indicated negligible variation. As necessary, additional runs were then performed to obtain a run suitable for code-to-code comparison. For the latter, the maximum change in total head, from the reference run, was required to be approximately equal to the adopted value ( $1 \mathrm{~cm}$ of total head). The tolerance settings derived for the Jornada-Trench Case $\mathbf{A}_{2}$, were then used for all subsequent executions of the code. Code-to-code evaluations of the comparison runs should thus be reasonably free of any bias introduced through the use of differing nonlinear convergence methods. Except for LLUVIA-II, this study therefore classifies the differing nonlinear convergence-control variables as nonessential differences.

The column labeled "Linearization Technique" identifies two different algorithms. Except in one case, the codes selected for testing apply the Newton-Raphson linearization technique to both accumulation and transport terms. VS2DT applies the Newton-Raphson technique to its accumulation term and the Picard technique to its transport terms. This procedure retains the computer-time advantages of the latter for weakly nonlinear applications while incorporating some of the robustness of the former technique for more nonlinear applications. As indicated by the results below, this represents and essential code difference.

\subsection{Matrix Solution}

For solution of the test problems, four different matrix-solution techniques have been used: direct, conjugate gradient/gmres, conjugate gradient/orthomin, and strongly implicit. For problems containing a few thousand grid blocks (elements) or more, observable differences should appear with the iterative techniques having a significant computer-time advantage. For such problems, the computer time required by the iterative solvers grows in proportion to the order of the matrix raised to a power slightly less than two, while the computer time required by the direct technique grows in proportion to the order of the matrix raised to the power of three. Essential code differences are indicated. 
This section presents results, all of which were obtained using a 486/33 personal computer. In its interpretation of these results, it continues the discussion of essential code differences.

\subsubsection{Jornada Trench}

Testing here includes both multiphase (FEHM, MSTS, and TOUGH2) and single-phase (LLUVIA-II, MSTS, TRACR3D, and VS2DT) implementations. One code (MSTS) permits both multiphase and single-phase implementations. Another, the one-dimensional TOSPAC, is inappropriate for this problem. Here, the authors note with gratitude that, in order to facilitate the present effort, J. McCord (private communication, 1992), R.R. Eaton (private communications, 1992 and 1993), and S.O. Magnuson (private communication, 1992, and Magnuson et al., 1990) provided their Jomada-Trench data sets for VS2DT, LLUVIA-II, and TRACR3D, respectively.

Figure 1 shows the calculated 30-day saturation profiles for Case $A_{2}$. All of the profiles agree nicely with each other. Figure 2 shows calculated 30-day saturation profiles for Case $B_{2}$. With only one exception, these profiles also agree nicely with each other. In comparison to the others, the VS2DT saturation front shows less lateral and vertical penetration. Apparently, the increased level of non-linearity in Case $B_{2}$ significantly impacts the robustness of VS2DT's linearization algorithm. Figures 3 and 4 give results for the three-dimensional Cases $A_{3}$ and $B_{3}$. For the code versions presently implemented by the CRWMS M\&O, only TRACR3D and FEHM have the three-dimensional capability and the efficiency necessary to solve unsaturated-flow problems of approximately 25,000 nodes. Given that report deadlines did not permit us to include the testing of FEHM, these figures show only the 30-day saturation profiles determined with TRACR3D. Newly released versions of TOUGH2 and NUFT and a version of MSTS to be released in the near future have the efficiency necessary to solve problems of this size, thus permitting the results shown in Figures 3 and 4 to be expanded in the future.

Table 8 presents the computational parameters for the Jornada Trench problems. It indicates that, as long as the level of non-linearity is not too great, VS2DT is a very efficient code. After a second-place finish behind VS2DT for Case $A_{2}$, the two-phase code FEHM posted the smallest run time for Case $B_{2}$. Like FEHM, the single-phase implementation of TRACR3D uses a gmres implementation of a conjugate-gradient solver. For Cases $A_{2}$ and $B_{2}$, the TRACR3D CPU times ranked next to those of FEHM. Although TRACR3D evidenced a smaller CPU time per time step, FEHM required fewer time steps to achieve the same level of convergence.

Thus, for a problem of approximately 2,400 nodes, the enhanced stability of the two-phase approach can overcome the CPU-time penalty which the conjugate-gradient method attaches to the added solution of a transport equation for the air component. In order to include the beneficial effects of a second phase in TRACR3D (private communication, 1993), LANL recently released a new version of the code containing a fully coupled gas phase. When tested on Cases $\mathrm{A}_{2}$ and $\mathrm{B}_{2}$, this version of TRACR3D should give CPU times which more closely resemble those of FEHM. 
Relatively large CPU times accompanied the Case- $A_{2}$ and Case- $B_{2}$ implementations of LLUVIA II, and the interpretation is quite interesting. For codes using matrix-solution techniques, CPU time generally increases monotonically with decreasing values of the tolerance parameter which controls nonlinear convergence. The procedure specified in Section 6.2 exploits this relationship in order to uniformly apply the same convergence criterion to all codes except LLUVIA II. For the method-of-lines solver used by LLUVIA II, the procedure was inappropriate. Here, CPU time decreased with decreasing values of the tolerance parameter until a minimum CPU time was .chieved. Beyond this point, CPU time increased with decreasing values of the tolerance pisameter.

In the error analysis for LLUVIA II, which was performed for Case $A_{2}$, the minimum CPU time corresponded to an accuracy level of approximately 4E-6 cm of total head with respect to the reference run. This represents a much higher level of accuracy than is generally required for hydrogeologic simulations. Attempts to degrade accuracy to the more reasonable level commensurate with that specified for the matrix-solution codes proved unsuccessful, yielding erratic results and excessive run times. Uniike the other codes listed in Table 8, the CPU times listed for LLUVIA II thus correspond to a minimum-CPU-time criterion, and not to a maximum total-head variation of $1 \mathrm{~cm}$. The relatively large CPU times registered for LLUVIA II in Table 8 thus result from its demand for high accuracy. This demand, coupled with the relatively large CPU times resulting therefrom, will likely restrict the future use of LLUVIA II to utility applications.

For the two-phase solution of Case $A_{2}$, MSTS's CPU time per iteration exceeds that of TOUGH2 by over 80 percent. This indicates that TOUGH2's direct solver is more efficient than MSTS's direct solver. Nevertheless, the CPU times for TOUGH2 and MSTS are much larger than those of FEHM and TRACR3D. This indicates the desirability of the conjugate-gradient type solver used by the latter, even for problems as small as 2,400 nodes. To make this point more forcefully, it would be desirable to use one of the three-dimensional cases, which have approximately 25,000 nodes. However, the long run times which would be required by the direct solvers of TOUGH2 and MSTS precluded this activity, which will be possible only when new versions of these codes have been implemented on CRWMS M\&O computers.

Expanding from two to three dimensions increases the number of nodes by a factor of ten. Table 8 shows that this increased the TRACR3D CPU time per iteration by a factor of approximately 20 for both Case $A_{3}$ and $C$ ase $B_{3}$. Assuming computer time to be proportional to $\mathrm{N}^{\mathrm{\beta}}$, where $\mathrm{N}$ is the number of nodes gives $\beta=1.3$, approximately. For the gmres solution method used by TRACR3D, one would expect $\beta$ to asymptotically approach a value closer to two. At 2,332 nodes, the two-dimensional problems are apparently too small to reveal the asymptotic behavior of this parameter.

\subsubsection{COVE2a}

Testing here includes both multiphase (FEHM and TOUGH2) and single-phase (MSTS, TOSPAC, TRACR3D, and VS2DT) implementations. Although MSTS permits both, only the single-phase implementation was employed on the COVE2a problem. 

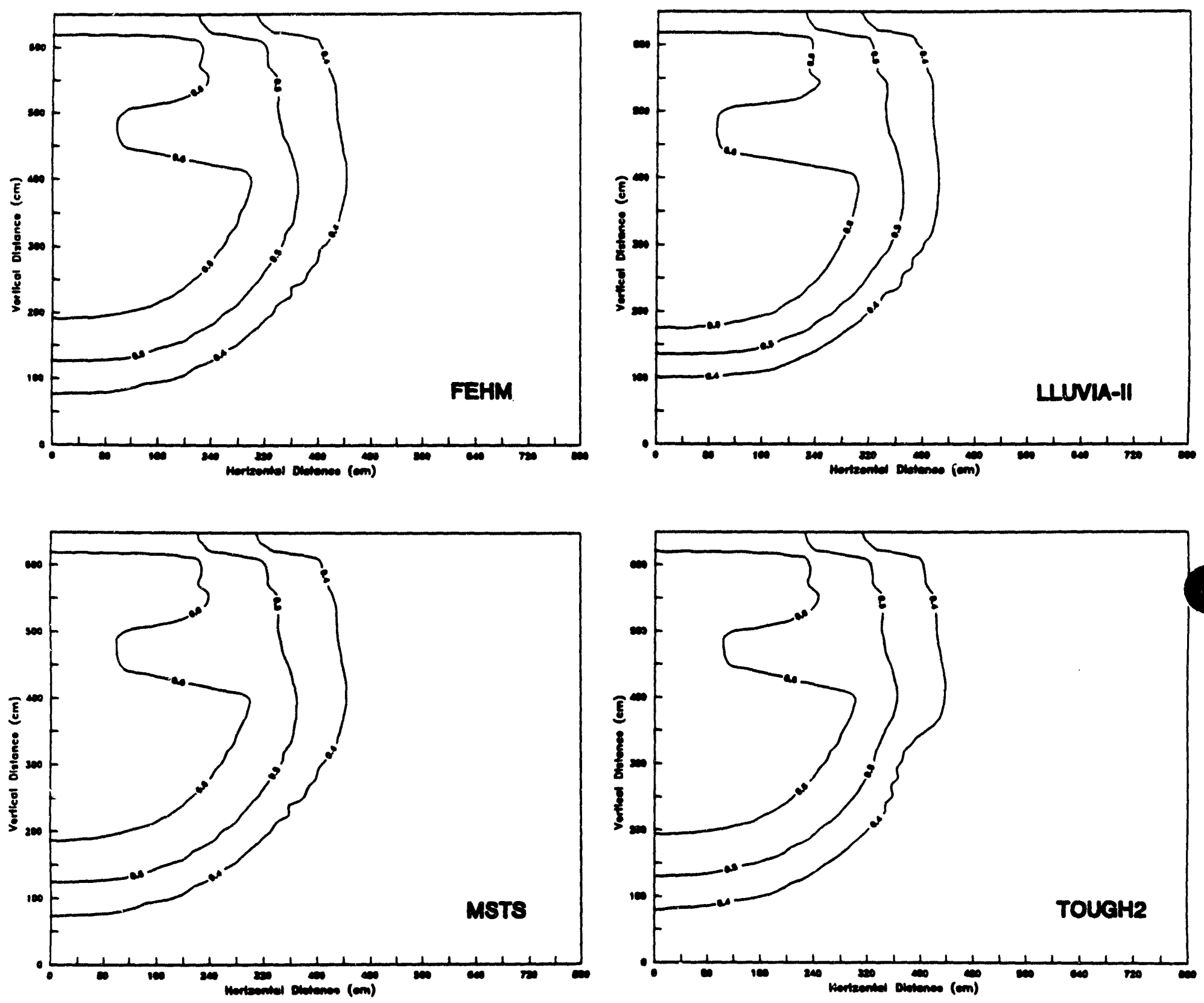

Fioure 1 Calculated Saturation Profiles at 30 Days for the Jornada-Trench Problem, Case $A_{2}$. 

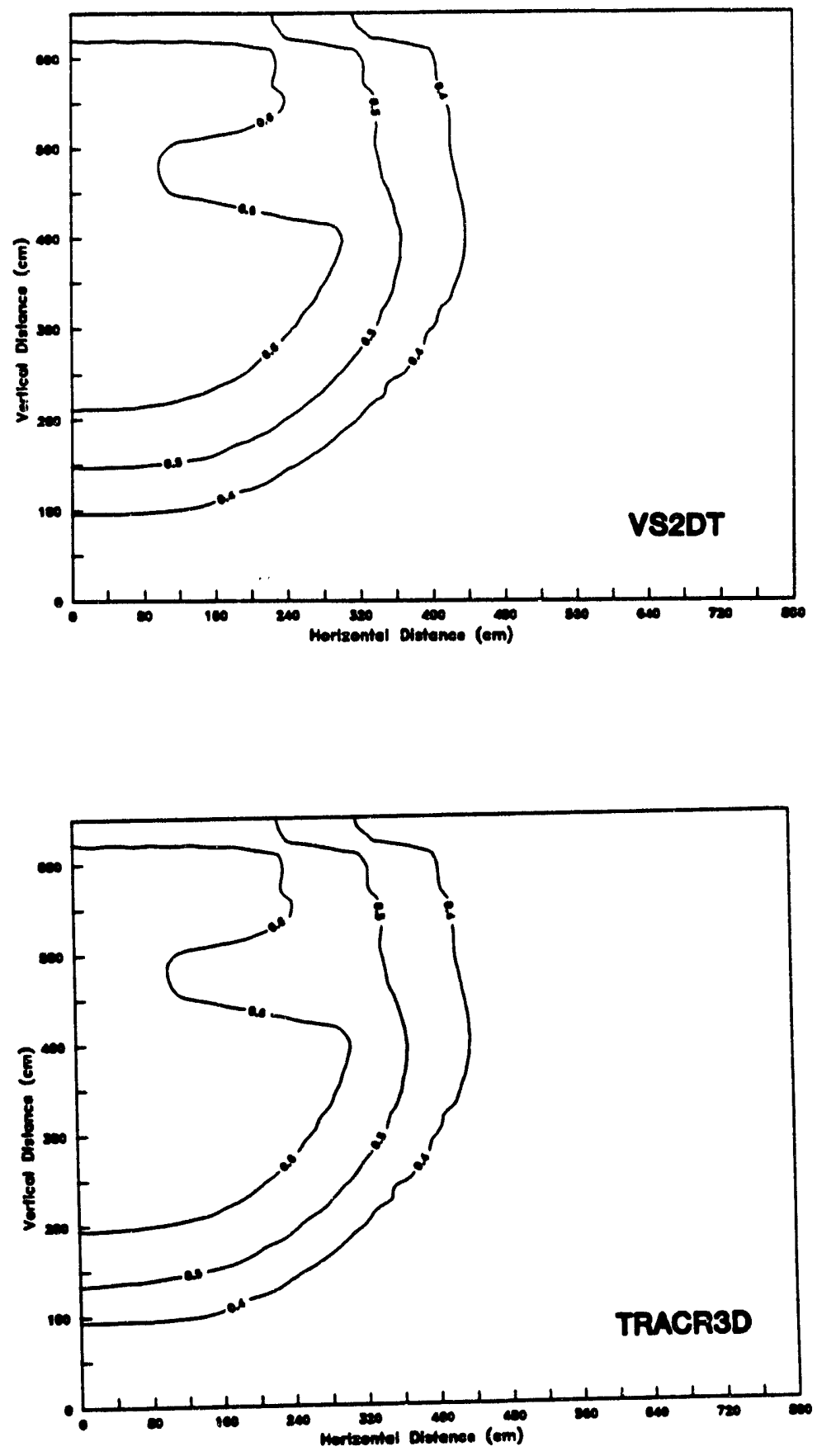

Figure 1. Culculated Saturation Proflles at 30 Days for the Jomada-Trench Problem, Case $A_{2}$ (Continued). 

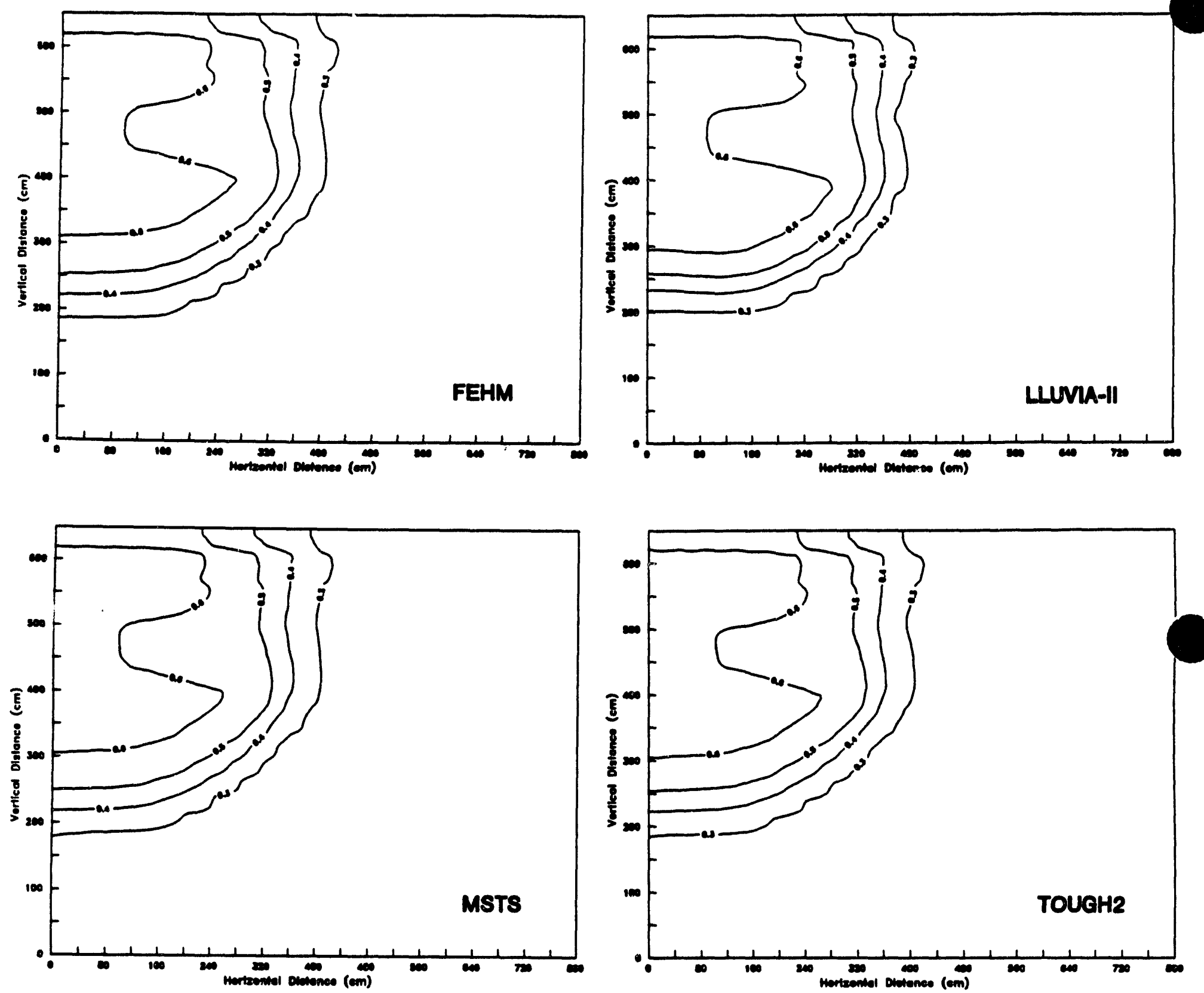

Fioure 2. Calculated Saturation Profiles at 30 Days for the Jomada-Trench Problem, Case B. 

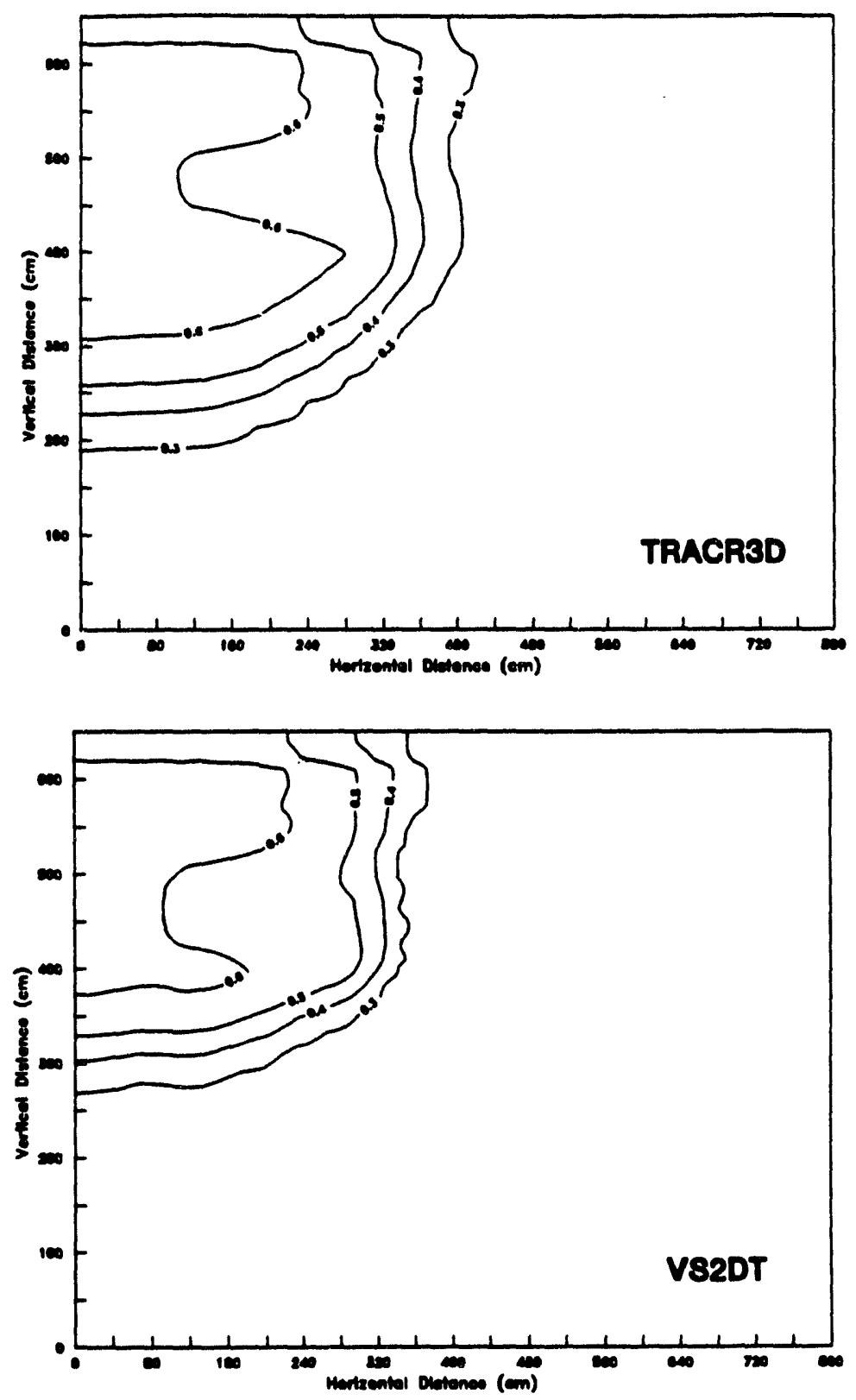

Flare 2 Calculated Saturation Profiles at 30 Days for the Jornada-Trench Problem, Caee B, (Continued). 

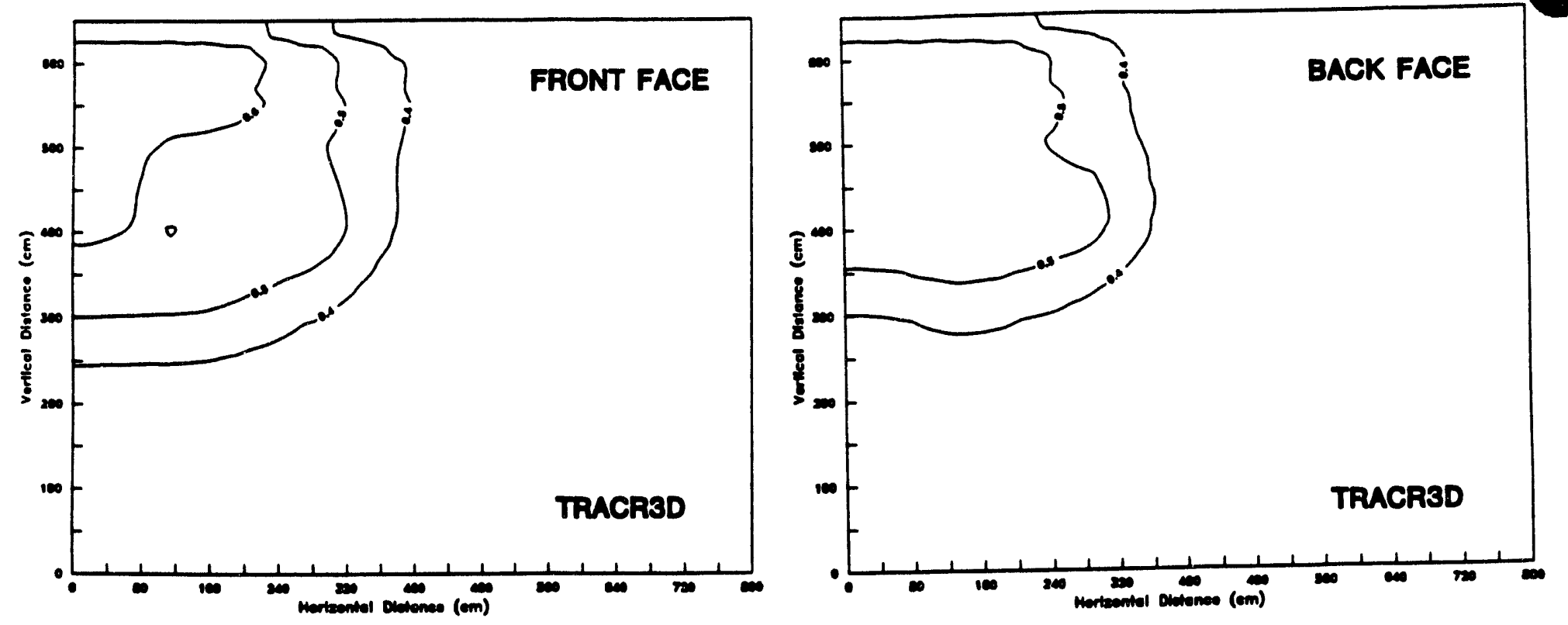

Fioure 3. Calculated Saturation Profiles at 30 Daye for the Jomada-Trench Problem, Case A.

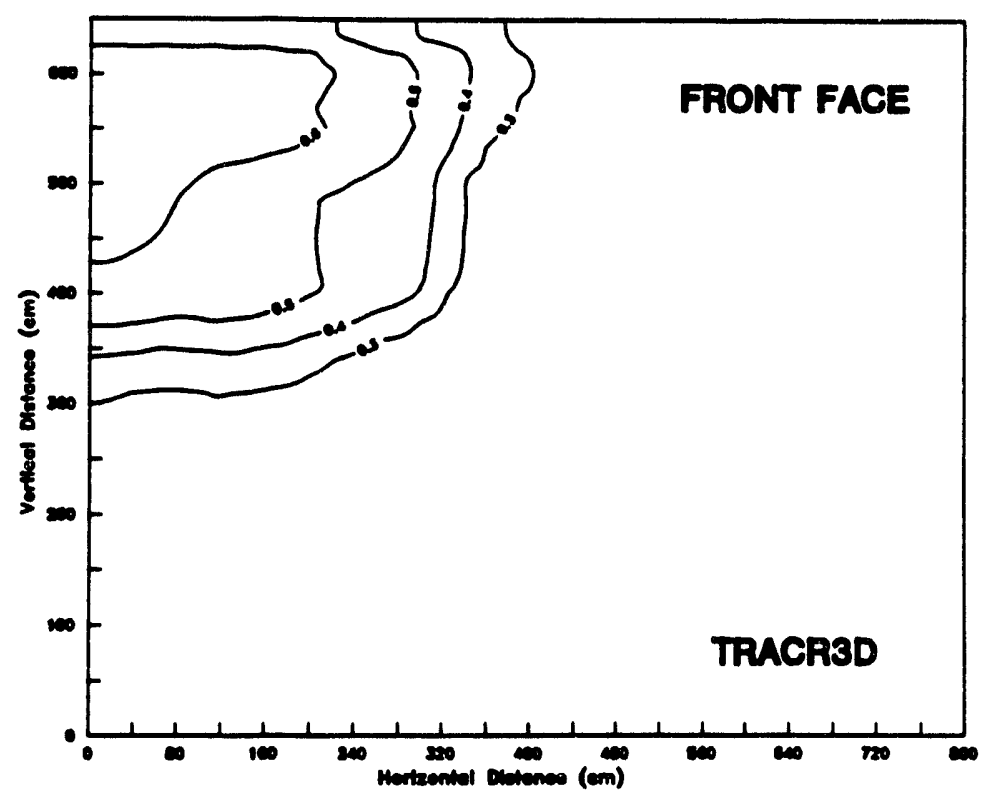

Fioure 4. Calculated Saturation Profilos at 30 Days for the Jomada-Trench Problem, Case B,. 
TABLE 8. Computational Parameters for the Jornada-Trench Problems

\begin{tabular}{|c|c|c|c|c|c|}
\hline CASE & CODE & $\begin{array}{l}\text { NUMBER OF } \\
\text { PHASES }\end{array}$ & $\begin{array}{l}\text { CPU TIME } \\
\text { (SOC) }\end{array}$ & $\begin{array}{l}\text { NUMBER OF } \\
\text { TIME STEPS }\end{array}$ & $\begin{array}{l}\text { NUMBER OF } \\
\text { ITERATIONS }\end{array}$ \\
\hline \multirow[t]{7}{*}{$A_{2}$} & \multirow{4}{*}{$\begin{array}{l}\text { LLUVIA-II } \\
\text { MSTS } \\
\text { TRACR3D } \\
\text { VS2DT }\end{array}$} & 1 & 16,200 & - & - \\
\hline & & 1 & 10,860 & 133 & 308 \\
\hline & & 1 & 1,811 & 131 & 819 \\
\hline & & 1 & 840 & 131 & 1,016 \\
\hline & \multirow{3}{*}{$\begin{array}{l}\text { FEHM } \\
\text { MSTS } \\
\text { TOUGHL } \\
\end{array}$} & 2 & 1,157 & 37 & 82 \\
\hline & & 2 & 45,180 & 45 & 176 \\
\hline & & 2 & 18,422 & 37 & 130 \\
\hline \multirow[t]{6}{*}{$B_{2}$} & \multirow{4}{*}{$\begin{array}{l}\text { LLUVIA-II } \\
\text { MSTS } \\
\text { TRACR3D } \\
\text { VS2DT } \\
\end{array}$} & 1 & 24,372 & - & - \\
\hline & & 1 & 27,288 & 162 & 731 \\
\hline & & 1 & 3,231 & 190 & 1,511 \\
\hline & & 1 & 7,320 & 1,521 & 9,138 \\
\hline & \multirow{2}{*}{$\begin{array}{l}\text { FEHM } \\
\text { TOUGH }\end{array}$} & 2 & 1,444 & 37 & 117 \\
\hline & & 2 & 40,743 & 37 & 182 \\
\hline$A_{3}$ & TRACR3D & 1 & 27,900 & 131 & 646 \\
\hline$B_{3}$ & TRACR3D & 1 & & 163 & 1,172 \\
\hline
\end{tabular}

(a) Time-stepping parameters depended on the number of phases according to the following:

\begin{tabular}{|c|c|c|c|}
\hline $\begin{array}{c}\text { NUMBER OF } \\
\text { PHASES }\end{array}$ & INITINL TIMESTEP (SOC) & $\begin{array}{c}\text { MAGNIFICATION } \\
\text { FACTOR }\end{array}$ & MAXIMUM TIME STEP (daY) \\
\hline 1 & 600 & 1.3 & 0.247 \\
\hline 2 & 600 & 2.0 & 1.0 \\
\hline
\end{tabular}

(b) LLUVIA-II automatically controlied time steps to achieve prescribed accuracy requirements. 
Figure 5 gives steady-state capillary pressure profiles for an infiltration rate of $0.1 \mathrm{~mm} / \mathrm{yr}$. Figure 6 gives corresponding saturation profiles. With only one exception, these profiles agree well both with each other and with those given in the COVE2a benchmarking reports (Birdsell and Travis, 1991b, and Gauthier et al., 1991). In comparison to those of other codes, the VS2DT capillarypressure (Figure 5) and saturation profiles (Figure 6) evidence insufficient wetting of the Paintbrush nonwelded unit. Just as for the Jornada-Trench Case $B_{2}$, excessive CPU times indicate poor convergence.

Through numerical experimentation, it was found that the poor convergence could be attributed primarily to hydraulic properties of the Paintbrush tuff. Here, the van Genuchten $\lambda$ parameter is largely responsible for the shape of the hydraulic-property curves, and larger values of this parameter increase the level of non-linearity. Figure 7 shows the conductivity curve specified by Appendix $B$, corresponding to the value $\lambda=0.8545$. It also shows a curve corresponding to a value $\lambda=0.5000$, for which improved convergence was obtained. Even so, the VS2DT computer time was excessive in comparison to other codes, indicating that the problem of poor convergence had not been completely removed by the reduced value of $\lambda$. In obtaining the steady-state solution with $\lambda=0.5000$ for the Paintbrush tuff, VS2DT required 1,020 seconds, and TRACR3D required 110 seconds. Figure 8 gives transient capillary pressure profiles, and Figure 9 gives corresponding saturation profiles. With initial conditions prescribed by the steady-state profiles of Figures 5 and 6, the transient analyses assume an infiltration rate of $0.2 \mathrm{~mm} / \mathrm{yr}$. These profiles agree well both with each other and with those given in the COVE2a benchmarking reports (Birdsell and Travis, 1991b, and Gauthier et al., 1991).

In its presentation of computational parameters, Table 9 shows the effects of two phases (TOUGH2 and FEHM) and two dimensions (FEHM) in slowing computer processing. Whereas the CPU times of TRACR3D and MSTS differed substantially for the Jornada-Trench analyses (Table 8), they differed insignificantly here. For a one-dimensional problem, this indicates an insensitivity of CPU time to solver differences. Thus, the principal advantage of the TOSPAC transient algorithm lies not in its efficiency, but in its user friendliness as a one-dimensional utility code.

\subsubsection{Pre-Emplacement Vapor Diffusion}

The test plan (Table 6) calls for testing FEHM, TOUGH2, and NUFT. Because of time constraints on the study, only TOUGH 2 analyses have been completed.

Using Kelvin's law to characterize the effect of vapor-pressure lowering, this problem assumes that capillary pressures maintain the surface soil gas at a 50 percent humidity level. This causes water vapor to diffuse to the surface from the near 100 percent levels at depth, resulting in a general drying of the system. Figure 10 presents liquid saturations. Calculated for a time period of one million years, it represents a steady-state solution to a two-phase, hydrothermal problem. Figure 5 (COVE2a problem) presents liquid saturations corresponding to a steady infiltration rate of $0.1 \mathrm{~mm} / \mathrm{yr}$. A comparison of Figures 5 and 10 indicates the extent to which this evaporation process affects moisture levels. 

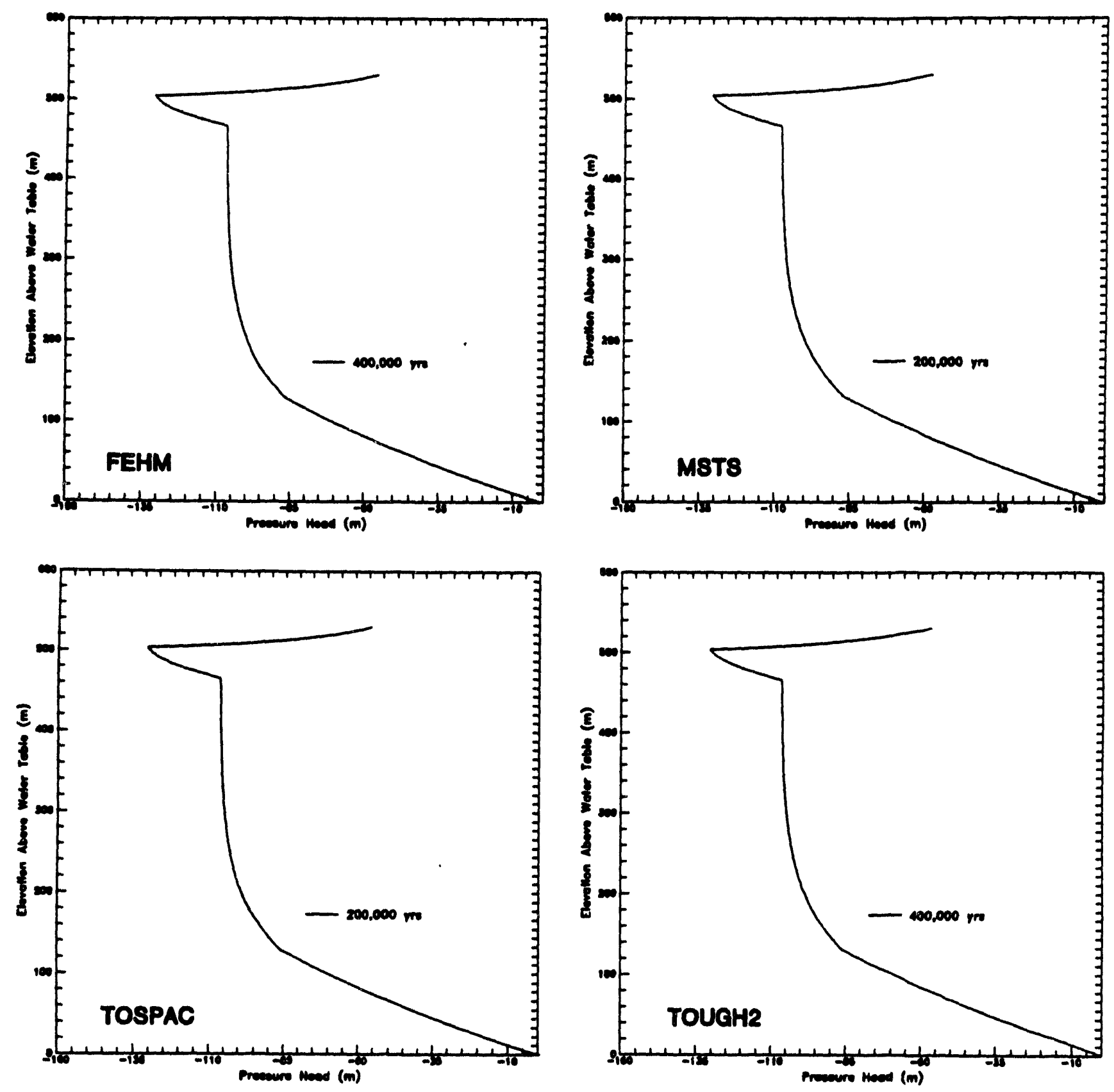

Fiouro 5. Calculated Capllary-Preacure Proflles at Bteady Siute for the COVE2a Problem. 


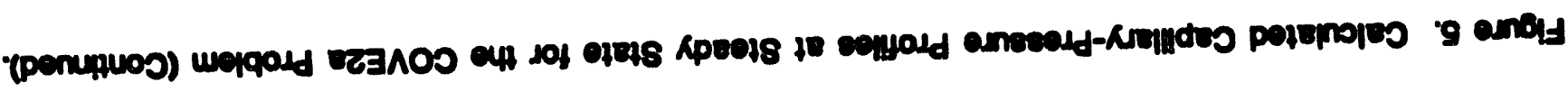
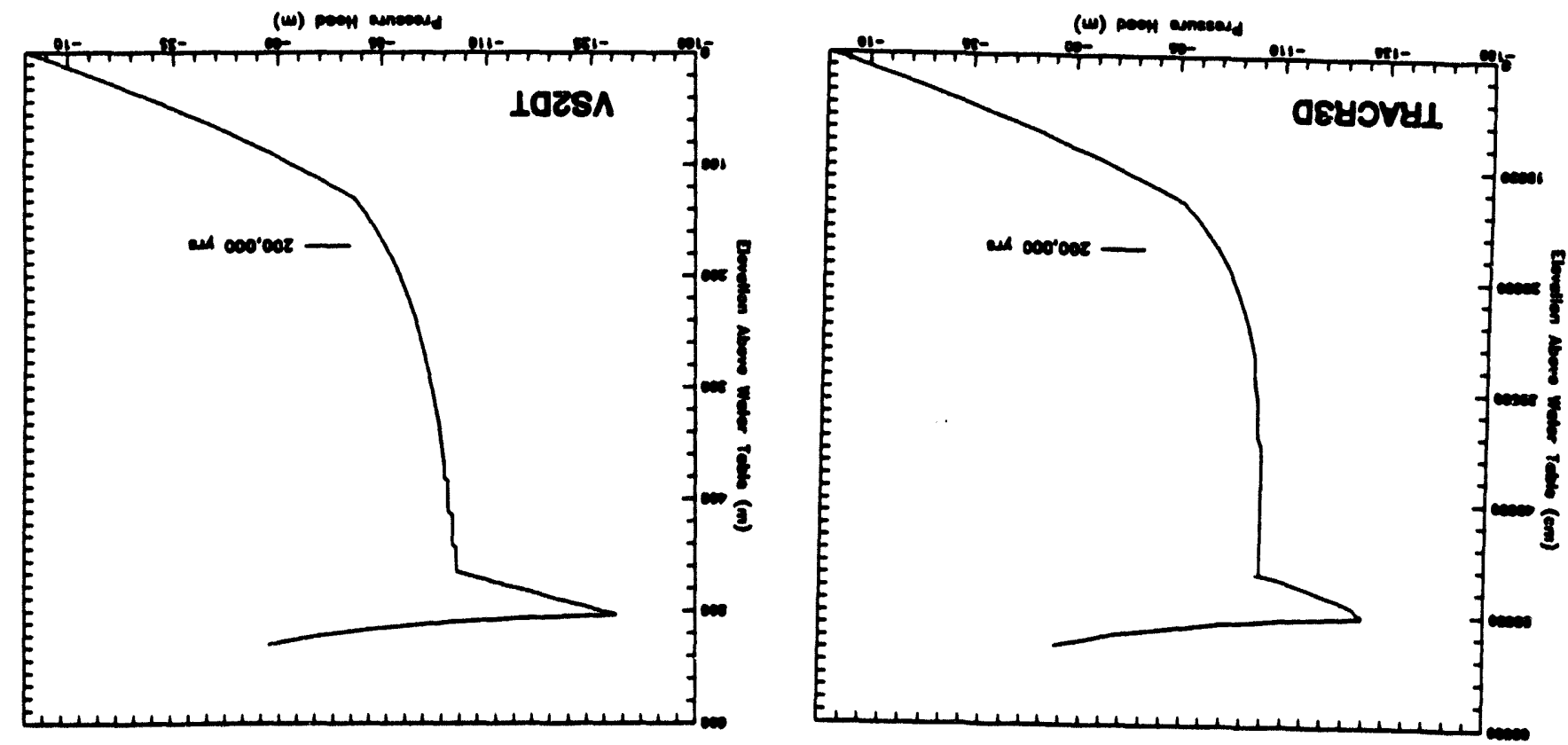

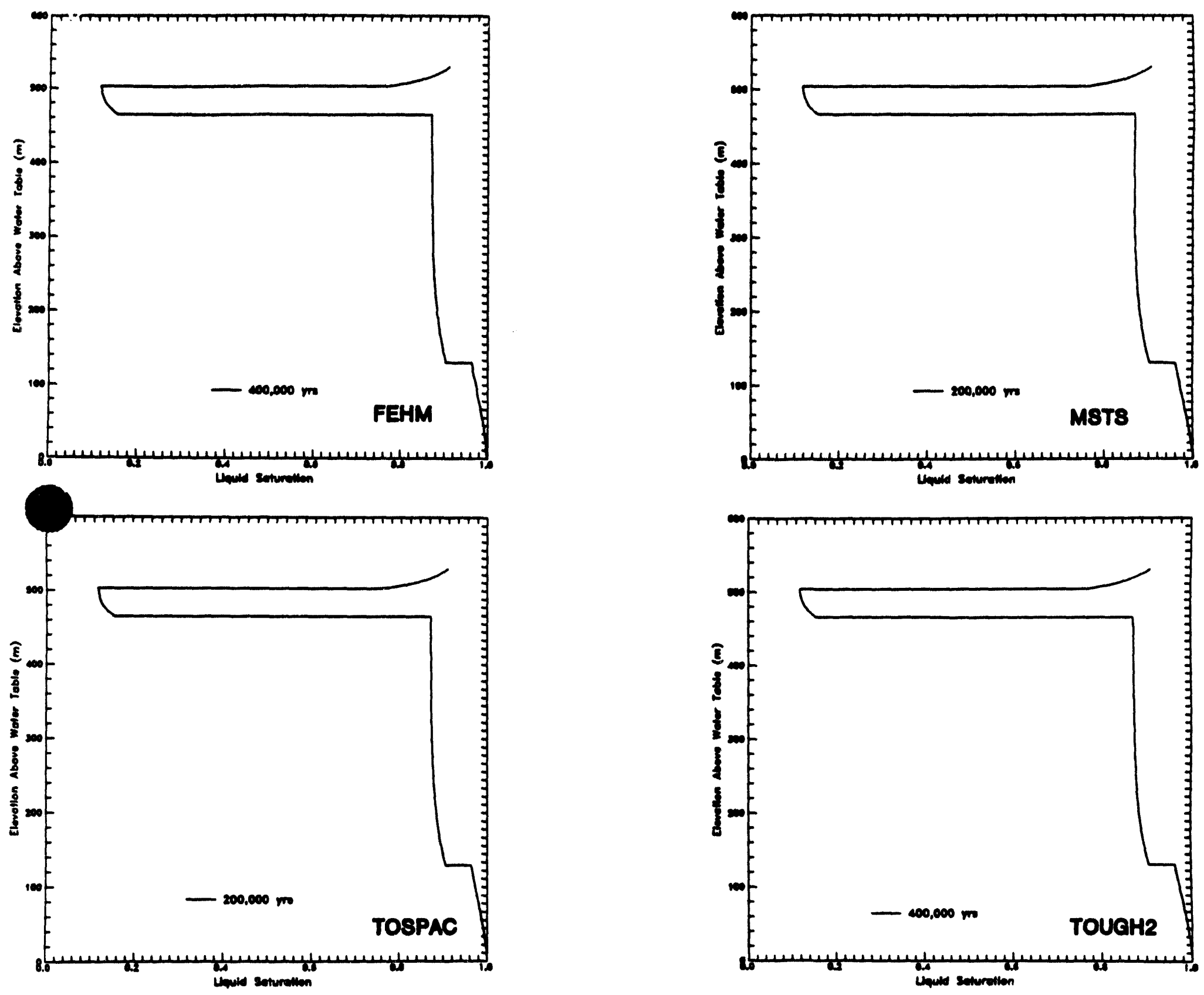

Figure 6. Caloulated Saturation Profiles at Stcady state for tho COVE2a Problem. 

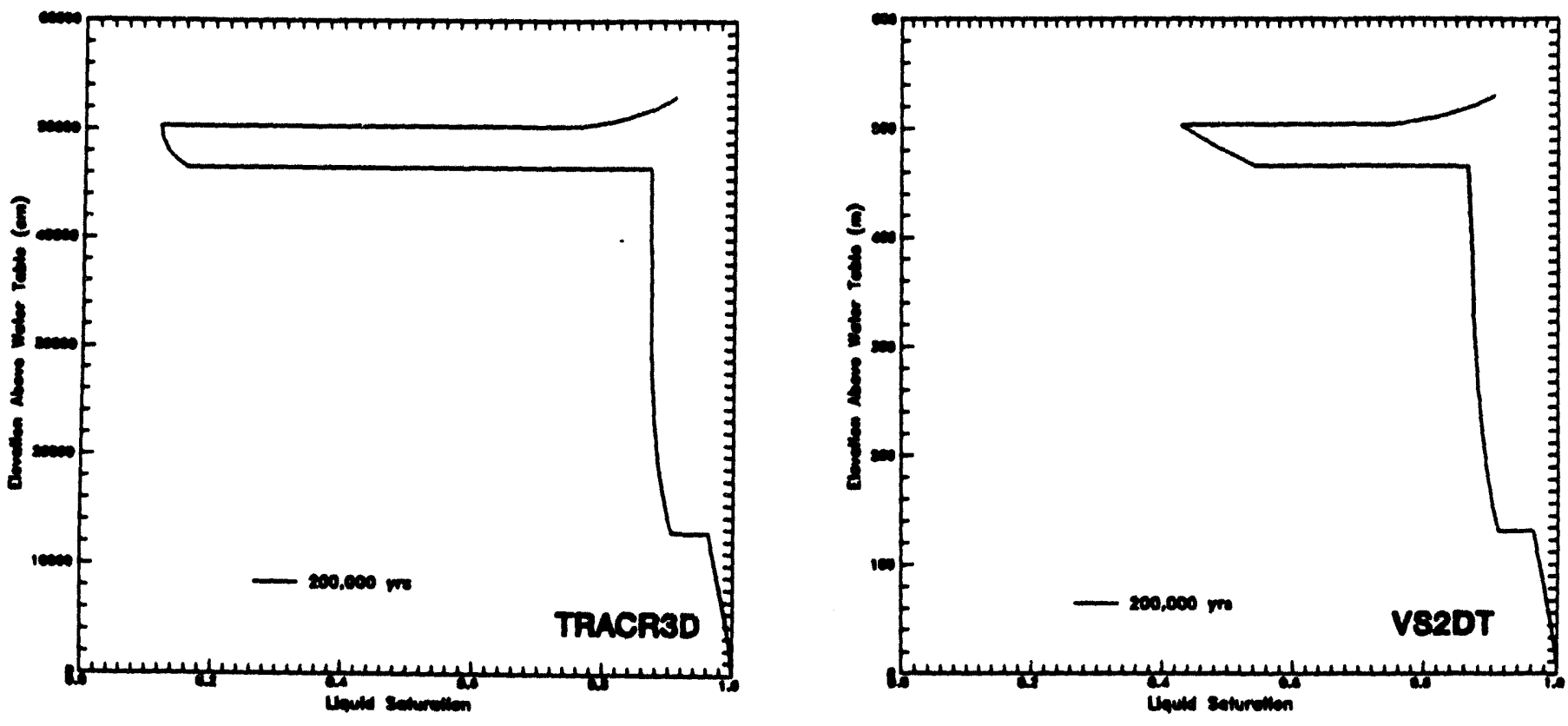

Fioure 6. Caloulatied Saturation Proflies at 8teady 8tate for the COVE2a Problem (Conthuad). 



Floure 7. Conductivity Carves for the Painttoriah Unit. 

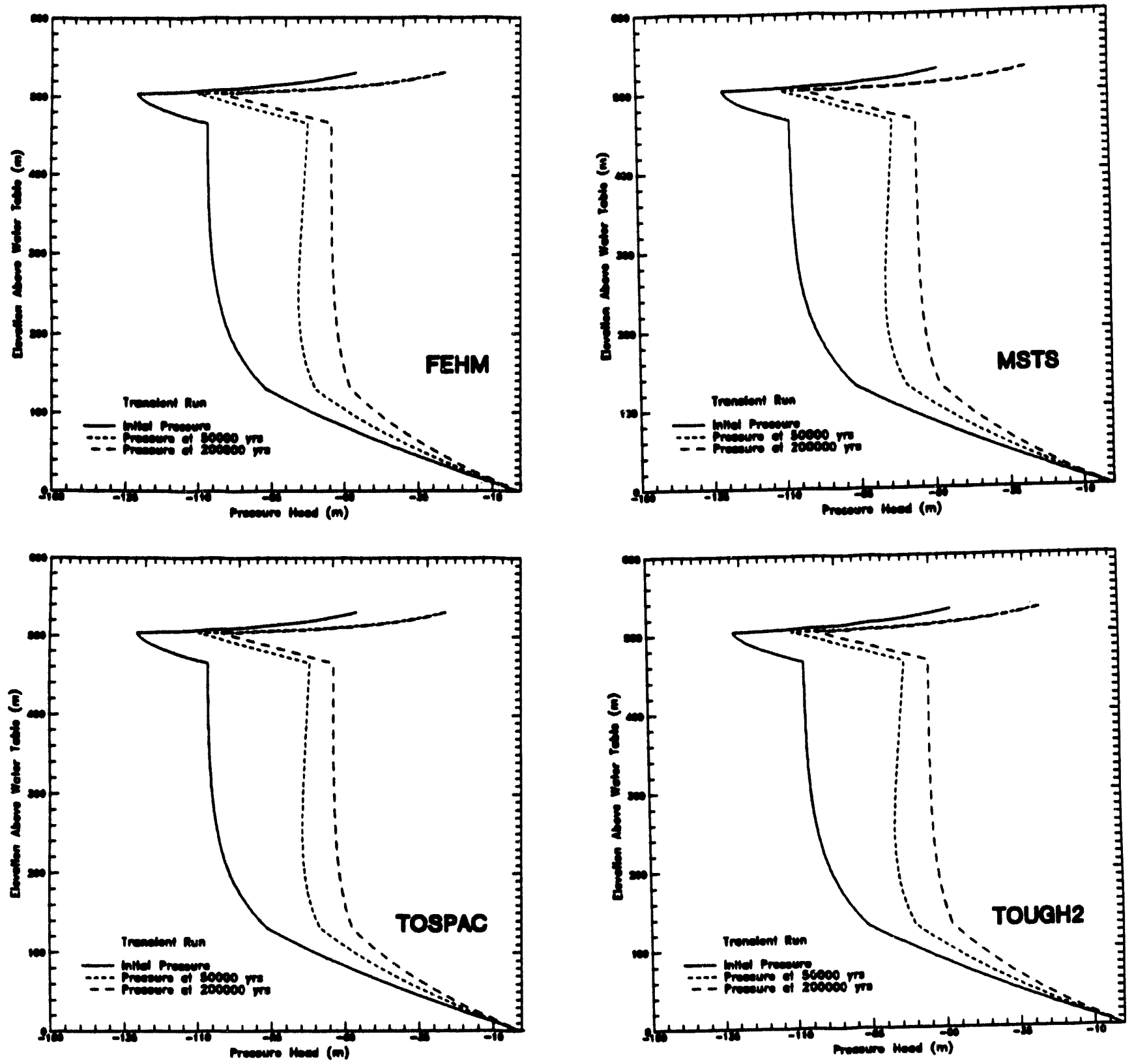

Fiare 8. Calculated Capllary-Preacurs Pronke for the COVE2a Problem 


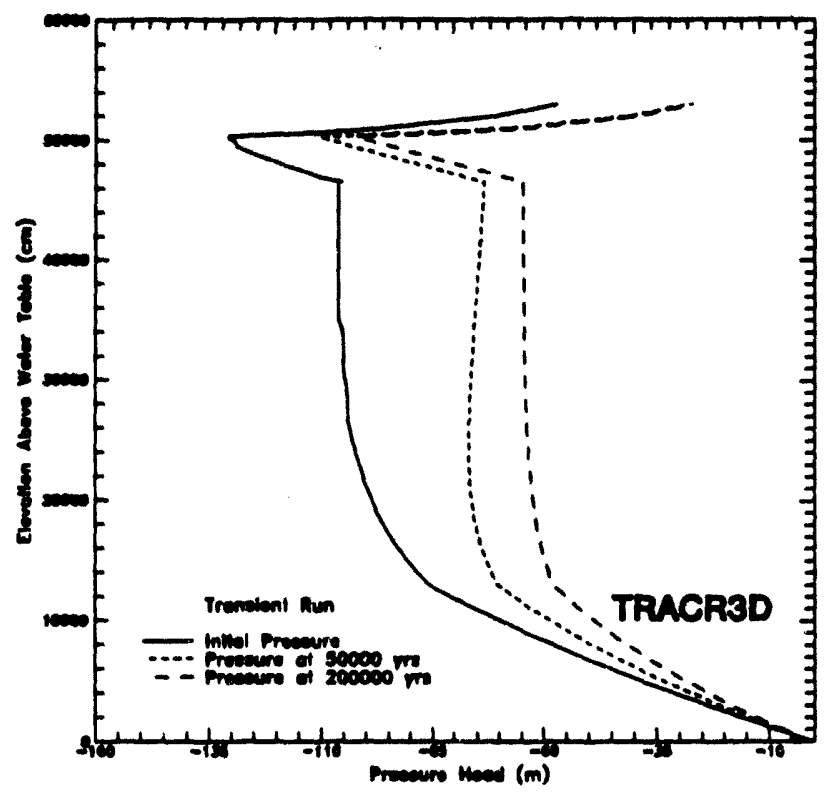

Figre \& Caloulated Caplibary-Preacure Proflles for the COVE2a Problem (Continued. 


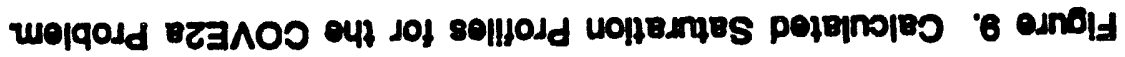
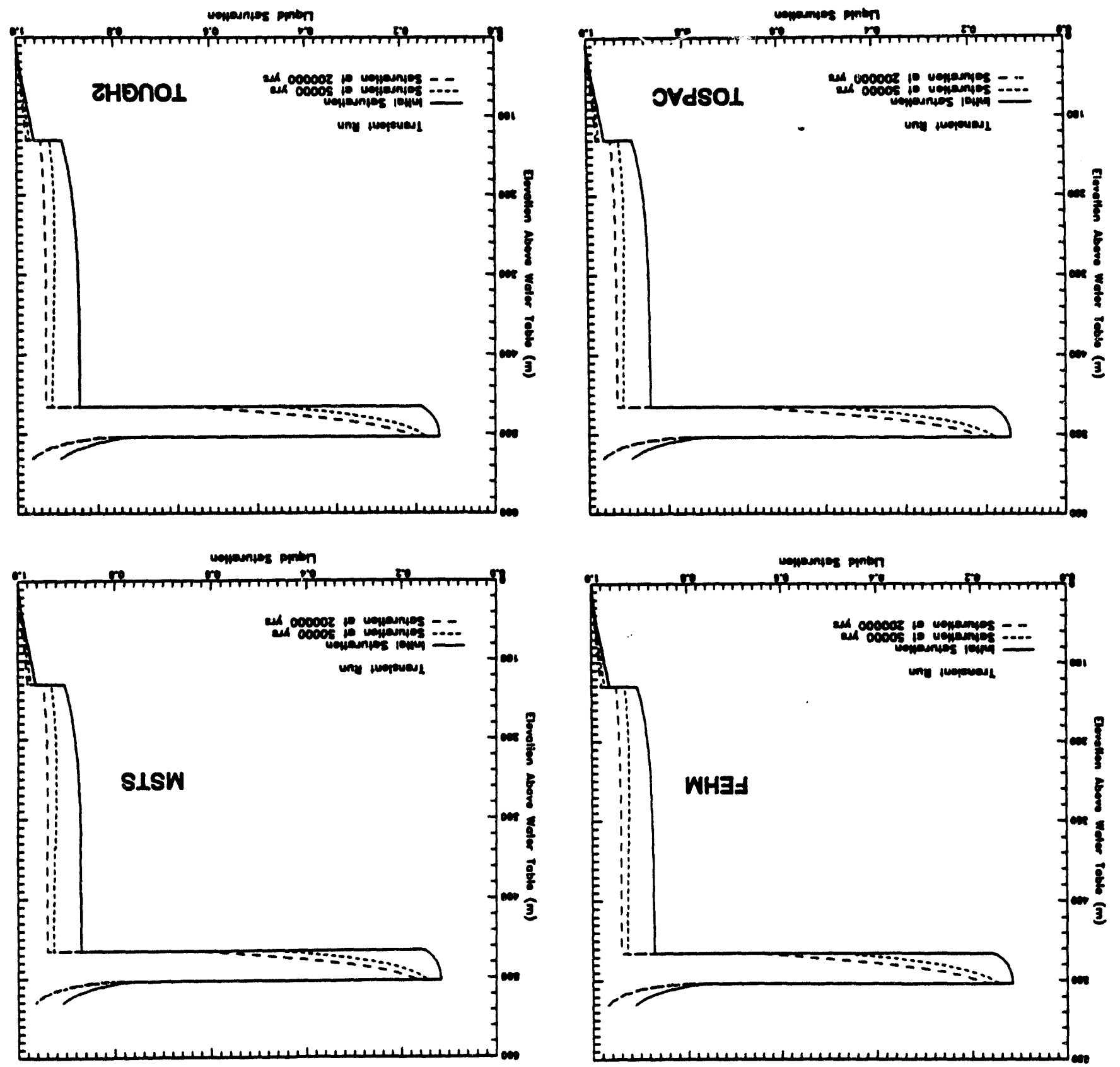


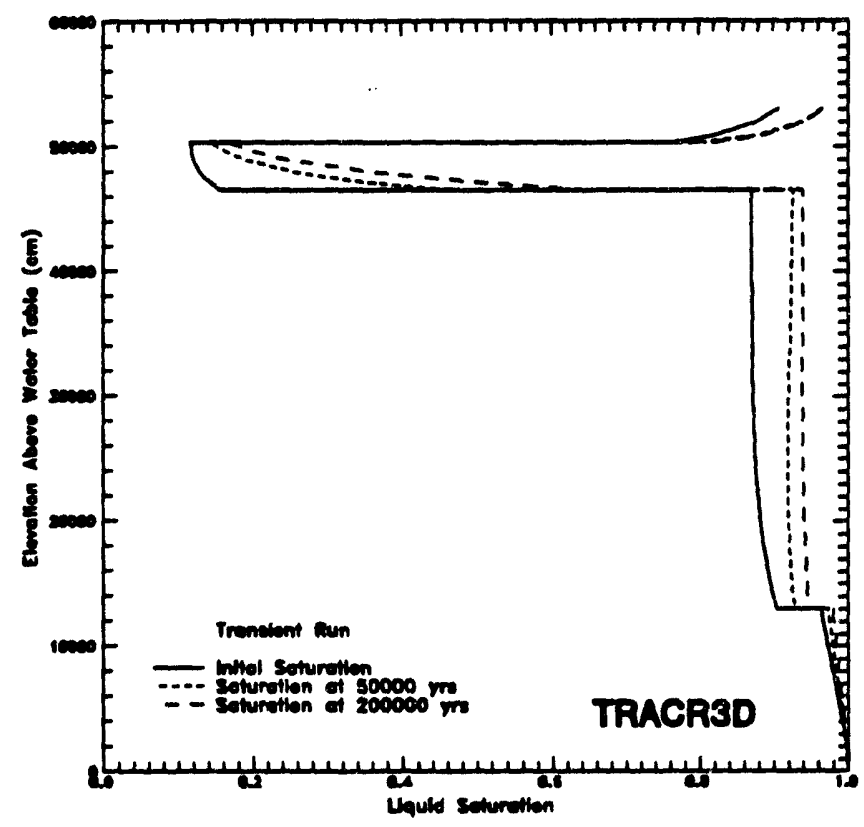

Figure 8. Calculated Saturation Profiles for the COVE2a Problem (Continued). 
TABLE 9. Computational Parameters for the COVE2a Problem

\begin{tabular}{|l|c|c|c|c|}
\hline CODE & $\begin{array}{c}\text { NUMBER OF } \\
\text { PHASES(0) }^{(0)}\end{array}$ & $\begin{array}{c}\text { CPU TIME } \\
(\mathbf{0 0 C})\end{array}$ & $\begin{array}{c}\text { NUMBER OF } \\
\text { TIME STEPS }\end{array}$ & $\begin{array}{c}\text { NUMBER } \\
\text { TTERATIONS }\end{array}$ \\
\hline MSTS & 1 & 120 & 48 & 86 \\
TOSPAC & 1 & 95 & - & 135 \\
TRACR3D & 1 & 108 & 65 & 231 \\
\hline FEHM(0) & 2 & 204 & 31 & 72 \\
TOUGH2 & 2 & 342 & 42 & 167 \\
\hline
\end{tabular}

(a) Time-stepping parameters depended on the number of phases according to the following table:

\begin{tabular}{|c|c|c|c|}
\hline NUMBER OF PHASES & $\begin{array}{c}\text { INITIAL } \\
\text { TIME STEP } \\
(\mathrm{yr})\end{array}$ & $\begin{array}{c}\text { MAGNIFICATION } \\
\text { FACTOR }\end{array}$ & $\begin{array}{c}\text { MAXIMUM } \\
\text { TIME STEP }(\mathrm{yr})\end{array}$ \\
\hline 1 & 3.0 & 1.3 & 10,000 \\
\hline 2 & 3.0 & 2.0 & 10,000 \\
\hline
\end{tabular}

(b) Two-dimensional calculation 

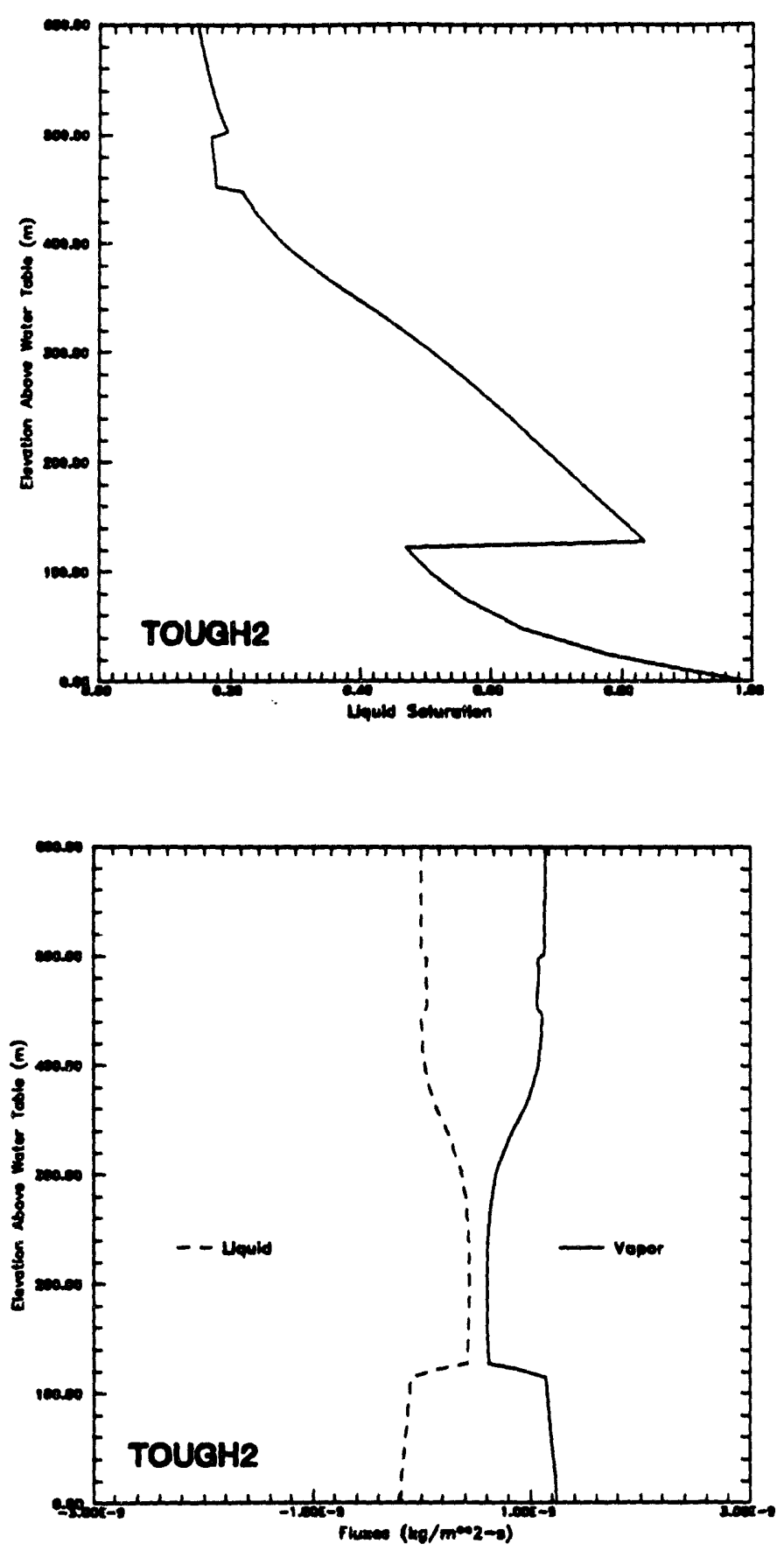

10. Calculated Saturation and Fux Proflies at Steady State for the Pri-Emplacement Vapor-Dithusion Problem. 
Figure 10 shows the extent to which liquid and vapor flows mirror each other. When combined, they yield a net upward flow of $0.03 \mathrm{~mm} / \mathrm{yr}$. The TOUGH2 CPU time measured 47.3 seconds on a $486 / 33$ personal computer.

\subsubsection{The Repository Heat Pipe}

The test plan (Table 6) calls for testing FEHM, TOUGH2, and NUFT. Because of time constraints on the study, this testing has not been completed. 


\section{CONCLUSIONS}

This study has led to two different sets of conclusions. One set, identified as "General Conclusions" considers a general comparison of model capabilities with model requirements. It identifies deficiencies which now exist. A second set of conclusions, identified as "ModelSpecific Conclusions" considers specific codes. It identifies noteworthy characteristics of the various implementations.

\subsection{GENERAL CONCLUSIONS}

Tables 2 and 3 list the model requirements. In addition to the regulations of 10 CFR 60 and 40 CFR 191, these model requirements derive from the geologic nature of Yucca Mountain and from the theory of unsaturated flow. A comparison of model capabilities with the model requirements of Tables 2 and 3 yields the following conclusions:

- Several models address the physical and numerical requirements of Tables 2 and 3 sufficiently well that they may be used as host structures for future development. Future development can thus focus manpower and financial resources on upgrading selected existing codes.

- Several models can simulate Yucca Mountain problems of moderate size using the approximation of a fracture-matrix continuum with isotropic fracture connectivity. However, Requirement 1 of Table 2 and Requirements 1, 5, and 7 of Table 3 will necessitate a consideration of the fracture-matrix discontinuum with anisotropic connectivity. Models in current use by the YMP cannot adequately characterize this effect.

- Only in one-dimensional implementations can currently available models characterize the effect of non-equilibrium fracture-matrix flow. Requirements 3 and 4 of Tables 2 and 3 indicate that this capability is inadequate.

- The efficiency demands for simulating a fracture-matrix discontinuum and non-equilibrium fracture-matrix flow are significant. Substantial improvements in both hardware and software are needed in order to meet these requirements.

- Single-phase, liquid-flow models based on the Richards equation are appropriate for site-characterization and test-design analyses relating to the system prior to waste emplacement. However, the inability of such models to characterize the effect of temperature on the movement of water in liquid and gaseous phases makes such models inappropriate for performance assessment of the post-emplacement system (Requirement 1 of Table 2 and Requirements 5, 6, and 7 of Table 3).

\subsection{CODE-SPECIFIC CONCLUSIONS}

This study has considered two different groups of models. One group comprises the various codes used within the project to characterize unsaturated liquid flow and transport. Here the 
conclusions derive both from a cross-comparison of model capabilities and code testing. The other group comprises the two relatively unique models, FracMan and TGIF.

\subsubsection{Model Capabilities}

A cross-comparison of model capabilities (Sections 4.3, 5.1, and 5.2) led to the following conclusions:

- The TOUGH2 model offers a very capable multiphase, nonisothermal flow model using a finite-difference implementation. However, NUFT has similar capabilities, and further examination of this recently released code may show it to be an attractive alternative to TOUGH2.

- FEHM offers the most capable multiphase, nonisothermal flow model using a finiteelement implementation.

- TRACR3D provides the most capable transport model. TRACR3D also provides the most capable single-phase flow model using a finite-difference implementation.

- MSTS has an excellent input preprocessor, and a flexible implementation of boundary conditions facilitates its application. The clarity of its coding is excellent. Otherwise, however, it does not add significantly to the capabilities present in TOUGH2.

- TOSPAC's user interface may be the best in the project and, like MSTS, the clarity of its coding is excellent. In addition to its usefulness as the flow and transport module of the total system analyzer TSA, TOSPAC makes an excellent utility code.

\subsubsection{Code Testing}

The above conclusions, together with a desire to test several relatively unique algorithms, led to a selection of codes for testing. Using the problems defined in Appendix B, four multiphase, nonisothermal flow models (FEHM, MSTS, NUFT, and TOUGH2) and four single-phase liquidflow models (LLUVIA-II, TOSPAC, TRACR3D, and VS2DT) were tested. The results (Section 6.3) may be summarized in the following manner:

- Except in special cases, the Picard and hybrid methods appear to be inappropriate for the non-linearities caused by Yucca Mountain moisture conditions and hydrogeologic properties.

- Because of enhanced robustness, the CPU times of two-phase simulations can be quite competitive with the CPU times of single-phase, Richards-equation simulations.

- For transient simulation of the one-dimensional COVE2a problem, the single-phase results were quite similar both in terms of the saturation profiles obtained and the CPU times required. Although TOSPAC's user friendliness make it highly desirable 
as a utility code, its one-dimensional coding appears to offer only marginal efficiency improvement over that obtainable through one-dimensional implementations of the three-dimensional codes TRACR3D and MSTS.

- For optimal efficiency, the method-of-lines solver used by LLUVIA-II requires a high level of accuracy. Here, the simulation error is several orders of magnitude smaller than is necessary for practical applications, and the CPU time is relatively large. The latter characteristic appears to rule out all but specialized applications of the method of lines to Yucca Mountain problems.

\subsubsection{FracMan}

Sections A.6 and A.14 (Appendix A) report the reviews of two models which have relatively unique capabilities. FracMan develops statistical fracture properties and, from them, develops geometrical realizations of fractured rock. TGIF simulates the mountain-scale movement of water vapor and gas. The review of FracMan may be summarized in the following manner:

- Requirement 1 of Table 2 and Requirements 1, 5, and 7 of Table 3 necessitate a consideration of the fracture-matrix discontinuum and its anisotropic connectivity.

- In its focus on the geometrical characteristics of fractured rock, FracMan provides one of two capabilities needed to satisfy these requirements.

- The second capability, namely the abilities to simulate the multiphase and unsaturated single-phase flow does not presently exist within the YMP.

\subsubsection{TGIF}

The review of TGIF may be summarized in the following manner:

- Requirement 1 of Table 2 and Requirements 1 and 5 of Table 3 call for a consideration of mountain-scale movements of water vapor and gas.

- Multiphase flow models can simulate the movements of water vapor and gas, but an excessive demand for computer resources rules out mountain-scale analyses. Thus, at the present time, TGIF alone is capable of performing such simulations.

- However, TGIF cannot adequately consider either the effect of the repository heat pipe on the mountain-scale movements of water vapor and gas or the effect of the latter on repository temperature.

- Furthermore, in common with other flow models used by the project, TGIF cannot account for the fracture-matrix discontinuum and its anisotropic connectivity. 


\section{RECOMMENDATIONS}

\subsection{GENERAL RECOMMENDATIONS}

Where the general recommendations below require additional development, selected codes should be the basis for that development.

- Several models address the physical and numerical requirements of Tables 2 and 3 sufficiently well that they may be used as host structures for future development. Thus, the development of new stand-alone models should be sharply curtailed, thereby permitting funure development to focus on upgrading selected existing codes.

- To satisfy the requirements of 10 CFR 60 and 40 CFR 191 relating to the prevalence of fractured rock at Yucca Mountain, future model development should consider a simulation capability for discrete-fracture effects, including an anisotropic connectivity.

- To satisfy the requirements of 10 CFR 60 and 40 CFR 191 relating to the prevalence of fractured rock at Yucca Mountain, future model development should consider a multidimensional simulation capability for non-equilibrium fracturematrix flow.

- The demands for improvement in computational efficiency are substantial. These demands stem both from the requirements of 10 CFR 60 and 40 CFR 191, as expressed above, and from the needs of site-characterization and design calculations. Strong focus and project-wide coordination is needed. Strategies for future development should consider software improvements, including those appropriate for massive parallelization. A suitable goal would be the solution of a multiphase, nonisothermal Yucca Mountain problem of 100,000 grid cells in a CPU time of less than 24 hours.

- Since future model-development problems will be difficult and funds are limited, the number of stand-alone codes to be carried forward should be minimized.

\subsection{CODE-SPECIFIC RECOMMENDATIONS}

This section presents recommendations for future model development. These recommendations assume that both finite-difference and finite-element codes are needed with one of them, the primary code, performing most of the calculations and the other, the secondary code, providing cross-verification. The recommendations also assume that, in addition to a multiphase capability, a single-phase flow capability is also needed, at least for the present. They are:

- To avoid unnecessary duplication of effort, future development should focus on certain selected codes. They may be regarded as host structures for future development. The selected codes are: FEHM, TGIF, TOUGH2, TRACR3D, and FracMan, with one possible exception. Further analysis of the NUFT code may show it to be an attractive altemative to TOUGH2. 
- As a primary multiphase, continuum model, use TOUGH2.

- As a primary multiphase, discrete-fracture flow model, link FracMan and FEHM.

- As a primary single-phase liquid-flow model, use TRACR3D.

- If a secondary single-phase liquid-flow model is desired, put a single-phase switch in FEHM.

- As a single-phase, discrete-fracture, gas-flow model, link FracMan and TGIF. Then expand TOIF to characterize the coupled effects of a repository heat pipe and mountain-scale gas flow. This expansion should be aimed at maintaining TGIF's mountain-scale advantage over the multiphase models. 


\section{REFERENCES}

Aziz, K and A. Settari, 1979. Petroleum Reservoir Simulation, Elsevier Applied Science Publishers, London and New York.

Birdsell, K.H., and B.J. Travis, 1991a. TRACR3D: A Model of Flow and Transport in Porous Media, LA-11798-M, Los Alamos National Laboratory, Los Alamos NM.

Birdsell, K.H., and B.J. Travis, 1991b. Results of the COVE2a Benchmarking Calculations Run with TRACR3D, LA-11513-MS, Los Alamos National Laboratory, Los Alamos NM.

Bixler, N.E., 1985. NORIA - A Finite Element Computer Program for Analyzing Water, Vapor, and Energy Transport in Porous Media, SAND84-2057, Sandia National Laboratories, Albuquerque NM.

Buscheck, T.A., and J.J. Nitao, 1992. The Impact of Thermal Loading on Repository Performance at Yucca Mountain, paper prepared for the 1992 International High Level Radioactive Waste Management Conference, April 12-16, 1992, Las Vegas, Nevada, Lawrence Livermore Laboratory, Livermore CA.

Dalen, V., 1979. Simplified Finite-Element Models for Reservoir Flow Problems, Soc. Pet. Eng. 19 333-343.

Dershowitz, W.S., G. Lee, and J.E. Geier, 1991. FracMan Version Beta 2.3 Interactive Discrete Feature Data Analysis, Geometric Modeling, and Exploration Simulation - User Documentation, Golder Associates Inc., Redmond WA.

Dudley, A.L., R.R. Peters, J.H. Gauthier, M.L. Wilson, M.S. Tierney, and E.A. Klavetter, 1988. Total System Performance Assessment Code (TOSPAC) Volume 1: Physical and Mathematical Bases, SAND85-0002, Sandia National Laboratories, Albuquerque NM.

Duguid, J.O., and M. Reeves, 1976. Material Transport Through Porous Media: A Finite Element Galerkin Model, ORNL-4928, Oak Ridge National Laboratory, Oak Ridge, TN.

Eaton, R.R., D.K. Gartling, and D.E. Larson, 1983. SAGUARO - A Finite Element Computer Program for Partially Saturated Porous Flow Problems, SAND82-2772, Sandia National Laboratories, Albuquerque NM.

Eaton, R.R. and P.L. Hopkins, 1991. LLUVIA-II: A Program for Two-Dimensional, Transient Flow Through Partially Saturated Porous Media, SAND91-2416, Sandia National Laboratories, Albuquerque NM.

Gauthier, J.H., M.L. Wilson, R.R. Peters, A.L. Dudley, and L.H. Skinner, 1992. Total System Performance Assessment Code (TOSPAC) Volume 2: User's Guide, SAND85-0004, Sandia National Laboratories, Albuquerque NM. 
Gauthier, J.H., N.B. Zieman, and W.B. Miller, 1991. TOSPAC Calculations in Support of the COVE 2A Benchmarking Activity, SAND88-2730, Sandia National Laboratories, Albuquerque NM.

Hindmarsh, S.C., 1981. ODE Solvers for Use With the Method of Lines, UCRL-85293, Lawrence Livermore National Laboratories, Livermore CA.

Hopkins, P.L., 1990. COVE 2A Benchmarking Calculations Using LLUVIA, SAND88-2511, Sandia National Laboratories, Albuquerque NM.

Hopkins, P.L., R.R. Eaton, and N.E. Bixler, 1991. NORIA-SP: A Finite Element Computer Program for Analyzing Liquid Water Transport in Porous Media, SAND90-2542, Sandia National Laboratories, Albuquerque NM.

Lappala, E.G., R.W. Healy, and E.P. Weeks, 1987. Documentation of Computer Program VS2D to Solve the Equations of Fluid Flow in Variably Saturated Porous Media, WaterResources Investigations Report 83-4099, U.S. Geological Survey, Denver CO.

Magnuson, S.O., R.G. Baca, and A.J. Sondrup, 1990. Independent Verification and Benchmark Testing of the PORFLO-3 Computer Code, Version 1.0, EGG-BG-9175, Idaho National Engineering Laboaratory, Idaho Falls, Idaho.

Martinez, M.J., 1985. FEMTRAN - A Finite Element Computer Program for Simulating Radionuclide Transport Through Porous Media, SAND84-0747, Sandia National Laboratories, Albuquerque, NM.

Miller, I., 1990. MAFIC Version Beta 1.2 Matrix/Fracture Interaction Code with Solute Transport - User Documentation, Golder Associates Inc., Redmond WA.

Nichols, W.E. and M.D. White, 1993. MSTS - Multiphase Subsurface Transport Simulator User's Guide and Reference, Pacific Northwest Laboratory, Richland, WA, to be published.

Nitao, J.J., 1989. V-TOUGH - An Enhanced Version of the TOUGH code for the Thermal and Hydrologic Simulation of Large-Scale Problems in Nuclear Waste Isolation, UCID-21954, Lawrence Livermore National Laboratory, Livermore CA.

Nitao, J.J., 1992. Main User's Manual for the NUFT Flow and Transport Code, Lawrence Livermore National Laboratory, Livermore, CA, to be published.

Prindle, R.W., 1986. "Benchmarking of Flow and Transport Codes, COVE2a-Yucca Mountain Hydrology," Memorandum, YMP Accession No. NNA.890523.0140, Sandia National Laboratories, Albuquerque NM.

Pruess, K., 1991. TOUGH2 - A General-Purpose Numerical Simulator for Multiphase Fluid and Heat Flow, LBL-29400, Lawrence Berkeley Laboratory, Berkeley CA. 
Reeves, M. and J.O. Duguid, 1975. Water Movement Through Saturated-Unsaturated Porous Media: A Finite-Element Galerkin Model, ORNL 4927, Oak Ridge National Laboratory, Oak Ridge, TN, 232 pp.

Ross, B., S. Amter, and N. Lu, 1991. Numerical Studies of Rock-Gas Flow in Yucca Mountain, SAND91-7034, Sandia National Laboratories, Albuquerque, NM.

Runchal, A.K., and B. Sagar, 1991. PORFLOW: A Model for Fluid Flow, Heat, and Mass Transport in Multifluid, Multiphase Fractured or Porous Media, User's Manual - Version 2.34, ACRi/016/Rev. E, Analytical and Computational Research, Inc., West Los Angeles CA.

Shampine, L.F., and H.A. Watts, 1980. DEPAC-Design of a User Oriented Package of ODE Solvers, SAND79-2374, Sandia National Laboratories, Albuquerque NM.

Smyth, J.D., S.B. Yabusaki, and G.W. Gee, 1989. Infiltration Evaluation Methodology - Letter Report 3: Selected Tests of Infiltration Using Two-Dimensional Numerical Models, Pacific Northwest Laboratory, Richland WA.

Tsang, Y.W., and K. Pruess, 1990. Further Modeling Studies of Gas Movement and Moisture Migration at Yucca Mountain, Nevada, LBL-29127, Lawrence Berkeley Laboratory, Berkeley CA.

Updegraff, C.D., C.E. Lee, and D.P. Gallegos, 1991. DCM3D: A Dual-Continuum, Three Dimensional, Ground-Water Flow Code for Unsaturated, Fractured, Porous Media, NUREG/CR-5536, SAND90-7015, Sandia National Laboratories, Albuquerque NM.

Yeh, G.T., 1987. FEMWATER: A Finite-Element Model of WATER Flow Through SaturatedUnsaturated Porous Media-First Revision, ORNL-5567/R1, Oak Ridge National Laboratory, Oak Ridge, TN.

Yeh, G.T., and D.S. Ward, 1981. FEMWASTE: A Finite-Element Model of WASTE Transport Through Porous Saturated-Unsaturated Media, ORNL-5601, Oak Ridge National Laboratory, Oak Ridge, TN.

White, M.D., and W.E. Nichols, 1993. MSTS - Multiphase Subsurface Transport Simulator Theory Manual, Pacific Northwest Laboratory, Richland, WA, to be published.

Zyvoloski, G., Z. Dash, and S. Kelkar, 1992. FEHMN 1.0: Finite Element Heat and Mass Transfer Code, LA-12062-MS, Los Álamos National Laboratory, Los Alamos, NM. 
APPENDIX A

MODEL REVIEWS 


\section{A.1 DCM3D}

1. Name of the Model

DCM3D

2. General Program Information

2.1 Program size. DCM3D has approximately 10,000 lines of source code.

2.2 Programming language. ANSI standard FORTRAN

2.3 Computer system on which it operates. The user's manual reports the use of a Cray XMP-24. Updegraff, the author, reports (private communication, 1991) that the program also operates on a VAX 8700 and an IBM PC.

2.4 Compiler(s) used. DCM3D uses standard compilers for each of these computers.

2.5 Location of code and availability. Inquiries on code availability should be directed to C.D. Updegraff at GRAM, Inc., 1709 Moon Street Northeast, Albuquerque, New Mexico 87112.

2.6 Brief description of model/code history. The U.S. Nuclear Regulatory Commission (NRC) is developing a performance assessment methodology for analyzing the longterm disposal of high-level radioactive waste (HLW). The program's development was prompted by the NRC's need to provide independent regulation and evaluation of the U.S. Department of Energy's (DOE) HLW disposal activities. As part of the program, NRC contracted Sandia National Laboratories (SNL) to assist in the development of a computer code to model isothermal ground-water flow in an unsaturated, fractured, porous medium. The result of this work is DCM3D, a code developed by Updegraff et al. (1991).

\section{Status of Model}

3.1 Development (Is the model now undergoing significant development or modification? or continuing maintenance?). To our knowledge, no new developments on DCM3D are currently underway.

3.2 Documentation. DCM3D: A Double-Continuum, Three-Dimensional, Ground-Water Flow Code for Unsaturated, Fractured, Porous Media (Updegraff et al., 1991)

3.3 Status of verification and validation. The DCM3D user's manual (Updegraff et al., 1991 ) includes four illustrative problems. Only one (Problem 2) is new. Two are recommended as benchmarks by an NRC-funded study (Ross et al., 1982) and have been executed by other codes. Updegraff (1989) and Moridis and Pruess (1992) report results for one of these (Problem 1) using NORIA (Bixler, 1985), TOUGH 
(Pruess, 1987), and PETROS (Hadley, 1985). For the other (Problem 3), an unpublished NRC benchmarking report gives results using several codes, including SWIFT II (Reeves et al., 1986). Problem 4 derives from the experimental work of Vauclin (1978). These problems are discussed separately below:

Problem 1 - One-Dimensional Infiltration. An infiltration front enters a semi-infinite horizontal tube filled with a homogeneous soil. Air is not accounted for and is a passive spectator. This problem, one of the benchmarks adopted by Ross et al. (1982), compares the DCM3D solution with the semi-analytical results of Philip (1955). To characterize infiltration for 9,504 s, 40 grid blocks were used. The Cray XMP-24 analysis required 90 time steps and $0.30 \mathrm{~s}$ of CPU time, and the VAX 8700 analysis required 162 time steps and $3.0 \mathrm{~s}$.

Problem 2 - One-Dimensional Flow Through a Saturated Fractured Medium. A constant flux of water enters one end of a horizontal column containing a fractured medium. As it flows through the fractures, water enters the rock matrix at a rate determined by the transfer coefficient. Water also moves horizontally within the rock matrix, but at a much slower rate than within the fractures. Updegraff et al. (1991) solved this problem both analytically and numerically. Using only 10 grid blocks, the Cray XMP-24 analysis required 293 time steps and 0.31 s of CPU time, and the VAX 8700 analysis required 221 time steps and $2.7 \mathrm{~s}$.

Problem 3 - Production from a Saturated Fractured Medium. As in the Theis problem, water is pumped from a well at a constant rate. Initially, the fractures provide most of the water, and the rate of production is relatively large. Later, following a period of transition, the rock matrix provides most of the water, and the rate of production is relatively small. This problem, one of the benchmarks adopted by Ross et al. (1982), compares the DCM3D solution with the analytical results of Streltsova-Adams (1978). Apparently, DCM3D does not have an option for cylindrical coordinates. For this, a radially symmetric problem, a two-dimensional 40-by-40 Cartesian grid was used. The Cray XMP-24 analysis required 412 time steps and $155 \mathrm{~s}$ of CPU time, and the VAX 8700 analysis required 227 time steps and $917 \mathrm{~s}$.

Problem 4 - Two-Dimensional Infiltration. In this problem, a 2-m-high by 3-m-long vertical slab of soil is recharged at a rate of $4.11 \mathrm{E}-5 \mathrm{~m} / \mathrm{s}$ over a $0.5-\mathrm{m}$ long region at the top left corner of the slab. The slab is bound on the bottom and one side by impermeable boundaries. A trench bounds the other side of the slab, the top portion of which comprises a seepage face. The lower portion of the trench contains water, which is maintained at a constant depth of $0.65 \mathrm{~m}$. This problem compares the numerical results of DCM3D with the experimental results of Vauclin et al. (1979). A 100-by-18 grid was chosen and, with exception to the seepage face, it faithfully implemented the boundary conditions specified by Vauchlin et al. (1979). Since DCM3D does not have a seepage-face option, a no-flow condition was prescribed along the top portion of the trench. Updegraff et al. (1991) note some differences between numerical and experimental results, perhaps arising from this boundarycondition or, as the authors suggest, from heterogeneities distributed throughout the 
slab and especially at a depth of $0.5 \mathrm{~m}$. The Cray XMP-24 analysis required 579 time steps and 245 s of CPU time, and the VAX 8700 analysis required 552 time steps and $2,330 \mathrm{~s}$.

Given a common data base and hydrogeologic characterization of the Yucca Mountain site, participants in the PACE-90 study determined the movement of radionuclides to the accessible environment. This exercise verified the ability of different researchers to independently conceptualize a complex site in a physically consistent manner. Although code implementations varied among the five participants, the study may be considered as a code-verification effort in a broad sense because of similarity of the results. To simulate flow, participants chose DCM3D and five other flow codes. The problem is briefly described as follows:

PACE-90 analysis. DCM3D simulated partially saturated flow in a one-dimensional column extending from the water table to the bottom of the repository and located near drill hole G-4. The conceptualization used fifteen materials with varying hydrologic characteristics and thicknesses. Flow was simulated in both the matrix and fractures. A total of 122 grid blocks discretized the column. At the upper boundary, a net infiltration rate of $0.01 \mathrm{~mm} / \mathrm{yr}$ recharged the system, and, at the lower boundary, a pressure of zero fixed the water-table elevation for matrix and fractures. The flow field calculated by DCM3D was then transferred to NEFTRAN (Longsine et al., 1987) for the radionuclide-transport simulation.

\subsection{Status of Quality Assurance (QA). DCM3D is under an NRC sponsored QA program.}

\section{Type of Model (Phenomena/Processes Modeled)}

DCM3D, a multi-dimensional (one-, two-, or three-dimensional) numerical model, simulates unsaturated flow in a fractured, porous medinm. It utilizes a dual-permeability approach with the continuum of one permeability characterizing the rock matrix and the other characterizing the fractures. A transfer term provides coupling between the two continua. Richards' relation provides the equation of motion for both fractures and matrix. Assumed to have a constant pressure throughout, the air component does not require a governing equation. Air, however, is not entirely a "passive spectator" since its presence leads to both capillary-pressure and relative-permeability effects.

\section{Governing Equations}

The model solves two coupled Richards equations in three dimensions for two continua. It assumes that fractures are sufficiently well connected and uniformly distributed that their effect upon the flow system can be adequately accounted for by means of REV averages. The fractures constitute one continuum; the porous matrix, the other. A transfer term, proportional to the pressure difference, couples the flow within the two continua. For this coupling strategy, known as a pseudo-steady-state approximation, the coefficient of proportionality is assumed to be proportional to the relative permeability of the porous matrix. Typically, DCM3D uses the functional forms developed by van Genuchten (1980) and Maulem (1976) to characterize the dependence of relative permeability and capillary 
pressure upon saturation. However, the model's function sub-programs may be rewritten to handle different functional forms. Water and rock are assumed to be only weakly compressible. The model accounts for changes in density and pore volume in the accumulation (temporal derivative) terms, but not in the transport (spatial derivative) terms.

\section{Method of Solution}

DCM3D applies the finite-difference technique only to the spatial domain, retaining the time variable as a continuous variable. The flow equations thus transform to a coupled set of ordinary differential equations (ODEs). This approach constitutes a significant departure from the approaches used by TOUGH, TRACR3D, MSTS, and NORIA. By employing a differencing procedure also within the time domain, the latter codes become dependent upon a linear-equation solver. In contrast, DCM3D becomes dependent upon ODE methods for stiff systems. Stiffness arises through the variability of specific-storage coefficients and relative permeabilities. DCM3D uses ODEPACK. Developed by Hindmarsh (1983), ODEPACK was applied by Brown and Hindmarsh (1987) to stif ODE systems similar to those anticipated for DCM3D.

\section{Type of Input Parameters}

Data input for DCM3D consists of two types: non-hydrologic parameters necessary to run the code and hydrologic data. The following data are grouped and presented in the order in which they are read by the code.

Non-Hydrologic Data:

- Title

- Subtitle

- Analyst

- Name of file to which plot data are to be written

- Options telling code to run and type of media being solved

- Density, dynamic viscosity, and compressibility of water

- Gravitational acceleration, including its $x-, y-$, and $z$-direction components

- Relative and absolute convergence criteria for LSODES

- Newton-Raphson convergence criteria

- Maximum number of time steps permitted

- Maximum number of time steps permitted between write times 
- Start time for the simulation

- Initial time-step size

- Minimum time-step size permitted between write times

- Maximum time-step size permitted between write times

- Maximum CPU time permitted

- Number of grid blocks in the $x-, y-$, and $z$-directions

- Information on grid-block spacing in the $x-, y-$, and $z$-directions

- Number of write times

- Time at which output is sent to an output file, plot file, or save file

- Control flag indicating whether to calculate moisture content, saturations, or Darcy velocities at particular write times.

Hydrologic/Material Data:

- Number of materials

- Name of material (rock) type

- Minimum and maximum index range for a particular material in $\mathbf{i}, \mathrm{j}$, and $\mathrm{k}$ directions

- Bulk compressibility of porous media

- Porosity of porous material

- Intrinsic permeability of porous material in the $x-, y$-, and $z$-directions

- Moisture content of porous material under fully saturated and residual moisture conditions

- van Genuchten capillary-pressure parameters for the power denominator and for the entire expression

- Parameter in the denominator of the van Genuchten equation

- Bulk compressibility of fractured material

- Porosity of fractured material 
- Intrinsic permeability of fractured material in $x-, y-$ and $z$-directions

- Transfer factor between porous and fractured materials

- Moisture content of fracture material under fully saturated and residual moisture conditions

- Initial conditions

- Number of non-zero flux and pressure boundary conditions tables

- Number of data pairs or triplets in the boundary-condition table

- Type of porous medium and fracture boundary conditions

- Distribution of the boundary conditions between porous and fractured media

- Boundary condition ranges, minimum and maximum index in the $x-, y-$, and $z-$ directions

- Time at which boundary conditions are to be applied

- Value of the boundary conditions for porous medium and fractures

- Number of source term tables in modeled region

- Number of data pairs or triplets in the table of source term data

- Distribution of source term between porous medium and fractures

- Source term range (i.e., minimum and maximum index in the $x-, y-$, and $z$-directions)

- Time at which source term is applied and value of the source term for the porous medium and fractures.

Restart Data:

- Restart information

- Name files, specify options

- Time step data

- Write times

- $\mathrm{X}-, \mathrm{y}-$, and $\mathrm{z}$-direction boundary condition data

- Source term data. 


\section{Type of Output and User Options}

Primary output from DCM3D includes porous media and fracture velocity fields, pressures, and moisture contents (or saturations). From these data, ground-water travel times can be obtained. The user has the option of specifying the times at which the above information is written to either a plot file, an output file, or a save file.

9. Model Interactions (emphasize needed processors)

9.1 Does the model interface with any other models? Yes, see below.

9.2 Source code and type of information needed. Not applicable.

9.3 Receiving code and type of information provided. DCM3D provides velocity fields, pressures, and moisture contents which may be transferred to a transport code. If flow occurs predominantly within the porous media, then the NRC-funded code NEFTRAN (Longsine et al., 1987) may be used. Currently, NRC is funding the development of a radionuclide transport code to simulate transport in a fractured porous media.

9.4 Any pre-or postprocessing needed? Postprocessing of the output data is needed since DCM3D has no graphics capability per se. DCM3D stores output data in a plot file. A FORTRAN computer code, READPL, reads this file, reformats the data, and creates the desired graphics. Assuming that the user will need to modify it, the user's guide (Updegraff et al., 1991) lists READPL.

\section{Model Application}

10.1 Usage within the Civilian Radioactive Waste Management System (CRWMS) program. Within the CRWMS program, DCM3D can be used for code-verification studies. However, it is unclear to what extent a NRC-developed code should be used in licensing calculations by the DOE. DCM3D has the ability to characterize flow and to determine travel times to the accessible environment.

10.2 Usage outside the program. At this point, DCM3D has been used only for analyses related to Yucca Mountain.

\section{Codes With Similar or Same Capabilities}

11.1 Within the program. The Yucca Mountain Site Characterization Project (YMP) has funded the development of several models which are comparable to DCM3D. These codes include TOUGH2 at LBL, V-TOUGH (Nitao, 1989) at LLNL, NORIA (Bixler, 1985) and LLUVIA-II (Eaton and Hopkins, 1992) at SNL, TRACR3D (Birdsell and Travis, 1991) and FEHM (Zyvoloski et al., 1992) at LANL (Los Alamos National Laboratory), and PORFLO-3 and MSTS at PNL (Pacific Northwest Laboratory). In terms of the processes considered, many of the latter codes are more general. Except for LLUVIA-II and PORFLO-3, which are also based on Richard's equation, all of 
the latter include a gas phase. Some of the latter also consider heat transport, and, appropriately, they include a condensing vapor component within the gas phase. Like DCM3D, TOUGH has the ability to perform dual-permeability calculations. Otherwise, DCM3D would be unique in this respect. Its major claim to uniqueness, however, is its method of solution. Only DCM3D and LLUVIA-II use a technique for coupled ordinary differential equations (ODEs) specially designed for stiff systems.

11.2 Outside the program. In addition to DCM3D, the NRC funded the documentation of TOUGH (Pruess, 1987). Further, a number of codes have been developed within the petroleum industry. In terms of the number of processes considered, the "black-oil" and compositional models (Peaceman, 1977) provide a capability which is superior to that of DCM3D. Developed for use in the area of reservoir engineering, these codes are proprietary, and that constitutes a major impediment to their use in licensing. They include ECLIPSE (Exploration Consultants, Ltd.), VIP (J.S. Nolen and Associates, Inc.), THERM (SSI-Intercomp, Inc.), and TETRAD (DYAD 88 Software, Inc.). All of these codes consider multiple phases and components. In addition, THERM and TETRAD simulate nonisothermal processes.

\section{Major Assumptions and Limitations}

DCM3D assumes the following:

- Applicability of the concept of a dual continuum

- Richards' extension of Darcy's law to partially saturated media

- Spatial changes in water density are much smaller than temporal changes and are therefore neglected

- Water is slightly compressible

- Both fracture and porous medium are slightly elastic

DCM3D does not consider the following:

- Fully transient coupling between fracture and porous matrix continua

- Radionuclide transport processes, eg deay-production, dispersion, or sorption

- Heat induced processes

- Vaporization and condensation

- Gas-phase diffusive or corrective tromepor. 


\section{Remarks/General Observations/Discussion}

DCM3D conceptualizes the fractured porous media of Yucca Mountain as a dualpermeability model. In using a transfer function, the model assumes a pseudo-steady-state coupling of fracture and porous-media continua. This represents a generalization of the equivalent-porous medium assumption of Klavetter and Peters (1986), but falls short of fully transient coupling such as that used by SWIFT II (Reeves et al., 1986).

The adequacy of a pseudo-steady-state coupling depends on the response of Yucca Mountain to storm events. It also relates to fracture separations and fracture skins. In his analysis of interference tests, Moench (1984) concludes that both fully transient and pseudo-steady-state approaches are appropriate within the saturated zone at the Nevada Test Site. DCM3D does not consider either heat or gas-phase transport processes. Depending on results of future characterization studies, such processes may be important in determining radionuclide release to the accessible environment.

Potentially, the method of lines can be useful for licensing studies. Apparently this approach is quite competitive with standardly used techniques. For Problems 1 and 4 above, DCM3D is faster than TOUGH by factors of three to four, and, for Problem 1, DCM3D is faster than NORIA (Bixler, 1985) by several orders of magnitude. Standard techniques are basically sequential. It is possible that the method of lines lends itself more readily to parallelization. The M\&O team should examine this issue in greater depth.

14. Comparison to Other Models

See Chapters 4, 5, and 6 of the main text. 


\section{Summary and Recommendations}

- The NRC developed DCM3D for use in their Yucca-Mountain project.

- DCM3D is a detailed process code which is useful for site characterization, site suitability, and detailed design review. For some applications, it may be limited by excessive computer time.

- DCM3D permits either equilibrium or disequilibrium between fracture and matrix. However, it is appropriate only for a pseudo-steady state and may be physically incorrect for a highly transient storm event.

- Like other process codes, DCM3D is too detailed for probabilistic analysis of the total system and is limited by excessive computer time.

- DCM3D does not consider gas-flow, heat-transport, or radionuclide transport processes. Although the last deficiency is remedied by using a compatible receiving code such as NEFTRAN (Longsine et al., 1987), the first two will require substantial code modification.

- DCM3D uses the method of lines. LLUVIA-II also uses the method of lines. The M\&O should evaluate this technique.

- Rather than DCM3D, however, it is recommended that the M\&O obtain a reference copy of LLUVIA-II. As a more simple implementation, the latter should offer a better vehicle for testing the method of lines. It is thus recommended that DCM3D not be considered for either component or site-representative testing. However, depending on the nature of future interactions with NRC, it may be appropriate to reconsider the latter recommendation.

\section{References}

Birdsell, K.H., and B.J. Travis, 1991. TRACR3D: A Model of Flow and Transport in Porous Media, LA-11798-M, Los Alamos National Laboratory, Los Alamos, NM.

Bixler, N.E., 1985. NORIA - A Finite Element Computer Program for Analyzing Water, Vapor, and Energy Transport in Porous Media, SAND84-2057, Sandia National Laboratories, Albuquerque, NM.

Eaton, R.R., and P.L. Hopkins, 1992. LLUVIA-II: A Program for Two-Dimensional, Transient Flow Through Partially Saturated Porous Media, SAND91-2416, Sandia National Laboratories, Albuquerque, NM.

Hadley, G.R., 1985. PETROS - A Program for Calculating Transport of Heat, Water, Water Vapor, and Air Through a Porous Material, SAND84-0878, Sandia National Laboratories, Albuquerque, NM. 
Longsine, D.E., Bonano, E.J., and Harlan, C.P., 1987. User's Manual for the NEFTRAN Computer Code, NUREG/CR-4766, U.S. Nuclear Regulatory Commission, Washington DC, and SAND86-4766, Sandia National Laboratories, Albuquerque, NM.

Moench, A.F., 1984. Double-Porosity Models for a Fissured Groundwater Reservoir With Fracture Skin, Water Resour. Res., 20(7), 831-846.

Moridis, G.J., and K. Pruess, 1992. TOUGH Simulations of Updegraff's Set of Fluid and Heat Flow Problems, LBL-32611, Lawrence Berkeley Laboratory, Berkeley, CA.

Nitao, J.J., 1989. V-TOUGH - An Enhanced Version of the TOUGH code for the Thermal and Hydrologic Simulation of Large-Scale Problems in Nuclear Waste Isolation, UCID21954, Lawrence Livermore National Laboratory, Livermore, CA.

Philip, J.R., 1955. Numerical Solution of Equations of the Diffusive Type with Diffusivity Concentration Dependent, Transactions, Faraday Society 51, 885-892.

Peaceman, D.E., 1977. Fundamentals of Numerical Reservoir Simulation, Elsevier Scientific Publishing Company, New York.

Pruess, K., 1987. TOUGH User' a Guide, NUREG/CR-4645, SAND86-7104, LBL-20700, Sandia National Laboratories, Albuquerque, NM.

Reeves, M., D.S. Ward, N.D. Johns, and R.M. Cranwell, 1986. Theory and Implementation for SWIFT II, The Sandia Waste-Isolation Flow and Transport Model for Fractured Media, Release 4.84, NUREG/CR-3328, U.S. Nuclear Regulatory Commission, Washington DC, and SAND83-1159, Sandia National Laboratories, Albuquerque, NM.

Ross, B., J.W. Mercer, S.D. Thomas, and G.H. Lester, 1982. Benchmark Problems for Repository Siting Models, NUREG/CR-3097, Geotrans, Inc., Reston, VA.

Streltsova-Adams, T.D., 1978. Well Hydraulics in Heterogeneous Aquifer Formations, in Advances in Hydroscience, V.T. Chow, Ed., Academic Press, NY, pp. 357-423.

Updegraff, C.D., 1989. Comparison of Strongly Heat-Driven Flow Codes for Unsaturated Media, NUREG/CR-5367, SAND88-7145, Sandia National Laboratories, Albuquerque, NM.

Updegraff, C.D., C.E. Lee, and D.P. Gallegos, 1991. DCM3D: A Dual-Continuum, Three Dimensional, Ground-Water Flow Code for Unsaturated, Fractured, Porous Media, NUREG/CR-5536, SAND90-7015, Sandia National Laboratories, Albuquerque, NM.

Vauchlin, M., K. Khanji, and G. Vachaud, 1979. Experimental and Numerical Simulation of a Transient Two-Dimensional Unsaturated-Saturated Water Table Recharge Problem, Water Resources Research 15(5), 1089-1101. 
Zyvoloski, G., Z. Dash, and S. Kelkar, 1992. FEHM 1.0: Finite Element Heat and Mass Transfer Code, LA--12062-MS, Rev. 1, Los Alamos National Laboratory, Los Alamos, NM. 


\section{A.2 FEHM}

1. Name of the Model

FEHM

\section{General Program Information}

2.1 Program size. Approximately 10,000 lines of source code

\subsection{Programming language. FORTRAN 77}

2.3 Computer system on which it operates. FEHM (Zyvolosky et al., 1992) runs on Cray, Sun, VAX, and IBM PC. The Sun version is under quality-assurance (QA) control. An in-house processor performs the relatively minor changes necessary to adapt the source rode to each computer.

2.4 Compiler(s) used. Standard compilers are used for each machine.

2.5 Location of code and availability. Only the QA Group EES-13 at LANL (Los Alamos National Laboratory) can release the quality-controlled FEHMN version. Uncontrolled versions of FEHM may be obtained from the author, G. Zyvoloski at LANL.

2.6 Brief description of model/code history. Using finite-element discretization, the original version of FEHM (Zyvoloski et al., 1988), was designed for geothermal applications. It simulated the nonisothermal, two-phase flow of a single component (water) in three dimensions. With the addition of a non-condensing gas component (air) to its flow module, FEHM (Zyvoloski et al., 1992) now simulates two-phase, non-isothermal flow problems which are of interest to the Yucca-Mountain Project. in two and three dimensions. It also simulates the transport of reactive tracers.

\section{Status of Model}

3.1 Development (Is the model now undergoing significant development or modification? or continuing maintenance?). As permitted by funding, LANL is adding facilities for radionuclide chains and for stress calculations.

3.2 Documentation. Zyvoloski et al. (1992) provide a model description and a user's manual. This document, which is thorough and easily followed, meets U.S. Nuclear Regulatory Commission (NRC) requirements as specified in NUREG-0856. A separate document (Zyvoloski and Dash, 1992) addresses the issues of verification and validation. 
3.3 Status of verification and validation. At the present time, the verification of FEHM is limited to the two example problems contained in (Zyvoloski et al., 1992). However, LANL has completed a draft verification document (Zyvoloski and Dash, 1992). When released, it will include nine problems designed to activate the major processes simulated by the code. These problems focus on heat transport, single and multiphase flow, coupled flow and heat transport, and tracer transport.

Of the example problems presented by Zyvoloski et al. (1992), the results of two have been compared with those of other codes. Both assume the presence of a production well in a geothermal reservoir. Water vapor represents the dominant component of the gas phase, with the non-condensible gas component having only a negligible effect on reservoir behavior. One of the problems is the Toronyi example (Toronyi and Farouq Ali, 1977). This problem has been used in the code-verification effort reported by Molloy (1980), which included Thomas and Pierson (1978). For a simulation time corresponding, approximately, to removal of 19 percent of the original water mass, the results of FEHM compare reasonably well with those of Thomas and Pierson (1978).

The other geothermal problem is Problem 5, Case A of the DOE Code-Comparison Project. A moving two-phase region characterizes this problem, with the produced fluid replaced by cold-water recharge at the outer boundaries. Zyvoloski et al. (1992) compare the results of FEHM with those of six researchers (Molloy, 1980). For the temperature of the produced fluid and the downhole pressure of both the production well and an observation well, the results of FEHM show good agreement with those of the other codes.

3.4 Status of Quality Assurance (QA). LANL has placed its FEHMN version under QA control.

\section{Type of Model (Phenomena/Processes Modeled)}

FEHM (Zyvoloski et al., 1992) is a multi-dimensional (one-, two-, or three-dimensional) numerical model designed to simultaneously simulate nonisothermal liquid and gas flow and multi-component tracer transport. Features present in the code include:

- Fluid flow in both liquid and gas phases under pressure, viscous, and gravity forces according to Darcy's equation

- Capillarity between liquid and gas phases

- Dual-porosity treatment of fracture-matrix coupling

- Dual-permeability treatment of fracture-matrix coupling

- Transport of sorbing tracers by advection dispersion, and diffusion in both liquid and gas phases. 


\section{Governing Equations}

For partially saturated nonisothermal flow, the model solves three governing equations in as many as three dimensions. One equation effects mass conservation for the water component in both liquid and gas phases, while a second effects mass conservation for a non-condensible gas component in both phases. A third equation yields energy conservation within liquid and gas phases and within the rock. Additional equations establish mass conservation for an arbitrary number of tracer components in both phases. Limited only by computer time and space requirements, the maximum number of tracer components is currently set at ten.

\section{Method of Solution}

FEHM (Zyvoloski et al., 1992) uses finite-element spatial discretization for both flow and transport. Rather than Gauss quadrature, one may elect to use Lobatto integrations over the volume of each element. In contrast to Gauss quadrature, Lobatto integration does not introduce corner connections, thereby reducing the density of the coefficient matrix and decreasing execution time. For a rectangular grid, Lobatto gives a node-connection pattern which is identical to that of a finite-difference algorithm. The resulting equations employ fully implicit finite-difference discretization in the temporal domain, obtaining thereby a coupled set of nonlinear difference equations.

A Newton-Raphson technique linearizes the solution of these equations. Application of the Newton-Raphson method yields a set of linear equations with a non-symmetrix oefficient matrix (the Jacobian matrix). FEHM solves the linearized equations for liquid pressure, temperature, and gas saturation using the minimum-residual technique gmres (Saad and Schultz, 1986), a variant of the conjugate-gradient approach which is suitable for non-symmetric matrices. As a preconditioner, the incompletely factorized Jacobian matrix is applied to the full Jacobian matrix. This minimizes core-storage requirements, and, depending on the size of the problem, it may also minimize the CPU time.

For simulation of fractured systems, FEHM provides dual-porosity and dual-permeability algorithms. Though somewhat limited in its design, the transient fracture-matrix coupling provided by its dual-porosity algorithm provides a substantial upgrade to the conventional pseudo-steady approach.

\section{Type of Input Parameters}

Preprocessor GENMSH and a number of input macros provide the input for FEHM (Zyvoloski et al., 1992). In order to simplify geometric considerations, GENMSH and FEHM divide the solution space into a number of blocks. Blocks are then subdivided into elements, the smallest computational units. Although element types may vary from block to block, each block contains elements of the same type. Volumetric weight factors, specified for each direction, control element volumes, which may vary within a block. For two-dimensional problems, GENMSH and FEHM permit either quadrilaterals with four nodes or triangles with three nodes. For three-dimensional problems, GENMSH and FEHM 
permit either quadrilateral polyhedrons of eight nodes or triangular prisms of six nodes. GENMSH writes FEHM input files for the COOD and ZONE macros.

The following discussion characterizes each of the FEHM input macros:

CAP. Capillary pressure data. Assignment of capillary pressure curve to specified nodes or to a spatial block. Optional.

COOR. Node coordinate data. GENMSH output may be used. Required.

COND. Thermal conductivity data. Assignment of values to specified nodes or to a spatial block. GENMSH output may be used. Required.

CONT. Contour plot data. Optional.

CTRL. Program control parameters. Control nonlinear and linear-solution iterations, time stepping, and implicitness of solution. Optional.

DUAL. Input for dual-porosity solution. Includes only geometric data for rock matrix. Optional.

ELEM. Element node data. GENMSH does generates this data. Required.

EOS. Equation-of-state data. Includes parameters for vapor-pressure, density, and viscosity submodels and reference enthalpy data. Optional.

FLOW. Source-strength data for heat and water component. Optional.

HFLX. Heat-flux data. Optional.

INIT. Initial-value data. Specification of initial data may also require PRES macor. Optional.

ITER. Iteration parameters. Additional nonlinear and linear-solution controls (see CTRL). Optional.

NGAS. Non-condensible gas (air) data. Includes data for partial-pressure submodel and gas sources (sinks). Optional.

NODE. Node numbers for output and time histories. Required.

PERM. Absolute-permeability data. Required.

PPOR. Data for variable porosity and permeability submodels. Optional.

PRES. Initial data for nonuniform pressure and enthalpy distributions. 
RLP. Relative permeability data. Assignment of relative-permeability curves to specified nodes or spatial block. Optional.

ROCK. Absolute rock-density, specific-heat, and porosity data. Required.

SOL. Solution specifications. Identifies flow and heat-transport equations to be solved. Specifies Labatto or Gauss quadrature for element integrations. Required.

STEA. Steady-state solution generated as initial condition. Optional.

STOP. Signals end of input. Required.

TEXT. Text input. Optional.

TIME. Time-stepping data (also see CTRL) for both simulation and output. Required.

TRAC. Tracer data. Includes initial data, implicitness, and linear-solution controls. Optional.

ZONE. Geometric definition of grid. GENMSH output may be used here. Optional.

\section{Type of Output and User Options}

In addition to hard copy, FEHM (Zyvoloski et al., 1992) provides graphical output. The documentation for FEHM describes two graphics routines. Technically both use the DISSPLA graphics package. However, since only primitive line-drawing commands are utilized, they are easily convertible to other systems. For each of the nodes specified through input macro CTRL, postprocessor FEHPLTR plots time histories of temperature, pressure, enthalpy, flow rate, concentration, and capillary pressure. For each of the output distributions specified through input macro CONT, postprocessor FECPLTR constructs contour plots.

\section{Model Interactions (emphasize needed processors)}

9.1 Does the model interface with any other models? See Section 9.4 below.

9.2 Source code and type of information needed. Not applicable.

9.3 Receiving code and type of information provided. Not applicable.

9.4 Any pre- or postprocessing needed? FEHM (Zyvoloski et al., 1992) uses preprocessor GENMSH and graphical postprocessors FEHPLTR and FECPLTR, as discussed above. 


\section{Model Application}

10.1 Usage within the Civilian Radioactive Waste Management Systems (CRWMS) program. If an equivalent continuum is assumed, FEHM (Zyvoloski et al., 1992) can be used to characterize the coupled nonisothermal flow and transport processes within the partially saturated zone. Potentially, FEHM could also be used to characterize the transport of gases although it is somewhat limited by its exclusion of decay processes.

For highly transient episodes, such as storm events, where the equivalent-continuum approximation is inappropriate, FEHM's dual-porosity algorithm is too restricted. For such periods, FEHM offers only a direct gridding approach, the poor efficiency of which makes it practical only for relatively small systems containing few fractures. Given that this deficiency is quite common, one may still note that, for the YuccaMountain unsaturated zone, FEHM is just as applicable to highly transient episodes as other detailed process models within the Yucca-Mountain Project.

FEHM may also be used for simulating saturated flow processes. This capability has been used to design tracer tests for the $\mathrm{C}$-well project.

10.2 Usage outside the program. Originally, FEHM (Zyvoloski et al., 1992) was developed for use as a geothermal simulator. It may still be used in that capacity. It might also have application for near-surface disposal of low-level radioactive and hazardous wastes.

\section{Codes With Similar or Same Capabilities}

11.1 Within the program. The Yucca-Mountain Project has funded the development of several codes with multiphase flow capabilities similar to those of FEHM. These codes include TOUGH2 (Pruess, 1991) at LBL (Lawrence Berkeley Laboratory), V-TOUGH (Nitao, 1989) at LLNL (Lawrence Livermore National Laboratory), NORIA (Bixler, 1985) at SNL (Sandia National Laboratory), MSTS at PNL (Pacific Northwest Laboratory), and TRACR3D (Birdsell and Travis, 1991) at LANL. Like FEHM (Zyvoloski et al., 1992), three of these codes (TOUGH2, V-TOUGH, and MSTS) also consider nonisothermal processes.

The codes differ in terms of conceptualization options, i.e., dimensionality (two or three dimensions) and fracture characterization (equivalent continuum, dual porosity, dual permeability, or discrete fractures). 'They also differ in terms of numerical solution, i.e., spatial-discretization (finite difference or finite element) and linearequations solver (direct solution, successive over-relaxation, method of lines, or gmres).

The Yucca-Mountain Project has funded the development of several codes with transport capabilities, some of which are superior to those of FEHM. With radionuclide chaining and a detailed chemical reaction model, TRACR3D at LANL provides a notable example of the latter. Other transport codes include stand-alone transport codes like FEMTRAN (Martinez, 1985) and LLUVIA-S at SNL. They also 
include total-system codes with imbedded transport routines, like SUMO (Eslinger et al., 1990) at PNL and TOSPAC (Dudley, et al., 1988) at SNL. In terms of conceptualization options and numerical solution, the codes differ in the same respects as the flow codes, with two important exceptions. In contrast to multiphase flow, the effects of non-linearity tend to be much less severe for transport, with transport and chemical-process parameters evidencing either independence or only a weak dependence on concentration.

If it were not for the second item, advection, this weak non-linearity would make the numerical simulation of transport much more efficient than the numerical simulation of flow. However, advection can be a much more dominant process for transport than for multiphase flow, and this tends to degrade computer efficiency.

11.2 Outside the program. In their Yucca-Mountain project, the NRC has funded the documentation of TOUGH (Pruess, 1987) and the development of DCM3D (Updegraff et al., 1991). The former has a general capability for treating multiphase flow while the capability of the latter is limited to that of a dual-permeability implementation of the Richards equation.

Further, a number of codes have been developed within the petroleum industry. In terms of the multiphase-flow processes considered, both black-oil and compositional models (Peaceman, 1977) provide a capability superior to FEHM (Zyvoloski et al., 1992). Developed for use in the area of reservoir engineering, these codes are proprietary, and that constitutes a major impediment to their use in licensing. Compositional models include THERM (SSI-Intercomp, Inc.) and TETRAD (DYAD 88 Software, Inc.). These codes consider more than two phases and two components, and they are nonisothermal.

Other federally funded projects have developed transport codes to characterize the movement of radionuclide chains. SWIFT II (Reeves et al., 1986), a saturated flow and transport code provides one example. The NRC developed this code for their salt-repository project.

\section{Major Assumptions and Limitations}

- A steady-state option is not available. For large problems, running through a transient sequence to achieve steady state represents a costly and needless expenditure of computer time. Since most transient characterization runs assume steady-state initial conditions, this is a significant consideration. Further development may be required.

- The dual-permeability treatment of FEHM (Zyvoloski et al., 1992) does not consider the transient fracture-matrix flow occurring during and after a rain-storm event.

- The dual-porosity treatment of FEHM permits only two nodes in a direction perpendicular to the fracture. This is not sufficient for characterizing the transient fracture-matrix flow and transport processes occurring during and after a rain-storm event. Transient matrix flow is particularly significant for nonwelded units, where it, 
most likely, removes most of the infiltration water from the fractures before it reaches the repository.

- An ideal gas is assumed. Uncertainties due to non-ideal behavior should be acceptable.

- The liquid is assumed to be compressible under saturated conditions, but incompressible under unsaturated conditions. This is an acceptable assumption requiring no additional development.

- FEHM assumes tracer concentrations to be small and thus includes only ordinary diffusion dependent on the concentration gradient. This is a standard assumption requiring no additional development. Bird et al. (1966, pp. 563 ff.) provide a general discussion of multicomponent diffusion.

- FEHM does not consider radionuclide decay and production processes.

- The dispersion tensor is assumed to be dependent on fluid velocity only. Although the literature has questioned this assumption, no acceptable alternative has yet been offered. Thus, no additional development is required at this time.

\section{Remarks/General Observations/Discussion}

In terms of the basic physics of its flow code, FEHM (Zyvoloski et al., 1992) is similar to TOUGH2 (Pruess, 1991) although the latter is more widely accepted. Since it permits an arbitrary number of nodes within the matrix, the TOUGH2 (Pruess, 1991) treatment of matrix flow by its MINC facility is more general than that of FEHM, which permits only two nodes within the matrix. However, in terms of its numerical efficiency, TOUGH2 would profit by implementing a static-condensation solution procedure like that of FEHM, suitably generalized to more than two nodes within the matrix. SWIFT II (Reeves et al., 1986) employs a generalized version of the static condensation procedure. In addition, TOUGH2 efficiency will benefit from the currently ongoing effort to install a gmres solver like that used by FEHM.

Although the models have similar transport capabilities, TRACR3D is superior to FEHM. TRACR3D offers radioactive decay and production processes, while FEHM offers only decaying tracers. TRACR3D also offers a more extensive menu of possible reactions between dissolved constituents and mineral substrates. In addition, TRACR3D offers a facility for high Peclet-number transport which is not currently included in FEHM.

Another significant point about FEHM consists in noting that it is a finite-element code using a gmres solver. The rather arbitrary node-to-node connection pattern (connection molecule) of a finite-element model severely restricts the choice of direct solvers to a banded or frontal solution technique. Consequently, finite-element codes employing only a direct solver generally are significantly less efficient than a comparable finite-difference code, which requires a standard connection molecule. However, the use of a gmres solver should even the gap between finite-element and finite-difference codes for the large problems to be 
encountered at Yucca Mountain. Such a possibility is significant for geometrically complex systems.

\section{Comparison to Other Models}

See Chapters 4, 5, and 6 of the main text.

\section{Summary and Recommendations}

- FEHM is a two-phase, detailed-process code. Its flow code is appropriate for non-stochastic applications, which may be either isothermal or nonisothermal.

- FEHM is the only three-dimensional, finite-element code in the Yucca-Mountain Project. Although the integrated finite-difference approach of TOUGH, also provides a general geometric capability, a finite-element model is the more common choice for geometric flexibility. Furthermore, if an alternative solution approach is necessary, then FEHM is a likely candidate.

- FEHM is one of the two operational codes within the project which currently use a gmres solver. TRACR3D, another LANL code, shares this distinction. For preconditioning, both use incomplete factorization. Gmres solvers, perhaps with alternative preconditioning options, and massive parallelization, may help alleviate the excessive demand for computer resources which now severely limits the application of detail-process codes.

- In consideration of the above, it is recommended that FEHM be included in the component-testing task. 


\section{References}

Bird, R.B, W.E. Stewart, and E.N. Lightfoot, 1960. Transport Phenomena, John Wiley and Sons, New York.

Birdsell, K.H., and B.J. Travis, 1991. TRACR3D: A Model of Flow and Transport in Porous Media, LA-11798-M, Los Alamos National Laboratory, Los Alamos, NM.

Bixler, N.E., 1985. NORIA - A Finite Element Computer Program for Analyzing Water, Vapor, and Energy Transport in Porous Media, SAND84-2057, Sandia National Laboratories, Albuquerque, NM.

Dudley, A.L., R.R. Peters, J.H. Gauthier, M.L. Wilson, M.S. Tierney, and E.A. Klavetter, 1988. Total System Performance Assessment Code (TOSPAC) Volume 1: Physical and Mathematical Bases, SAND85-0002, Sandia National Laboratories, Albuquerque, NM.

Eslinger, P.W., T.B. Miley, and D.W. Engel, 1990. SUMO-System Performance Assessment for a High-Level Nuclear Waste Repository: Mathematical Models, PNL-7581, Pacific Northwest Laboratory, Richland, WA.

Hindmarsh, A.C, 1980. ODE Solvers for Use with the Method of Lines, UCRL-85293, Lawrence Livermore Laboratory, Livermore, CA.

Martinez, M.J., 1985. FEMTRAN - A Finite Element Computer Program for Simulating Radionuclide Transport Through Porous Media, Sandia National Laboratories, SAND840747.

Molloy, M.W., 1980. Geothermal Reservoir Engineering Code Comparison Project, Proceedings of the Sixth Workshop on Geothermal Reservoir Engineering, Stanford University.

Narasimhan, T.N., 1985. A Unified Numerical Model for Saturated-Unsaturated Groundwater Flow, Ph.D dissertation, University of California, Berkeley, CA.

Nitao, J.J., 1989. V-TOUGH - An Enhanced Version of the TOUGH code for the Thermal and Hydrologic Simulation of Large-Scale Problems in Nuclear Waste Isolation, UCD-21954, Lawrence Livermore National Laboratory, Livermore, CA.

Peaceman, D.W., 1977. Fundamentals of Numerical Reservoir Simulation, Elsevier Scientific Publishing Company, New York.

Pruess, K., 1987. TOUGH User's Guide, NUREG/CR-4645, SAND86-07104, LBL-20700, Sandia National Laboratories, Albuquerque, NM.

Pruess, K., 1991. TOUGH2 - A General-Purpose Numerical Simulator for Multiphase Fluid and Heat Flow, LBL-29400, Lawrence Berkeley Laboratory, Berkeley, CA. 
Reeves, M., D.S. Ward, N.D. Johns, and R.M. Cranwell, 1986. Theory and Implementation for SWIFT II, The Sandia Waste-Isolation Flow and Transport Model for Fractured Media, Release 4.84, NUREG/CR-3328, U.S. Nuclear Regulatory Commission, Washington DC, and SAND83-1159, Sandia National Laboratories, Albuquerque, NM.

Saad, Y., and M.H. Schultz, 1986. GMRES: A Generalized Minimal Residual Algorithm for Solving Non-Symmetric Linear Systems, SIAM Journal of Scientific and Statistical Computation 7(3), 856-869.

Thomas, L.K., and R.G. Pierson, 1978. Three Dimensional Reservoir Simulation, Soc. Pet. Eng. J. 18, 151-161.

Toronyi, R.M., and S.M. Farouq Ali, 1977. Two-phase, Two-dimensional Simulation of a Geothermal Reservoir and Wellbore System, Soc. Pet. Eng. J. 17, 171-183.

Updegraff, C.D., C.E. Lee, and D.P. Gallegos, 1991. DCM3D: A Dual-Continuum, Three Dimensional, Ground-Water Flow Code for Unsaturated, Fractured, Porous Media, NUREG/CR-5536, SAND90-7015, Sandia National Laboratories, Albuquerque, NM.

Zyvoloski, G., Z. Dash, and S. Kelkar, 1988. FEHM: Finite Element Heat and Mass Transfer Code, LA-11224-MS, Los Alamos National Laboratory, Los Alamos, NM.

Zyvoloski, G., Z. Dash, and S. Kelkar, 1992. FEHMN 1.0: Finite Element Heat and Mass Transfer Code, LA-12U62-MS, Los Alamos National Laboratory, Los Alamos, NM.

Zyvoloski, G., and Z. Dash, 1992. Verification Report for the Code FEHMN, LA-UR-91-609, Los Alamos National Laboratory, Los Alamos, NM. 


\section{A.3 FEMTRAN}

1. Name of the Model

FEMTRAN

2. General Program Information

2.1 Program size. FEMTRAN (Martinez, 1985) contains approximately 3,000 source statements.

\subsection{Programming language. FORTRAN 77}

2.3 Computer system on which it operates. VAX and Cray.

2.4 Compiler(s) used. Standard compilers.

2.5 Location of code and availability. A copy of FEMTRAN resides in a permanent-file library at Sandia National Laboratories (SNL).

2.6 Brief description of modellcode history. Duguid and Reeves (1976) developed the original version of FEMTRAN under DOE (U.S. Department of Energy) funding. At that time the code was used, in conjunction with the flow code reported by Reeves and Duguid (1975), to analyze partially saturated flow and transport problems for the low-level waste-burial grounds at Oak Ridge, TN. Yeh and Ward (1980) revised the original flow code in order to obtain a continuous velocity field. They named the flow code "FEMWATER" and the transport code "FEMWASTE". Martinez (1985), using DOE funding from the Yucca-Mountain Project, upgraded FEMWASTE. He added a capability for solving radionuclide chains and named the new version "FEMTRAN".

\section{Status of Model}

3.1 Development (Is the model now undergoing significant development or modification? or continuing maintenance?). No.

3.2 Documentation. Martinez (1985) provides a readable discussion of governing equations and data input. The model has changed insignificantly since 1985.

3.3 Status of verification and validation. At the present time, the verification of FEMTRAN consists of three different items.

Sample Problems. In addition to illustrating the application of FEMTRAN, their intended use, the three sample problems of Martinez (1985) also serve as code verifications. Each of these problems considers the transport of a three-member chain. Problem 1, a one-dimensional implementation, assumes equal retention factors, an 
assumption which simplifies the corresponding analytic solution. The result of the FEMTRAN calculation compares quite favorably with analytic results in spite of a rather poor mass balance near the radionuclide source. This circumstance may be understood by recognizing that bilinear basis functions do not conserve mass, a fact that may be proved theoretically. Nevertheless, the minimization of residuals, inherent in the Galerkin weighted-residuals method, generally yields accuratc results at nodal points.

Problems 2 and 3 are taken from the INTRACOIN Level-1 Study (SKI, 1984). These problems are quite similar, with dimensionality being the primary difference. Problem 2 is one dimensional, and Problem 3 is two dimensional. Both assume unequal retention factors. Although many similar codes have executed these two problems, Martinez (1985) compared FEMTRAN results for Problem 2 only with the results of RANCH (Haderman and Patry, 1981). Again, the results compare nicely in spite of a poor mass balance near the radionuclide source. Martinez (1985) compares the results of Problem 3 only with the results of Problem 2 to show the effect of transverse dispersion.

Cove-1 Benchmark Calculations. COVE-1 exercises focused on a two-dimensional isothermal water-drainage and contaminant-transport problem for variably saturated porous media (Hayden, 1985 and Eaton and Martinez, 1986). Six flow-transport code combinations participated, including FEMTRAN, which was coupled with the singlephase flow code SAGUARO (Eaton et al., 1983).

In COVE 1N, material properties and boundary conditions were consistent with those of Pickens et al. (1979), who assume a system consisting of a medium-grained sand. In COVE 1 YMa and $1 \mathrm{YMb}$, material properties were representative of a nonwelded tuff, and boundary conditions were varied. All three problems used the same geometric configuration. In order to add transport to the problem definition of Pickens et al. (1979), a non-decaying contaminant was assumed to be initially distributed within the upper $0.1 \mathrm{~m}$.

Using the flow field generated by SAGUARO, FEMTRAN successfully completed the three COVE-1 problems and provided transport results which weresimilar to those of other participants. The discussion of Hayden (1985, pp. 4-15 ff.), is quite interesting. It focuses on discrepancies between the results of FEMTRAN and the results of LANL's finite-difference code TRACR3D (Birdsell and Travis, 1991). Hayden (1985) attributes the discrepancies to two factors. Except for the portion of the boundary adjacent to a tile drain, the right-hand boundary of the system is specified by a no-flow condition. The bilinear basis functions used by SAGUARO and by FEMTRAN cannot reproduce this condition exactly, and this results in a small, but spurious, flow of contaminants from the system. In addition, the FEMTRAN analysis uses approximately one-third as many time steps as the TRACR3D analysis. Since both analyses use backward-in-time differencing, it is assumed that enhanced levels of numerical dispersion also caused the FEMTRAN results to deviate from those of TRACR3D. 
PACE-90 Radionuclide Transport Problem. Given a common data base and a common hydrogeologic characterization of the Yucca-Mountain Site, participants in the PACE-90 study determined the movement of radionuclides to the accessible environment assuming an undisturbed, isothermal flow field. This exercise verified the ability of different researchers to independently conceptualize a complex site in a physically consistent manner. Nevertheless, computed results largely agreed, thus providing verification of code executions. To simulate flow, participants chose FEMTRAN and NORIA and five other codes, or code combinations.

The FEMTRAN-NORIA analysis considers a two-dimensional cross-section lying between drill holes G-4 and UE-25a. With a total of 1,260 quadrilateral elements, the NORIA analysis divides this cross-section into nine hydrogeologic units extending from the water table to the top of the Tpt-TM section of the Topapah Spring unit. With the bottom boundary held at a pore pressure of zero to characterize the water table, the two sides are assumed to be no-flow boundaries. For the top boundary, a net infiltration of $0.01 \mathrm{~mm} / \mathrm{y}$ is prescribed.

Using Darcy velocities and an average moisture-content value taken from NORIA results and a source strength generated by the AREST code (Apted, 1989), the FEMTRAN analysis focuses on a small section of the total cross-section considered by the NORIA analysis. Containing both wells, it extends vertically downward from the repository horizon and measures $100 \mathrm{~m}$ in thickness. It is divided into 552 elements. The FEMTRAN analysis indicates that the peak concentration travels only $20 \mathrm{~m}$ below the repository and that the farthest extremity of the plume travels less than $50 \mathrm{~m}$ in 100,000 years. As a check, FEMTRAN is also used in a onedimensional vertical analysis. As expected, one- and two-dimensional results agree nicely except near the sides of the repository.

\subsection{Status of Quality Assurance. FEMTRAN is not under QA control.}

\section{Type of Model (Phenomena/Processes Modeled)}

FEMTRAN is a two-dimensional, finite-element model for simulating radionuclide transport in a saturated or unsaturated porous medium. Processes considered include the following:

- Advection

- Dispersion and diffusion

- Linear sorption

- Radioactive decay and production.

\section{Governing Equations}

FEMTRAN solves the coupled mass-conservation equations for a chain of radionuclides. Only two spatial dimensions are permitted, and branching is not allowed. 


\section{Method of Solution}

To spatially discretize the transport equations, FEMTRAN uses the Galerkin finite-element method with bilinear basis functions. The Galerkin approach requires that weighting and basis functions be identical. Vinlike SAGUARO (Eaton et al., 1983) and NORIA (Bixler, 1985), which allow subparumetric mappings from global to local coordinate systems, FEMTRAN permits only isoparametric mappings. Like the basis function, the mapping function is also bilinear. The code employs the upstream-weighting formulation of Huyakom and Nilkuha (1979).

To temporally discretize the transport equations, FEMTRAN input allows the analyst to specify a weighting factor $\omega$, denoting differing degrees of implicitness in the solution algorithm. A value $\omega=1 / 2$ corresponds to centered (Crank-Nicholson) differencing, while a value $\omega=1$ corresponds to backward differencing. FEMTRAN input also allows the analyst to select mass lumping. Rather than to prescribe off-diagonal accumulation terms, a masslumping procedure adds them to the diagonal term.

\section{Type of Input Parameters}

Data input required for the execution of FEMTRAN may be divided into the 15 data sets listed below:

Data Set 1: Problem Identification. Contains problem number and problem title.

Data Set 2: Control Parameters. Contains control parameters for defining the problem including mesh input control, boundary control, time increments, and number of materials.

Data Set 3: Conversion Factors. Provides for conversion of the hydrodynamic solution when computed by SAGUARO (Eaton et al., 1983). Optional.

Data Set 4: Time Integration Parameters. Contains parameters for controlling the time step sequence. Includes specification of leach times under transient boundary conditions.

Data Set 5: Printed Output Control. Specifies the time planes at which printed output is desired.

Data Set 6: Auxiliary Storage and Flow Field Control. Allows for control of the amount of flow field print output and the timeplanes for which species concentration solutions are stored.

Data Set 7: Material Properties. Data set specifies material properties for the number of materials present. Data includes bulk density, dispersivities, porosity, etc.

Data Set 8: Species and Material Dependent Properties. Contains data on properties which depend both on species and material type. Includes such properties as decay constants and distribution coefficients. 
Data Set 9: Nodal Point Coordinates. Optional.

Data Set 10: Element Connectivities. Optional.

Data Set 11: Material Corrections. Used if material changes are made. Optional.

Data Set 12: Initial Conditions. Initial conditions are specified for all members of the decay chain being analyzed.

Data Set 13: Dirichlet Boundary Conditions. Optional.

Data Set 14: Neumann Boundary Conditions. Default boundary condition, need not be specified explicitly.

Data Set 15: Cauchy Boundary Condition. Optional.

Input requirements needed for mesh specifications and hydrodynamic variables may either be provided by the user or obtained from other sources. FEMTRAN contains the same mesh generation subroutine found in FEMWATER (Yeh and Ward, 1980) to facilitate mesh specification. Mesh data can also be provided from a disk file after construction by the mesh generator codes QMESH or DECODE (Martinez and Bixler, 1984). Hydrodynamic variables may be specified through a user-supplied subroutine, or they may be computed using one of the following codes: FEMWATER (Yeh and Ward, 1980), MARIAH (Gartling and Hickox, 1982), or SAGUARO (Eaton et al., 1983).

\section{Type of Output and User Options}

In addition to an echo of input data, FEMTRAN allows the user to choose the time planes at which computed data are desired. Output at the specified times may include mass-balance data, concentrations, and material fluxes. Additionally, the user may control the amount and type of flow-field output obtained. Flow-field output may include mass balances, Darcy velocities, moisture contents, and the hydraulic heads.

9. Model Interactions (emphasize needed processors)

9.1 Does the model interface with any other models? Yes, see below.

9.2 Source code and type of information needed. FEMTRAN assumes a prior calculation of the flow field. The COVE-1 exercises demonstrate the coupling procedure. Here SAGUARO (Eaton et al., 1983) computed transient Darcy-velocity and moisturecontent fields, which were transferred to FEMTRAN. Other flow codes such as NORIA (Bixler, 1985), MARIAH (Gartling and Hickox, 1982), and FEMWATER (Yeh and Ward, 1980) may be used as well, providing that a reformatting facility is provided. DECODE (Martinez and Bixler, 1984) and MERLIN (Gartling, 1981) provide examples of such a facility.

9.3 Receiving code and type of information provided. Not applicable. 

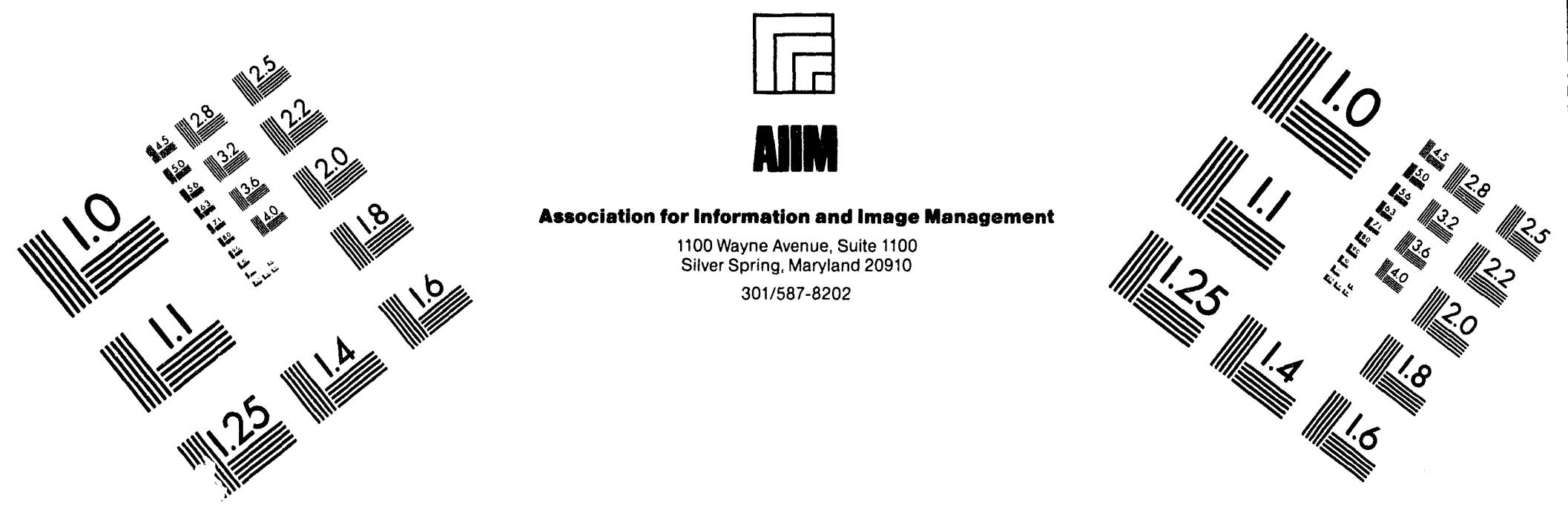

\section{Centimeter}

$\begin{array}{llllllllllllllll}1 & 2 & 3 & 4 & 5 & 6 & 7 & 8 & 9 & 10 & 11 & 12 & 13 & 14 & 15 & \mathrm{~mm}\end{array}$

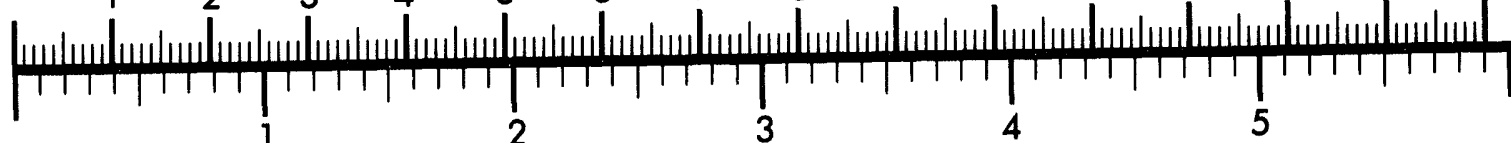
Inches
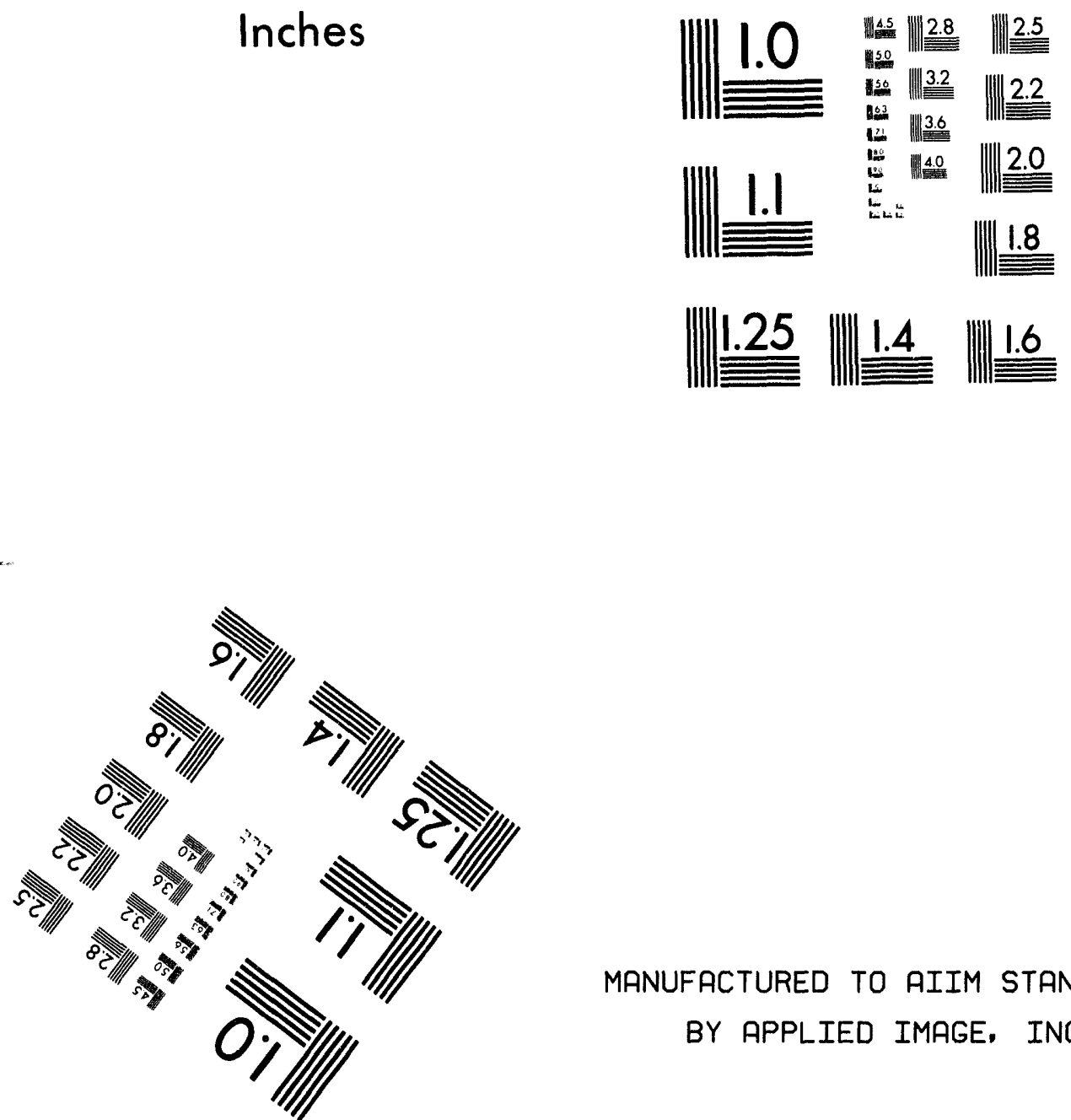

MANUFACTURED TO AIIM STANDARDS

BY APPLIED IMAGE, INC.

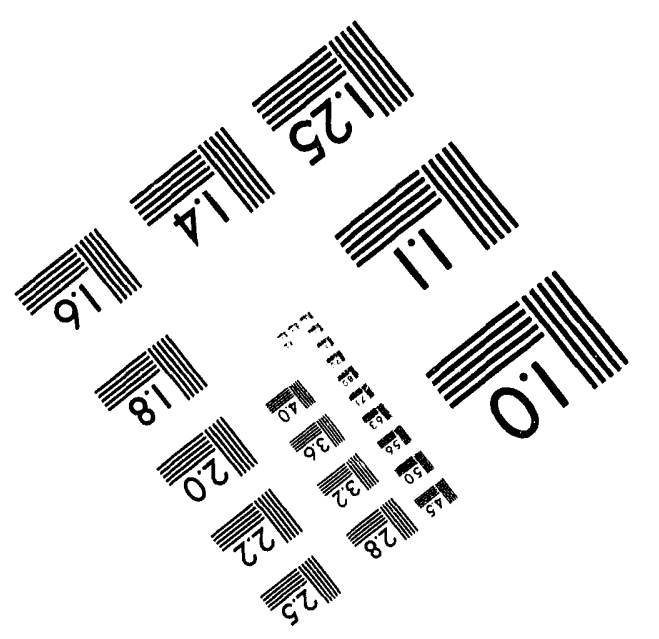



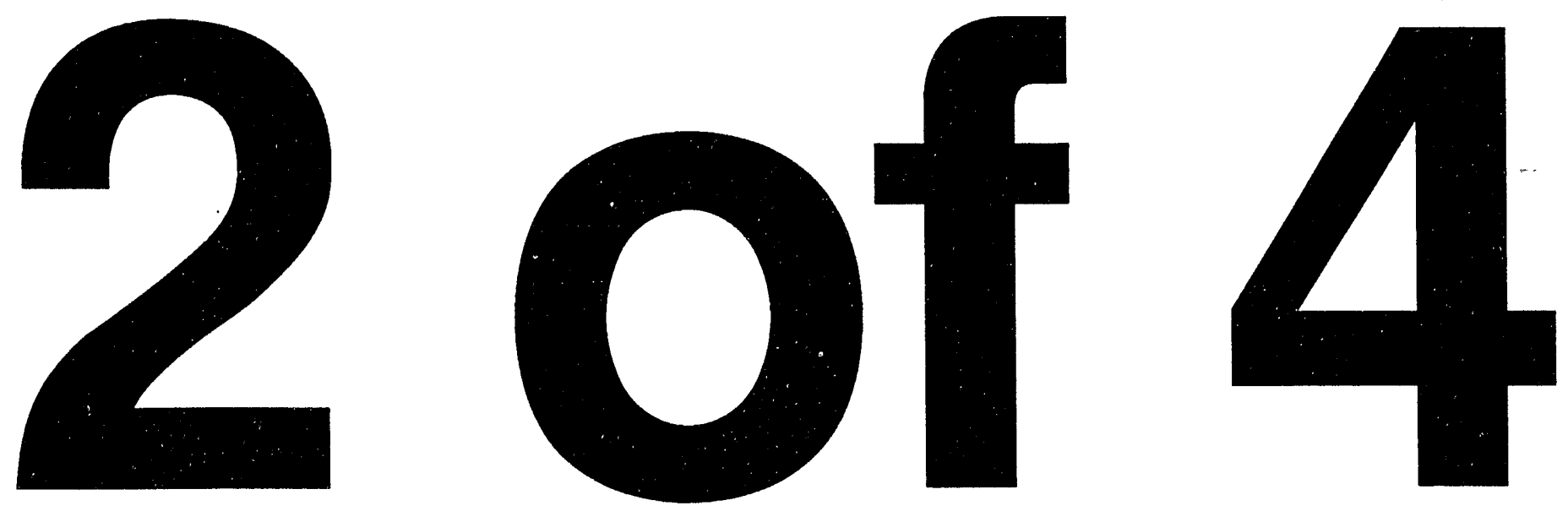
9.4 Any pre- or postprocessing needed? Plotting packages provide time histories of radionuclide transport. For the PACE- 90 calculations, the output was reformatted for the BLOT graphics package.

10. Model Application

10.1 Usage within the CRWMS program. FEMTRAN provides a stand-alone transport capability for those, principally SNL, flow codes (MARIAH, SAGUARO, and NORIA) which do not have a built-in transport capability. It may be used for both near- and far-field applications.

10.2 Usage outside the program. Potentially, FEMTRAN could be used in a variety of waste-management areas, including hazardous waste and low-level nuclear waste. However, the availability of many other codes with similar or enhanced capabilities may limit its use.

\section{Codes With Similar or Same Capabilities}

11.1 Within the program. The Yucca Mountain Project has funded the development of several transport capabilities. In some cases, these capabilities are implemented within modules of a general flow and transport simulator. TRACR3D (Birdsell and Travis, 1991) and FEHM (Zyvoloski et al., 1992) at LANL (Los Alamos National Laboratory), MSTS, SUM0, and PORFLO-3 (Sagar and Runchal, 1989) at PNL (Pacific Northwest Laboratory), TOSPAC (Dudley et al., 1988) and SPARTAN (Sinnock and Lin, 1989) at SNL, VS2DT (Lappala et al., 1987 and Healy, 1990) at USGS (U.S. Geological Survey) have transport modules. In other cases, a transport capability is implemented in a separate stand-alone code. SNL's LLUVIA-S, a version of the Dykhuizen (1987) fractured media transport simulator, and FEMTRAN are stand-alone transport simulators.

11.2 Outside the program. The Nuclear Regulatory Commission has funded the development of DCM3D (Updegraff et al., 1991) with its Yucca-Mountain project. Other government funded efforts have yielded codes with capabilities similar to those of FEMTRAN. SWIFT (Reeves et al., 1984) and NEFTRAN (Longsine et al., 1987) provide examples of such efforts.

12. Major Assumptions and Limitations

- A dual-continuum option is not available. Without substantial modification, fracturematrix disequilibrium cannot be accounted for in field-scale simulations.

- A high-order differencing option is not available for the advection term. Without substantial code modification, code applications will require a highly refined spatial mesh.

- An iterative solution option is not available. This limits rather severely the size of the problem the code can consider. 
- A stand-alone flow calculation is required. The amount of data transfer and the required synchronization of time steps makes this a cumbersome procedure.

- Only liquid-phase transport components may be considered. Vapor flow is not allowed.

- Only two spatial dimensions are considered. This will be sufficient for many applications. However, some applications will undoubtedly require three dimensions.

\section{Remarks/General Observations/Discussion}

Relative to the ORNL versions which preceded it, FEMTRAN contains a few organizational changes. For example, a facility for obtaining a continuous flow field was first implemented in the flow code by Yeh and Ward (1980). Martinez (1985) made this facility available as an option for the transport code. He also generalized the mass-balance calculations. The major modification in FEMTRAN appears to be that of chain decay and production. (The ORNL versions do not consider radioactive production.) Unfortunately, however, many of the limitations present in the earlier versions still appear in FEMTRAN.

To date, all FEMTRAN applications to Yucca Mountain have assumed an undisturbed repository, a steady-state isothermal flow field, and negligible fracture flow. If the isothermal condition is removed with transients limited to the relatively long-term behavior inherent in the heat source, then liquid-flow vectors will, most likely, point inward. In this case, there may be little or no transport from the repository for 10,000 years. If a transport code is necessary for analyzing the nonisothermal problem for a steady-state recharge, FEMTRAN should be appropriate. If transients due to large storm events are permitted, then fracture flow will likely occur, and FEMTRAN will not be appropriate. If, further, the effects of climate change, volcanism, or seismic events are considered, then FEMTRAN's limitation to relatively small systems dominated by porous-media flow will prove disabling for many, perhaps most, applications.

\section{Comparison to Other Models}

See Chapters 4, 5, and 6 of the main text.

\section{Summary and Recommendations}

Section 12 lists the limitations of FEMTRAN, and Section 13 suggests the areas in which they may affect future licensing calculations. Since other codes within the project have overcome many of these lis.ritations, it is recommended that FEMTRAN not be considered further.

\section{References}

Apted, M.J., Liebetrau, A.M. Liebetrau, and D.W. Engel, 1989. The Analytical Repository Source-Term (AREST) Model: Analysis of Spent Fuel as a Nuclear Waste Form, PNL-6347, Battelle Pacific Northwest Laboratory, Hanford, WA. 
Birdsell, K.H., and B.J. Travis, 1991. TRACR3D: A Model of Flow and Transport in Porous Media, LA-11798-M, Los Alamos National Laboratory, Los Alamos, NM.

Bixler, N.E., 1985. NORIA - A Finite Element Computer Program for Analyzing Water, Vapor, Air, and Energy Transport in Porous Media, Sandia National Laboratories, SAND84-2057, Albuquerque, NM.

Dudley, A.L., R.R. Peters, J.H. Gauthier, M.L. Wilson, M.S. Tierney, E.A. Klavetter, 1988. Total System Performance Assessment Code (TOSPAC) Volume 1: Physical and Mathematical Bases, SAND85-0002, Sandia National Laboratories, Albuquerque, NM.

Duguid, J.O., and M. Reeves, 1976. Material Transport Through Porous Media: A Finite Element Galerkin Model, ORNL 4928, Oak Ridge National Laboratory, Oak Ridge, TN.

Dykhuizen, R.C., 1987. "Transport of Solutes Through Unsaturated Fractured Media", Water Resour. Res., 21 (12), 1531-1539.

Eaton, R.R., D.K. Gartling, and D.E. Larson, 1983. SAGUARO - A Finite Element Computer Program for Partially Saturated Porous Flow Problems, SAND82-2772, Sandia National Laboratories, Albuquerque, NM.

Eaton, R.R. and M.J. Martinez, 1986. Cove Benchmark Calculations Using SAGUARO and FEMTRAN, SAND85-0051, Sandia National Laboratories, Albuquerque, NM.

Gartling, D.K., and C.E. Hickox, 1982. MARIAH - A Finite Element Computer Program for Incompressible Porous Flow Problems: Theoretical Background, SAND79-1622, Sandia National Laboratories, Albuquerque, NM.

Gartling, D.K., 1981. MERLIN - A Computer Program to Transfer Data Between Finite Element Meshes, SAND81-0463, Sandia National Laboratories, Albuquerque, NM.

Haderman, J., and J. Patry, 1981. Nucl. Technol., 54, pp. 226.

Hayden, N.K., 1985. Benchmarking NNWSI Flow and Transport Codes: Cove 1 Results, SAND84-0996, Sandia National Laboratories, Albuquerque, NM.

Healy, R.W., 1990. Simulation of Solute Transport in Variably Saturated Porous Media With Supplemental Information on Modifications to the U.S. Geological Survey's Computer Program VS2D, Water-Resources Investigations Report 90-4025, U.S. Geological Survey, Denver, CO.

Huyakom, P.S., and K. Nilkuha, 1979. Solution of Transient Transport Equation Using an Upstream Finite Element Scheme, Appl. Math. Model. 3, IPC Business Press.

Jones, R.E. QMESH: A Self-Organizing Mesh Generation Program, SLA-73-1088, Sandia National Laboratories, National Technical Information Service. 
Lappala, E.G., R.W. Healy, and E.P. Weeks, 1987. Documentation of Computer Program VS2D to Solve the Equations of Fluid Flow in Variably Saturated Porous Media, WaterResources Investigations Report 83-4099, U.S. Geological Survey, Denver, CO.

Longsine, D.E., E.J. Bonano, C.P. Harlan, 1987. User's Manual for the NEFTRAN Computer Code, SAND86-2405, Sandia National Laboratories, Albuquerque, NM.

Martinez, M.J., 1985. FEMTRAN - A Finite Element Computer Program for Simulating Radionuclide Transport Through Porous Media, SAND84-0747, Sandia National Laboratories, Albuquerque, NM.

Martinez, M.J. and N.E. Bixler, 1984. Memo to Distribution, "DECODE - A Direct Data Transfer Routine for Using SAGUARO Mesh and Solution Data in FEMTRAN," Sandia National Laboratories, Albuquerque, NM.

Pickens, J.F., R.W. Gillham, and D.K. Cameron, 1979. "Finite Element Analysis of the Transport of Water and Solutes in Tile-Drained Soils", J. Hydrology., 40, pp. 243-264.

Reeves, M., and J.O. Duguid, 1975. Water Movement Through Saturated-Unsaturated Porous Media: A Finite Element Galerkin Model, ORNL 4927, Oak Ridge National Laboratory, Oak Ridge, TN.

Reeves, M., D.S. Ward, N.D. Johns, and R.M. Cranwell, 1986. Theory and Implementation for SWIFT II, The Sandia Waste-Isolation Flow and Transport Model for Fractured Media, Release 4.84, NUREG/CR-3328, U.S. Nuclear Regulatory Commission, Washington DC, and SAND83-1159, Sandia National Laboratories, Albuquerque, NM.

Sagar, B., and Runchal, A.K., 1990. PORFLO-3: A Mathematical Model for Fluid Flow, Heat, and Mass Transport in Variably Saturated Geologic Media, Theory and Numerical Methods, Version 1.0, WHC-EP-0042, Westinghouse Hanford Company, Richland, WA.

Sinnock, S., and Y.T. Lin, 1989. Preliminary Estimates of Groundwater Travel Time at Yucca Mountain, Radioactive Waste Management and the Nuclear Fuel Cycle, Vol. 13(1-4), pp. 121-145.

SKI, 1984. INTRACOIN International Nuclide Transport Code Intercomparison Study, Final Report Level 1, Swedish Nuclear Power Inspectorate, Stockholm, Sweden.

Updegraff, C.D., C.E. Lee, and D.P. Gallegos, 1991. DCM3D: A Dual-Continuum, Three Dimensional, Ground-Water Flow Code for Unsaturated, Fractured, Porous Media, NUREG/CR-5536, SAND90-7015, Sandia National Laboratories, Albuquerque, NM.

Yeh, G.T., and D.S. Ward, 1980. FEMWATER: A Finite-Element Model of WATER Flow Through Saturated-Unsaturated Porous Media, ORNL-5567, Oak Ridge National Laboratory, Oak Ridge, TN. 
Yeh, G.T., and D.S. Ward, 1981. FEMWASTE: A Finite-Element Model of WASTE Transport Through Porous Saturated-Unsaturated Media, ORNL-5601, Oak Ridge National Laboratory, Oak Ridge, TN.

Zyvoloski, G., Z. Dash, and S. Kelkar, 1992. FEHMN 1.0: Finite Element Heat and Mass Transfer Code, LA--12062-MS, Los Alamos National Laboratory, Los Alamos, NM. 


\section{A.4 FEMWASTE}

1. Name of the Model

FEMWASTE

\section{General Program Information}

2.1 Program size. FEMWASTE (Yeh and Ward, 1981) contains approximately 2,000 source statements.

\subsection{Programming language. FORTRAN 77}

2.3 Computer system on which it operates. Duguid and Reeves (1976) ran the model on IBM-360 computers at ORNL (Oak Ridge National Laboratory). Since that time, it has been used on other machines, as well, including VAX, CDC, and personal computers.

2.4 Compiler(s) used. Standard compilers.

2.5 Location of code and availability. The model may be obtained from the Environmental Sciences Division at ORNL.

2.6 Brief description of model/code history. A variety of modeling problems in the early 1970 s led to the development of the original model. These problems related to the Oak Ridge burial grounds for radioactive wastes, to the International Biological Program, and to several projects funded by the EPA (U.S. Environmental Protection Agency). Since that time, the model has been enhanced using funding both from the NRC (U.S. Nuclear Regulatory Commission) and the DOE (U.S. Department of Energy).

\section{Status of Model}

3.1 Development (Is the model now undergoing significant development or modification? or continuing maintenance?). Since 1981, the model has been enhanced in several ways. Point Gauss-Seidel and conjugate-gradient solvers have been added, and a high-order treatment of the convection term has been implemented. A mass-balance algorithm has been written. In addition, algorithms for nonlinear sorption and ionexchange have been added, and the model has been expanded to three dimensions.

3.2 Documentation. Yeh and Ward (1981) update the original documentation of Reeves and Duguid (1976). These two documents provide a comprehensive and readable description of the model, including both theory and data input. 


\subsection{Status of verification and validation.}

Lapidus and Amundson's (1952) Equilibrium Case (Duguid and Reeves, 1976): Water moves at a constant velocity through a one-dimensional ion-exchange column. With an initial concentration of zero, the boundary concentration is fixed at a constant value. For the same values of retardation, interstitial velocity, and dispersion, the numerical results of Duguid and Reeves agree nicely with the analytic results of Lapidus and Amundson.

Seepage Pond (Duguid and Reeves (1976), Yeh and Ward (1980), Yeh and Ward (1981) and Yeh (1987)]: Water from a seepage pond moves through a highly permeable sand to a sloping seepage face and a stream. Infiltration due to rainfall is small in comparison to seepage from the pond and is neglected. Assuming a concentration of unity in the pond, the problem calls for concentration contours at 20 years. To approximate the dependence of sorption on the exposed surface area, Reeves and Duguid assume that sorption is proportional to water content. Yeh and Ward assume that sorption is independent of water content. Results are quite similar to those of Reeves and Duguid, except near the seepage face. There, the change in the sorption model plus the improved calculations of Darcy-velocity and mass flux give concentration contours which are more physically reasonable than those of Duguid and Reeves. All calculations use a grid consisting of 595 nodes and 528 elements.

3.4 Status of Quality Assurance (QA). The EPA (U.S. Environmental Protection Agency) has brought FEMWASTE under QA control.

\section{Type of Model (Pheniomena/Processes Modeled)}

FEMWASTE simulates radionuclide transport in either a two-dimensional $(x-y)$ plane or a two-dimensional vertical ( $\mathrm{x}-\mathrm{z}$ ) cross-section. As indicated by its name, the code uses the finite-element method. a variably saturated porous medium. Processes considered include the following:

- Advection

- Dispersion and diffusion

- Sorption and ion exchange

- Radioactive decay.

\section{Governing Equations}

FEMWASTE solves the advective-dispersion equation for a decaying radionuclide.

\section{Method of Solution}

Yeh and Ward (1981) made two major changes to the code of Duguid and Reeves (1976). After solving for the concentration at a given time step, Duguid and Reeves differentiate this variable to obtain mass-flux components. This procedure can lead to non-conservation of 
mass at element interfaces. To avoid the problem, Yeh and Ward apply the Galerkin approach and then use an implicit solution procedure like that used to obtain concentration values. The procedure is identical to that used to obtain Darcy velocities. Generally, the computer time will increase by a factor less than three for a two-dimensional problem (Yeh, 1981). This is of little consequence, however, since the solution of the flow equation is, by far, the time-limiting factor.

Following the work of Huyakorn and Nilkuha (1979), Yeh and Ward introduce an upstreamweighting option into the code. For advection-dominated transport, this option ailows the analyst to stabilize the solution algorithm with numerical dispersion. However, the analyst must exercise caution since the solution so obtained may be physically unrealistic.

Yeh and Ward also made three relatively minor changes to the code of Duguid and Reeves. The latter authors take the distribution coefficient $\mathbf{k}_{d}$ to be linearly dependent on moisture content. An unsaturated soil, it is assumed, will incompletely expose its sorbing surfaces. This is consistent with the sorption mechanism identified by a soil chromatograph (Reeves, Francis, and Duguid, 1977). Citing several references, Yeh and Ward argue that, in general, $k_{d}$ depends on moisture content in a complicated manner but that, to first order, one should assume $\mathbf{k}_{\mathrm{d}}$ is independent of water content. They change the code accordingly. Consistent with changes introduced in FEMWATER, Yeh and Ward also introduce mass lumping and mid-difference weighting into the time-integration algorithm.

\section{Type of Input Parameters}

Generally speaking, integer and real parameters appear on separate records with formats of 1615 and 8F10.0, respectively. Control and temporal gridding parameters come first, followed by material properties. Then, depending on the option selected by the analyst, spatial gridding information may be either input or read from a file prepared by a prior execution of FEMWATER. If the former option is chosen, then some rudimentary facilities for automatic mesh generation are available. Typically, mesh generation is a non-trivial exercise for a finite-element model.

Mesh dependent quantities follow. Initial conditions are prescribed. Then, as the final items of the data set, come the specification of sources and sinks and the specification of possibly three different types of boundary conditions. Dirichlet conditions (constant concentrations) may be prescribed at either interior or exterior nodes. Neumann conditions (constant fluxes) may be prescribed on exterior element sides. Cauchy conditions (convective transfer through boundary) may also be prescribed on exterior element sides.

\section{Type of Output and User Options}

FEMWASTE output includes an echo of all input data, initial conditions, and boundary conditions. Concentration, mass-flux, and Darcy-velocity tables are output at times specified by the input. This output includes time increment, time-step number, and elapsed simulation time. In addition to hard copy, plot files may be prepared during execution. 
9. Model Interactions (emphasize needed processors)

9.1 Does the model interface with any other models? Yes, see below.

9.2 Source code and type of information needed. FEMWASTE assumes a prior calculation of the flow field. FEMWATER writes Darcy velocities on a file, which, FEMWASTE reads during the course of the mass-transport calculation.

9.3 Receiving code and type of information provided. Not applicable.

9.4 Any pre- or postprocessing needed? A plotting package provides time histories and contour plots.

10. Model Application

10.1 Usage within the Civilian Radioactive Waste Management System (CRWMS) program. FEMWASTE provides a stand-alone transport capability for FEMWATER. It may be used for both near- and far-field applications.

10.2 Usage outside the program. FEMWASTE has been used in a variety of wastemanagement areas, including hazardous waste and low-level nuclear waste. However, the availability of many other codes with similar or enhanced capabilities limit its usefulness.

\section{Codes With Similar or Same Capabilities}

11.1 Within the program. The Yucca Mountain Project has funded the development of several transport capabilities. In many cases, these capabilities are implemented within modules of a general flow and transport simulator. TRACR3D (Birdsell and Travis, 1991) and FEHM (Zyvoloski et al., 1992) at LANL (Los Alamos National Laboratory), MSTS and SUMO at PNL (Pacific Northwest Laboratory), TOSPAC (Dudley et al., 1988) and SPARTAN (Sinnock and Lin, 1989) at SNL, VS2DT (Lappala et al., 1987 and Healy, 1990) at USGS (U.S. Geological Survey) and PORFLOW (Runchal and Sagar, 1991) have transport modules. In other cases, a transport capability is implemented in a separate stand-alone code. SNL's LLUVIA-S, a version of the Dykhuizen (1987) fractured media transport simulator, and FEMTRAN are stand-alone transport simulators.

11.2 Outside the program. The NRC has funded the development of DCM3D (Updegraff et al., 1991) with its Yucca-Mountain project. Other government funded efforts have yielded codes with capabilities similar to or exceeding those of FEMWASTE. SWIFT (Reeves et al., 1986) provides an example of such an effort.

12. Major Assumptions and Limitations

- A dual-continuum option is not available. Without substantial modification, fracturematrix disequilibrium cannot be accounted for in field-scale simulations. 
- Radioactive chaining is not considered.

- A stand-alone flow calculation is required. The amount of data transfer and the required synchronization of time steps makes this a cumbersome procedure.

- Only liquid-phase transport components may be considered. Vapor flow is not allowed.

- Only two spatial dimersions are considered. This will be sufficient for many applications. However, some applications will undoubtedly require three dimensions. 


\section{Remarks/General Observations/Discussion}

Although the precursor to FEMWASTE (Duguid and Reeves, 1976) was one of the first of its kind, FEMWASTE's general performance capabilities are now duplicated by many other codes, as indicated in Section 11. Most have built-in transport modules, which are more convenient to use than stand-alone transport modules like FEMWASTE, and some have capabilities which are more advanced than those of FEMWASTE.

Nevertheless, the current evolution of FEMWASTE, now called HYDROGEOCHEM, should be followed by the M\&O. The expanded capabilities for convection-dominated transport and for sorption and ion exchange may rival those offered by TRACR3D (Birdsell and Travis, 1991), which are the most advanced such capabilities in the Yucca-Mountain project.

\section{Comparison to Other Models}

(See Chapters 4, 5 and 6 of the main text.)

\section{Summary and Recommendations}

Section 12 lists the limitations of FEMWASTE. Since several transport modules of other codes within the project overcome many of these limitations, it is recommended that FEMWASTE not be considered further.

16. References

Birdsell, K.H., and B.J. Travis, 1991. TRACR3D: A Model of Flow and Transport in Porous Media, LA-11798-M, Los Alamos National Laboratory, Los Alamos, NM.

Dudley, A.L., R.R. Peters, J.H. Gauthier, M.L. Wilson, M.S. Tierney, E.A. Klavetter, 1988. Total System Performance Assessment Code (TOSPAC) Volume 1: Physical and Mathematical Bases, SAND85-0002, Sandia National Laboratories, Albuquerque, NM.

Duguid, J.O., and M. Reeves, 1976. Material Transport Through Porous Media: A Finite Element Galerkin Model, ORNL-4928, Oak Ridge National Laboratory, Oak Ridge, TN.

Dykhuizen, R.C., 1987. "Transport of Solutes Through Unsaturated Fractured Media", Water Resour. Res., 21 (12), 1531-1539.

Healy, R.W., 1990. Simulation of Solute Transport in Variably Saturated Porous Media With Supplemental Information on Modifications to the U.S. Geological Survey's Computer Program VS2D, Water-Resources Investigations Report 90-4025, U.S. Geological Survey, Denver, CO.

Huyakorn, P.S., and K. Nilkuha, 1979. Solution of Transient Transport Equation Using an Upstream Finite Element Scheme, Appl. Math. Model. 3, IPC Business Press. 
Lapidus, L., and N. Amundson, 1952. Mathematics of Adsorption in Beds. VI. The Effect of Longitudinal Diffusion in Ion Exchange and Chromatographic Columns, J. Phys. Chem. 56, 984-988.

Lappala, E.G., R.W. Healy, and E.P. Weeks, 1987. Documentation of Computer Program VS2D to Solve the Equations of Fluid Flow in Variably Saturated Porous Media, WaterResourı os Investigations Report 83-4099, U.S. Geological Survey, Denver, CO.

Martinez, M.J., 1985. FEMTRAN - A Finite Element Computer Program for Simulating Radionuclide Transport Through Porous Media, SAND84-0747, Sandia National Laboratories, Albuquerque, NM.

Reeves, M.: and J.O. Duguid, 1975. Water Movement Through Saturated-Unsaturated Porous Media: A Finite Element Galerkin Model, ORNL-4927, Oak Ridge National Laboratory, Oak Ridge, TN.

Reeves, M., C.W. Francis, and J.O. Duguid, 1977. Quantitative Analysis of Soil Chromatography: 1. Water and Radionuclide Transport, ORNL-5337, Oak Ridge National Laboratory, Oak Ridge, TN.

Reeves, M., D.S. Ward, N.D. Johns, and R.M. Cranwell, 1986. Theory and Implementation for SWIFT II, The Sandia Waste-Isolation Flow and Transport Model for Fractured Media, Release 4.84, NUREG/CR-3328, U.S. Nuclear Regulatory Commission, Washington DC, and SAND83-1159, Sandia National Laboratories, Albuquerque, NM.

Runchal, A.K., and B. Sagar, 1991. PORFLOW: A Model for Fluid Flow, Heat, and Mass Transport in Multifluid, Multiphase Fractured or Porous Media, User's Manual - Version 2.34, ACRi/016/Rev. E, Analytical and Computational Research, Inc., West Los Angeles, CA.

Sinnock, S., and Y.T. Lin, 1989. Preliminary Estimates of Groundwater Travel Time at Yucca Mountain, Radioactive Waste Management and the Nuclear Fuel Cycle, Vol. 13(1-4), pp. 121-145.

Updegraff, C.D., C.E. Lee, and D.P. Gallegos, 1991. DCM3D: A Dual-Continuum, Three Dimensional, Ground-Water Flow Code for Unsaturated, Fractured, Porous Media, NUREG/CR-5536, SAND90-7015, Sandia National Laboratories, Albuquerque, NM.

Yeh, G.T., 1981. On the Computation of Darcian Velocity and Mass Balance in the Finite Element Modeling of Groundwater Flow, Water Resour. Res., vol. 17(5), pp. 1529-1534.

Yeh, G.T., 1987. FEMWATER: A Finite-Element Model of WATER Flow Through Saturated-Unsaturated Porous Media - First Revision, ORNL-5567/R1, Oak Ridge National Laboratory, Oak Ridge, TN. 
Yeh, G.T., and D.S. Ward, 1980. FEMWATER: A Finite-Element Model of WATEK Flow Through Saturated-Unsaturated Porous Media, ORNL-5567, Oak Ridge National Laboratory, Oak Ridge, TN.

Yeh, G.T., and D.S. Ward, 1981. FEMWASTE: A Finite-Element Model of WASTE Transport Through Porous Saturated-Unsaturated Media, ORNL-5601, Oak Ridge National Laboratory, Oak Ridge, TN.

Zyvoloski, G., Z. Dash, and S. Kelkar, 1992. FEHMN 1.0: Finite Element Heat and Mass Transfer Code, LA--12062-MS, Los Alamos National Laboratory, Los Alamos, NM. 


\section{A.5 FEMWATER}

1. Name of the Model

FEMWATER

2. General Program Information

2.1 Program size. FEMWATER (Yeh, 1987) contains approximately 4,500 source statements.

\subsection{Programming language. FORTRAN 77}

2.3 Computer system on which it operates. Reeves and Duguid (1975) developed and ran the original version of FEMWATER on IBM-360 computers at ORNL (Oak Ridge National Laboratory). Since that time, the code has been used on other machines, as well, including VAX, CDC, and personal computers.

2.4 Compiler(s) used. Standard compilers.

2.5 Location of code and availability. The code may be obtained from the Environmental Sciences Division at ORNL.

2.6 Brief description of model/code history. A variety of modeling problems in the early 1970s led to the development of the original model by Reeves and Duguid (1975). These problems related to the Oak Ridge burial grounds for radioactive wastes, to the International Biological Program, and to several projects funded by the EPA (U.S. Environmental Protection Agency). Since that time, the model has been enhanced using funding from a variety of sources, including the NRC (U.S. Nuclear Regulatory Commission) and DOE (U.S. Department of Energy). Two documents (Yeh and Ward, 1980) and Yeh (1987) discuss the more recent versions of the model.

\section{Status of Model}

3.1 Development (Is the model now undergoing significant development or modification? or continuing maintenance?). Since 1987, the model has been expanded to three dimensions, and anuther iterative-solver option has been added. The latter is based on the preconditioned conjugate-gradient method.

3.2 Documentation. Yeh and Ward (1980) and Yeh (1987) update the original documentation of Reeves and Duguid (1975). These three documents provide a comprehensive and readable description of the model, including both theory and data input.

3.3 Status of verification and validation. Several different documents report problems which have been solved with FEMWATER. These problems illustrate the use of the 
code. Furthermore, since many of them have been run with other codes, these problems also verify FEMWATER.

Coweeta Inclined Soil Column (Reeves and Duguid, 1975): Investigators of The Coweeta Hydrologic Laboratory in North Carolina have made extensive use of inclined physical soil models. This problem focuses on one of their studies. An inclined concrete trough is filled, for the most part, with Halewood sandy loam. Under the outflow level, the soil is graded to sand, gravel, and rock to simulate stream bank conditions. After soaking the upper surface for several days, the structure was covered with plastic to prevent evaporation. A physically reasonable estimate of the unsaturated hydraulic-conductivity curve yielded simulated outflow rates which, for the simulated 10-day period, matched the measured values to a reasonable degree of apprnximation. The spatial mesh for this two-dimensional problem consisted of 612 elements and 690 nodes.

Freeze's Idealized Flow System (Reeves and Duguid (1975) and Yeh and Ward (1980)]: Freeze (1971a, 1971b, 1972a, and 1972b) applied his finite-difference code to a number of partially saturated flow systems. Parenthetically, it is interesting to note the closing comments of his (1971b) article. There, he identifies computer performance as the major limitation of a physics-based approach. Ironically, computer performance remains a major limitation in determining performance at the YuccaMountain site, in spite of the software and hardware advances of the last twenty years.

The flow system of interest assumes recharge through an upland plateau, seepage along a sloping surface, and discharge downdip to a stream. Steady-state heads, as calculated by Reeves and Duguid and by Yeh and Ward, show good agreement with those determined by Freeze. However, the discharge rates calculated by Reeves and Duguid differ from those calculated by Freeze. This may be due to the error inherent in the velocity calculation of Reeves and Duguid, and, hence, it would have been interesting to see the discharge rates determined by the velocity algorithm of Yeh and Ward. Unfortunately, these authors do not report their results. The spatial mesh for this two-dimensional problem consisted of 571 nodes.

Seepage Pond [Duguid and Reeves (1976), Yeh and Ward (1980), Yeh and Ward (1981) and Yeh (1987)]: Water from a seepage pond moves through a highly permeable sand to a sloping seepage face and a stream. Infiltration due to rainfall is small in comparison to seepage from the pond and is neglected. Duguid and Reeves, Yeh and Ward (1980), Yeh and Ward (1981) and Yeh calculate steady-state pressure and velocity fields. Results differ negligibly. Each uses a grid consisting of 595 nodes and 528 elements.

Huyakorn's (1986) One-Dimensional Column (Yeh, 1987): During a 10-day period, water, at a rate of $5 \mathrm{~cm} /$ day, infiltrates into a $200-\mathrm{cm}$ vertical column containing a highly permeable soil (saturated conductivity, $10 \mathrm{~cm} /$ day). At the end of the tenth day, infiltration ends and evaporation begins, at a rate of $0.5 \mathrm{~cm} /$ day. This problem, which is simulated for a twenty-day period, tests the algorithm used to chop the time 
step. To calculate head as a function of depth and time, the analysis uses a grid consisting of 40 elements and 82 nodes.

Two-Dimensional Drainage Problem (Yeh, 1987): Two parallel drains, separated by a distance of $20 \mathrm{~m}$, extend downward to the top of an impermeable aquifuge, a depth of $10 \mathrm{~m}$. Infiltrating water, which enters the top surface at a flux of $0.006 \mathrm{~m} /$ day, discharges through the drains, the levels of which are maintained at a height of $2 \mathrm{~m}$ above the top of the aquifuge. Above the water level, the walls of the drains are assumed to be impermeable. The analysis determines the steady-state head distribution using 121 nodes and 100 elements.

\subsection{Status of Quality Assurance (QA). The EPA has brought FEMWATER under QA control.}

\section{Type of Model (Phenomena/Processes Modeled)}

Using a single-phase approximation to the two-phase equations, FEMWATER simulates variably saturated flow in a two-dimensional geometry, which may be a horizontal Cartesian $(\mathrm{x}-\mathrm{y})$ plane, a vertical Cartesian $(\mathrm{x}-\mathrm{z})$ cross-section, or a vertical radial $(\mathrm{r}-\mathrm{z})$ cross-section. As indicated by its name, the model uses the finite-element method.

\section{Governing Equations.}

FEMWATER uses the Richards equation.

\section{Method of Solution}

Yeh and Ward (1980) made one major change to the code of Reeves and Duguid (1975). After solving for head at a given time step, Reeves and Duguid differentiate this variable. This procedure can lead to discontinuous velocity components at element interfaces. Generally, the effect worsens with increasing permeability contrast between neighboring elements. To avoid this problem, Yeh and Ward apply the Galerkin approach and then use an implicit solution procedure like that used to obtain heads. If the availability of core storage permits, then the coefficient matrix of the velocity equation may be factored and stored. Then, the additional computer time required to obtain the velocities will be negligible. Otherwise, the computer time will increase by a factor less than three for a twodimensional problem (Yeh, 1981).

Yeh (1987) made three major changes. First, to the direct method used by the original code, he added a Gauss-Seidel point-iteration method. Second, he improved the implementation of triangular elements. The original model permits the user to coalesce two nodes of a quadrilateral to obtain a triangular element. Yeh directly implements the basis functions for a triangular element, thereby decreasing the number of nodes and replacing a numerical element quadrature with an analytic integration. For a gridding containing mostly triangular elements, this represents a significant improvement in efficiency. Third, Yeh added a radialgeometry option. 
Yeh and Ward (1980) made several relatively minor changes to the code of Reeves and Duguid (1975). To the variable-weighting scheme of the original model, they added middifference and mass-lumping options. Instead of allowing nonlinear parameters such as conductivity and water capacity to vary across an element, Yeh and Ward use the element average. Here they introduce numerical dispersion in an apparent effort to stabilize the algorithm.

Yeh (1987) also added several relatively minor changes. Although it requires relatively few coding changes, the mass-balance facility is quite useful. It provides a check on the numerical scheme and the consistency of the computer code. Treating conductivity tensors whose axes deviate from the coordinate axes improves the ability of the code to simulate anisotropic and heterogeneous media. A facility for time-step chopping enables the code to automatically reset the time step, thereby alleviating the need for troublesome external manipulations. The addition of Cauchy and time-dependent boundary conditions further broadens the model's range of application.

\section{Type of Input Parameters}

Generally speaking, integer and real parameters appear on separate records with formats of 1615 and 8F10.3, respectively. Control and temporal gridding parameters come first, followed by material properties. Spatial gridding information comes next, including some rudimentary facilities for automatic mesh generation. Typically, mesh generation is a non-trivial exercise for a finite-element model.

Mesh dependent quantities follow. Initial or, if steady-state initial conditions are to be calculated, pre-initial conditions are prescribed. Then come source and boundary conditions. This input can be quite substantial since four different boundary conditions (Dirichlet, Neumann, Cauchy, and variable) are permitted and since each source and boundary condition may be specified by a table of time-dependent values.

In addition, SPROP may be regarded as input. Rather than to offer specific options for relative conductivity and moisture characteristic, the authors of FEMWATER expect the code user either to input these curves in tabular form or to write a SPROP routine which will generate them from analytical formulas. Section 5.2 of Yeh (1987) provides the necessary instructions for writing this routine.

\section{Type of Output and User Options}

FEMWATER output includes an echo of all input data, initial conditions, and boundary conditions. Pressure heads, total heads, moisture contents, and mass balances are output at the times specified by the input. Output also includes the time-step number, elapsed simulation time, and convergence characteristics, including the number of iterations. In addition to hard copy, plot files, and FEMWASTE files of moisture contents and Darcy velocities may be prepared during execution. 
9. Model Interactions (emphasize needed processors)

9.1 Does the model interface with any other models? Yes, see below.

9.2 Source code and type of information needed. Not applicable.

9.3 Receiving code and type of information provided. FEMWATER writes Darcy velocities and water contents on a file, which FEMWASTE reads during the course of the mass-transport calculation.

9.4 Any pre-or postprocessing needed? Separate preprocessors and postprocessors plot the grid and provide time histories and contour plots.

10. Model Application

10.1 Usage within the Civilian Radioactive Waste Management System (CRWMS) program. Possibly the best use of FEMWATER within the CRWMS program would be the design of laboratory and field experiments. Under appropriate approximations, FEMWATER could also be used as a performance-assessment model. However, because of its assumption of isothermal flow, its role would be limited to analysis of the undisturbed case.

10.2 Usage outside the program. FEMWATER has been used in a variety of waste management areas, including hazardous waste and low-level nuclear waste. However, the availability of many other codes with similar capabilities limits its usefulness.

\section{Codes With Similar or Same Capabilities}

11.1 Within the program. The Yucca Mountain Project has funded the development of other flow and transport codes with capabilities which are either similar to or greater than those of FEMWATER. To characterize variably saturated flow, LLUVIA-2, NORIA-SP, and TOSPAC (Dudley et al., 1988) from SNL (Sandia National Laboratories) and SUMO (Eslinger et al., 1990) from PNL (Pacific Northwest Laboratory), TRUST (Reisenauer et al., 1982 and Narasimhan, 1975) from both PNL and LBL (Lawrence Berkeley Laboratory), and VS2DT (Lappala et al., 1987 and Healy, 1990) solve the single-phase Richards equation, as does FEMWATER. TOUGH2 (Pruess, 1991) at LBL (Lawrence Berkeley Laboratory), TRACR3D (Birdsell and Travis, 1991) and FEHM (Zyvoloski et al., 1992) at LANL (Los Alamos National Laboratory), MSTS at PNL, PORFLOW (Runchal and Sagar, 1991), and NORIA (Bixler, 1985) at SNL solve general multiphase equations, which include the Richards equation as a special case.

11.2 Outside the program. With its Yucca-Mountain project, the Nuclear Regulatory Commission has funded the documentation of TOUGH (Pruess, 1987), a multiphase solver, and DCM3D (Updegraff et al., 1991), a single-phase solver. Other government funded efforts yielded UNSAT2 (Davis and Neuman, 1983) and VAM2D (Huyakorn et al., 1989). 


\section{Major Assumptions and Limitations}

- Thermal effects are not considered. Such effects may be quite significant at Yucca Mountain.

- Vapor flow is not considered.

- The Picard sequential updating procedure is used to linearize the nonlinear flow equation. For simulating dry environments, a Newton-Raphson procedure is required.

- A dual-continuum option is not available. Without substantial modification, fracturematrix disequilibrium cannot be accounted for in field-scale simulations.

- Upstream conductivity weighting is not permitted.

- Only two spatial dimensions are considered. This will be sufficient for many applications. However, some applications will undoubtedly require three dimensions.

\section{Remarks/General Observations/Discussion}

For a relatively wet environment, such as that encountered at Oak Ridge, non-linearities can generally be handled with the Picard method. For relatively dry environments, like that of Yucca Mountain, non-linearities can be more severe. For an equivalent-continuum conceptualization, this is particularly apparent during a change from fracture to matrixdominated flow. There, a Newton-Raphson option is desirable. After testing the NewtonRaphson algorithm on a suite of problems, Reeves and Duguid (1975) concluded that the algorithm increased both computer time and code complexity for the class of problems they were considering. They elected not to include this algorithm in the public-release version of the code. For the rock properties present at Yucca Mountain, their conclusion is not valid, and the more powerful Newton-Raphson method is required.

As indicated in Section 12, and as amplified above, FEMWATER has major limitations when considered in the context of the Yucca-Mountain project. Nevertheless, its current evolution is not without merit. In fact, Yeh's currently unpublished work with the multi-grid technique should be watched carefully since the implementation of such a technique may ease the computer-performance limitation which currently afflicts physics-based models in the Yucca-Mountain project.

\section{Comparison to Other Models}

See Chapters 4, 5, and 6 of the main text.

\section{Summary and Recommendations}

The relevance of a Richards-equation code is an issue at the Yucca-Mountain site. Nevertheless, the M\&O needs to be prepared to perform simulations with such a code. However, the performance capability of FEMWATER is duplicated by many other codes, 
some of which employ algorithms which are more appropriate for the Yucca-Mountain site. It is therefore recommended that FEMWATER not be considered for component testing.

16. References

Birdsell, K.H., and B.J. Travis, 1991. TRACR3D: A Model of Flow and Transport in Porols Media, LA-11798-M, Los Alamos National Laboratory, Los Alamos, NM.

Bixler, N.E., 1985. NORIA - A Finite Element Computer Program for Analyzing Water, Vapor, Air, and Energy Transport in Porous Media, Sandia National Laboratories, SAND84-2057, Albuquerque, NM.

Davis, L.A., and S.P. Neuman, 1983. Documentation and Users Guide--UNSAT2-Variably Saturated Flow Model, U.S. Nuclear Regulatory Commission, NUREG/CR-3390, 200 p.

Dudley, A.L., R.R. Peters, J.H. Gauthier, M.L. Wilson, M.S. Tierney, E.A. Klavetter, 1988. Total System Performance Assessment Code (TOSPAC) Volume 1: Physical and Mathematical Bases, SAND85-0002, Sandia National Laboratories, Albuquerque, NM.

Duguid, J.O., and M. Reeves, 1976. Material Transport Through Porous Media: A Finite Element Galerkin Model, ORNL 4928, Oak Ridge National Laboratory, Oak Ridge, TN, 198 pp.

Eslinger, P.W., T.B. Miley, and D.W. Engel, 1990. SUMO-System Performance Assessment for a High-Level Nuclear Waste Repository: Mathematical Models, PNL-7581, Pacific Northwest Laboratory, Richland, WA.

Freeze, R.A., 1971a. Three-Dimensional, Transient, Saturated-Unsaturated Flow in a Groundwater Basin, Water Resour. Res., vol. 7(2), pp. 347-366.

Freeze, R.A., 1971b. Influence of the Unsaturated Flow Domain on Seepage Through Earth Dams, Water Resour. Res., vol. 7(4), pp. 929-941.

Freeze, R.A., 1972a. Role of Subsurface Flow in Generating Surface Runoff. 1. Base Flow Contributions to Channel Flow, Water Resour. Res., vol. 8(3), pp. 609-623.

Freeze, R.A., 1972b. A Physics-Based Approach to Hydrologic Response Modeling. Phase I: Model Development, Water Resour. Res., vol. 8(5), pp. 1272-1283.

Healy, R.W., 1990. Simulation of Solute Transport in Variably Saturated Porous Media With Supplemental Information on Modifications to the U.S. Geological Survey's Computer Program VS2D, Water-Resources Investigations Report 90-4025, U.S. Geological Survey, Denver, CO.

Huyakom, P.S., J.B. Kool, and J.B. Robertson, 1989. VAM2D - Variably Saturated Analysis Model in Two Dimensions, NUREG/CR-5352, HGL-8901, U.S. Nuclear Regulatory Commission, Washington, DC (1989). 
Huyakom, P.S., 1986. A Three-Dimensional Finite-Element Model for Simulating Water Flow in Variably Saturated Porous Media, Water Resour. Res., vol. 22(13), pp. 1790-1809.

Lappala, E.G., R.W. Heary, and E.P. Weeks, 1987. Documentation of Computer Program VS2D to Solve the Equations of Fluid Flow in Variably Saturated Porous Media, WaterResources Investigations Report 83-4099, U.S. Geological Survey, Denver, CO.

Narasimhan, T.N., 1975. A Unified Numerical Model for Saturated-Unsaturated Groundwater Flow, Ph.D dissertation, University of California, Berkeley, CA.

Pruess, K., 1987. TOUGH User's Guide, NUREG,'CR-4645, SAND86-07104, LBL-20700, Sandia National Laboratories, Albuquerque, NM.

Pruess, K., 1991. TOUGH2 - A General-Purpose Numerical Simulator for Multiphase Fluid and Heat Flow, LBL-29400, Lawrence Berkeley Laboratory, Berkeley, CA.

Reeves, M. and J.O. Duguid, 1975. Water Movement Through Saturated-Unsaturated Porous Media: A Finite-Element Galerkin Model, ORNL 4927, Oak Ridge National Laboratory, Oak Ridge, TN, pp 232.

Reisenauer, A.E., K.T. Key, T.N. Narasimhan, and R.W. Nelson, 1982. TRUST: A Computer Program for Variably Saturated Flow in Multidimensional, Deformable Media, NUREG/CR-2360, U.S. Nuclear Regulatory Commission, Washington DC, and PNL3975, Pacific Northwest Laboratory, Richland, WA.

Runchal, A.K., and B. Sagar, 1991. PORFLOW: A Model for Fluid Flow, Heat, and Mass Transport in Multifluid, Multiphase Fractured or Porous Media, User's Manual - Version 2.34, ACRi/016/Rev. E, Analytical and Computational Research, Inc., West Los Angeles, CA.

Updegraff, C.D., C.E. Lee, and D.P. Gallegos, 1991. DCM3D: A Dual-Continuum, Three Dimensional, Ground-Water Flow Code for Unsaturated, Fractured, Porous Media, NUREG/CR-5536, SAND90-7015, Sandia National Laboratories, Albuquerque, NM.

Yeh, G.T., 1987. FEMWATER: A Finite-Element Model of WATER Flow Through Saturated-Unsaturated Porous Media - First Revision, ORNL-5567/R1, Oak Ridge National Laboratory, Oak Ridge, TN.

Yeh, G.T., 1981. On the Computation of Darcian Velocity and Mass Balance in the Finite Element Modeling of Groundwater Flow, Water Resour. Res., vol. 17(5), pp. 1529-1534.

Yeh, G.T., and D.S. Ward, 1980. FEMWATER: A Finite-Element Model of Water Flow Through Saturated-Unsaturated Porous Media, ORNL-5567, Oak Ridge National Laboratory, Oak Ridge, TN. 
Yeh, G.T., and D.S. Ward, 1981. FEMWASTE: A Finite-Element Model of Waste Transport Through Porous Saturated-Unsaturated Media, ORNL-5601, Oak Ridge National Laioratory, Oak Ridge, TN.

Zyvoloski, G., Z. Dash, and S. Kelkar, 1992. FEHMN 1.0: Finite Element Heat and Mass Transfer Code, LA--12062-MS, Los Alamos National Laboratory, Los Alamos, NM. 


\section{A.6 FRACMAN}

1. Name of the Model

FracMan

\section{General Program Information}

2.1 Program size. While FracMan can run with just 640 kilobytes, of memory, an additional $384 \mathrm{k}$ to 2 megabytes of RAM is recommended to improve performance. A high-speed hard drive with at least one megabyte of available memory is also recommended.

2.2 Programming language. The goal is to convert FracMan entirely to the $\mathrm{C}$ language. This will facilitate use of the code on a work station in a "windows" environment. All of the FracSys module and approximately 30 percent of the FracWorks module are written in C. Overall, however, FracMan remains 60 to 65 percent FORTRAN 77.

2.3 Computer systems on which it operates. FracMan runs on MS-DOS compatible computers with Intel CPU and math coprocessor, including 8088/8087, 80286/80287, 80386/80387, and i486 class computers.

2.4 Compiler(s) used. Standard FORTRAN and C compilers are used.

2.5 Location of code and availability. Copies of the object code may be obtained from Golder Associates Inc. at their Redmond WA offices.

2.6 Brief description of model/code history. FracMan interprets and geometrically simulates discrete features in rock. For convenience, the documentation refers to such features as "fractures." Using pull-down menus to invoke them, one can invoke the various modules and options which comprise FracMan. Graphical displays provide the primary mode of user interaction.

Fracture data derive from borehole logs, trace maps of exposed surfaces, and borehole packer tests. The FracSys module analyzes these data to obtain statistical information regarding fracture-set orientations, locations, and sizes as well as statistical information regarding properties such as transmissivities, storativities, and aperatures.

From such statistical information, the FracWorks module generates geometrical realizations of the fractured rock. Using these realizations, the FracWorks module can develop borehole and traceplane statistics, thereby providing a useful supplement to an exploration program. Discrete features are assumed to be planar and to have finite extents. Between any two points, continuous hydrological pathways may be formed by individual faults or fractures or by networks of interconnected features. Excluding the possibility of short bridges through intact rock, FracWorks' pathway analysis 
algorithm can identify and characterize the pathways between any two points for each fracture realization.

The MeshMaker module provides the user with a capability for transforming FracWorks files into finite-element meshes for MAFIC (Miller, 1990) flow and solute transport simulations. MeshMaker considers only fractures. For three-dimensional systems, it generates triangular finite elements within these planar features.

Initial development of FracMan began during 1982 as a part of Dershowitz's Ph.D. thesis at Massachusetts Institute of Technology. Under funding from the Office of Crystalline Rock Development (OCRD), the code went through significant development phases in 1985 and 1988. Currently, Japan, Sweden, and the U.S. (via the Yucca-Mountain Project) are funding development and application of FracMan.

\section{Status of Model}

3.1 Development (Is the model now undergoing significant development or modification? or continuing maintenance?). Japanese interests focus on relatively small block tests, and detailed interpretation of a relatively small number of fractures. Here geostatic and fractal algorithms are being implemented to generate transmissivity and storativity distributions within single fractures. Under both Japanese and Swedish funding, algorithms are being added to facilitate the interpretation of packer tests on individual fractures. The U.S. Department of Energy's (DOE) Yucca Mountain funding is focused primarily on upgrading MAFIC, and only relatively minor FracMan modifications are being developed within the mesh-generation module.

3.2 Documentation. Dershowitz et al. (1991) provides a good discussion of FracMan's graphical input structure and devotes one appendix to the theory.

3.3 Status of verification and validation. Both Dershowitz et al. (1991) and Schwartz and Lee (1991) provide verification tests. These tests confirm that the various statistical distributions are being sampled to an acceptable level of accuracy. They also confirm that fracture systems generated by FMG (Billaux et al., 1988) from LBL (Lawrence Berkeley Laboratory), NAPSAC (Grindrod 4 al., 1992) from the U.K. AEA (United Kingdom Atomic Energy Authority), and FracMan yield similar flow solutions. Tests performed at Stripa have validated FracMan-MAFIC flow and transport results to an acceptable degree of accuracy (i.e., about a factor of ten).

3.4 Status of Quality Assurance (QA). FracMan is under configuration management and QA control. The Golder QA program has been approved by the Yucca Mountain Project.

\section{Type of Model (Phenomena/Processes Modeled)}

FracMan interprets fracture data and geometrically simulates discrete features in rock, including faults, fractures, paleochannels, karsts, and stratigraphic contacts. 


\section{Governing Equations}

FracMan provides a variety of probability distribution functions. For scalar data, such as equivalent fracture radius, fracture aspect ratio (ratio of major and minor axes), or fracture intensity, one may choose from among uniform, exponential, normal, lognormal, power-law, gamma, or Dirac-delta distributions. For directional data, such as dip or direction of fracture elongation, one may choose from among univariate Fisher, bivariate Fisher, bivariate normal, bivariate Bingham, or spherical Dirac-delta distributions. Fracture properties such as transmissivity, storativity, or aperature, may be correlated to effective radius or orientation.

\section{Method of Solution}

To generate fracture sets based on the statistical information, conceptual models are used.

The FracMan module FracWorks offers six different such models as options. They are: (1) Enhanced Baecher, (2) Levy-Lee Clustering, (3) Nearest Neighbor, (4) War Zone, (5) Poisson Rectangle, and (6) Bart. The first four models are described in Geier, Lee, and Dershowitz (1989). All generate polygonal fractures that may or may not terminate at intersections with other fractures. The models differ from one another only with regard to the spatial distribution of the fractures, and the interrelationship of fracture size and fracture location.

According to fracture-mechanics theory, isolated fractures in homogeneous rock are elliptical. With regard to the polygonal fracture shape used by FracMan, Dershowitz argues that, in a practical sense, no error is introduced in representing the ideal shape with a manysided polygon of equal area. He argues further that observed fractures are generally polygonal due to terminations at intersections with other fractures. Both the Veneziano Model (Veneziano, 1984) and the Dershowitz Model (Dershowitz, 1984) treat fractures as polygons.

\section{Type of Input Parameters}

The FracMan package uses a graphical user interface. Generally, one begins with the command "fracman", which executes the FracMan shell and provides options to run different modules of the FracMan package. Alternatively, the user may skip the shell and directly execute one of the modules, using a command such as "fracsys". The FracMan package contains the three major modules: FracSys, FracWorks, and MeshMaker. Also included in the package are two graphics modules FracSimile, a dot-matrix, hard-copy facility which has been outmoded by commercial screen-capture software, and FracView. FracView produces a variety of plots for a number of different variables, including mesh generated for MAFIC by MeshMaker and output variables from both FracMan and MAFIC. This module is not documented in Dershowitz et al. (1991).

FracSys itself contains a number of modules designed to analyze field data. Assisted by various menus, one properly loads ASCII files of data. For example, with appropriate interactive input such as that relating to a Terzaghi correction for orientation bias or weighting factors for the various properties used to make set definitions, FracSys can group 
the fractures in sets and can obtain the orientation dispersion of the pole and dip vectors for each set.

FracWorks can either generate discrete fracture sets or, if such fractures have already been generated, it can predict results which would be obtained from a contemplated borehole or traceplane study. The former is identified as "geometric modeling" and the latter as "exploration simulation". FracWorks generates single fractures and fracture sets within a "box", wherein each $c$ : the three coordinates varies from -1 to +1 fracmeters. The conversion from fracmeter to meter is user defined. In viewing the contents of the box, one can change both the plotting scale and the viewing perspective. Using interpretative data obtained with FracSys whenever possible, the user specifies one of the six models mentioned in Section 6 above. Other fracture characteristics include intensity (area/volume or volume/volume), size, direction of elongation, dip, and appropriate statistical information for each of these quantities. Fracture properties are specified, and, if desired, they may be correlated to either size or orientation. FracWorks can generate shear and torsional faults.

Exploration simulation requires first that one geometrically define the contemplated exploration borehcles or traceplanes from which samples are to be taken. For the designated boreholes or traceplanes, FracWorks will, for example, display statistics such as the number of fractures and the number of intersections, provide histograms of inverse fracture spacings and property (e.g., transmissivity) data, and display a Schmidt steroplot of either pole or dip vectors. From a pathways analysis, FracWorks, for example, will identify the number of pathways between designated boreholes, the number of fractures in each set, the conductance of each pathway, and the net conductance.

\section{Type of Output and User Options}

\section{See Section 7.}

9. Model Interactions (emphasize needed processors)

9.1 Does the model interface with any other models? FracMan generates fracture sets. It then generates finite-element mesh for the fractures to be used by MAFIC (Miller, 1990).

9.2 Source code and type of information needed. Not applicable.

9.3 Receiving code and type of information provided. Not applicable.

9.4 Any pre- or postprocessing needed? The FracMan p'otting package FracView is rarely used. Usually, a commercially available plotting package such as Gnuplot or Lotus Excel is used instead.

\section{Model Application}

10.1 Usage within the Civilian Radioactive Waste Management System (CRWMS) program. FracMan (Dershowitz et al., 1991) and MAFIC (Miller, 1990) provide the program 
with the ability to interpret geologic data, to construct statistical realizations of discrete-fracture systems which are consistent with this data, and to predict flow and transport within such systems.

10.2 Usage outside the program. The development and application of MAFIC has been funded by Japanese and Swedish repository programs and by the U.S. OCRD.

\section{Codes With Similar or Same Capabilities}

11.1 Within the program. Within the CRWMS program, Golder's FracMan (Dershowitz et al., 1991) and LBL's FMG3D (Gilmour et al., 1986) provide alternative approaches to fracture simulation. The former approach emphasizes the forward problem and therefore provides results which compare most readily with geologic data. The latter approach, using a less realistic pipe model, emphasizes the inverse problem. Here, one constructs systems of pipe networks which will permit a characterization of packer-test data using the simulated annealing algorithm of Long et al. (1991).

11.2 Outside the program. In contrast to FracMan's more realistic polygonal fractures, the U.K.'s Atomic Energy Act NAPSAC (Grindrod et al., 1992) assumes rectangular fractures. NAPSAC's statistical capabilities are more limited for both scalar and directional data. Finally, in contrast to MAFIC's transient flow capability, NAPSAC is limited to steady flow analyses only.

12. Major Assumptions and Limitations

For completeness, this section considers both FracMan and MAFIC.

- FracMan does not generate mesh within the rock matrix, thus leaving this laborious process to the user of MAFIC.

- MAFIC considers only a weakly compressible fluid. Thus, it cannot consider the effect of fractures on gas flow. This deficiency is being remedied at the present time.

- MAFIC considers only saturated flow. Thus, it cannot consider the effect of partially saturated liquid movement at Yucca Mountain. Plans for a code upgrade are being developed.

- MAFIC does not consider nonisothermal flow. Thus, it cannot consider the effect of fractures upon a repository heat pipe.

- Except for its consideration of pseudo-steady flow in the rock matrix, MAFIC couples fracture and rock matrix using an inefficient iteration scheme. A fast, noniterative method for one-dimensional rock-matrix units will be published in the near future (Reeves et al., 1992). 


\section{Remarks/General Observations/Discussion}

Within the Yucca-Mountain project, continuum modeling is considerably more advanced than discrete-fracture modeling. And it is apparent that the former has received most of the funding. Nevertheless, before developing either realistic or conservative conceptualizations for Yucca Mountain, the effect of fractures must be considered. Relatively small implementations of tractable analogues may be adequate in many cases. Preferably, creative thinking by staff members of the $\mathrm{M} \& \mathrm{O}$, and/or its associated contractors can effect breakthroughs in software technology which will permit realistic geometries to be considered.

\section{Comparison to Other Models}

(See Section 11 of this review.)

\section{Summary and Recommendations}

For completeness, this section considers both FracMan and MAFIC.

- Preliminary investigations indicate that FracMan can more accurately account for the geometry of Yucca Mountain than either FMG3D or NAPSAC. In a public forum, this should make its results the most defensible.

- In many ways, FracMan is already adequate for the M\&O. Definitely, the most important development should focus on a replacement for MAFIC.

- Future FracMan developments should concentrate on compatibility with the replacement code for MAFIC. Improvements in FracMan's mesh generation within the rock matrix should be carefully considered.

- Already, the M\&O has a copy of the FracMan's object deck, thus permitting M\&O personnel to become familiar with the graphical interface.

- FEHM, a finite-element code from LANL (Los Alamos National Laboratory), simulates nonisothermal flow and transport processes. The M\&O should encourage a cooperative arrangement between LANL and Golder Associates Inc., the purpose of which would be to link FracMan and FEHM.

- The M\&O should pursue the development of an advanced solver, specially adapted for the mathematical matrices which arise from fractured-rock systems.

16. References

Billaux, D., S. Bodea, and J.C.S. Long, 1988. FMG, RENUM, LINEL, ELLFMG, ELLP, and DIMES: Chain of Programs for Calculating and Analyzing Fluid Flow through TwoDimensional Fracture Networks-Theory and Design, LBL-24914. 
Dershowitz, W.S., 1984. Rock Joint Systems, Ph.D. Dissertation, Massachusetts Institute of Technology, Cambridge, MA.

Dershowitz, W.S., G. Lee, and J.E. Geier, 1991. FracMan Version Beta 2.3 Interactive Discrete Feature Data Analysis, Geometric Modeling, and Exploration Simulation - User Documentation, Golder Associates Inc., Redmond, WA.

Dershowitz, W.S., J.C.S. Long, and A.W. Herbert, 1989. Stripa Report TR89-02.

Geier, J.E., K. Lee, and W.S. Dershowitz, 1989. Field Validation of Conceptual Models for Fracture Geometry, submitted to Rock Mechanics and Rock Engineering.

Grindrod, P., A.W. Herbert, D.L. Roberts, and P.C. Robinson, 1992. NAPSAC Technical Document, AEA D\&R 0270, United Kingdom Atomic Energy Authority Decommissioning and Radwaste, Harwell Laboratory, Oxon OX11 0RA.

Long, J.C.S., K. Karasaki, A. Davey, J. Peterson, M. Landsfeld, J. Kemeny, S. Martel, 1991. An Inverse Approach to the Construction of Fracture Hydrology Models Conditioned by Geophysical Data: An Example from the Validation Exercises at the Stripa Mine, Int. J. Rock Mech. Min. Sci. \& Geomech. Abstr. Vol. 28, No.2/3, 121-142.

Miller, I., 1990. MAFIC Version Beta 1.2 Matrix/Fracture Interaction Code with Solute Transport - User Documentation, Golder Associates Inc., Redmond, WA.

Reeves, M., A. Haug, and G.E. Grisak, 1992. To be published.

Schwartz, F.W., and G. Lee, 1991. Stripa report TR91-29.

Veneziano, 1979. Probabilistic Model of Joints in Fractured Rock, Technical Report, Department of Civil Engineering, Massachusetts Institute of Technology, Cambridge, MA. 


\section{A.7 LLUVIA AND LLUVIA-II}

\section{Name of the Models}

LLUVIA and LLUVIA-II

\section{General Program Information}

2.1 Program sizes. Both LLUVIA and LLUVIA-II consist of two modules. Both use a method-of-lines solver module containing approximately 5,300 source statements. The LLUVIA module for executive and support functions contains approximately 650 source statements, while a similar LLUVIA-II module contains approximately 1,300 source statements.

\subsection{Programming language. FORTRAN 77}

2.3 Computer system on which it operates. LLUVIA runs on VAX, Sun, Cray, SPARK, and personal computers.

2.4 Compiler(s) used. LLUVIA-II uses the standard compiler of each machine.

2.5 Location of code and availability. The code may be obtained from the authors or from the current Department 1510 contact person at SNL (Sandia National Laboratories).

2.6 Brief description of model/code history. Severe non-linearities in the material properties of highly fractured volcanic tuffs cause the ground-water flow modeling of Yucca Mountain to be a computer-time-intensive activity. In an effort to alleviate this problem, the authors of the LLUVIA codes have examined a possible alternative to the matrix-solution methods which are customarily used.

In the development and application of LLUVIA, Hopkins and Eaton (1990) apply a solver for stiff ordinary differential equations (ODEs) to the space domain of the onedimensional steady-flow problem. In the development and application of LLUVIA-II, Eaton and Hopkins (1992) apply the same solver to the time domain of the twodimensional, transient flow problem. (This approach is identified as the method of lines.)

\section{Status of Model}

3.1 Development (Is the model now undergoing significant development or modification? or continuing maintenance?). Current work focuses on the testing of LLUVIA-II to determine its suitability for large-scale transient problems. Thus far, Eaton and Hopkins (1992) find the method of lines to be well adapted for solution of nonlinear, parabolic partial-differential equations. 
At SNL, long-term development focuses on COYOTE (Gartling, 1978), using this code as a prototype. Changes include expansion to three dimensions, an enhanced element library, dynamic dimensionsing, and vectorization for SNL's massively parallel computer. After identifying successful algorithms, SNL will implement them on other codes, including LLUVIA-II.

3.2 Documentation. Hopkins and Eaton (1990) and Eaton and Hopkins (1992) provide readable descriptions of the numerical implementation and data input of LLUVIA and LLUVIA-II.

3.3 Status of verification and validation. Eaton and Hopkins (1992) report excellent comparisons with analytic solutions for two soils having exponential properties. The authors also report the results of a comparison between LLUVIA-II and the finiteelement code NORIA-SP (Hopkins, et al., 1991). Taken from the COVE2a study (Hopkins, 1990), the problem chosen for the comparison is quite similar to that described in Section B.2. Using a one-dimensional stratigraphy taken from Yucca Mountain, the problem assumes that a steady initial moisture state based on an infiltration of $0.5 \mathrm{~mm} / \mathrm{y}$ is perturbed by the sudden increase of the infiltration to $1.0 \mathrm{~mm} / \mathrm{y}$. Eaton and Hopkins (1992) find that LLUVIA-II results compare adequately both with those of NORIA-SP and with those reported for five other codes (Dykhuizen et al., 1991).

As a part of a code-comparison study at SNL, an internal memo (Eaton, January 8, 1992) reports LLUVIA-II results for two versions of the Jornada-Trench problem which, except for the gridding, are identical to Cases $A_{2}$ and $B_{2}$ (Section B.1). This memo noted good agreement between the results obtained using LLUVIA-II and the USGS code VS2DT (Healy, 1990). It also noted that, for a Cray Y-MP computer, the LLUVIA-II CPU times were larger than the VS2DT CPU times by a factor of about 3.5 and 1.5, respectively, for Cases $A_{2}$ and $B_{2}$.

3.4 Status of Quality Assurance (QA). Like LLUVIA, LLUVIA-II has been placed under QA control at SNL.

\section{Type of Model (Phenomena/Processes Modeled)}

In contrast to LLUVIA which simulates partially saturated steady flow in a one-dimensional system, LLUVIA-II simulates partially saturated transient flow in a two-dimensional system. To treat a fractured media, both codes employ an equivalent-continuum model. Such a model assumes capillary-pressure equilibrium between fracture and matrix.

\section{Governing Equations}

LLUVIA solves the one-dimensional Richards equation for steady flow. This equation is a second-order ODE in the spatial variable. LLUVIA-II solves the two-dimensional Richards equation for transient flow. This equation is a partial differential equation (PDE) which is first order in the time variable and second order in the two space variables. 


\section{Method of Solution}

To integrate the second-order ODE for steady, one-dimensional flow, LLUVIA applies the SLATEC library routine DEBDF (Shampine and Watts, 1980) to the second-order derivatives in the space variable. Based on the work of Hindmarsh (1981), this routine is specially adapted to the solution of stiff systems. Stiffness, like non-linearity, arises from the unsaturated material properties, the values of which can vary by many orders of magnitude over a physical system.

To integrate the PDE for transient, two-dimensional flow, LLUVIA-II discretizes the spatialderivative terms. It then applies DEBDF to the resulting set of first-order ODEs in the time variable.

Spatial discretization employs the point-distributed method described by Aziz and Settari (1979). LLUVIA-II's implementation of this method positions nodes on boundaries and material interfaces. Within the interior of the system, it places cell interfaces equidistant between nodes. For the Cartesian coordinate system used by LLUVIA-II, this ensures convergence of the solution for increasing levels of refinement.

\section{Type of Input Parameters}

Both LLUVIA and LLUVIA-II require the following types of data: spatial discretization, material properties, and boundary conditions. To change capillary-pressure and relativepermeability relations, both codes also require that the user to rewrite property subroutines (EVAL for LLUVIA, CON and FLUIDC for LLUVIA-II).

Because of its inclusion of the time domain, LLUVIA-II additionally requires a specification of the initial condition and the simulation times at which output is desired. It is interesting to note here that DEBDF generates its own time steps according to error criteria which are "hard coded" into the main routine of LLUVIA-II. Thus, unlike similar codes, LLUVIA-II does not require time-discretization input. However, depending on the difficulty of the simulation, it may be necessary to alter the error criteria and recompile the main routine.

In addition, because of its consideration of two dimensions rather than one, LLUVIA-II requires more definition of the spatial domain. With appropriate input, it divides the spatial domain into subregions, each of which is assumed to have homogeneous properties. Also, according to user specifications, it distributes nodes both within and on the boundaries of each subregion.

LLUVIA requires a Neumann flux condition at one end of its one-dimensional system (the top) and a Dirichlet head condition at the other (the bottom). LLUVIA-II permits a general distribution of such conditions, as specified by the user.

\section{Type of Output and User Options}

LLUVIA and LLUVIA-II calculate capillary pressure (head), total pressure, liquid saturations, Darcy fluxes and interstitial velocities within each grid cell. LLUVIA further 
divides the velocities into fracture and matrix components. With relatively minor additions to its coding, LLUVIA-II could also perform this function. With existing options, or with straightforward coding changes, any of these dependent variables may be written to the output file.

9. Model Interactions (emphasize needed processors)

9.1 Does the model interface with any other models? Yes, see below.

9.2 Source code and type of information needed. Not applicable.

9.3 Receiving code and type of information provided. LLUVIA and LLUVIA-II interface with transport simulators such as LLUVIA-S (Dykhuizen, 1987) and FEMTRAN (Martinez, 1985).

9.4 Any pre- or postprocessing needed? A graphics software package must be supplied by the user.

10. Model Application

10.1 Usage within the Civilian Radioactive Waste Management System (CRWMS) program. LLUVIA is designed to determine two performance criteria established by the regulations. These criteria, relating to pre-emplacement ground-water travel time and 10,000-year cumulative release, are both stochastically based, thus leading to computer-time-intensive calculations. This has strongly influenced the specialization of LLUVIA to steady one-dimensional problems.

LLUVIA-II is designed to test the applicability of the method of lines to nonlinear flow analyses. If the method of lines proves to be superior to the more conventional matrix-solution methods, then LLUVIA-II would be useful for site-characterization, design, and some performance-assessment calculations.

10.2 Usage outside the program. At this point, neither LLUVIA nor LLUVIA-II has been used outside the program.

\section{Codes With Similar or Same Capabilities}

11.1 Within the program. The steady-flow modules of the SNL code TOSPAC (Dudley et al., 1988 and Gauthier et al., 1992) duplicate LLUVIA's capabilities.

Many codes duplicate LLUVIA-II's capabilities. Its uniqueness lies only in its use of the method of lines.

11.2 Outside the program. Undoubtedly, many soil physicists have unpublished codes such as LLUVIA in their personal files. The same may be said of LLUVIA-II. 


\section{Major Assumptions and Limitations}

LLUVIA-II has the following restrictions:

- Thermal effects are not considered. Such effects may be quite significant for Yucca Mountain.

- The flow of vapor and air is not considered. The effect of vapor flow may be quite significant even for pre-emplacement conditions at Yucca Mountain.

- Fracture-matrix disequilibrium cannot be accounted for in field-scale simulations.

- Transport simulations require an interface with a separate stand-alone code. The large files required to transfer the flow can be inconvenient for large simulations.

- Only two spatial dimensions are considered. This will be sufficient for many applications. However, some applications will undoubtedly require three dimensions.

LLUVIA has the following added restrictions:

- Only steady state is considered. If non-equilibrium fracture flow significantly affects repository conditions, this assumption will not be appropriate. Further considering that hundreds of thousands of years are required to effectively reach a steady state, this assumption may not be appropriate for the rock matrix.

- It is a single phase model.

- The use of one vertical dimensional may not be adequate, even if multidimensional hydrothermal and mountain-scale gas-flow effects can be reasonably neglected.

\section{Remarks/General Observations/Discussion}

In their introductory remarks, Eaton and Hopkins (1992) characterize the development of LLUVIA-II as a "continued effort to investigate other numerical techniques in which fewer restrictions must be applied." This remark appears to be crucial to an appraisal of both LLUVIA and LLUVIA-II. In spite of the fact that their capabilities duplicate those of other codes within the Project, the LLUVIA and LLUVIA-II codes permit an appraisal of the method-of-lines solver.

Excessive CPU time is perhaps the most pressing modeling issue at the present time. Excessive CPU time not only prevents many stochastic applications of detailed-process models, it also blocks the resolution of other issues relating to the analysis of mountain-scale vapor flow, non-equilibrium fracture flow, and discrete-fracture effects. Thus, the key question for LLUVIA and LLUVIA-II is the extent to which their method-of-lines solver will reduce the CPU times obtained with commonly used matrix-solution methods. 


\section{Comparison to Other Models}

See Chapters 4,5 , and 6 of the main text.

15. Summary and Recommendations

Because of its computer efficiency, LLUVIA has been used in probabilistic studies. However, TOSPAC has been used and tested much more extensively and has more capabilities. It is therefore recommended that the M\&O not advance LLUVIA to the component-testing phase.

Because of its more general implementation, LLUVIA-II offers a better setting in which to test the method-of-lines solver. For the purpose of testing this solver, then, it is recommended that LLUVIA-II be advanced to the component-testing phase. 


\section{References}

Aziz, K., and A. Settari, 1979. Petroleum Reservoir Simulation, Elsevier Applied Science Publishers, pp. 476.

Dudley, A.L., R.R. Peters, J.H. Gauthier, M.L. Wilson, M.S. Tierney, E.A. Klavetter, 1988. Total System Performance Assessment Code (TOSPAC) Volume 1: Physical and Mathematical Bases, SAND85-0002, Sandia National Laboratories, Albuquerque, NM.

Dykhuizen, R.C., 1987. Transport of Solutes Through Unsaturated Fractured Media, Water Resour. Res., 21 (12), 1531-1539.

Dykhuizen, R.C., 1990. A New Coupling Term for Dual Porosity Models, Water Resour. Res., 26 (2), 351-356.

Dykhuizen, R.C., R.R. Eaton, P.L. Hopkins, and M.J. Martinez, 1991. PACE90 Water and Solute Transport Calculations for $0.01,0.1$, and $0.5 \mathrm{~mm} / \mathrm{yr}$ Infiltration into Yucca Mountain, SAND90-3165, Sandia National Laboratories, Albuquerque, NM.

Eaton, R.R., and P.L. Hopkins, 1992. LLUVIA-II: A Program for Two-Dimensional Transient Flow Through Partially Saturated Porous Media. SAND91-2146, Sandia National Laboratories, Albuquerque, NM.

Gartling, D.K, 1978. COYOTE -- A Finite Element Computer Program for Nonlinear Heat Conduction Problems, SAND77-1333, Sandia National Laboratories, Albuquerque, NM.

Gauthier, J.H., M.L. Wilson, R.R. Peters, A.L. Dudley, L.H. Skinner, 1992. Total System Performance Assessment Code (TOSPAC) Volume 2: User's Guide, SAND85-0004, Sandia National Laboratories, Albuquerque, NM.

Healy, R.W., 1990. Simulation of Solute Transport in Variably Saturated Porous Media With Supplemental Information on Modifications to the U.S. Geological Survey's Computer Program VS2D, Water-Resources Investigations Report 90-4025, U.S. Geological Survey, Denver, CO.

Hindmarsh, S.C., 1981. ODE Solvers for Use With the Method of Lines, UCRL-85293, Lawrence Livermore National Laboratories, Livermore, CA.

Hopkins, P.L., 1990. COVE 2A Benchmarking Calculations Using LLUVIA, SAND882511, Sandia National Laboratories, Albuquerque, NM.

Hopkins, P.L., and R.R. Eaton, 1991. A Finite-Element Computer Program for Analyzing Liquid Water Transport in Porous Media, SAND908-2542, Sandia National Laboratories, Albuquerque, NM. 
Martinez, M.J., 1985. FEMTRAN-A Finite Element Computer Program for Simulating Radionuclide Transport Through Porous Media, SAND84-0747, Sandia National Laboratories, Albuquerque, NM.

Mualem, Y., 1976. A New Model for Predicting the Hydraulic Conductivity of Unsaturated Porous Materials, Water Resources Research, 12 (3) 513-522.

Prindle, R.W. and P.L. Hopkins, 1990. On Conditions and Parameters Important to Model Sensitivity for Unsaturated Flow Through Layered, Fractured Tuff: Results of Analyses for HYDROCONN Level 3 Case 2, SAND89-0652, Sandia National Laboratories, Albuquerque, NM.

Shampine, L.F., and H.A. Watts, 1980. DEPAC-Design of a User Oriented Package of ODE Solvers, SAND79-2374, Sandia National Laboratories, Albuquerque, NM.

van Genuchten, R., 1978. Calculating the Unsaturated Hydraulic Conductivity with a New Closed-Form Analytical Model, Water Resources Bulletin, Princeton University Press (HQS.880517.1859). 


\section{A.8 MAFIC}

\section{Name of the Model}

MAFIC (Matrix/Fracture Hydraulic Interaction Code with Solute Transport)

\section{General Program Information}

\subsection{Program size. Approximately 5,000 lines of source coding}

\subsection{Programming language. FORTRAN 77}

2.3 Computer systems on which it operates. Versions of MAFIC are available for Sun, Alliant, Convex, VAX/VMS and IBM RS/6000 work stations.

\subsection{Compiler(s) used. Standard compilers are used on each machine.}

2.5 Location of code and availability. Copies of the code may be obtained from Golder Associates Inc. at their Redmond, Washington offices.

2.6 Brief description of model/code history. Several researchers have shown that, in many cases, flow and solute transport through fracture networks cannot be accurately modeled with equivalent porous media models (Long et al., 1982; Robinson, 1984; Anderson and Deverstorp, 1987; Smith and Schwartz, 1984). To provide for more realistic simulations of fractured rock masses, flow models incorporating networks of discrete fractures may be required.

After predicting fracture patterns using three-dimensional stochastic simulation, FracMan generates finite-element mesh to be used by MAFIC. At present, MAFIC considers only saturated moisture conditions. It models fracture flow through a network of interconnecting "plates" and matrix flow through a three-dimensional volume. The retarding effects of matrix diffusion are not considered.

The initial development of Fracman and MAFIC began during 1982 as a part of W. Dershowitz's Ph.D. thesis at Massachusetts Institute of Technology. Under funding from the Office of Crystalline Rock Development (OCRD), the codes went through significant development phases in 1985 and 1988, which included the addition of mesh-generation and solute-transport capabilities. Currently, Japan, Sweden, and the U.S. (via the Yucca-Mountain Project) are funding the development and application of FracMan and MAFIC.

\section{Status of Model}

3.1 Development (Is the model now undergoing significant development or modification? or continuing maintenance?). Under Japanese funding, matrix diffusion is being added. Under Yucca-Mountain funding, a program is underway to extend the flow 
capabilities of MAFIC. The ultimate goal here is a comparison of discrete and continuum approaches for a flow system like that of Yucca Mountain. As an interim goal, gas flow is being added. This capability will permit the Yucca-Mountain project to assess the effect of fractures upon the results of air-injection tests.

3.2 Documentation. Miller (1990) discusses theory and data input and provides sample input and output files.

3.3 Status of verification and validation. MAFIC uses approximately six verification problems and approximately six validation problems, the latter having been developed from data taken by the Stripa Project.

3.4 Status of Quality Assurance (QA). MAFIC is under configuration management and QA control at Golder. The Golder QA program has been approved by the Yucca Mountain Project.

\section{Type of Model (Phenomena/Processes Modeled)}

A discrete-fracture model, MAFIC considers saturated flow in both fractures and rock matrix. Both fluid and porous structure are assumed to be slightly compressible. For transport in fractures only, MAFIC considers dispersion, diffusion, and advection. Radioactive and geochemical effects are not accounted for.

\section{Governing Equations}

Standard flow and transport equations are used. For flow, boundary-source conditions consist of (1) specified head, (2) specified flux, and (3) specified nodal-group flux, each of which may be time varying. Generally, Condition (3) corresponds to a well whose zone of completion extends over several nodes.

For transport, solute sources are specified as the concentration of in-flowing water at a nodal group. Sink concentrations may be time varying. Solute sinks are not specified by the user but may occur at any node with specified outflow or head boundary conditions.

\section{Method of Solution}

Flow in the rock matrix may be simulated using one of three different submodels. Considering only the added storativity due to the rock matrix, a pseudo-steady analytical approximation employs the approach of Warren and Root (1963). Considering the possibility of unsteady flow, a second submodel employs a one-dimensional set of finite elements within the rock matrix. Either spherical or slab geometries may be used, yielding tri-diagonal matrices with relatively simple direct solution. An iterative algorithm couples fractures and rock matrix. Considering also the possibility of large-scale flow, a third method employs a multi-dimensional finite-element grid within the rock matrix. Triangular and tetrahedral elements are used for two- and three-dimensional problems, respectively, with either linear or quadratic basis functions. 
In a two-dimensional system, MAFIC represents the fractures by a network of onedimensional "pipes", each with one-dimensional elements. In a three-dimensional system, the configuration is generalized to a two-dimensional network of "plates", each with triangular elements. Consistent with the analysis of rock-matrix flow, assembly of the fracture equation employs the Galerkin procedure for either linear or quadratic basis functions. Matrix solution employs the conjugate-gradient method, preconditioned with incomplete Choleski decomposition.

The transport simulation employs a particle-tracking approach. Here, a solute concentration is represented by a finite number of discrete particles of equal mass. At each time step, particles are moved according to a deterministic convective component and a stochastic dispersive-diffusive component.

\section{Type of Input Parameters}

The MAFIC input structure consists of a fixed number of records, each of which contains fields of format-free data. Several different types of data are required. Physical parameters characterize both flow and transport. Flow data include storativities and transmissivities for both fractures and rock matrix, fracture aperatures, and boundary-source conditions. Transport data include diffusivities, dispersivities, a random seed used to stochastically simulate the diffusion and dispersion phenomena, and source concentrations.

Geometric data characterize both system boundaries and internal mesh structure. Such data identify locations for various source and boundary types. They also specify the type of rockmatrix discretization (pseudo-steady, generic one-dimensional matrix block, or fully discretized). For finite-element models, this information can be quite lengthy and can require a significant number of person-days in its preparation. Complex discrete-fracture patterns make this preparation even more time consuming. MAFIC allows the user to enter a separate mesh definition file resulting, for example, from FracMan's automatic mesh generation.

Calculational controls regulate time steps, iterations, and matrix solution. Input-output controls specify simulation times and the nodal points for which hard-copy and plot output are to be prepared. Since MAFIC assumes a consistent set of units, output controls also supply names of the units.

\section{Type of Output and User Options}

Fiogram output contains a summary of basic input and problem-size parameters. Either a summary or a full print of the input may be specified. The latter effects the output of geometric data. Output is also printed at the end of each time step. Various items may be specified for output, ranging from summary data to tables of hydraulic heads and concentrations. At every time step, MAFIC tabulates time versus hydraulic heads and concentrations in a plot file. At the end of a successful execution, MAFIC writes a restart file if so directed by the user. 
9. Model Interactions (emphasize needed processors)

9.1 Does the model interface with any other models? Using statistical input data, FracMan generates and spatially orients sets of fractures. It then generates mesh for the fractures to be used by MAFIC.

9.2 Source code and type of information needed. Not applicable.

9.3 Receiving code and type of information provided. Not applicable.

9.4 Any pre- or postprocessing needed? The FracMan plotting package FRACVIEW is rarely used. Usually, the commercially available plotting packages Gnuplot and Lotus Excel are used instead.

10. Model Application

10.1 Usage within the Civilian Radioactive Waste Management System (CRWMS) program. FracMan is the only code in the Yucca-Mountain Project with a capability for generating sets of discrete fractures. MAFIC interfaces with FracMan.

10.2 Usage outside the program. The development and application of MAFIC has been funded by Japanese and Swedish repository programs and by the U.S. OCRD.

\section{Codes With Similar or Same Capabilities}

11.1 Within the program. In upgrading MAFIC's capability to simulate a compressible fluid (gas), the goal is basically to upgrade the equivalent-continuum conceptualization of the Yucca-Mountain TGIF code (Ross et al., 1991) t :ie discrete-fracture conceptualization of FracMan. TGIF's ability to implicitly consider a saturated vapor phase within the gas would be desirable for MAFIC.

In adding to MAFIC a capability to include multiphase, nonisothermal flow, one might consider FEHM (Zyvoloski et al., 1992), developed at LANL (Los Alamos National Laboratory). Like MAFIC, FEHM is a three-dimensional finite-element model. FEHM also has a general transport capability which includes both radioactive and geochemical processes. Rather than to consider adding a multiphase, nonisothermal capability to MAFIC, it might be more cost effective to link FEHM to the FracMan discrete-fracture model.

One might also consider the finite-element code NORIA (Bixler, 1985) developed at SNL (Sandia National Laboratory). However, because of its three-dimensionality, its general transport capability, and its more efficient matrix solution, FEHM is believed to be a better alternative for MAFIC enhancement.

11.2 Outside the program. Except for FracMan, very few discrete-fracture codes exist both inside and outside the Yucca-Mountain Program. MAFIC's present capability to simulate only saturated flow in a dual-porosity, variable geometry system is 
non-unique and may be found outside the Yucca-Mountain Program. With the ability to treat a partially saturated medium, codes such as VAM2D (Huyakorn et al., 1989) provide a greater capability than MAFIC. MAFIC's claim to uniqueness lies only in its compatibility with FracMan, a facility that could be added to other codes with limited expense.

\section{Major Assumptions and Limitations}

- FracMan does not generate mesh within the rock matrix, thus leaving this laborious process to the user of MAFIC.

- MAFIC considers only a weakly compressible fluid. Thus, it cannot consider the effect of fractures on gas flow. This deficiency is being remedied at the present time.

- MAFIC considers only saturated flow. Thus, it cannot consider the effect of partially saturated liquid movement at Yucca Mountain. Plans for a code upgrade are being developed.

- MAFIC does not consider nonisothermal flow. Thus, it cannot consider the effect of fractures upon the repository heat pipe.

- Except for its consideration of pseudo-steady flow in the rock matrix, MAFIC couples fracture and rock matrix using an inefficient iteration scheme. A fast, noniterative method for one-dimensional rock-matrix units will be published in the near future (Reeves et al., 1992). In addition to improving MAFIC's use of one-dimensional units, this method may be extended to provide a noniterative treatment of multidimensional rock-matrix units.

\section{Remarks/General Observations/Discussion}

Sections 10.1 and 11.1 identify MAFIC's potential usefulness to the Yucca-Mountain Program. These sections also make two suggestions for upgrading MAFIC's capabilities in a cost-effective manner so that it can simulate flow and transport processes at Yucca Mountain.

\section{Comparison to Other Models}

Except for its compatibility with the discrete-fracture simulator FracMan, MAFIC has little to offer the Yucca-Mountain Project as a saturated-flow code. Consequently, a detailed comparison of its present capabilities with those of other models would not be fruitful.

\section{Summary and Recommendations}

- For FracMan and MAFIC, the ultimate goal is a comparison of discrete and continuum approaches for the Yucca-Mountain flow system. This capability will permit the Yucca-Mountain project to assess the adequacy of the continuum approach. 
- Because of its ability to realistically characterize a fractured system, FracMan is unique, both inside and outside the Yucca-Mountain Project.

- MAFIC's uniqueness lies only in its compatibility with FracMan. Otherwise, its capabilities may be duplicated both inside and outside the Yucca-Mountain Project.

- The M\&O should continue to assist Golder in combining the gas-flow capability of TGIF with MAFIC. In addition, the M\&O should seriously consider combining the multiphase, nonisothermal capability of FEHM with the fracture simulating capability of FracMan.

- Not only will this permit realistic comparisons of continuum and discrete-fracture simulations. It will, at the same time, further develop a finite-element alternative for TOUGH2 (Pruess, 1991).

- The M\&O should obtain source-code listings of MAFIC, TGIF, and FEHM so that plans may be developed and work may be monitored at Golder and perhaps other locations.

- Since little of the present coding in MAFIC will survive the proposed changes, component testing of the current version of MAFIC is not recommended.

\section{References}

Anderson, J., and B. Deverstorp, 1987. Conditional Simulations of Fluid Flow in ThreeDimensional Networks of Discrete Fractures, Water Resour. Res. 23, No. 10, pp. 1876-1886.

Bixler, N.E., 1985. NORIA - A Finite Element Computer Program for Analyzing Water, Vapor, and Energy Transport in Porous Media, SAND84-2057, Sandia National Laboratories, Albuquerque, NM.

Huyakom, P.S., J.B. Kool, and J.B. Robertson, 1989. VAM2D - Variably Saturated Analysis Model in Two Dimensions. NUREG/CR-5352, U.S. Nuclear Regulatory Commission, Washington, DC.

Miller, I., 1990. MAFIC Version Beta 1.2 Matrix/Fracture Interaction Code with Solute Transport - User Documentation, Golder Associates, Inc., Redmond, WA.

Pruess, K., 1991. TOUGH2 - A General-Purpose Numerical Simulator for Multiphase Fluid and Heat Flow, Lawrence Berkeley Laboratory, Berkeley, CA.

Reeves, M., A. Haug, G.E. Grisak, and F.G. Wolf, 1992. Dynamic Coupling - A New Tool for Three-Dimensional Flow and Transport Simulations, to be published in Ground Water.

Ross, B., S. Amter, and N. Lu, 1991. Numerical Studies of Rock-Gas Flow in Yucca Mountain, SAND91-7034, Sandia National Laboratories, Albuquerque, NM. 
Long, J.C.S., J.S. Remer, C.R. Wilson, and P.A. Witherspoon, 1982. Laboratory and Simulation Studies of Solute Transport in Fracture Networks, Water Resour. Res. 18, No. 3, pp. 645-658.

Robinson, P.L., 1984. Connectivity, Flow, and Transport in Network Models of Fractured Media, Ph.D. Dissertation, Oxford University.

Smith, L., and F.W. Schwartz, 1984. An Analysis of the Influence of Fracture Geometry on Mass Transport in Fractured Media, Water Resour. Res. 20, No. 9, pp. 1241-1252.

Warren, T.E., and P.J. Root, 1963. The Behavior of Naturally Fractured Reservoir, Soc. of Pet. Eng. J. 3, pp. 245-255.

Zyvoloski, G., Z. Dash, and S. Kelkar, 1992. FEHMN 1.0: Finite Element Heat and Mass Transfer Code, LA--12062-MS, Los Alamos National Laboratory, Los Alamos, NM. 


\section{A.9 MSTS}

1. Name of the Model

MSTS (Multiphase Subsurface Transport Simulator)

2. General Program Information

2.1 Program size. Approximately 16,000 lines of source code.

2.2 Programming language. ANSI FORTRAN 77

2.3 Computer system on which it operates. MSTS runs on Cray, Convex, HewlettPackard, Macintosh, Sun, Vax, and IBM-compatible personal computers.

2.4 Compiler(s) used. A standard compiler has been used on each machine.

2.5 Location of code and availability. MSTS is being developed at Pacific Northwest Laboratory (PNL) in Richland, Washington by Mark White and W.E. Nichols. A copy of the code may be obtained from one of the authors.

2.6 Brief description of model/code history. Active development of MSTS has been underway for approximately two years.

\section{Status of Model}

3.1 Development (Is the model now undergoing significant development or modification? or continuing maintenance?) Implementation of gmres conjugate-gradient solver has recently been completed. The code is now being generalized to treat more complex mixtures of phases so that it may be applied to the Hanford Environmental Restoration Program. Other upgrades being planned include implementing MSTS on a massively parallel computer and adding a hysteresis option for the capillary-pressure curve.

3.2 Documentation. White and Nichols (1992) provide a discussion of theory, and Nichols and White (1992) provide a user's guide. Both are well written and thorough. In addition, the code itself is well organized and commented throughout.

3.3 Status of verification and validation. The user's guide (Nichols and White, 1992) includes eight sample problems. With highly simplified spatial gridding, three of these problems show the code's ability to conserve mass and energy under rather severe conditions involving phase changes. Five others provide comparisons with known semi-analytical or numerical results. The latter are separately identified below:

Problem 4 - One-Dimensional Infiltration. A wetting front enters a semi-infinite horizontal tube filled with a homogeneous soil. This problem, one of the benchmarks 
adopted by Ross et al. (1982), considers the effect of capillarity. MSTS results show excellent agreement with the semi-analytical calculations of Phillip (1955).

Problem 5 - Two-Dimensional Infiltration. A wetting surface, imposed on a portion of one vertical boundary, causes a wetting front to propogate through a twodimensional, vertical cross section. This problem, another of the benchmarks adopted by Ross et al. (1982), considers the effects of both gravity and capillarity. MSTS results are essentially the same as those reported by Pruess (1987).

Problem 6 - One-Dimensional, Two-Phase Infiltration. Problems 4 and 5 assume a single-phase, Richards approximation. Problem 6 considers differences between single- and two-phase characterizations of the infiltration process. Taken from the work of Touma and Vauclin (1986), the problem assumes that a vertical soil column is drained to hydraulic equilibrium. Surface ponding then causes a wetting front to propogate through the column. Two simulations are required. One allows air to move freely through the lower boundary. It resembles a single-phase simulation, with a constant air pressure throughout. The other simulation permits air to move only through the upper boundary. MSTS results, like those of Touma and Vauclin (1986), show that the rate of advance of the wetting front is drastically reduced in the second simulation. The competition at the surface between infiltrating water and escaping air also reduces the maximum water content of the wetting front.

Problem 7 - One-Dimensional Heat Pipe. Taken from the work of Udell and Fitch (1985), this problem considers a horizontal porous tube containing both gaseous and liquid phases. With constant values of liquid saturation, gas pressure, and temperature maintained on one end of the column, a constant heat flux is applied to the other. This causes a countercurrent flow of the two phases, with the liquid phase flowing toward the heat source and the gas phase flowing away from the heat source. Although some of the rock and fluid properties used by the MSTS analysis were more general than those used by the semi-analytic analysis of Udell and Fitch, the two sets of results exhibit good agreement.

Problem 8 - One-Dimensional Transport. This problem, another benchmark from Ross et al. (1982), considers transient flow and transport. From a constant boundary concentration, the flow system of Phillip (Problem 4) advects and disperses a dissolved constituent into a horizontal, one-dimensional soil column. As the gridblock size is reduced, MSTS results converge to the semi-analytical results of Smiles et al. (1977).

3.4 Status of Quality Assurance (QA). Level-3 quality-assurance procedures have been applied to MSTS. These procedures include benchmarking, verification, and documentation, followed by internal peer review.

\section{Type of Model (Phenomena/Processes Modeled)}

MSTS is a multi-dimensional (one-, two- or three-dimensional) numerical model for simolnting the nonisothermal flow of liquid and gas and the transport of a dilute species in 
a geologic medium. The code has several different solution options which, for example, allow it to consider single-phase, unsaturated flow, or heat transport with no fluid flow. In its most general nonisothermal two-phase, two-component mode, the liquid is comprised of water and dissolved gas components, and the gas is comprised of condensable vapor and gas components. The geologic medium may be anisotropic, heterogeneous, and fractured. MSTS takes into account the following physical processes:

- Fluid flow in both liquid and gas phases, occurring under pressure, viscous, and gravity forces according to Darcy's law

- Binary and Knudsen diffusion of gaseous components. When mean free paths become comparable to pore sizes, then Knudsen diffusion arises.

- Capillarity between water and gas phases

- Dissolution of non-condensing gas component in water as represented by Henry's law

- Phase equilibrium between vapor and water as represented by steam-table equations (ASME, 1967)

- Conduction of heat with thermal conductivity dependent on degree of saturation

- Convection of heat in both gas and water phases

- Latent-heat effects

- Vapor pressure lowering. At small saturations, the liquid becomes relatively more tightly bound both to itself and to the rock, resulting in a lowering of the vapor pressure.

- Two-phase dilute-species transport, including the effects of convection, diffusion, dispersion, sorption, and decay

- Discrete or equivalent-continuum fracture models. Discrete-fracture modeling uses refined gridding to explicitly include major fractures. Assuming fracture and matrix to be in capillary-pressure equilibrium, the equivalent-continuum approach composites the hydraulic property curves for fracture and matrix.

\section{Governing Equations}

The model can solve up to four governing equations in as many as three dimensions. Both Cartesian and cylindrical geometries are permitted. One governing equation treats mass conservation for the liquid component, which may be present both in the liquid phase and, as a vapor, in the gas phases. Another treats mass conservation for the non-condensing gas (e.g., air), which is assumed to be present both in the gas phase and, as a soluble component, in the liquid phase. The third, an energy-conservation equation, treats heat transport. These three equations are strongly coupled by auxiliary conditions. Such conditions enforce a total 
saturation of unity and total component mass fractions of unity in each phase. Henry's law characterizes the inter-phase equilibrium of the non-condensing gas component, while steamtable equations characterize the inter-phase equilibrium of liquid water and water vapor. The fourth governing equation treats mass conservation of a dilute species, which may be present in both phases.

\section{Method of Solution}

The model employs the finite-difference technique for both spatial and temporal discretization. The hydraulic-property curves, together with the phase-equilibrium relations lead to highly nonlinear and strongly coupled conservation equations for liquid, gas, and energy. Here, linearization is accomplished by the Newton-Raphson technique. The linear sorption model employed by MSTS leads to a linear mass conservation equation for a dilute species. Furthermore, the equation is only weakly coupled to the conservation equations for liquid, gas, and energy. Here, linearization is not necessary.

The presence of advection can lead to numerical difficulties. For the strongly coupled equations, MSTS offers five different permeability-weighting options. Applied only to the absolute permeability (the product of saturated and relative quantities), these options include upwinding and harmonic averaging. For the weakly coupled, species mass-conservation equation, the Peclet number provides a convenient measure of advection relative to dispersion, and, without specialized coding, a Peclet number greater than two can cause numerical difficulties. MSTS employs upstream power-law weighting on the concentration variable in order to solve problems with large Peclet numbers, i.e., numbers greater than about two.

MSTS provides both direct and iterative solvers. The former assigns node numbers based on the standard ordering method. It then solves the resulting banded system of equations using LU factorization, a form of Gaussian elimination. This method is most efficient for problems involving several thousand equations, or less. For larger problems, MSTS provides a gmres conjugate-gradient algorithm, employing preconditioning.

\section{Type of Input Parameters}

Control and model-parameter specification is accomplished through an input file. This file can be prepared either by using a text editor or by using the MSTS Graphical Input preprocessor. Operating only on a Macintosh computer, the latter speeds the creation of input-data files and reduces input errors. The input file is divided into groups of cards, or records, with a descriptive input phrase used to identify each group. These groups may appear in any order. 
The table below presents the descriptive phrases recognized by MSTS:

\section{DESCRIPTIVE INPUT PHRASES}

\begin{tabular}{|c|c|}
\hline Simulation Title & Gas Relative Permeability \\
Solution Schemes & Liquid Boundary Conditions \\
Numerical Control & Gas Boundary Conditions \\
Grid Geometry & Vapor Boundary Conditions \\
Inactive Nodes & Energy Boundary Conditions \\
Rock or Soil Types & Species Boundary Conditions \\
Mechanical Properties & Initial Condition \\
Hydraulic Properties & Sources and Sinks \\
Thermal Properties & Output Control \\
Species Properties & Liquid Pathline Trace \\
Soil Characteristics & Surface Flux Integrator \\
\hline
\end{tabular}

Several of the card groups deserve comment. The group identified by the phrase "solution schemes" specifies which combination of the four governing equations are to be solved. This provides the analyst a number of solution options. For example, selecting "on" for the liquid conservation equation and "off" for the gas and energy equations yields a solution of the Richards' equation for partially saturated liquid flow. Similarly, selecting "on" for the energy conservation equation and "off" for the liquid and gas equations, yields a solution to the heat-transport equation. Following this procedure, one may choose to solve the analogue of the Richards' equation for partially saturated gas flow. However, the resulting solution is not the same as that of TGIF (Ross et al., 1991). The difference arises from TGIF's assumption that partially saturated gas flow is accompanied by a 100-percent humidity level.

The group identified by the phrase "grid geometry" specifies whether the grid geometry is Cartesian or cylindrical. Limiting the geometry selection is a part of a strategy, the object 
of which is to control the structure of the coefficient matrix. In the application of a banded direct solver, MSTS exploits this structure to minimize computer time. For a direct solver, such a strategy may have a significant advantage. For an iterative solver, such as will be required for multidimensional Yucca-Mountain simulations, the advantage of such a strategy may not be significant.

The use of five different boundary-condition groups allows the analyst to independently specify boundary conditions for each component. Not generally present in other codes, such a facility greatly enhances the utility of MSTS.

\section{Type of Output and User Options}

The MSTS output consists of two files. Nichols and White (1992) provide several examples of the "output" file. This neatly organized file contains run-identification information, a record of input data, and a reference-node output record. The analyst identifies the field variables and selects the space and time domains over which they are to be printed.

Usually, the analyst will wish to plot his results. Through its structure and format, the "plot" file makes this easier to do. Following header information, this file presents a tabulation of selected field variables as a function of spatiai and temporal coordinates.

9. Model Interactions (emphasize needed processors)

9.1 Does the model interface with any oth' models? Yes, see below.

9.2 Source code and type of information ni eded. Not applicable.

9.3 Receiving code and type of information provided. None.

9.4 Any pre- or postprocessing needed? Use of the MSTS Graphical Input preprocessor is optional. In addition, the code writ s an output file which may be postprocessed with a commercially available NCFA color-graphics package.

10. Model Application

10.1 Usage within the Civilian Radioactive Management Waste System (CRWMS) program. The simultaneous transport of ${ }^{14} \mathrm{C}$ through both liquid and gas pathways will provide one of the first applications for Yucca Mountain. Other applications within the CRWMS program could include calculation of the near-field thermal and hydrological environment around a waste package. Such calculations are needed for waste-package design and for radionuclide transport, and they can predict the behavior of the condensation front as it returns to the area surrounding the waste package during the cool-down period (Nitao, 1988).

Potentially MSTS can be used to characterize many aspects of the physical system. Like other detail process models, its application is limited primarily by efficiency considerations. In addition to analysis of the near field, MSTS potentially can 
characterize the following effects: the impact of gas flow and vaporization on liquid flow, disequilibrium fracture flow, the transport of radioactive gases to the accessible environment, and the travel time required for dissolved radioactive species to reach the accessible environment.

10.2 Usage outside the program. MSTS is being applied to the Hanford Environmental Restoration Program.

\section{Codes With Similar or Same Capabilities}

11.1 Within the program. The Yucca-Mountain Project has funded the development of several codes with capabilities similar to that of MSTS. These codes include TOUGH2 (Pruess, 1991) at LBL (Lawrence Berkeley Laboratory), V-TOUGH (Nitao, 1989) at LLNL (Lawrence Livermore National Laboratory), NORIA (Bixler, 1985) at SNL, TRACR3D (Birdsell and Travis, 1991) and FEHM (Zyvoloski et al., 1992) at LANL (Los Alamos National Laboratory), and PORFLO-3, at PNL (Pacific National Laboratory). All of these codes simulate multiphase flow. They differ in terms of spatial-discretization (finite difference vs. finite element), linearization (Picard vs. Newton-Raphson), and linear-equations solvers (direct solution, successive over-relaxation, or conjugate-gradient gmres). They also differ in terms of the processes considered (heat and radionuclide transport, for example).

11.2 Outside the program. The Nuclear Regulatory Commission funded documentation of the multiphase TOUGH (Pruess, 1987) model and the single-phase DCM3D (Updegraff, 1991) model for partially saturated fractured media. Further, a number of codes have been developed within the petroleum industry. In terms of the processes considered, compositional models (Peaceman, 1977) provide a flow capability that is more general than that of MSTS. Compositional models can simulate more than two components and more than two phases. Developed for use in the area of reservoir engineering, these codes are proprietary, and that constitutes a major impediment to their use in licensing. They include THEFM (SSI-Intercomp, Inc.) and TETRAD (DYAD 88 Software, Inc.).

\section{Major Assumptions and Limitations}

- The gridding required to characterize non-equilibrium fracture-matrix exchange of mass and phase pressures may severely restrict the size of field-scale simulations. White (private communication, 1991) agrees that this limitation is significant for most Yucca-Mountain flow codes and is seeking to focus his research toward a solution of this problem.

- A steady-state option is not available. For large problems, running through a transient sequence to achieve a steady state represents a costly and needless expenditure of computer time. Since most transient characterization runs assume steady-state initial conditions, this is a significant consideration. 
- MSTS considers the transport of only one decaying species. It does not consider a radionuclide chain subject to both decay and production processes.

- The gas is assumed to be ideal thereby ensuring the additivity of partial pressures (Dalton's Law). In view of much larger uncertainties present at the site, this limitation represents a moot point at this time. Dalton's Law, which may be proved rigorously for an ideal gas, states that the total pressure of a mixture of gasses equals the sum of the individual pressures each gas would exert if it alone occupied the entire container.

- The temperature dependence of Henry's constant is neglected due to the very small air solubility in water. This limitation also represents a moot point at this time, easily correctable should the need arise. Henry's Law relates the concentration of a dissolved gas in solution to the partial pressure of the same gas in the atmosphere contacting the solution.

- Like most models developed by the Yucca-Mountain Project, MSTS does not account for capillary hysteresis. For many applications in a wetter climate, such an omission may not be justified. However, assuming relatively long drying periods between rain storms, such an omission appears to be adequate for Yucca-Mountain simulations.

- Thermal equilibrium exists between pore fluids and rock. Current LBL analyses of a condensation front surrounding the repository assert the validity of this assumption.

- MSTS makes the physically reasonable assumption that there is no conductive heat transfer through the gas phase.

- An infinitely dilute species is another standard assumption which should be adequate except, possibly, within the repository near field.

\section{Remarks/General Observations/Discussion.}

In terms of its finite-difference discretization and its solution techniques, MSTS is quite similar to TOUGH (Pruess, 1987), and it is instructive to compare the two. To the capability of TOUGH, it adds the transport of a single species. While this added capability is relatively minor compared to the better transport codes of the Yucca-Mountain Project, it is nevertheless sufficient for calculating ${ }^{14} \mathrm{C}$ transport. Through its explicit boundarycondition and solution-option facilities, MSTS gains increased utility relative to TOUGH. The MSTS Graphical Input Preprocessor provides a user-friendly input mode which could spe $\mathrm{d}$ data-input preparation significantly. This facility appears to be the most advanced input preprocessor within the Project, and, for complex multidimensional simulations of Yucca Mountain, it could reduce data-preparation time significantly.

Undoubtedly, MSTS's banded solver is faster than TOUGH's direct solver, which is appropriate for nonbanded matrix structures. However, the latter advantage should not be significant for large simulations, involving several tens of thousand simultaneous equations. Such simulations require an iterative solver, and both MSTS and TOUGH2 (Pruess, 1991) 
now have iterative conjugate-gradient, gmres solvers (White, private communication; Pruess, private communication). The TOUGH program organization appears to be superior to that of MSTS. The TOUGH equation-of-state modules separate fluids-specific algorithms from the matrix assembly and solution algorithms. This means that code generalizations such as the addition of components or phases is accomplished primarily by adding additional equation-of-state modules. A casual reading of the source code suggests that fluids-specific dependencies are scattered throughout the MSTS code. The TOUGH codes should be significantly easier to upgrade than MSTS.

In one area TOUGH is unquestionably superior. It has a large group of users, and it is widely accepted by the academic community.

\section{Comparison to Other Models}

See Chapters 4, 5, and 6 of the main text.

\section{Summary and Recommendations}

- MSTS is a detailed process code which is useful for site characterization, site suitability, and detailed design review. For some applications, it will be limited by excessive computer time. All multiphase models of the Yucca Mountain Project share this deficiency.

- MSTS has an excellent input preprocessor, superior by a large margin to that of other detailed process codes in the Yucca-Mountain Project. The M\&O should consider adapting this preprocessor to an IBM-compatible, personal-computer environment and altering it to prepare input for other codes.

- The MSTS explicit boundary-condition option facilitates code application. This option should be added to all codes used by the M\&O.

- In terms of its facility to treat flow processes, MSTS is roughly equivalent to TOUGH and inferior to TOUGH2. Though coded independently, both MSTS and the TOUGH codes use finite-difference discretization, Newton-Raphson linearization, direct and conjugate-gradient, gmres solvers.

- In terms of its facility to treat transport processes, MSTS is inferior to TRACR3D.

- MSTS cannot easily consider disequilibrium between fracture and matrix on a realistic spatial scale. A prohibitively time-consuming direct-gridding procedure is required. All detailed process codes developed to date by the Yucca-Mountain Project appear to be flawed in this regard. Although the efficiency of TOUGH's MINC facility is suspect, it is superior to the MSTS treatment of fracture-matrix disequilibrium.

- Since it is a relatively new, MSTS is not as widely accepted as other codes such as TOUGH2 (Pruess, 1991), TRACR3D (Birdsell and Travis, 1991), and PORFLOW (Runchal and Sagar, 1991). 
- In consideration of all of the above, a component-verification effort is considered to be appropriate for MSTS.

\section{References}

ASME, 1967. Thermodynamic and Transport Properties of Steam. The American Society of Mechanical Engineers, United Engineering Center, New York.

Birdsell, K.H., and B.J. Travis, 1991. TRACR3D: A Model of Flow and Transport in Porous Media, LA-11798-M, Los Alamos National Laboratory, Los Alamos, NM.

Bixler, N.E., 1985. NORIA - A Finite Element Computer Program for Analyzing Water, Vapor, and Energy Transport in Porous Media, SAND84-2057, Sandia National Laboratories, Albuquerque, NM.

Nichols, W.E., and M.D. White, 1992. Multiphase Subsurface Transport Simulator User's Reference Guide, Pacific Northwest Laboratory, Richland, WA.

Nitao, J.J., 1988. Numerical Modeling of the Thermal and Hydrological Environment Around a Nuclear Waste Package Using the Equivalent Continuum Approximation: Horizontal Emplacement, UCID-2144, Lawrence Livermore National Laboratory, Livermore, CA.

Nitao, J.J., 1989. V-TOUGH - An Enhanced Version of the TOUGH code for the Thermal and Hydrologic Simulation of Large-Scale Problems in Nuclear Waste Isolation, UCID21954, Lawrence Livermore National Laboratory, Livermore, CA.

Peaceman, D.W., 1977. Fundamentals of Numerical Reservoir Simulation, Elsevier Scientific Publishing Company, New York.

Phillip, J.R., 1955. Numerical Solution of Equations of the Diffusive Type with Diffusivity Concentration Dependent, Transactions, Faraday Society 51, pp 885-892.

Pruess, K., 1987. TOUGH User's Guide, NUREG/CR-4645, SAND86-07104, LBL-20700, Sandia National Laboratories, Albuquerque, NM.

Pruess, K., 1991. TOUGH2 - \& Generai-Purpose Numerical Simulator for Multiphase Fluid and Heat Flow, Lawrence Bejikeley Laboratory, Berkeley, CA.

Ross, B., J.W. Mercer, S.D. Thomas, and G.H. Lester, 1982. Benchmark Problems for Repository Siting Models, NUREG/CR-3097, Geotrans, Inc., Reston, VA.

Ross, B., S. Amter, and N. Lu, 1991. Numerical Studies of Rock-Gas Flow in Yucca Mountain, SAND91-7034, Sandia National Laboratories, Albuquerque, NM. 
Runchal, A.K., and B. Sagar, 1989. PORFLO-3: A Mathematical Model for Fluid Flow, Heat, and Mass Transport in Variably Saturated Geologic Media, WHC-EP--0041, DE89-013977, Westinghouse Hanford Company, Richland, WA.

Runchal, A.K., and B. Sagar, 1991. PORFLOW: A Model for Fluid Flow, Heat, and Mass Transport in Multifluid, Multiphase Fractured or Porous Media, User's Manual - Version 2.34, ACRi/016/Rev. E, Analytical and Computational Research, Inc., West Los Angeles, CA.

Smiles, D.E., J.R. Phillip, J.H. Knight, and D.E. Elrick, 1977. Hydrodynamic Dispersion During Absorption of Water by Soil, Soil Sci. Soc. Amer. Jour. 42, pp 229-234.

Touma, J., and M. Vauclin, 1986. Experimental and Numerical Analysis of Two-Phase Infiltration in a Partially Saturated Soil, pp 27-55.

Udell, K.S., and J.S. Fitch, 1985. Heat and Mass Transfer in Capillary Porous Media Considering Evaporation. Condensable and Non-Condensable Gas Effects, presented at the 23rd ASME/AIChE National Heat Transfer Conference, Denver CO, 103-110, American Society of Mechanical Engineers, New York.

Updegraff, C.D., C.E. Lee, and D.P. Gallegos, 1991. DCM3D: A Dual-Continuum, Three Dimensional, Ground-Water Flow Code for Unsaturated, Fractured, Porous Media, NUREG/CR-5536, SAND90-7015, Sandia National Laboratories, Albuquerque, NM.

White, M.D., and W.E. Nichols, 1992. Multiphase Subsurface Transport Simulator Theory Manual, Pacific Northwest Laboratory, Richland, WA.

Zyvoloski, G., Z. Dash, and S. Kelkar, 1992. FEHM 1.0: Finite Element Heat and Mass Transfer Code, LA--12062-MS, Rev. 1, Los Alamos National Laboratory, Los Alamos, NM. 


\section{A.10 NORIA AND NORIA-SP}

1. Name of Models

NORIA and NORIA-SP

2. General Program Information

2.1 Program sizes. NORIA contains 10,000 source statements. NORIA-SP is somewhat smaller.

2.2 Programming language. FORTRAN 77

2.3 Computer system on which it operates. Cray 1S, Cray XMP-24

2.4 Compiler(s) used. Standard compilers are used on each machine.

2.5 Location of code and availability. NORIA and NORIA-SP are maintained in the permanent file library at Sandia National Laboratories (SNL).

2.6 Brief description of code/code history. NORIA and NORIA-SP are members of a sequence of codes developed at SNL for the analysis of partially saturated flow. All employ a two-dimensional, finite-element discretization method using either eightnode quadrilaterals or six-node triangles. NORIA, the most advanced of these codes, assumes two phases, two components, and nonisothermal flow. It simultaneously solves three flow equations and one heat-transport equation. NORIA-SP, a "stripped" version of NORIA, solves only one equation, the Richards equation for partially saturated flow.

\section{Status of Model}

3.1 Development (Is the model now undergoing significant development or modification? or continuing maintenance?). Much of the current development focuses on COYOTE (Gartling, 1978), using this code as a prototype. Changes include expansion to three dimensions, an enhanced element library, addition of a PCG (preconditioned conjugate gradient) algorithm, removal of frontal solution (Irons, 1970) because of its inefficiency, dynamic dimensioning, and vectorization for SNL's massively parallel computer. After identifying the successful algorithms, SNL will implement them on other codes, including NORIA.

3.2 Documentation. The NORIA user's guide (Bixler, 1985) has a thorough and readable description of theory, numerical implementation, and input requirements. For completeness, the NORIA-SP user's guide (Hopkins et al., 1991) repeats the discussion of Bixler (1985) as necessary. 
3.3 Status of verification and validation. The present review has identified four NORIA verification problems. Bixler's (1985) example problem for NORIA represents a suitable candidate for code-to-code comparisons. This problem analyzes the flow of moisture and vapor in a cylindrically shaped tuff block which results from a symmetrical emplacement of a small heater. The problems engage three of the four transport equations employed by NORIA.

In a U.S. Nuclear Regulatory Commission (NRC)-funded study, Updegraff (1989) evaluated NORIA using analytic and code-to-code comparisons. Moridis and Pruess (1992) also considered these comparisons. With NORIA, Updegraff successfully executed three verification problems. These problems, all of which were run on the SNL Cray XMP-24, are briefly described below:

Problem 1.1 - One-Dimensional Infiltration. An infiltration front enters a semi-infinite horizontal tube filled with a homogeneous soil. Air is not accounted for and is a passive spectator. This problem, one of the benchmarks adopted by Ross et al. (1982), compares the NORIA solution with the semi-analytical results of Phillip (1955). To characterize infiltration for 9,504 s, Updegraff's (1989) analysis used 20 elements and 935 time steps. The code required 1,980 s of CPU time.

Problem 12 - One-Dimensional Heat Transport. Cold water is injected into a hot-water aquifer of thickness $110 \mathrm{~m}$. A production well, located $40 \mathrm{~m}$ away, pumps at a rate equal to the rate of injection. This problem, which considers both convection and thermal conduction, was originally solved analytically by Avdonin (1964). Ross et al. (1982) adopt it as a code benchmark. To calculate the temperature profile 1.3E5 $s$ after initiation of the injection, Updegraff's (1989) analysis used 150 elements and 225 time steps. The code required 3,850 s of CPU time.

Problem 1.3 - One-Dimensional Radial Heat Transport. Except for its geometry, the radial heat problem is essentially the same as the above linear problem. Solved analytically by Avdonin (1964), it is also adopted as a benchmark by Ross et al. (1982). Updegraff's (1989) analysis used 117 elements and 459 time steps to simulate 4.6E6 s. He displays the temperature profile at 1.0E6 $\mathrm{s}$. The code required $2 \mathrm{~h}$ of CPU time. A problem with the automatic time-stepping algorithm was noted.

Updegraff's (1989) Problem 1.4 deals with production from a geothermal well, and Problem 1.5 with heat transport through a heat pipe. Problem 2.1 focuses on twodimensional infiltration, Problem 2.2 on a two-dimensional convection-cell experiment, and Problem 2.3 focuses on a one-dimensional, two-phase flow involving vaporization and heat transport. Updegraff (1989) was unsuccessful in using NORIA to simulate these five problems. 
The present review has also identified four NORIA-SP verification problems. Hopkins et al. (1991) present two sample calculations, the results of which are reported elsewhere in greater detail.

Comparison with two analytic results. In their description of LLUVIA-II, Eaton and Hopkins (1992) present two one-dimensional analytical solutions for materials with exponential properties. They then present the numerical solutions of LLUVIA and NORIA-SP, showing excellent agreement among the three solution methods. Case la assumes sand properties. Here, the LLUVIA-II analysis employed 41 equally spaced nodes, and the NORIA-SP analysis used a column of 40 eight-node, equally spaced quadratic elements. For a simulation time of 5E4 s, LLUVIA-II required a CPU time of eight seconds on SNL's Cray XMP-24, and NORIA-SP required a CPU time of 250 seconds on the same computer.

Case $1 \mathrm{~b}$ assumes tuff properties. Here, the LLUVIA-II analysis employed 81 equally spaced nodes, and the NORIA-SP analysis used 80 eight-node, equally spaced quadratic elements. For a simulation time of 5E4 s, LLUVIA-II required a CPU time of seven seconds on SNL's Cray XMP-24, and NORIA-SP required a CPU time of 273 seconds on the same computer. One might be tempted to conclude that LLUVIA-II is a much faster code than NORIA-SP. However, the differences in CPU times may be explained by the fact that the NORIA-SP analyses use approximately five times as many nodes as the LLUVIA-II analyses.

COVE2a analysis. Eaton and Hopkins (1992) also present results for one of the COVE2a problems. The problem chosen is quite similar to that described in Section B.2. Using a one-dimensional stratigraphy taken from Yucca Mountain, the problem assumes that a steady initial moisture state, based on an infiltration of $0.5 \mathrm{~mm} / \mathrm{y}$, is perturbed by the sudden increase of the infiltration to $1.0 \mathrm{~mm} / \mathrm{y}$. Eaton and Hopkins (1992) find that LLUVIA-II and NORIA-SP results compare adequately both with each other and with the results reported for five other codes (Dykhuizen et al., 1991).

PACE-90 analysis. Given a common data base and hydrogeologic characterization of the Yucca Mountain Site, participants in the PACE-90 study determined the movement of radionuclides to the accessible environment. This exercise verified the ability of different researchers to independently conceptualize a complex site in a physically consistent manner. Computed results largely agreed, thus providing verifications for the participating codes. To simulate flow, participants chose NORIA-SP and five other flow codes. The problem is briefly described as follows:

The NORIA-SP conceptualization considers a two-dimensional cross-section lying between drill holes G-1 and UE-25a. With a total of 1,260 eight-node quadrilateral elements, the NORIA-SP analysis divides this cross-section into nine hydrogeologic units extending from the water table to the top of the Tpt-TM section of the Topopah Spring unit. With the bottom boundary held at a pore pressure of zero to characterize the water table, the two sides were assumed to be 
no-flow boundaries. For the top boundary, a net infiltration of $0.01 \mathrm{~mm} / \mathrm{y}$ was prescribed.

This analysis includes explicitly the nonnwelded Topopah Spring Tpt-TVN unit, and this is an important aspect of the work. With a lateral permeability six orders of magnitude higher than most other units, coupled with the natural formation slope to the southeast, the Tpt-TVN unit permits considerable lateral diversion of the predominately vertical flow pattern. Starting from a somewhat arbitrary specification of the initial condition, the NORIA-SP transient simulation reached steady state after 1,090 time steps and ten hours of CPU time on SNL's Cray XMP-24.

3.4 Status of Quality Assurance (QA). Both NORIA and NORIA-SP are under quality assurance control at SNL.

\section{Type of Model (Phenomena/Processes Modeled)}

NORIA is a two-dimensional numerical model for simulating the coupled flow and transport of water, vapor, air, and heat in anisotropic media. Like its parent code, NORIA-SP is a two-dimensional model. Unlike its parent code, however, NORIA-SP simulates only the partially saturated flow of water. With both codes, the presence of discrete fractures may be treated by explicit gridding, and the presence of distributed fractures, by the equivalentcontinuum approach. The solution procedures utilize finite-element discretization of the spatial domain and finite-difference discretization in the time domain. Both Cartesian and cylindrical coordinate systems are permitted.

NORIA-SP includes the following mechanisms:

- Fluid flow due to pressure, viscous, and gravity forces in the liquid phase, according to Darcy's law.

- Capillarity between liquid and gas phases.

NORIA additionally includes:

- Fluid flow due to pressure, viscous, and gravity forces in the gas phase, according to Darcy's law.

- Binary diffusion of vapor and air

- Knudsen diffusion of vapor and air

- Thermo-diffusion of vapor and air

- Non-equilibrium and equilibrium vapor-pressure models

- Conduction of heat with thermal conductivity dependent on the degree of saturation 
- Convection of heat in both gas and liquid phases

- Evaporation and condensation.

\section{Governing Equations}

.NORIA solves up to four governing equations in as many as two dimensions. Three characterize the mass conservation of liquid-water, water-vapor, and non-condensing-gas components. A fourth equation characterizes the conservation energy. Equations of motion define mass and heat transport in terms of pressure, temperature, and density gradients. When combined with the conservation laws, the equations of motion yield the flow and heattransport equations. Constitutive relations characterize capillarity, relative permeability, and a possibly non-equilibrium rate of vaporization.

\section{Method of Solution}

To spatially discretize the flow and heat-transport equations, NORIA uses the Galerkin finite-element method. The Galerkin approach requires that weighting a:d basis functions be identical. NORIA uses quadratic basis functions to span either eight-node quadrilaterals or a six-node triangles. The Galerkin approach permits mapping and basis functions to differ. Accordingly, NORIA uses both isoparametric and subparametric functions for transformation from global to local coordinates. The former use quadratic mapping functions, and the latter use linear mapping functions, resulting in local elements with either curved or straight sides.

To temporally discretize these equations, NORIA uses finite-difference algorithms. The first two time steps employ backward differencing to damp out the oscillations that might otherwise occur. After that, the time stepping employs a central-difference (CrankNicholson) procedure implemented with a predictor-corrector method and automatic timestep selection. To begin the integration across a time step, a second-order Adams-Bashforth predictor (Shampine and Gordon, 1975) is used to obtain estimates of the dependent variables at the next time step. This permits estimation of all nonlinear coefficients. The Adams-Bashforth technique employs extrapolations based on values of the dependent variables at the most recent time plane and values of their temporal derivatives at the two most recent time planes.

Depending on the rate of convergence occurs, a number of corrector steps follow. Here, the Newton-Rhapson method linearizes the discretized equations, and a frontal method developed by Irons (1970) and by Gartling (1978) yields a solution of the resulting coupled set of equations. If, after the prescribed number of Newton-Rhapson iterations, convergence has not occurred, the time step is reduced and recalculated. Because the algorithm seeks to maintain a uniform level of truncation error in the solution, time steps are obtained automatically using an estimate of the local truncation error. 


\section{Type of Input Parameters}

User input to the NORIA codes consists of fixed data and user-supplied subroutines to generate variable data. The latter provide material properties and boundary conditions as functions of the dependent variables. Through a series of commands and associated data, the user directs the code to perform various tasks. Except for a few obvious limitations, the order of the command groups is arbitrary, and, within any such group, a free-field format separates successive entries by commas. Input command SETUP, together with associated input, defines nodes, elements, material properties, input and boundary conditions. Input command FORMKF fixes initial and final times, as well as output times. For any given output time, input command OUTPUT limits dependent-variable output both to selected nodal points and to selected other points within the system being modeled. Other input commands fix the velocity output, control restarts, and terminate execution.

\section{Type of Output and User Options}

Code output consists of an output file, together with a plot file. These files contain arrays of dependent variables (pressures, saturations, temperature, Darcy velocity, and heat flux) and associated information (print time, number of iterations, and the convergence measure).

9. Model Interactions (emphasize needed processors)

9.1 Does the model interface with any other models? Yes, see below.

9.2 Source code and type of information needed. Not applicable.

9.3 Receiving code and type of information provided. Data from NORIA may be used in conjunction with finite-element codes such as FEMTRAN (Martinez, 1985) to perform radionuclide transport analyses.

9.4 Any pre- or postprocessing needed? Reflecting recent advances in commercially available plotting packages, the younger of the NORIA codes, NORIA-SP, contains no intemal plotting capability. In contrast, NORIA contains a rather extensive plotting package that plots the finite-element mesh, material outlines, contours, time histories, and profiles. For any of the dependent variables, contour, time-history, and profile plots can be made.

\section{Model Application}

10.1 Usage within the Civilian Radioactive Waste Management System (CRWMS) program. Assuming isothermal conditions, NORIA-SP may be used to predict pre-emplacement ground-water flow. Potentially, it can be used for engineering and design studies and for the determination of pre-emplacement ground-water travel times. Assuming nonisothermal conditions, NORIA may be used to predict liquid and gas flow in the repository near field. Potentially, it can be used for engineering and design studies and, in conjunction with a transpart simulator, for cumulative-release analyses. 
10.2 Usage outside the program. The calculation of partially saturated, isothermal flow is pertinent to remediation studies. Furthermore, the calculation of two-phase, nonisothermal flow is of interest in fields such as geothermal energy production and tertiary petroleum recovery. However, the availability of three-dimensional codes with advanced solvers may limit the usefulness of NORIA and NORIA-SP in other areas.

\section{Codes With Similar or Same Capabilities}

11.1 Within the program. The Yucca Mountain Site Characterization Project (YMP) has funded the development of several codes with capabilities similar to those of NORIA. These codes include TOUGH2 (Pruess, 1991) at LBL (Lawrence Berkeley Laboratory); V-TOUGH (Nitao, 1989) at LLNL (Lawrence Livermore National Laboratory); TRACR3D (Birdsell and Travis, 1991) and FEHM (Zyvoloski et al., 1992) at LANL (Los Alamos National Laboratory), MSTS at PNL (Pacific Northwest Laboratory). All these codes simulate multiphase flow.

The YMP has also funded the development of flow and transport codes with capabilities similar to those of NORIA-SP. To characterize variably saturated, singlephase flow, LLUVIA-2 (Eaton and Hopkins, 1992) and TOSPAC (Dudley et al., 1988 and Gauthier et al., 1992) from SNL, SUMO (Eslinger et al., 1990) from PNL (Pacific Northwest Laboratory), and VS2DT (Lappala et al., 1987 and Healy, 1990) solve the single-phase Richards equation. In addition, three of the multiphase codes (MSTS, TRACR3D, and PORFLOW) can be specialized to solve the Richards equation.

11.2 Outside the program. The petroleum has developed a number of codes. In terms of the number of processes considered, "black-oil" and compositional models (Peaceman, 1977) have a capability superior to that of NORIA. Developed for use in the area of reservoir engineering, these codes are proprietary, and that constitutes a major impediment to their use in repository licensing. They include ECLIPSE (Exploration Consultants, Ltd.), VIP (J.S. Nolen and Associates, Inc.), THERM (SSI-Intercomp, Inc.), and TETRAD (DYAD 88 Software, Inc.). All these codes consider multiple phases and components. In addition, THERM and TETRAD simulate nonisothermal processes.

In addition, the NRC has funded the development of DCM3D (Updegraff, 1991). Like NORIA-SP, DCM3D solves the Richards equation for partially saturated flow. Unlike NORIA-SP, DCM3D also considers transport, dual-permeability, and threedimensional effects.

\section{Major Assumptions and Limitations}

The NORIA-SP model contains the following assumptions and limitations:

- Only two dimensions are considered. 
- A dual-continuum option is not available. Without substantial modification, fracturematrix disequilibrium cannot be accounted for in field-scale simulations.

- An iterative-solution option is not available.

- The liquid phase behaves as a Boussinesq fluid. Thus, density is assumed to be independent of pressure and to vary linearly as a function of temperature. Since the compressibility of water is small compared to that of gas, such an approximation is adequate for partially saturated flow, providing that dissolved components are present in dilute concentrations.

- The rock matrix is incompressible. Since the compressibility of rock is small compared to that of gas, such an approximation is adequate for partially saturated flow.

- Viscous flows are laminar and obey Richard's equation, a form of Darcy's law for unsaturated media. This is a standard assumption common to most models. Some codes, such as TRACR3D add a term to this equation to account for inertial effects at relatively large Reynolds number, but this should be a minor effect, even within the fractures.

The NORIA model additionally contains the following assumptions and limitations:

- The liquid phase consists of but a single component with the gas assumed to be insoluble in liquid. The liquid phase can have two components, liquid vapor and non-condensing gas. If dissolution may be assumed to be a minor effect, then transport of a radioactive gas can be performed with a second, receiving code.

- Both gas and vapor are assumed to be ideal, and partial pressures are additive. In view of much larger uncertainties present at the site, this limitation represents a moot point at this time. Dalton's Law, which may be proved rigorously for an ideal gas, states that the total pressure of a mixture of gases equals the sum of the individual pressures each gas would exert if it alone occupied the entire container.

- Liquid and gas phases are assumed to be in thermal equilibrium with each other and with the rock matrix. Such an assumption has been used by LBL and may be appropriate for locating the condensation front surrounding the repository as a function of time.

13. Remarks/General Observations/Discussion. When compared to TOUGH2, NORIA has two, perhaps minor, advantages. NORIA offers a non-equilibrium rate of vaporization. With an appropriate choice for the value of an empirical constant of proportionality, this algorithm causes the vaporization rate to fall smoothly to with decreasing moisture content. As a second advantage, NORIA provides a finite-element altermative should the geometric advantages of such an altemative be desirable. 
However, NORIA has significant disadvantages. Updegraff's (1989) comparison of the two codes showed NORIA to be much slower than TOUGH. This is exacerbated by the fact that, for a two-phase, two-component analysis, NORIA solves four governing equations and TOUGH, only three. Updegraff (1989) achieved successful executions with NORIA in about half as many cases as with TOUGH. In addition, NORIA's limitation to two dimensions will limit the class of problems to which it may be applied. TOUGH2 provides a three-dimensional capability. Though its numerical solver may be inefficient in its treatment of a dual continuum, TOUGH2 does offer such an alternative while NORIA does not. Unlike NORIA, TOUGH2 is now being upgraded with an iterative solver. Such a capability, which is now offered by TRACR3D and FEHM, likely will be essential for site characterization problems of the magnitude to be considered for Yucca Mountain.

\section{Comparison to Other Models}

See Chapters 4, 5, and 6 of the main text.

\section{Summary and Recommendations}

- For a field-scale problem, NORIA must assume equilibrium between fracture and matrix. TOUGH2 and FEHM permit dual-porosity and dual-permeability analyses.

- NORIA and NORIA-SP do not have a three-dimensional capability.

- NORIA and NORIA-SP do not have iterative solvers.

- When comparing the finite-element codes, NORIA with FEHM, the latter's three dimensionality and efficient interactive solver make it the better choice for Yucca Mountain simulations.

- NORIA's uniqueness, i.e., its ability to consider non-equilibrium vaporization, likely will not be important on a 10,000-year time scale.

- It is therefore recommended that neither NORIA nor NORIA-SP be considered for component testing.

16. References

Avdonin, N.A., 1964. Some Formulas for Calculating the Temperature Field of a Stratum Subject to Thermal Injection, Neft' $i$ Gaz 3, 37-41.

Birdsell, K.H., and B.J. Travis, 1991. TRACR3D: A Model of Flow and Transport in Porous Media, LA-11798-M, Los Alamos National Laboratory, Los Alamos, NM.

Bixler, N.E., 1985. NORIA - A Finite Element Computer Program for Analyzing Water, Vapor, Air, and Energy Transport in Porous Media, Sandia National Laboratories, SAND84-2057. 
Dudley, A.L., R.R. Peters, J.H. Gauthier, M.L. Wilson, M.S. Tierney, E.A. Klavetter, 1988. Total System Performance Assessment Code (TOSPAC) Volume 1: Physical and Mathematical Bases, SAND85-0002, Sandia National Laboratories, Albuquerque, NM.

Dykhuizen, R.C., R.R. Eaton, P.L. Hopkins, and M.J. Martinez, 1991. PACE90 Water and Solute Transport Calculations for $0.01,0.1$, and $0.5 \mathrm{~mm} / \mathrm{yr}$ Infiltration into Yucca Mountain, SAND90-3165, Sandia National Laboratories, Albuquerque, NM.

Eaton, R.R., D.K. Gartling, and D.E. Larson, 1983. SAGUARO-A Finite Element Computer Program for Partially Saturated Porous Flow Problems, Sandia National Laboratories, SAND82-2772.

Eaton, R.R., and P.L. Hopkins, 1992. LLUVIA-II: A Program for Two-Dimensional Transient Flow Through Partially Saturated Porous Media. SAND91-2146, Sandia National Laboratories, Albuquerque, NM.

Eslinger, P.W., T.B. Miley, and D.W. Engel, 1990. SUMO-System Performance Assessment for a High-Level Nuclear Waste Repository: Mathematical Models, PNL-7581, Pacific Northwest Laboratory, Richland, WA.

Gartling, D.K., 1978. NACHOS - A Finite Element Computer Program for Incompressible Flow Problems, Sandia National Laboratories, SAND77-1333 and SAND77-1334.

Gartling, D.K., 1978. COYOTE - A Finite Element Computer Program for Nonlinear Heat Conduction Problems, SAND77-1332, Sandia National Laboratories, Albuquerque, NM.

Gartling, D.K., and C.E. Hickox, 1982. MARIAH-A Finite Element Computer Program for Incompressible Porous Flow Problems: Theoretical Background, Sandia National Laboratories, SAND79-1622.

Gauthier, J.H., M.L. Wilson, R.R. Peters, A.L. Dudley, L.H. Skinner, 1992. Total System Performance Assessment Code (TOSPAC) Volume 2: User's Guide, SAND85-0004, Sandia National Laboratories, Albuquerque, NM.

Healy, R.W., 1990. Simulation of Solute Transport in Variably Saturated Porous Media With Supplemental Information on Modifications to the U.S. Geological Survey's Computer Program VS2D, Water-Resources Investigations Report 90-4025, U.S. Geological Survey, Denver, CO.

Hopkins, P.L. and R.R. Eaton, 1991. NORIA-SP - A Finite Element Computer Program for Analyzing Liquid Water Transport in Porous Media, SAND90-2542, Sandia National Laboratories, Albuquerque, NM.

Irons, B.M., 1970. A Frontal Solution Program for Finite Element Analysis, Int. J. Num. Meth. Engng. 2, pp. 5-32. 
Lappala, E.G., R.W. Healy, and E.P. Weeks, 1987. Documentation of Computer Program VS2D to Solve the Equations of Fluid Flow in Variably Saturated Porous Media, WaterResources Investigations Report 83-4099, U.S. Geological Survey, Denver, CO.

Martinez, M.J., 1985. FEMTRAN-A Finite Element Computer Program for Simulating Radionuclide Transport Through Porous Media, Sandia National Laboratories, SAND840747.

Moridis, G.J., and K. Pruess, 1992. TOUGH Simulations of Updegraff's Set of Fluid and Heat Flow Problems, LBL-32611, Lawrence Berkeley Laboratory, Berkeley, CA.

Nichols, W.E., and M.D. White, 1992. Multiphase Subsurface Transport Simulator User's Reference Guide, Pacific Northwest Laboratory, Richland, WA.

Nitao, J.J., 1989. V-TOUGH - An Enhanced Version of the TOUGH code for the Thermal and Hydrologic Simulation of Large-Scale Problems in Nuclear Waste Isolation, UCDD-21954, Lawrence Livermore National Laboratory, Livermore, CA.

Peaceman, D.W., 1977. Fundamentals of Numerical Reservoir Simulation, Elsevier Scientific Publishing Company, New York.

Phillip, J.R., 1955. Numerical Solution of Equations of the Diffusive Type with Diffusivity Concentration Dependent, Transactions, Faraday Society 51, 885-892.

Pruess, K., 1987. TOUGH User's Guide, NUREG/CR-4645, SAND86-07104, LBL-20700, Sandia National Laboratories, Albuquerque, NM.

Pruess, K., 1991. TOUGH2 - A General-Purpose Numerical Simulator for Multiphase Fluid and Heat Flow, LBL-29400, Lawrence Berkeley Laboratory, Berkeley, CA.

Reeves, M., and J.O. Duguid, 1975. Water Movement Through Saturated-Unsaturated Porous Media: A Finite-Element Galerkin Model, ORNL-4927, Oak Ridge, Tennessee.

Ross, B., J.W. Mercer, S.D. Thomas, and G.H. Lester, 1982. Benchmark Problems for Repository Siting Models, NUREG/CR-3097.

Shampine, L., and M. Gordon, 1975. Cornputer Solution of Ordinary Differential Equations: The Initial Value Problem, W> Fresman and Company, San Francisco, CA.

Updegraff, C.D., 1989. Comparison oi Strongly Heat-Driven Flow Codes for Unsaturated Media, NUREG/CR-5367, SAND88-7145, Sandia National Laboratories, Albuquerque, NM.

Updegraff, C.D., C.E. Lee, and D.P. Gallegos, 1991. DCM3D: A Dual-Continuum, Three Dimensional, Ground-Water Flow Code for Unsaturated, Fractured, Porous Media, NUREG/CR-5536, SAND90-7015, Sandia National Laboratories, Albuquerque, NM. 
White, M.D., and W.E. Nichols, 1992. Multiphase Subsurface Transport Simulator Theory Manual, Pacific Northwest Laboratory, Richland, WA.

Worgan, K.J., J. Pearson, and T. Nunez-McNally, 1990. A Review of Modelling of Gas Migration in Porous and Fractured Rock, Department of Environment, U.K., Commissioned Research on Radioactive Waste Management 1988/89, DOE Report No: $\mathrm{DOE} / \mathrm{RW} / 89 / 101$.

Zyvoloski, George, Zora Dash, and Sharad Kelkar, 1992. FEHMN 1.0: Finite Element Heat and Mass Transfer Code, LA-12062-MS, Los Alamos National Laboratory, Los Alamos, NM. 


\section{A.11 NUFT}

1. Name of the Model

NUFT (Nonisothermal Unsaturated-Saturated Flow and Transport Model)

\section{General Program Information}

2.1 Program size. NUFT, together with all of its interchangeable modules and solver options, requires about 33,000 lines of source code.

2.2 Programming languages. About ten percent of NUFT uses FORTRAN 77, and about 90 percent of the code uses the "C" Language.

2.3 Computer system on which it operates. NUFT is readily portable to machines running the Unix operating system. It is currently running on Sun and IBM workstations and on a Cray mainframe.

2.4 Compiler(s) used. A compiler for the " $\mathrm{C}$ " language is required.

2.5 Location of code and availability. According to current plans, Lawrence Livermore National Laboratory (LLNL) will make NUFT available to DOE personnel and to DOE contractors during 1993.

2.6 Brief description of model/code history. The development of NUFT, which is still in progress, evolved from a three-fold need for (1) a very modular code capable of simulating multiphase, multi-component, nonisothermal problems, (2) a code that was, at the same time, enhanceable, maintainable, and more user friendly, and (3) a more efficient code than is presently available. As a part of its strategy to achieve efficiency, the NUFT design uses specialized flow and transport modules in an effort to optimally match the degree of algorithmic complexity with problem requirements.

At present, there are four modules. USNT simulates nonisothermal flow and transport of $N$ phases and $N_{c}$ components, where $N$ and $N_{c}$ are arbitrary. US1P simulates twophase (Richards-equation) flow with a passive gas, and a companion module US1C sequentially simulates the transport of a single dissolved species. UNCSAT solves the equations for unconfined saturated flow. All modules are three dimensional.

When the USNT module is fully implemented and tested, NUFT-USNT will replace V-TOUGH at LLNL.

\section{Status of Model}

3.1 Development (Is the model now undergoing significant development or modification? or continuing maintenance?). Though current development is rather limited, plans call for the implementation of dual-porosity and dual-permeability algorithms. 
3.2 Documentation. The documentation currently consists of four draft reports. A main user's manual (Nitao, 1992a) and a reference manual (Nitao, 1992b) characterize installation, data structures, input data, and numerical algorithms. Separate reports then discuss model-specific input for the two flow and transport modules USNT (Nitao, 1992c) and US1 (Nitao, 1992d). At the present time, the UNCSAT draft report is incomplete.

3.3 Status of verification and validation. Several test cases have been identified and executed, but additional work is planned.

3.4 Status of Quality Assurance (QA). Though such an activity is planned, NUFT has not been integrated into the Yucca Mountain QA system at the present time.

\section{Type of Model (Phenomena/Processes Modeled)}

NUFT is a three-dimensional numerical model for simulating the coupled nonisothermal flow and transport of $\mathrm{N}$ phases and $\mathrm{N}_{c}$ component, where $\mathrm{N}$ and $\mathrm{N}_{c}$ are specified by the user. Its most general flow and transport module USNT takes into account the following physical processes:

- Fluid flow under pressure, viscous, and gravity forces according to Darcy's law

- Fickian diffusion of all components in all phases

- Capillarity between phases

- Phase partitioning of components governed by pressure and temperature-dependent partitioning coefficients

- Local phase equilibrium between phases

- Conduction of heat with thermal conductivity dependent on the degree of saturation

- Mixing laws to determine phase-dependent values of density, viscosity, and specific enthalpy as functions of pressure, temperature, and phase composition.

- Convection of heat in all phases

- Latent-heat effects.

NUFT's specialized companion modules USIP and US1C take into account the following physical processes:

- Fluid flow under pressure, viscous, and gravity forces according to Darcy's law

- Capillarity between phases 
- Liquid-phase transport of a tracer by advection, dispersion, and diffusion

- Radioactive decay

- Equilibrium sorption.

\section{Governing Equations}

The general USNT module solves $\mathrm{N}_{\mathrm{c}}+1$ governing equations in as many as three dimensions. One governing equation characterizes energy transport, and $\mathrm{N}_{c}$ equations characterize the transport of each component. In addition to immiscible quantities such as liquid or gas, some of the components can represent miscible components. The transport equations of miscible components are solved simultaneously with those for the immiscible components.

The specialized US1 modules sequentially solve unsaturated flow (US1P) in the Richards approximation and transport of a single species (US1C). One component characterizes liquid flow and the other, the transport of a single dissolved species.

\section{Method of Solution}

The model employs the integrated finite-difference technique for space discretization, which allows considerable flexibility in specifying the problem geometry. Time stepping is generally accomplished by a fully implicit procedure, and the resulting set of nonlinear difference equations is linearized by the Newton-Raphson technique.

For solution of the linearized equations, NUFT offers both block-banded gaussian elimination and orthomin preconditioned conjugate-gradient methods. Five options are available for preconditioning. Specifically, they are: (1) first-degree incomplete ILU factorization, (2) first-degree incomplete ILU factorization with D4 ordering, (3) combination method, (4) block Gauss-Seidel method, and (5) no preconditioning. For sequential solution of the transport equation with US1C, NUFT offers an explicit high-order differencing solution.

\section{Type of Input Parameters}

NUFT divides the input data file into the following general categories:

- Mesh-generation parameters

- Time-stepping and numerical-solution parameters

- Output specification

- Specification of initial conditions

- Rock-property specification

- Source-term specification

- Boundary-condition specification

- Other options. 
The NUFT input processor uses the lisp input language. This flexible language permits one to embed commands within the input stream, such as those which would be required for error checking, for defaulting certain data, or for reading data from another file.

Spatial grid divides the system geometry into elements, the volumes and interface areas of which must be specified. The NUFT input processor automatically generates grids in either Cartesian or cylindrical coordinate systems. For other coordinate systems, an externally generated grid may be used. To characterize special geometrical features of the system, which are not derivable from a standard coordinate system, the code permits the analyst to alter volumes and interface areas as desired.

Since an ideal temporal grid depends, in general, on a rather complex set of time constants inherent to the physical system, temporal grid must be defined automatically. Many codes within the Yucca Mountain Project adjust time-step sizes so as to keep the number of Newton-Raphson iterations within a specified window of values. In common with such codes, NUFT chops the time step whenever the number of iterations exceeds a value specified in the input. However, in contrast to such codes, NUFT adjusts time-step sizes so as to keep maximum changes in the dependent variables within specified tolerances. NUFT's time-stepping algorithm is much like that of V-TOUGH (Nitao, 1989).

\section{Type of Output and User Options}

NUFT, like V-TOUGH, allows the analyst to exercise variable degrees of control over the output. One may direct the code, in a rather standard manner, to write variable values at all spatial locations at specified times. Or, he may alternatively specify the identity of output variables, their locations, and a trigger mechanism to obtain so-called extraction sets. Both element variables (e.g., saturations, pressures, and mass fractions) and connection variables (e.g., velocities and flow rates) make acceptable output variables. Specified groups of elements and connections provide spatial control. Specified triggers may identify output times and restrict output at those times to variable values that exceed a specified level of significance.

9. Model Interactions (emphasize needed processors)

9.1 Does the model interface with any other models? Yes, see below.

9.2 Source code and type of information needed. Not applicable.

9.3 Receiving code and type of information provided. None.

9.4 Any pre-or postprocessing needed? LLNL's SAC graphics software package is used for plotting. However, commercially available graphics packages may also be used.

10. Model Application

10.1 Usage within the Civilian Radioactive Waste Management System (CRWMS) program. NUFT applications within the CRWMS program include the simulation of the near- 
field thermal and hydrological environment around a nuclear waste package. Such calculations are needed for waste-package design and for radionuclide transport. Simulations of this type predict the behavior of water as it returns to the area surrounding the waste package during the cool-down period after emplacement (Nitao, 1988).

Potentially NUFT can be used to characterize many aspects of the physical system. Though NUFT represents the state of the art in computational efficiency, the scope of possible Yucca Mountain simulations is limited. Potentially, however, it can characterize the following effects: the impact of gas flow and vaporization on water flow, the effect of fractures, the transport of radioactive gases to the accessible environment, and the travel time required for dissolved radioactive species to reach the accessible environment. Some analyses can be performed now, while others must await software and hardware improvements.

10.2 Usage outside the program. LLNL plans to use NUFT to model hazardous waste migration in both saturated and unsaturated zones and to model vacuum vapor extraction in the unsaturated zone.

\section{Codes With Similar or Same Capabilities}

11.1 Within the program. The Yucca Mountain Site Characterization Project (YMP) has funded the development of several codes with capabilities similar to those of NUFT. These codes include V-TOUGH (Nitao, 1989) at LLNL, TOUGH and TOUGH2 (Pruess, 1987 and 1991) at Lawrence Berkeley Laboratory, NORIA (Bixler, 1985) at Sandia National Laboratories, TRACR3D (Birdsell and Travis, 1991) and FEHM (Zyvoloski et al., 1991) at Los Alamos National Laboratory, and PORFLOW (Runchal and Sagar, 1991) and MSTS (White and Nichols, 1992) at Pacific Northwest Laboratory. All these codes simulate multiphase flow. They differ in terms of spatial-discretization methods (finite difference vs. finite element), linearization techniques (Picard vs Newton-Raphson), and linear-equations solvers (direct solution $v s$ conjugate gradient). They also differ in terms of the processes considered (heat transport, radionuclide transport, phase equilibrium or disequilibrium, and diffusion).

11.2 Outside the program. In addition to the documentation of TOUGH, the U.S. Nuclear Regulatory Commission (NRC) funded the development of DCM3D (Updegraff, 1991). Further, a number of codes have been developed within the petroleum industry. In terms of the processes considered, compositional models (Peaceman, 1977) provide a capability similar to that of the NUFT. Developed for use in reservoir engineering, these codes are proprietary, and that constitutes a major impediment to their use in licensing. They include THERM (SSI-Intercomp, Inc.) and TETRAD (DYAD 88 Software, Inc.). Like NUFT, these codes consider multiple phases and components and are nonisothermal. 
12. Major Assumptions and Limitations

- A steady-state option is not available. Generally, running through a transient sequence to achieve steady state represents a costly expenditure of computer time. Since most transient characterization runs assume steady-state initial conditions, this is a significant consideration. Pruess (private communication) cautions, however, that for a multiphase simulation, establishing gravity equilibrium is somewhat difficult. In addition, for Yucca Mountain simulations, the enormous difference in the various physical time constants causes a sequence of pseudo steady states to evolve, thus obscuring the definition of steady state.

- Although the transport of a single miscible species is simulated, the transport of a radionuclide chain is not considered.

- Air is treated as an ideal gas and additivity of partial pressures (Dalton's Law) is assumed for air-vapor mixtures. In view of much larger uncertainties present at the site, this limitation represents a moot point at this time. Dalton's Law, which may be proved rigorously for an ideal gas, states that the total pressure of a mixture of gases equals the sum of the individual pressures each gas would exert if it alone occupied the entire container.

\section{Remarks/General Observations/Discussion}

Documentation suggests that, like TOUGH2, NUFT also offers an open modular architecture which facilitates maintenance and enhancement. Of course, TOUGH2's merit here lies in its organizational separation of specialized fluid-property algorithms most subject to change into equation-of-state modules. NUFT uses the " $\mathrm{C}$ " language to further enhance maintainability. The M\&O should read NUFT, particularly the USNT module, to assess its organizational merit in comparison to TOUGH2.

With respect to efficiency, NUFT appears to be leading TOUGH2, although a forthcoming release of TOUGH2 could reduce this lead substantially. Given that LLNL's V-TOUGH development focused on efficiency, NUFT's leadership in efficiency is to be expected. The LLNL strategy for V-TOUGH included vectorizing much of the TOUGH coding, installing faster direct solvers, and optimizing the steam-table look-up procedure. By so doing, LLNL was able to achieve more than an order-of-magnitude reduction in Cray-2 CPU time (Nitao, 1989).

With NUFT, LLNL has expanded its optimization strategy to include non-vectorized machines, such as the Sun and IBM workstations. In addition, the LLNL strategy has expanded to include a conjugate gradient - orthomin solver with five different options for preconditioning.

\section{Comparison to Other Models}

See Sections 4 and 5 of the main text. 


\section{Summary and Recommendations}

- NUFT is a detailed process model which is useful for site characterization, site suitability, and detailed design review.

- The NUFT implementation recognizes that, for detailed process models, computer efficiency is a significant problem.

- Nevertheless, the NUFT efficiency is not sufficient to permit probabilistic analysis of the total system.

- NUFT assumes equilibrium between fracture and matrix.

- Though only in draft form, NUFT's draft documentation is quite adequate.

- NUFT C-language is unfamiliar to many scientists. However, NUFT's advanced capabilities may entice many to learn this language.

- NUFT appears to be an excellent code. It is therefore recommended that NUFT be moved to the next step, i.e., component testing.

\section{References}

Birdsell, K.H., and B.J. Travis, 1991. TRACR3D: A Model of Flow and Transport in Porous Media, LA-11798-M, Los Alamos National Laboratory, Los Alamos, NM.

Bixler, N.E., 1985. NORIA - A Finite Element Computer Program for Analyzing Water, Vapor, and Energy Transport in Porous Media, SAND84-2057, Sandia National Laboratories, Albuquerque, NM.

Nitao, J.J., 1988. Numerical Modeling of the Thermal and Hydrological Environment Around a Nuclear Waste Package Using the Equivalent Continuum Approximation: Horizontal Emplacement, UCID-21444, Lawrence Livermore National Laboratory, Livermore, CA.

Nitao, J.J., 1989. V-TOUGH - An Enhanced Version of the TOUGH code for the Thermal and Hydrologic Simulation of Large-Scale Problems in Nuclear Waste Isolation, UCID21954, Lawrence Livermore National Laboratory, Livermore, CA.

Nitao, J.J., 1992a. Main User's Manual for the NUFT Flow and Transport Code, Lawrence Livermore National Laboratory, Livermore, CA, to be published.

Nitao, J.J., 1992b. Reference Manual for the NUFT Flow and Transport Code, Lawrence Livermore National Laboratory, Livermore, CA, to be published.

Nitao, J.J., 1992c. Reference Manual for the USNT Module of the NUFT Code, Lawrence Livermore National Laboratory, Livermore, CA, to be published. 
Nitao, J.J., 1992d. Reference Manual for the US1 Module of the NUFT Code, Lawrence Livermore National Laboratory, Livermore, CA, to be published.

Pruess, K., 1987. TOUGH User's Guide, NUREG/CR-4645, SAND86-07104, LBL-20700, Sandia National Laboratories, Albuquerque, NM.

Pruess, K., 1991. TOUGH2 - A General-Purpose Numerical Simulator for Multiphase Fluid and Heat Flow, Lawrence Berkeley Laboratory, Berkeley, CA.

Runchal, A.K., and B. Sagar, 1991. PORFLOW: A Model for Fluid Flow, Heat, and Mass Transport in Multifluid, Multiphase Fractured or Porous Media, User's Manual - Version 2.34, ACRi/016/Rev. E, Analytical and Computational Research, Inc., West Los Angeles, CA.

Updegraff, C.D., 1989. Comparison of Strongly Heat-Driven Flow Codes for Unsaturated Media, NUREG/CR-5367, SAND88-7145, Sandia National Laboratories, Albuquerque, NM.

White, M.D., and W.E. Nichols, 1992. Multiphase Subsurface Transport Simulator Theory Manual, Pacific Northwest Laboratory, Richland, WA.

Zyvoloski, George, Zora Dash, and Sharad Kelkar, 1991. FEHMN 1.0: Finite Element Heat and Mass Transfer Code, LA-12062-MS, Los Alamos National Laboratory, Los Alamos, NM. 


\section{A.12 PORFLOW}

1. Name of the Model

PORFLOW

2. General Program Information

2.1 Program size. Approximately 10,000 lines of source code, about 40 percent of which is devoted to input processing

\subsection{Programming language. American National Standard FORTRAN 77}

2.3 Computer system on which it operates. PORFLOW has a user's group numbering approximately $\mathbf{5 0}$ individuals. It is being used at Pacific Northwest Laboratories, Westinghouse Hanford Company, Idaho National Engineering Laboratory, Oak Ridge National Laboratory, and at Savannah River Plant. Consequently, the PORFLOW coding has become reasonably machine independent.

2.4 Compiler(s) used. A standard compiler has been used on each machine.

2.5 Location of code and availability. The latest version of PORFLOW (Version 2.4) may be obtained from ACRi (Analytic and Computational Research, Inc.) at 3106 Inglewood Boulevard, West Los Angeles, CA 90066.

2.6 Brief description of model/code history. PORFLOW history dates back to 1976. At that time, the Office of Waste Isolation, headquartered at Oak Ridge, TN, sponsored generic repository analyses for several different geologic media. As a part of that project, Akshai K. Runchal added saturated flow and transport capabilities to Dames and Moore's thermal model GWTHERM. In 1979, this version of GWTHERM was renamed "PORFLOW". Through the sponsorship of a number of governmental and industrial agencies, PORFLnWy's flow capability expanded to include first a Richard's equation solution for uns: ated flow and then a multiphase solution with phase conservation. The mas is progressing toward a general thermal compositional model. The most recent Version 2.4 contains three phases, e.g., gas, water, and oil with one condensible component (water). Only this component may move from one phase to another, i.e., from gas to water phases and vice versa. Future versions will also permit inert components to move from one phase to another.

\section{Status of Model}

3.1 Development (Is the model now undergoing significant development or modification? or continuing maintenance?) The code is being developed continuously. Since the release of Version 2.34, the role of the governing equation for water has changed from one ensuring phase conservation to one ensuring component conservation. The architecture of Version 2.4 has been generalized to permit the use of a wide variety 
of solvers, including user-supplied solvers. When funding permits, a Newton-Raphson linearization procedure will be added, and solution of conservation equations will be generalized to permit inert components to move from one phase to another.

3.2 Documentation. Sagar and Runchal (1990) and Runchal and Sagar (1991) provide readable discussions of theory and data input for PORFLO-3, Version 1, and PORFLOW, Version 2.34. Documentation for Version 2.4 has not been released.

3.3 Status of verification and validation. Two code verification and benchmarking studies have been performed for earlier versions of PORFLOW. Although they do not test PORFLOW's recently added multiphase-multicomponent capability, one (Magnuson et al., 1990) does examine its ability to solve a single-phase partially saturated flow domain. Both studies systematically rate the comparisons of PORFLOW results and those of other approaches. They use similar rating schemes based on computed values of the relative root-mean square error and a consistent definition of the terms "excellent," "good", "acceptable," and "unacceptable".

\section{Eyler and Budden (1984)}

As was appropriate for a study sponsored by the Basalt Waste Isolation Program (BWIP), this problem set considered a fully saturated flow domain only. The ten problems were designated according to the code capability they were designed to test, "HT" for heat transfer, "FF" for fluid flow, and "MT" for mass transfer. The version of PORFLO used in this study is documented in Kline et al. (1983).

- HT-1: Heat Transfer in a Cylindrical Geometry with Heat Generation. This problem considers steady-state heat conduction within a right circular cylinder of finite length. A uniformly distributed and constant source of heat maintains temperatures at elevated levels within the interior of the cylinder. Boundary conditions control the temperature of the exterior surface. The PORFLO grid comprises a $22 \times 22$ noding with constant incremental spacings ini both radial and axial directions. PORFLO results are in good agreement both with analytic calculations and with numeric calculations using TEMPEST (Trent et al., 1983).

- HT-2: Heat Transfer in Unidirectional Flow. Uniform, one-dimensional flow is assumed within a horizontal, semi-infinite column. Initially, the water temperature is uniform. Subsequently, a step-increase in temperature is applied to the left boundary. The problem is the same as that used by Ward et al. (1983) in verifying the SWIFT code (Reeves et al., 1984). The analytic solution is well known and may be found in many references, including Coats and Smith (1964). Spatial and temporal grids, corresponding to grid Peclet and Courant numbers of 1.6 and 0.3 , respectively, yielded an "excellent" comparison with analytic results.

- HT-3: Repository-Scale Transient Heat Conduction. Two repository banks provide underground sources of heat throughout the 50,000-year simulation 
period. Initially, the thermal field is characterized by a geothermal gradient. Consistent with this gradient, constant temperatures provide boundary conditions at both the surface and at the bottom of the region of the simulated system, a depth of 1,575 meters below the surface. Heat generation rates are identical for the two banks and decrease as a function of time. Although water fills the porous media, it is assumed to be stagnant. Problem FF-3 (below) examines the buoyancy effect upon the heated water.

Here PORFLO-3 is benchmarked against TEMPEST. The PORFLO analysis used a grid consisting of $119 \times 63$ nodals, whereas the TEMPEST analysis used a grid consisting of $36 \times 41$ computational cells. Simulation results were obtained for four different times, i.e., 50, 500, 5,000, and 50,000 years. In spite of differences in gridding, results of the two codes are well within expected agreement limits.

- FF-1: Steady Flow in a Regional Ground-Water System. A uniform slope in the $x$ direction, together with a spatially variable set of boundary conditions, combine to give a somewhat unusual ground-water flow pattern. A twodimensional $(x, z)$ vertical cross-section is considered. Ground-water divides, with no-flow symmetry conditions, bound the system on sides $(0, z)$ and $\left(L_{x}, z\right)$. Impermeable rock, again with a no-flow condition, bounds the bottom of the system $(x, 0)$. On the top $\left(x, L_{2}\right)$, total head varies according to the relation $h\left(x, L_{2}\right)=H+x \tan \alpha$, where $H$ is the elevation of the water table above datum and $\alpha$ is the slope. The resulting flow system recharges upstream, near $x=L_{x}$, and discharges downstream, near $x=0$. Since a direct steady-state algorithm is not included in PORFLO-3, a transient solution is advanced to 80,000 years, at which time heads become effectively steady state. Agreement with the analytic solution (Domenico, 1980) is "excellent" over the entire solution domain.

- FF-2: Transient Flow in a Rectangular Areal Domain. The problem assumes that, initially, the hydraulic-head distribution forms a potential mound with a sinusoidal distribution. With boundary heads held constant, the system moves in time toward a steady-state, constant-head distribution. Obtained with a $41 \times 21$ nodal array, transient PORFLO results at three spatial locations show excellent agreement with analytical results.

- FF-3: Repository-Scale Coupled Flow and Heat Transfer. The physical setting is identical to that of HT-3. Here, however, the analysis considers the effect of heat upon the flow field. Buoyancy of the heated water causes the development of circulation cells. In benchmarking PORFLO-3 against SWENT (INTERA, 1983), sirnulation results were obtained for four different times, i.e., 50, 500, 5,000, and 50,000 years. Except at 50 years, there is good agreement between the codes. Although an effort was made to make the two simulations similar, certain differences were unavoidable. The number of nodes differed, and the two codes determine density and specific heat in 
different ways. Most likely, these differences are responsible for differing results at 50 years.

- MT-1: Radionuclide Transport in a Unidirectional Flow. This problem is similar to HT-2 except that mass transport is assumed rather than heat transport. Here, as in HT-2, the analytic analysis uses the solution of Coats and Smith (1964), corresponding to a semi-infinite column. Assuming a length of 10,000 meters and a grid corresponding to a maximum cell Peclet number of 0.9995 , PORFLO results showed good agreement with analytic results.

- MT-2: Two-Dimensional Radionuclide Transport from a Line Source. Groundwater flows across a 40-meter line source oriented perpendicular to the direction of flow. The flow is unidirectional and of constant magnitude. Radionuclides leave the source at a constant concentration and enter the flow, where they disperse both laterally and longitudinally. Radioactive decay is assumed to be negligible during the period of interest (100 years), and there is no retardation. Bruch and Street (1967) provide the analytic solution.

For mass-transport problems, gridding represents an important component of a numerical solution. In the longitudinal direction, the chosen nodal spacings (25 meters) are relatively small compared with the dispersivity (192.304 meters) for distances of 3,000 meters or less. Beyond this distance, out to the full length of the numeric simulation system $(5,000$ meters), the nodal spacing ( 50 meters) is relatively immaterial. Radionuclide migration distances are substantially less than 3,000 meters during the period of interest.

In the lateral direction, the chosen nodal spacings (10 meters) are somewhat more coarse when compared to the dispersivity (19.227 meters). This may explain some of the discrepancies between PORFLO and analytic results, particularly within a few 10 s of meters from the source. Nevertheless, the overall agreement between the two solutions is good.

- MT-3: Radionuclide Transport with Decay and Retardation. A unidirectional grcund-water flow leaches radionuclides from a repository. The source rate, which is specified by tabular input, decreases as a function of time. The problem setup may be visualized by assuming a one-dimensional system, 10,000 meters in length with flow moving from left to right. The source is located 1,000 meters from the left-hand end of the system.

Although the solution is one-dimensional, the PORFLO solution employed a two-dimensional grid with $261 \times 4$ noding. Longitudinally, grid spacings were set at 25 meters for the first 3,000 meters and 50 meters beyond. Both spacings compare favorably with the longitudinal dispersivity (50 meters). The SWENT solution employed a one-dimensional grid comprised of 401 nodes in the longitudinal direction. 
PORFLO used centered differencing in both space and time domains. Although SWENT offers either backward or centered differencing, the authors, for reasons unexplained, chose backward differencing in both space and time domains. The resulting level of numerical dispersion, though small, was noticeable. Nevertheless, PORFLO and SWENT results evidenced good agreement throughout the 5,000-year simulation period for all spatial locations.

- MT-4: Radionuclide Transport on a Repository Scale with Coupled Flow and Heat Transfer. This problem is the same as FF-3, but with an added feature. ${ }^{129} \mathrm{I}$, with a half life of $1.59 \mathrm{E} 7$ years, is released over the time span from 1,050 years to 9,200 years. Using a prescribed tabular release rate, the analysis examines the effect of the buoyancy-affected flow field on radionuclide transport. Without buoyancy, the flow would be stagnant, and there wrould be no transport.

At 5,000 years, PORFLO and SWENT results are similar. At 50,000 years, the results show some variance. Both solutions contain numerical dispersion. The PORFLO gridding, though more refined than that used by SWENT, has a maximum Peclet number of nine, indicating that PORFLO's automatic differencing has incorporated numerical dispersion for cell Peclet numbers greater than two in order to stabilize the algorithm. Using backward-in-space differencing with a coarser grid, SWENT's level of numerical dispersion exceeds that of PORFLO. Presumably, both PORFLO and SWENT used backward-in-time differencing.

Because of these excessive levels of numerical dispersion, the authors, in 1983, chose to draw no conclusions regarding the accuracy of PORFLO or SWENT. The large amounts of memory available on modern computers, would, in 1991, permit one to refine the grid and thereby to reduce substantially the level of numerical dispersicn in both codes.

Magnuson et al. (1990)

In a task sponsored by the Westinghouse Hanford Company, Idaho National Engineering Laboratory (INEL) conducted a verification and benchmarking study of PORFLO-3, Version 1.0. Nine problems were chosen. For the four verification problems, PORFLO-3 results were compared with either analytic or quasi-analytic solutions. For the five benchmark problems, PORFLO-3 results were compared with those of four other codes, FEMWATER (Yeh and Ward, 1979), TRACR3D (Birdsell and Travis, 1991), FLASH, and MAGNUM-2D (England et al., 1985). For the benchmark problems, Magnuson et al. (1990) report CPU times for a Cray XMP using UNICOS 5.0. CPU times for the multiphase PORFLOW, Version 2.4, may be somewhat larger. In the brief descriptions to follow, "VT" denotes a verification test, while "BT" denotes a benchmarking test.

-VT-1: Philip's Solution for a Vertical Column. In this unsaturated-flow test, capillary and gravitational forces cause fluid to flow vertically downward 
through a 15-cm soil column filled with Yolo light clay. For comparison, the INFIL code (El-Kadi, 1987) was used to generate the Philip (1957) quasianalytic solution. For the PORFLO-3 solution, the $15-\mathrm{cm}$ column was divided by 101 nodes and grid cells. Interfacial hydraulic conductivities were generated using both harmonic and geometric averaging with the latter showing the best agreement with the quasi-analytic results. Based on the chosen rating scheme, the VT-1 test was classified as "acceptable."

- VT-2: Theis Solution for Transient Drawdown. This problem involves simulating transient drawdown due to pumping a confined aquifer of constant thickness with a fully penetrating well. The PORFLO-3 solution, when compared to the classical Theis solution (Theis, 1935), was classified as "good".

- VT-3: Transport of Heat by Unidirectional Flow. This test is identical to HT-2 of Eyler and Budden (1984) with exception to an increased Darcy velocity. As in HT-2, the spatial and temporal grids were chosen to correspond to grid Peclet and Courant numbers of 1.6 and 0.3 , respectively. The results were classified as "excellent" when compared with analytic results.

- VT4: Three-Dimensional Solute Transport. The physical setting is a homogeneous, isotropic confined aquifer with properties similar to those of the Snake River Plain Aquifer (Rood et al., 1989). Initially, the uniform horizontal flow is uncontaminated. A rectangularly shaped source area located along the top surface continuously loads the aquifer with contaminants. Advective transport moves the contaminants downstream while dispersive movement causes spreading in each of the spatial directions.

A collection of mathematical models by Codell and Duguid (1983) and the GRDFLX computer code (Codell et al., 1982) provide the quasi-analytic solution. The spatial and temporal grids, though variable, correspond to maximum Peclet and Courant numbers of 5.5 and 0.04, respectively. Near the center of the waste plume, PORFLO-3 results showed excellent agreement with the quasi-analytic solution. The agreement degraded somewhat near the edges of the plume and could have been improved with more refined gridding. Nevertheless, the overall agreement was classified as "satisfactory."

- BT-1: Two-Dimensional Saturated-Unsaturated Flow. Taken from the VAM2D user's guide (Huyakom et al., 1989), this test considered twodimensional partially saturated flow. FEMWATER is a finite-element model which, like PORFLO-3, employs Picard linearization. An excellent comparison with results from FEMWATER demonstrated PORFLO-3's ability to simultaneously solve both saturated and unsaturated flow regimes. Computer CPU times were 37 seconds (PORFLO-3) and 8.2 seconds (FEMWATER). 
- BT-2: Two-Dimensional Unsaturated Flow - the Jornada Test Trench. This test considers infiltration of water into a relatively dry, heterogeneous soil using soil hydraulic properties taken directly from the Jornada, New Mexico site. The two-dimensional system is divided into four regions. Although each has its own unique set of hydraulic properties, one region has a permeability which is approximately an order of magnitude greater than any of the other three. The problem is highly nonlinear and much more difficult numerically to solve than BT-1.

For a computational grid of 56 by 47 nodes, PORFLO-3 employed the ADI solution method and gave the required steady-state solution in 5.95 minutes of CPU time. TRACR3D is a finite-difference model, and FLASH, a finiteelement model. Unlike PORFLO-3, both employ Newton-Raphson linearization. Using grids similar to that used by PORFLO-3, TRACR3D and FLASH required CPU times of 5.79 and 16.8 minutes, respectively. PORFLO-3 and FLASH results agree exceptionally well. However, TRACR3D results indicated more numerical dispersion than those of the other two codes, perhaps due to an inappropriate choice of the interfacial hydraulic conductivity.

- BT-3: Saturated Flow in a Fractured Porous Medium. This test assumes a vertical cross-section with hydrologic properties similar to those of basalts at the INEL site. At the exterior of the rectangularly shaped system, no-flow conditions eliminate flow from the sides, while held-pressure conditions cause vertical flows to enter the system at the top and to exit from the bottom. Within the interio: of the system, two highly permeable vertical fractures diverted some of the flow, thereby perturbing the generally vertical steadystate flow pattern.

The computational grid consists of 49 horizontal rows and 96 vertical columns of nodes with superimposed line elements to represent the fractures. Using the conjugate gradient solution method, PORFLO-3 gave the steady-state solution in 3.6 seconds. FLASH required 6.0 seconds. Results agree very well.

- BT-4: Buoyancy-Affected Flow in the Vicinity of a Hypothetical Waste Repository. A repository provides a constant source of heat to an initially stagnant flow field. Buoyancy of the heated water causes the development of circulation cells. Here PORFLO-3 is benchmarked against the finite-element code MAGNUM-2D. Simulation results were obtained for three different times, i.e., 5, 25, and 50 years with PORFLO-3 employing the conjugategradient solution method.

For the thermal field, the agreement between the three codes is excellent. For the flow field, PORFLO-3 and MAGNUM-2D results do not agree, and the authors do not venture an explanation. However, the good agreement of PORFLO-3 and SWENT (INTERA, 1983) results in a similar test (Problem FF-3 above) casts suspicion on MAGNUM-2D. 
- BT-5: Three-Dimensional, Unsaturated Contaminant Transport at the Hanford Site. This test examines the T-106 tank leak at the Hanford site in Washington. It considers both flow and transport in a partially saturated flow domain. The problem is quite large, as evidenced by a computational grid containing approximately 50,000 nodes. The input data set is identical to that of an earlier study by Smoot and Sagar (1990).

During a 54-day period, ${ }^{106} \mathrm{Ru}$ and ${ }^{137} \mathrm{Cs}$ leak from tank T-106 into the vadose zone of the stratified, non-indurated sediment at the Hanford site. For a 100-day period, the simulation tracks the development of the plume. The physical system, which extended from the ground surface to the water table, 62 meters below, was divided into five layers, or zones, with each zone characterized by the same soil-property functions. The soil-property functions are representative of the site.

For both flow and transport, the physical system was discretized spatially by a $36 \times 36 \times 39$ nodal grid. Vertically, nodal spacing ranged from $0.5 \mathrm{~m}$ at the surface to $8 \mathrm{~m}$ near the water table. Laterally, it ranged from $2 \mathrm{~m}$ in the central portion of the domain to $14 \mathrm{~m}$ near the lateral boundaries. In the central portion of the grid, near the tank, grid spacings must be kept reasonably close to the value of longitudinal dispersivity ( 1 meter) to control numerical errors in solution of the transport solution. Magnuson et al. (1990) do not comment regarding the temporal grid. It is assumed, however, that the authors also sought to minimize numerical errors in their specification of time steps.

PORFLO-3 employed the conjugate-gradient method for solution of the flow equation and the ADI method for solution of the transport equation. The total solution time was 27.0 minutes. For a similar discretization, TRACR3D required 164.3 minutes. It should be pointed out, however, that the most recent version of TRACR3D (Birdsell and Travis, 1991) contains new and more efficient methods for both flow and transport solutions. Although results differ, the authors conclude that, for an extremely complex problem like the T-106 tank leak, the agreement is adequate and that differences in results can be explained by differences in calculational methods.

3.4 Status of Quality Assurance (QA). Some versions have been entered in quality assurance programs. However, the latest Version 2.4 is not under QA.

\section{Type of Model (Phenomena/Processes Modeled)}

PORFLOW provides a general multiphase, nonisothermal analysis of flow. It also provides a general analysis of transport for radionuclide chains. The geologic medium may be anisotropic, heterogeneous, and fractured. PORFLOW takes into account the following physical processes: 
- Fluid flow in two liquid phases and one gas phase, occurring under pressure, viscous, and gravity forces according to Darcy's law

- Binary diffusion of gaseous components

- Capillarity between phases

- Phase equilibrium or disequilibrium of vaporizing gas component, with a functional representation of the steam tables.

- Conduction of heat with thermal conductivity dependent on degree of saturation

- Convection of heat in gas and liquid phases

- Non-equilibrium vaporization and condensation of water

- Dilute-species transport, including the effects of advection, diffusion, dispersion, sorption, and chain decay. A dilute species may not change from one phase to another.

- Discrete, embedded, or equivalent-continuum fracture models. The embedded approach may be conceptualized as resistors in parallel or in series, depending upon whether the flow is parallel or normal to the direction of the fractures. The equivalent-continuum approach assumes fracture and matrix to be in capillary-pressure equilibrium.

\section{Governing Equations}

PORFLOW can solve up to four governing flow equations in as many as three dimensions. Three of the equations characterize the movement of fluid components while a fourth characterizes the heat transport. Typically, they are highly nonlinear. Auxiliary conditions provide a strong intercoupling between the flow equations. Such conditions express material properties in terms of the dependent variables and enforce a total saturation of unity and a total component mass fractions of unity in each phase. Other conditions characterize inter-phase equilibria (or disequilibria). Currently, the model permits but one condensible component (water) to move between its gas and water phases. For comparison, one may note that a "black oil" implementation permits two non-condensible components, gas and oil, to move between its gas and oil phases.

PORFLOW can also solve up to four radionuclide transport equations, again in three dimensions. As implied above, radionuclide components may not move from one phase to another. Typically, the equations here are only weakly nonlinear. In addition, assuming dilute concentrations results in a relatively weak coupling between radionuclide equations, consisting primarily of expressions for radioactive production and decay. 


\section{Method of Solution}

The model discretizes the spatial domain with a node-distributed grid. For such a grid, user input fixes node positions, and grid-cell surfaces are optimally positioned between nodes to yield convergence to the analytic solution in the steady-state limit. Node positions do not necessarily coincide with cell centers. Such a grid differs from a block-centered grid. For the latter, user input fixes grid-cell surfaces, and nodes are placed at cell centers. Practical considerations favor the latter, while mathematical considerations favor the former. With a cell-centered grid, cell boundaries may be more easily specified to coincide with formation interfaces, where material property changes occur. However, such a grid may yield a finitedifference solution which is inconsistent with the theoretical solution. Aziz and Settari (1979) note, however, that such inconsistencies are generally confined to a highly localized region, with inconsequential effects.

Like a standard finite-difference implementation, a mass-conservation equation is formed for each cell. However, rather than to assume constant values of the dependent variables within a grid cell, the PORFLOW implementation assumes that dependent variables vary continuously between adjacent nodes in accordance with piecewise continuous basis functions. On the surface, this resembles one aspect of a finite-element implementation. The method is therefore dignified with a new name: "the nodal-point integration method". However, when one examines the result of using simple polynomial basis functions for the various transport terms, he finds discretized equations that are identical to standard finitedifference expressions.

Nevertheless, nodal-point integration is potentially the more powerful method. Only one example may be cited to this contention. A one-dimensional analytic solution of the convection-dispersion equation inspired the use of exponential basis functions. With these functions, a straightforward application of nodal-point integration yielded difference equations with exponential weighting, a weighting which is not derivable from a straightforward application of finite differencing. Exponential weighting has not proved to be as important as might have been expected. Although it has limited use for some applications with grid-cell Peclet numbers exceeding two, the CONDIF method (Runchal, 1987) has proved superior, and the exponential-weighting option is being phased out (Runchal, private conservation).

The addition of a Newton-Raphson algorithm is planned for the future. Nevertheless, linearization is now accomplished through a modified Picard technique. The latter may not converge for highly nonlinear applications. The Picard technique updates nonlinear terms in the governing equations using the dependent variable values obtained from the most recent iteration. Recognizing the critical importance of the solver in the solution of large problems, the most recent Version 2.4 permits the use of a wide variety of solvers. The user may select from a menu consisting of the following types of solvers: point successive over-relaxation, alternating direction implicit, Cholesky decomposition, Gaussian elimination, and conjugate gradient. In addition, the user may select the Harvard, Yale, or Texas solvers, or he may supply his own routine. 


\section{Type of Input Parameters}

PORFLOW uses the FREEFORM command language. This language, developed by ACRi, is a keyword oriented language. This popular input style consists of a set of keyword commands, written with all letters capitalized and followed by several records. Within each record, parameter values may be delimited not only by commas and/or spaces but also by text written entirely in the lower case. This unique feature of the FREEFORM language permits clarifying, sentence-like text to be mixed with parameter values.

In general, the keywords (and their associated records) may be specified in any order. However, some constraints are imposed by common sense. For example, boundary (BOUN) and initial-condition (INIT) keywords must follow the coordinate specifying keyword (COOR). In addition, the solve (SOLV) command must follow a complete specification of coordinates, boundary-initial conditions, and physical parameters.

Since the (approximately 50) keywords are rather numerous, the users manual suggests that they be considered in functional groups given in Table 1. The manual also suggests that the input be ordered accordingly. Since the FREEFORM language does not recognize letters in lower case, one may complete the spelling of keyword commands as shown.

The input has many convenient features. For example, any consistent set of units may be used. However, when using a system other than the SI system, one must not permit the code to use any default value. PORFLOW always supplies SI values for defaulted parameters. Sub-regions or windows may be specified. The ZONE keyword command divides the domain of interest into subdomains, each with its own distinct or unique properties. Although the input of most codes provides a similar capability, PORFLOW's facility appears to be very user friendly. The WINDow keyword command also divides the domain of interest into subdomains. Used in conjunction with the OUTPut command, the WINDow command permits one to output only those computational results which pertain to the subdomain of interest. Recognizing that errors will occur, even under the most rigid of QA systems, PORFLOW input provides another convenience, i.e., the DEBUg and DIAGnostic keywords. These commands activate the printing of error messages and calculational results for designated nodes at each time step.

Before closing this section, it should be noted that input documentation for Version 2.4 has not yet been released. However, it should be quite close to that of Version 2.34 (Runchal and Sagar, 1991).

\section{Type of Output and User Options}

Appendix B of the PORFLO-3 manual (Runchal and Sagar, 1989) provides an example output. It consists of an echo of the input, a record of the data setup with physical parameters and initial-boundary conditions, and calculated values of dependent values. Since the latter can become quite voluminous for large problems, it is tightly regulated by the output-control group of keywords (see Table 1), which permit output of designated variables only for specified space and time nodes. 
9. Model Interactions (emphasize needed processors)

9.1 Does the model interface with any other models? Yes, see below.

9.2 Source code and type of information needed. Not applicable.

9.3 Receiving code and type of information provided. None.

9.4 Any pre- or postprocessing needed? Using computed data from PORFLOW, routine ACRi's ACRPLOT produces an assortment of plots, as specified by the analyst.

10. Model Application

10.1 Usage within the Civilian Radioactive Waste Management System (CRWMS) program. Calculations of the thermal flow field constitutes an important aspect of the Yucca Mountain site characterization. Such calculations, which can be executed successfully by PORFLOW, are needed both for waste-package design and for radionuclide transport. They will show the behavior of the condensation envelope as it responds to various effects including a gradual cooling of the wastes, fracture flow, and a rise in the water table.

Potentially PORFLOW can be used to characterize many aspects of the physical system. It is constrained primarily by efficiency considerations. In addition to analysis of the near field, PORFLOW potentially can characterize the following effects: the impact of gas flow and vaporization on water flow, the effect of fractures, the effect of matrix flow in nonwelded units on downward flow through fractures, the transport of radioactive gases to the accessible environment, and the travel time required for dissolved radioactive species to reach the accessible environment. Some analyses can be performed now, while others must await software and hardware improvements.

10.2 Usage outside the program. PORFLOW is now being applied to the management of low-level wastes at Hanford, Idaho National Engineering Laboratory, Oak Ridge National Laboratory, and Savannah River Plant. It is also being used in several foreign countries. It has a variety of uses, which may be summarized in the following manner:

- Low-level nuclear-waste storage

- Chemical and organic contamination of ground water

- Ground-water resource and pumping studies

- Aquifer storage and withdrawal of hot water

- Salt-water intrusion into coastal aquifers

- Thawing/freezing of ground due to buried oil and gas pipelines

- Mine dewatering. 


\section{Codes With Similar or Same Capabilities}

11.1 Within the program. The Yucca Mountain Site Characterization Project (YMP) has funded the development of several codes with capabilities similar to that of PORFLOW. These codes include TOUGH2 (Pruess, 1990) at LBL (Lawrence Berkeley Laboratory), V-TOUGH (Nitao, 1989) at LLNL (Lawrence Livermore National Laboratory), NORIA (Bixler, 1985) at SNL (Sandia National Laboratories), TRACR3D (Birdsell and Travis, 1991) and FEHM (Zyvoloski et al., 1992) at LANL (Los Alamos National Laboratory), and MSTS, a derivative of the PORFLOW line of codes at PNL (Pacific Northwest Laboratory). All of these codes simulate multiphase flow. They differ in terms of spatial-discretization methods, linearization techniques and linear-equations solvers. They also differ in terms of the processes considered (heat and radionuclide transport, for example).

11.2 Outside the program. The NRC (U.S. Nuclear Regulatory Commission) funded the documentation of TOUGH (Pruess, 1987) and DCM3D (Updegraff et al., 1991). Further, a number of multiphase and thermal compositional models have been developed within the petroleum industry. Developed for use in the area of reservoir engineering, these codes are proprietary, and that constitutes a major impediment to their use in licensing. Thermal compositional models include THERM (SSIIntercomp, Inc.) and TETRAD (DYAD 88 Software, Inc.).

\section{Major Assumptions and Limitations}

- PORFLOW does not provide a Newton-Raphson linearization option. For the low saturation levels and highly nonlinear material properties present at Yucca Mountain, one should therefore expect poor convergence or even nonconvergence in some simulations.

- None of PORFLOW's three fracture-matrix options adequately accounts for the non-equilibrium exchange of mass and phase pressures between fracture and matrix. In addition, using the direct-gridding option to accurately characterize such exchanges will severely restrict the size of field-scale simulations.

- Runchal (private communication) makes the reasonable assumption that a realistic three-dimensional simulation of Yucca Mountain will require approximately 100,000 grid cells. It is generally conceded that excessive storage requirements will prevent the use of direct solvers on such a problem. Runchal suggests that a conjugategradient solver like the Zyvolosky solver, which is widely used in the YMP, has a similar problem. This leaves ADI and SOR as viable options with the viability yet to be determined for the method of lines and other conjugate-gradient implementations.

- Inert components cannot move from one phase to another. Such a facility would be appropriate for modeling ${ }^{14} \mathrm{C}$ release from the repository. 
- A steady-state option is not available. For large problems, running through a transient sequence to achieve a steady state represents a costly and needless expenditure of computer time. Since most transient characterization runs assume steady-state initial conditions, this is a significant consideration.

- The gas is assumed to be ideal thereby ensuring the additivity of partial pressures (Dalton's Law). In view of much larger uncertainties present at the site, this limitation represents a moot point at this time. Dalton's Law, which may be proved rigorously for an ideal gas, states that the total pressure of a mixture of gases equals the sum of the individual pressures each gas would exert if it alone occupied the entire container.

- Like most models developed by the YMP, PORFLOW does not account for capillary hysteresis. For many applications in a wetter climate, such an omission may not be justified. However, assuming relatively long drying periods between rainstorms, such an omission appears to be acceptable for Yucca Mountain simulations.

- Thermal equilibrium exists between pore fluids and rock. Current analyses, at LBL and LLNL, of a condensation front surrounding the repository support the validity of this assumption.

- PORFLOW makes the physically reasonable assumption that there is no conductive heat transfer through the gas phase.

- An infinitely dilute species is another standard assumption which should be adequate except, possibly, within the repository near field.

- The use of PORFLOW entails some legal restrictions which could possibly limit its usefulness in repository licensing. These restrictions require further investigation.

\section{Remarks/General Observations/Discussion}

One might visualize the ideal multiphase flow and transport model in the following manner. This ideal model would contain a flow and heat-transport module comparable to TOUGH2, a transport module like that of TRACR3D, and a graphical input module similar to that of MSTS. Since site conceptualization cannot rule out the possibility of fracture-matrix disequilibrium, the model should be able to treat this phenomenon in a reasonably accurate and efficient manner. The ideal model would be robust for all nonlinear Yucca Mountain applications. It would be at least two orders of magnitude faster than any of the above codes, and it would be able to perform a 10,000-year transient simulation having 100,000 grid cells within the fast memory of currently available computers.

A multiphase flow and transport model with these characteristics should be able to perform the most demanding analyses for site characterization, site suitability, and detailed design review, and, in conjunction with total-systems models, such a model should be able to show compliance with regulatory requirements. 
PORFLOW Version 2.4 does not measure up to these specifications, most particularly in the numerical-efficiency areas. However, our object is to identify the best starting point from which to achieve these specifications, and in toto PORFLOW may be as close to ideal as any other Yucca-Mountain model. In fact, none of the competing models measures up to the desired numerical-efficiency specifications. PORFLOW Version 2.4 has good flow and transport capabilities. In addition, its free-form input, though inferior to MSTS, is more user friendly than the input of either TOUGH2 or TRACR3D.

\section{Comparison to Other Models}

See Chapters 4, 5, and 6 of the main text.

\section{Summary and Recommendations}

- PORFLOW is a detailed process code which is useful for site characterization, site suitability, and detailed design review. For some applications, it will be limited by excessive computer time.

- In terms of the breadth of flow-process options which it offers, PORFLOW Version 2.4, though limited in comparison to TOUGH2's fully compositional capability, is adequate for maisy Yucca Mountain problems.

- In terms of the breadth of transport-process options which it offers, PORFLOW is inferior to TRACR3D. However, the additional TRACR3D options, which pertain to nonlinear sorption and chemical reaction, should not be necessary for Yucca Mountain simulations.

- PORFLOW offers a large menu of solvers, the greatest selection, by far, of any code in the YMP. This represents an important first step in addressing the critical problem of matrix solution time.

- PORFLOW does not offer a Newton-Raphson linearization algorithm. Though it represents a non-trivial exercise, adding such an algorithm is essential for highly nonlinear analyses of Yucca Mountain.

- PORFLOW cannot easily consider disequilibrium between fracture and matrix. A prohibitively time-consuming direct-gridding procedure is required. All detailed process codes developed to date by the YMP appear to be flawed in this regard. Although the efficiency of TOUGH's MINC facility is suspect, that facility is superior to the PORFLOW treatment of fracture-matrix disequilibrium.

- In consideration of all of the above, it is recommended that PORFLOW be included in the component-testing task. 


\section{References}

Aziz, K, and A. Settari, 1979. Petroleum Reservoir Simulation, Elsevier Applied Science Publishers, London and New York, 476 pp.

Birdsell, K.H., and B.J. Travis, 1991. TRACR3D: A Model of Flow and Transport in Porous Media, LA-11798-M, Los Alamos National Laboratory, Los Alamos, NM.

Bixler, N.E., 1985. NORIA - A Finite Element Computer Program for Analyzing Water, Vapor, and Energy Transport in Porous Media, SAND84-2057, Sandia National Laboratories, Albuquerque, NM.

Bruch, J.C., and R.L. Street, 1967. Two-Dimensional Dispersion, Journal of the Sanitary Engineering Division, Proceedings of the American Society of Civil Engineers, 17-39.

Coats, K.H. and B.D. Smith, 1964. Dead-End Pore Volume and Dispersion in Porous Media, Soc. Pet. Eng. J., 4, 73.

Codell, R.B. and J.O. Duguid, 1983. "Transport of Radionuclides in Groundwater," Chapter 4, Radiological Assessment, J. Till and H. Meyer, eds., U.S. Nuclear Regulatory Commission, Washington, DC.

Codell, R.B., T.K. Key, and G. Whelan, 1982. A Collection of Mathematical Models for Dispersion in Surface Water and Groundwater, NUREG-0868, Division of Engineering, Office of Nuclear Reactor Regulation, Washington, DC.

Domenico, P.A., 1980. Concepts and Models in Groundwater Hydrology, McGraw-Hill, New York.

El-Kadi, A.I., 1987. INFIL, International Groundwater Modeling Center, Holcomb Research Institute, $\mathbf{I N}$.

England, R.L., N.W. Kline, K.J. Ekblad, and R.G. Baca, 1985. MAGNUM-2D Computer Code: Users Guide, RHO-BW-CR-143, Rockwell International, Richland, WA.

Eyler, L.L. and M.J. Budden, 1984. Verification and Benchmarking of PORFLO: An Equivalent Porous Continuum Code for Repository Scale Analysis, PNL-5044, Pacific Northwest Laboratory, Richland, WA.

Huyakom, P.S., J.B. Kool, and J.B. Robertson, 1989. VAM2D - Variably Saturated Analysis Model in Two Dimensions, NUREG/CR-5352, HGL-8901, prepared by HydroGeologic, Inc. for the U.S. Nuclear Regulatory Commission, Washington, DC.

INTERA, Inc., 1983. SWENT: A Three-Dimensional Finite-Difference Code for the Simulation of Fluid, Energy, and Solute Radionuclide Transport, ONWI-457, Office of Nuclear Waste Isolation, Columbus, $\mathbf{O H}$. 
Kline, N.W., A.K. Runchal, and R.G. Baca, 1983. PORFLO Computer Code: User's Guide, RHO-BW-CR-138, Rockwell Hanford Operations, Richland, WA.

Magnuson, S.O., R.G. Baca, and A.J. Sondrup, 1990. Independent Verification and Benchmark Testing of the PORFLO-3 Computer Code, Version 1.0, EGG-BG-9175, Idaho National Engineering Laboratory, Idaho Falls, ID.

Nitao, J.J., 1989. V-TOUGH - An Enhanced Version of the TOUGH code for the Thermal and Hydrologic Simulation of Large-Scale Problems in Nuclear Waste Isolation, UCID21954, Lawrence Livermore National Laboratory, Livermore, CA.

Philip, J.R., 1957. Numerical Solution of Equations of the Diffusion Type with Diffusivity Concentration-Dependent II, Australian Journal of Physics, 10(2), 29-42.

Pruess, K., 1987. TOUGH User's Guide, NUREG/CR-4645, SAND86-07104, LBL-20700, Sandia National Laboratories, Albuquerque, NM.

Pruess, K., 1991. TOUGH2 - A General-Purpose Numerical Simulator for Multiphase Fluid and Heat Flow, LBL-29400, Lawrence Berkeley Laboratory, Berkeley, CA.

Reeves, M., D.S. Ward, and R.M. Cranwell, 1984. Theory and Implementation for SWIFT II: The Sandia Waste-Isolation Flow and Transport Model for Fractured Media, Release 4.84, SAND83-1159, Sandia National Laboratories, Albuquerque, NM.

Rood, A.S., R.C. Arnett, and J.T. Barraclough, 1989. Contaminant Transport in the Snake River Plain Aquifer: Phase I, Part 1: Simple Analytical Model of Individual Plumes, Informal Report, EGG-ER-8623, Idaho National Engineering Laboratory, Idaho Falls, ID.

Runchal, A.K., 1987. CONDIF: A Modified Central-Difference Scheme for Convective Flows, Int'l J. Num. Methods in Engg., 24, 1593-1608.

Runchal, A.K., and B. Sagar, 1989. PORFLO-3: A Mathematical Model for Fluid Flow, Heat, and Mass Transport in Variably Saturated Geologic Media Users Manual, Version 1.0, DE89-013977, Westinghouse Hanford Company, Richland, WA.

Runchal, A.K., and B. Sagar, 1991. PORFLOW: A Model for Fluid Flow, Heat, and Mass Transport in Multifluid, Multiphase Fractured or Porous Media, User's Manual - Version 2.34, ACRi/016/Rev. E, Analytical and Computational Research, Inc., West Los Angeles, CA.

Sagar, B., and A.K. Runchal, 1990. PORFLO-3: A Mathematical Model for Fluid Flow, Heat, and Mass Transport in Variably Saturated Geologic Media, Theory and Numerical Methods, Version 1.0, WHC-EP--0042, DE90-007935, Westinghouse Hanford Company, Richland, WA. 
Smoot, J.L., and B. Sagar, 1990. Three-Dimensional Contaminant Plume Dynamics in the Vadose Zone: Simulation of the 241-T-106 Single-Shell Tank Leak at Hanford, PNL-7221, Pacific Northwest Laboratory, Richland, WA.

Theis, C.V., 1935. The Relation Between the Lowering of the Piezoimetric Surface and the Rate and Duration of Discharge of a Well Using Groundwater Storage, Trans. Amer. Geophys. Union, 2, 519-524.

Travis, B.J., 1984. TRACR3D: A Model of Flow and Transport in Porous/Fractured Media, LA-9667-MS, Los Alamos National Laboratory, Los Alamos, NM.

Trent, D.S., L.L. Eyler, and M.J. Budden, 1983. TEMPEST - A Three-Dimensional TimeDependent Computer Program for Hydrothermal Analysis, Volume I: Numerical Methods and Input Instructions, PNL-4348, Pacific Northwest Laboratory, Richland, WA.

Updegraff, C.D., C.E. Lee, and D.P. Gallegos, 1991. DCM3D: A Dual-Continuum, Three Dimensional, Ground-Water Flow Code for Unsaturated, Fractured, Porous Media, NUREG/CR-5536, SAND90-7015, Sandia National Laboratories, Albuquerque, NM.

Ward, D.S., M. Reeves, and L.E. Duda, 1984. Verification and Field Comparison of the Sandia Waste-Isolation Flow and Transport Model (SWIFT), SAND83-1154, Sandia National Laboratories, Albuquerque, NM.

Yeh, G.T., and D.S. Ward, 1980. FEMWATER: A Finite-Element Model of WATER Flow Through Saturated-Unsaturated Porous Media, ORNL-5567, Oak Ridge National Laboratory, Oak Ridge, TN.

Zyvoloski, G., Z. Dash, and S. Kelkar, 1992. FEHMN 1.0: Finite Element Heat and Mass Transfer Code, LA-12062-MS, Los Alamos National Laboratory, Los Alamos, NM. 


\section{A.13 SAGUARO}

1. Name of the Model

SAGUARO

2. General Program Information

2.1 Program size. SAGUARO (Eaton et al., 1983) contains approximately 7,500 source statements.

2.2 Programming language. FORTRAN 77.

2.3 Computer system on which it operates. CDC 7600, CYBER 76, and Cray 1S.

2.4 Compiler(s) used. Standard compilers.

2.5 Location of code and availability. A copy of SAGUARO resides in a permanent-file library at Sandia National Laboratories (SNL).

2.6 Brief description of model/code history. SAGUARO is second in a sequence of similar codes developed at SNL. All treat non-isothermal flow regimes using a two-dimensional finite-element discretization method employing either eight-node quadrilaterals or six-node triangles. All consider an incompressible liquid. The codes differ in the number of phases and components which they treat. NORIA (Bixler, 1985) assumes two phases and two components. Taking gas-pressure gradients to be minimal, SAGUARO (Eaton et al., 1983) treats a single flow phase using a nonisothermal extension of the Richards' equation. Assuming further that no gas is present, MARIAH (Gartling and Hickox, 1982) considers non-isothermal saturated flow.

Recently, Sandia has developed a single-phase version of NORIA. Like SAGUARO, NORIA-SP treats a single flow phase using a nonisothermal extension of the Richards' equation. NORIA-SP algorithms, most notably its Newton-Raphson linearization technique, upgrade those used by SAGUARO.

3. Status of Model

3.1 Development (Is the model now undergoing significant development or modification? or continuing maintenance?). Sandia is phasing out SAGUARO in favor of NORIA-SP.

3.2 Documentation. Eaton et al. (1983) provide a readable discussion of governing equations and data input. Gartling and Hickox (1982) discuss numerical implementation, which is identical to that of MARIAH. 
3.3 Status of verification and validation. SAGUARO participated in both COVE-1 and HYDROCOIN Level-One benchmarking exercises. For COVE 1, the exercises focused on a two-dimensional isothermal water-drainage and contaminant-transport problem for variably saturated porous media (Hayden, 1985 and Eaton and Martinez, 1986). Six hydrologic-flow codes and radionuclide-transport codes participated, including SAGUARO, which was successfully coupled with the radionuclide transport code FEMTRAN (Martinez, 1985).

In COVE $1 \mathrm{~N}$, material properties and boundary conditions were consistent with those of Pickens et al. (1979), who assume a system consisting of a medium-grained sand. In COVE $1 \mathrm{YMa}$ and $1 \mathrm{YMb}$, material properties were representative of a nonwelded tuff, and boundary conditions were varied. All three problems used the same geometric configuration.

SAGUARO successfully completed the three COVE 1 problems and provided results which are qualitatively similar to those of other participants and to those of Pickens et al. (1979). For COVE 1N, COVE 1YMa, and COVE 1YMb, SAGUARO required 493, 226, and 760 seconds of CPU time, 247, 247, and 221 elements, and 81, 21, and 84 time steps, respectively. All runs utilized a Cray 15 computer. Hayden (1985), Table A-1, which compares the computer statistics for all participating codes, shows TRUST (Narasimhan and Witherspoon, 1976 and 1977 and Narasimhan, et al., 1978) to be the most efficient.

The HYDROCOIN Project (Cole, 1986) consisted of three levels of which Level One was concerned with verification through code intercomparison and comparison to analytical solutions. Of the seven cases comprising Level One, SAGUARO participated in Cases 2, 3 and 4. Although available documentation does not provide details on the performance of SAGUARO, a brief description of the cases is provided below:

CASE 2: This problem deals with saturated, two-dimensional, steady-state flow in a rock mass intersected by permeable fracture zones. This problem tests the codes's ability to handle high permeability contrasts for a complicated geometry. SAGUARO results were qualitatively and quantitatively consistent with those of the three other codes used on this problem.

CASE 3: This problem simulates variably saturated flow through a layered sequence of sedimentary rocks. It tests the cocie's ability to locate the position of the water table in layered sedimentary rocks with completely different hydraulic properties. SAGUARO, the only code used for this problem, provided an approximate solution for the steady-state position of the water table which compares reasonably with the solution determined by Grundfelt (1984).

CASE 4: This problem describes transient, buoyancy-driven flow in a saturated, permeable, homogeneous, isotropic medium resulting from a decaying heat source. This problem tests a code's ability to predict a vertical driving force that decreases travel time to the biosphere. Temperatures and pressures calculated by 

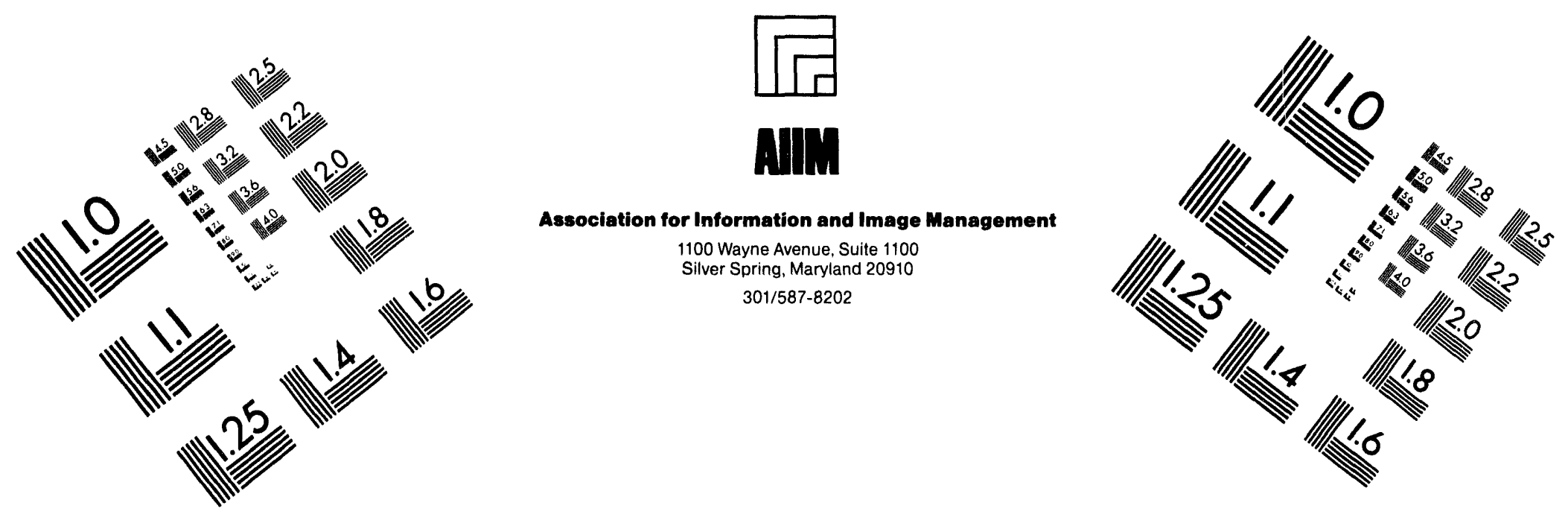

Centimeter

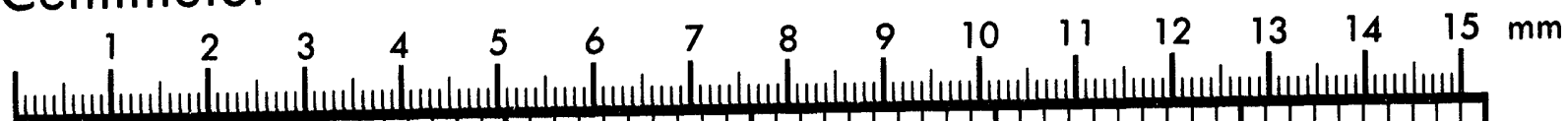

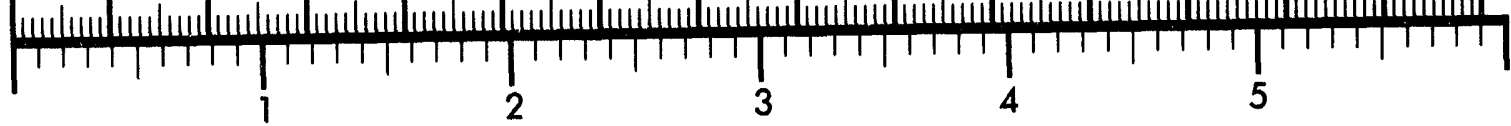
Inches
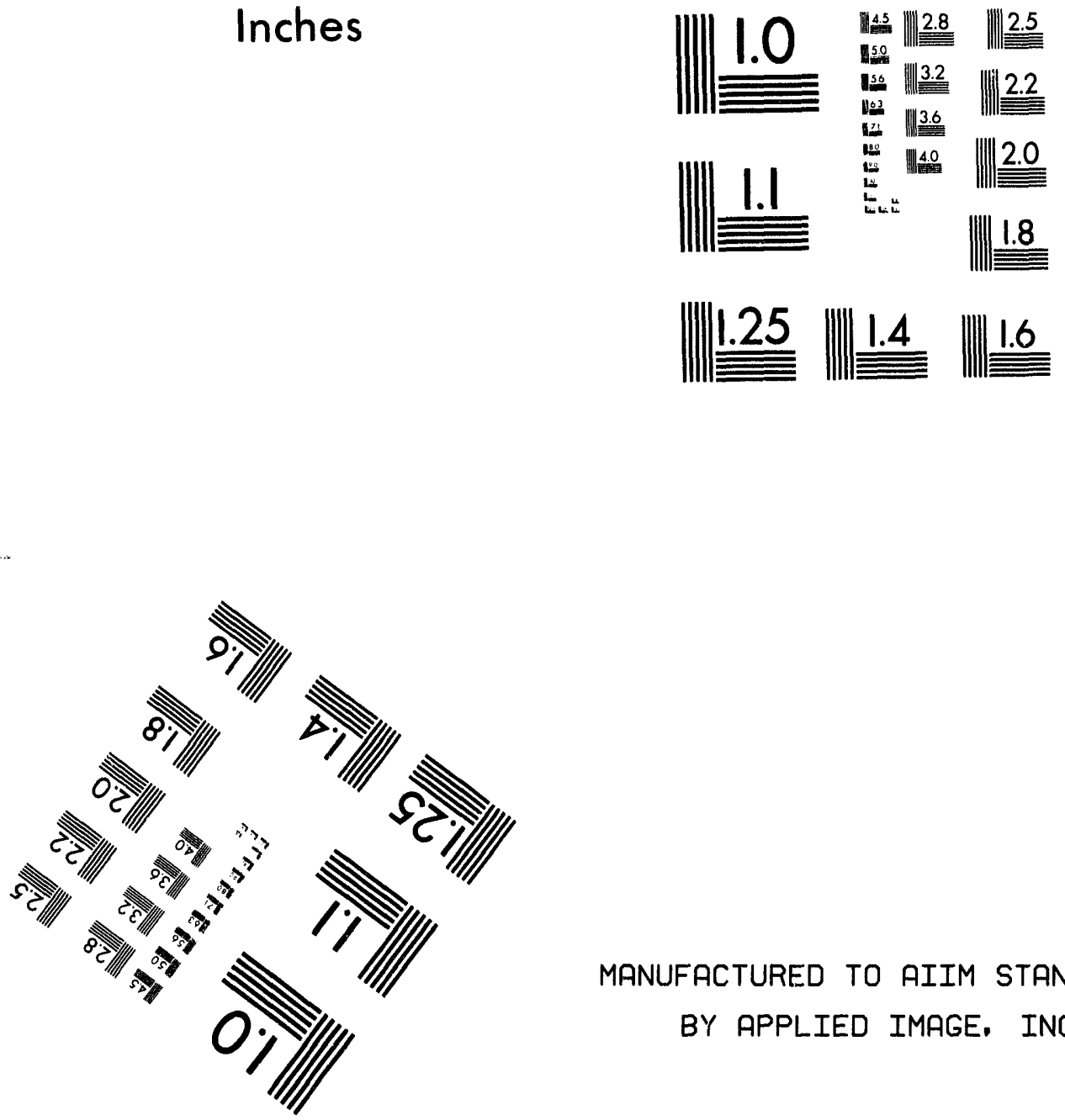

MANUFACTURED TO AIIM STANDARDS

BY APPLIED IMAGE, INC.

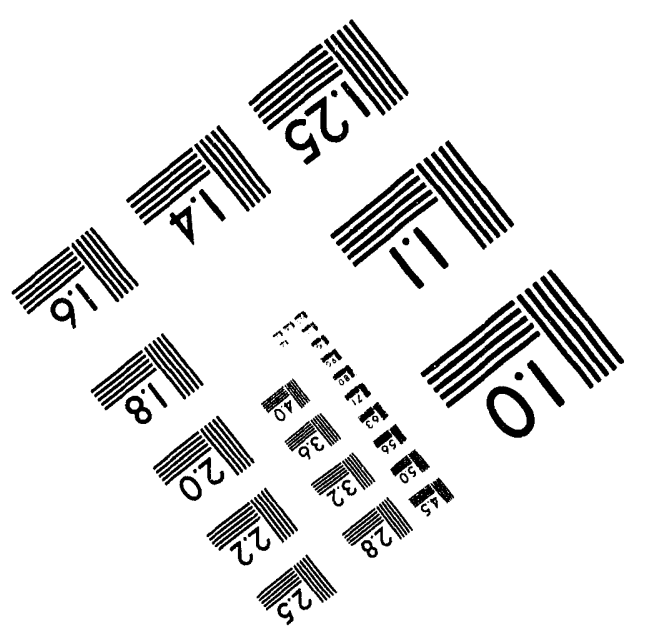



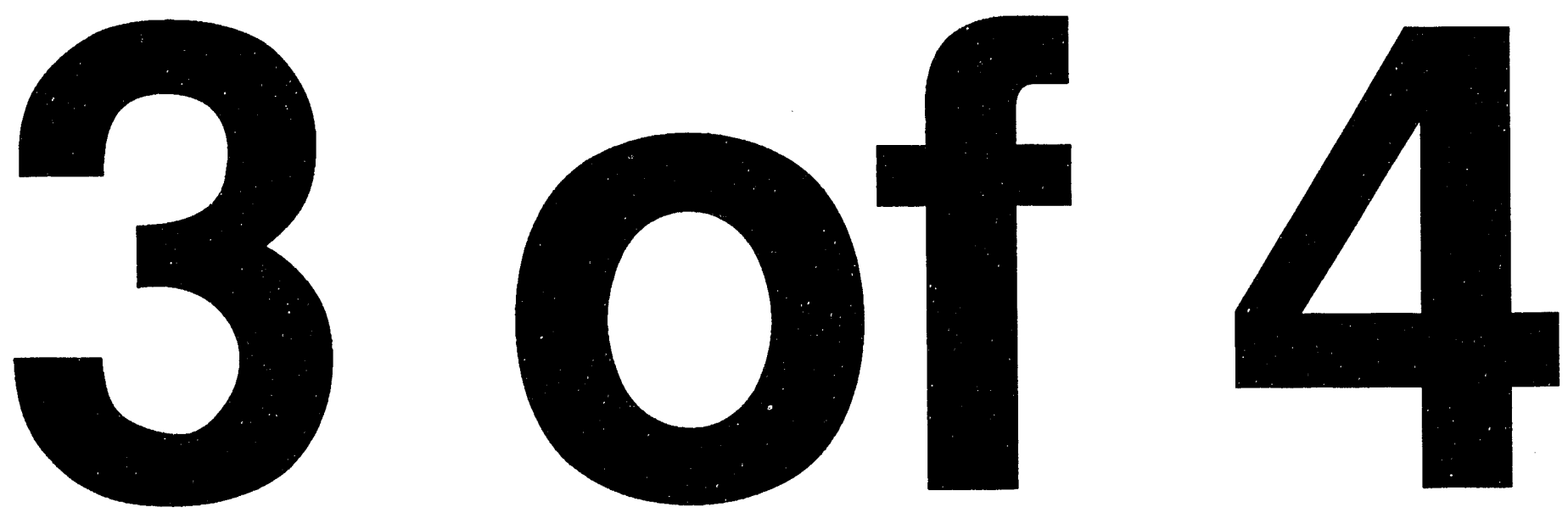
SAGUARO as a function of time and space are in excellent agreement with the analytical solution. However, for all codes, greater deviations from the analytical solution were observed in vector results such as fluxes, velocities, and streamlines. Such vector results require derivatives of the pressure field, thus leading to a lower order of accuracy and to greater deviations in the results derived from different numerical techniques.

\subsection{Status of Quality Assurance (QA). SAGUARO is not under QA control.}

\section{Type of Model (Phenomena/Processes Modeled)}

SAGUARO is a two-dimensional numerical model for simulating, in a fully coupled manner, the flow of partially or fully saturated water and the transport of heat in a porous medium. The code equates capillary and air pressures assuming that the latter is small relative to pressures within the liquid. The solution procedure utilizes finite-element discretization of the spatial domain and a finite-difference discretization of the time domain. Processes considered by SAGUARO include the following:

- Fluid flow due to pressure, viscous, and gravitational forces, consistent with Darcy's law

- Fluid flow via thermodiffusion consistent with the Soret effect, which assumes that fluid flow is proportional to the thermal gradient

- Heat transport due to conduction through both solid and liquid phases

- Heat transport due to convection and dispersion through the liquid phase

- Capillarity between the fluid and a passive gas phase.

\section{Governing Equations}

SAGUARO solves two governing equations in as many as two spatial dimensions. One characterizes fluid flow and the other, heat transport. Equations of motion define fluid and heat fluxes in terms of pressure, temperature, and density gradients. Considering the fluid to be Boussinesq means that the fluid is incompressible, and density becomes a function of temperature only. Density gradients, which characterize buoyancy, are thus proportional to thermal gradients. Constitutive relations characterize the capillarity and relative permeability of the fluid.

\section{Method of Solution}

To spatially discretize the conservation and flux equations, SAGUARO uses the Galerkin finite-element method. The Galerkin approach requires that weighting and basis functions be identical. SAGUARO uses quadratic basis functions to span either eight-node quadrilaterals or six-node triangles. The Galerkin approach permits mapping and basis functions to differ. Accordingly, SAGUARO uses both isoparametric and subparametric 
functions for transformation from global to local coordinates. The former use quadratic mapping functions, and the latter use linear mapping functions, resulting in local elements with either curved or straight sides.

To temporally discretize these equations, SAGUARO uses the central-difference (CrankNicholson) algorithm. With the resulting set of coupled equations linearized by an iterative (Picard) updating procedure, SAGUARO performs a fontal solution (Irons, 1970), a form of Gaussian elimination. For strongly coupled problems, the heat-transport equation is solved first. Then, with nonlinear coefficients updated as each new solution becomes available, the equations for fluid conservation and fluid flux are solved sequentially. This procedure then repeats in an iterative fashion until convergence is obtained for each time step. For isothermal and weakly coupled problems, the procedure is streamlined.

\section{Type of Input Parameters}

The input data deck for SAGUARO contains nine cards out of which the SETUP, FORMKF, and the UNZIPP command cards require data input. The SETUP command card consists of three associated data cards which require the following data:

Material Data Card:

- Material name and number

- Fluid density

- Fluid dynamic viscosity

- Fluid specific heat

- Fluid thermal conductivity

- Fluid volumetric expansion coefficient

- Gravitational acceleration

- Temperature dependence of fluid properties

- Reference temperature for the buoyancy force

- Material density

- Material specific heat

- Components of the material thernal conductivity tensor

- Angle between the principle material axes (for conductivity) and the coordinate axes 
- Components of the material permeability tensor for the saturated state of the material

- Angle between principle material axes for permeability and the coordinate axes

- Indicate whether dispersion is included in the analysis

- Temperature dependence of material properties

- Volumetric heat source

- Initial temperature and effective pressure for the material

- Thermal mass diffusion coefficient

- Angle between the principle material axis for thermal mass diffusion and the coordinate axis

- Coefficient of the time derivative term in the mass transport equation

- Saturation

- Thermal conductivity of air or any gas in the porous medium.

Grid Data Card:

- I,J limits for the region being generated, difference between maximum and minimum determine the number of grid points generated in a particular direction

- Specify the gradients for the node spacing along the four sides of the region

- Specify whether polar coordinates are used

- Define the coordinates of the four comer and optional side nodes for each part

- Information for locating a specific node or line of nodes.

Element and Boundary Condition Data Cards:

- Element type

- Matrix material number for the element

- List of $I, J$ values for the node points in the element boundary condition type

- I,J identification of the element to which the boundary condition applies 
- Identify the side or node of the element to which the boundary condition is to be applied

- Numerical value of the applied boundary condition

- Number of the time history curve for time dependent boundary conditions

- Number of the boundary condition data card SET in the case of a convective or radiative boundary condition.

SET data card:

- Boundary condition type

- Number of particular data set

- Parameters required for specifying a convective or radiative boundary condition.

\section{FORMKF Command Card:}

- Indicate type of coordinate system desired

- Indicate type of flow problem being considered

- Indicate type of velocity computation, either continuous or discontinuous.

\section{UNZIPP Command Card:}

- Specify how often the solution field is printed

- Initial and final times

- Size of time step

- Number of time steps to be taken in the transient analysis

- Specify source of initial conditions.

\section{Type of Output and User Options}

At the end of each output interval, SAGUARO automatically prints full tables of a standard set of dependent variables, unless special output options are selected. The standard set consists of hydraulic heads, temperatures, velocities, and moisture contents. The user may limit the amount of printout by specifying the elements at which printout is desired. Values of the dependent variables may also be printed at spatial locations within the mesh other than the nodal points. The user may also specify the amount of output produced during the setup operation.

Included as part of the optional output are seven basic types of plots. These plots include a grid-point plot, a plot of the element mesh, contour plots of the stream function, pressure or temperature, an outline plot of the problem domain with material boundaries indicated, time-history plots of any of the dependent variables (as well as heat fluxes), and profile plots of dependent variable versus position with time as a parameter. 
9. Model Interactions (emphasize needed processors)

9.1 Does the model interface with any other models? Yes, see below.

9.2 Source code and type of information needed. Not applicable.

9.3 Receiving code and type of information provided. Flow-field output from SAGUARO may be used with radionuclide transport codes such as FEMTRAN (Martinez, 1985). The COVE-1 exercises demonstrate the coupling procedure. Here SAGUARO transferred velocity and moisture-content fields to FEMTRAN as functions of time. Since both codes used the same grid, no interpolation was required, and routine DECODE (Martinez and Bixler, 1984) simply reformatted the SAGUARO output to effect the transfer.

9.4 Any pre- or postprocessing needed? Because SAGUARO is a self-contained program with its own mesh-generator, data-analysis, and plotting packages, extensive pre- or postprocessing is not required. The plotting package provides graphic output of element meshes, nodal-point location, and contour plots of temperature, hydraulic head, and stream functions. The plotting package also provides profile plots and time histories of any dependent variable. Depending on problem setup, SAGUARO may require as many as 16 different user-supplied subroutines. Conditions requiring the use of subroutines include variable material properties, time- or temperature-dependent heat sources, dispersion, a general radiation-convection boundary, and time-dependent boundary conditions.

10. Model Application

10.1 Usage within the Civilian Radioactive Waste Management System (CRWMS) program. SAGUARO was developed for nonisothermal modeling of water flow in both nearand far-field applications. SNL has used SAGUARO to perform phenomenological studies of water-flow mechanisms at Yucca Mountain and to identify preferential water-flow pathways for sensitivity studies.

10.2 Usage outside the program. To date, SAGUARO has not been used outside the program.

\section{Codes With Similar or Same Capabilities}

11.1 Within the program. The Yucca Mountain Site Characterization Project (YMP) has funded the development of several flow and transport codes with capabilities superseding those of SAGUARO. These codes include TOUGH2 (Pruess, 1991) at LBL (Lawrence Berkeley Laboratory); V-TOUGH (Nitao, 1989) at LLNL (Lawrence Livermore National Laboratory); TRACR3D (Birdsell and Travis, 1991) and FEHM (Zyvoloski et al., 1992) at LANL (Los Alamos National Laboratory), MSTS and PORFLO-3 (Runchal and Sagar, 1989) at PNL (Pacific Northwest Laboratory), and NORIA (Bixler, 1985) at SNL. 
In contrast to SAGUARO, all the above-mentioned codes simulate multiphase flow, and, with exception to NORIA, they can consider three-dimensional problems. Many (e.g., TOUGH2, V-TOUGH, FEHM, MSTS, and NORIA) can simulate heat transport as well, permitting them to characterize heat-related processes which lie outside the scope of SAGUARO. Processes like vaporization, vapor movement, and condensation control the amount of liquid moisture within the repository as well as the movement of radioactive ${ }^{14} \mathrm{C}$. They also influence the direction of ground-water flow around the repository.

SAGUARO does have one capability (thermodiffusion), which is matched only by NORIA. However, as pointed out in the documentation (Eaton et al., 1983, p. 4), typically flow resulting from temperature gradients is much smaller than flow resulting from pressure gradients. It would appear then that, for Yucca Mountain, a thermodiffusion capability is unnecessary.

11.2 Outside the program. The U.S. Nuclear Regulatory Commission (NRC) has funded the documentation of TOUGH (Pruess, 1987) and DCM3D (Updegraff et al., 1991). The M\&O team is reviewing both of these codes. A number of codes have also been developed within the petroleum industry. In terms of the number of processes considered, compositional models (Peaceman, 1977) have a capability for flow simulations which is superior to all the Yucca Mountain codes except TOUGH2. Developed for use in the area of reservoir engineering, these codes are proprietary, and that constitutes a major impediment to their use in licensing. Examples of compositional models include THERM (SSI-Intercomp, Inc.), and TETRAD (DYAD 88 Software, Inc.). These codes consider a nonisothermal system with multiple phases and components.

\section{Major Assumptions and Limitations}

- Only a single-phase, single-component liquid is explicitly included in the model. Gas is included passively by accounting for its volume and capillarity with respect to the liquid.

- Water-vapor effects are neglected. These effects, which will be important near the repository, include vaporization, condensation, and vapor flow.

- Only two spatial dimensions are considered. This will be sufficient for many applicatiolis. However, some applications will undoubtedly require three dimensions.

- A dual-continuum option is not available. Without substantial modification, fracturematrix disequilibrium cannot be accounted for in field-scale simulations.

- An iterative-solution option is not available. This limits rather severely the size of the problem the code can consider.

- A steady-state option is not available. For large problems, running through a transient sequence to achieve steady state represents a costly and needless expendirure of 
computer time. Since most transient characterization runs assume steady-state initial conditions, this is a significant consideration.

- For nonisothermal flow, fluid and rock matrix are assumed to be in local equilibrium.

- The liquid phase behaves as a Boussinesq fluid. Thus, density is assumed to be independent of pressure and to vary linearly as a function of temperature. Since the compressibility of water is small compared to that of gas, such an approximation is adequate for partially saturated flow, providing that dissolved components are present only in dilute concentrations.

- The rock matrix is incompressible. Since the compressibility of rock is small compared to that of gas, such an approximation is adequate for partially saturated flow.

- The fluid is assumed to follow Newton's law of viscosity. Inertial effects are neglected and Darcy's law is assumed. These are standard assumptions which are generally valid. Although, it is remotely possibly that non-Newtonian flow may arise during some storm events, such effects may be safely ignored at the present time.

\section{Remarks/General Observations/Discussion}

Sandia has replaced SAGUARO with NORIA-SP. NORIA-SP offers the same processes as SAGUARO, but with improved numerical algorithms. Multi-phase, heat-transport codes such as TOUGH2, V-TOUGH, MSTS, and FEHM offer both additional processes and improved algorithms. Apparently, SAGUARO has been superseded. Among the codes mentioned above, SAGUARO is the only one which relies on the Picard linearization technique. For transient problems, the successive-updating (Picard) technique can be ineffective, and, for highly transient storm events, it can be nonconvergent. Thus, a NewtonRaphson option is required.

SAGUARO shares one deficiency with TOUGH2, V-TOUGH, and MSTS in that it offers only a direct linear-equation solver. Such a solver severely restricts the number of grid blocks or elements that these codes can consider. Because of its use of finite elements, SAGUARO is restricted to a banded solver, a relatively slow implementation. LANL employs a conjugate gradient iterative approach with their codes FEHM and TRACR3D, thereby expanding problem-size capability to tens of thousands of grid blocks.

\section{Comparison to Other Models}

See Chapters 4, 5, and 6 of the main text.

\section{Summary and Recommendations}

- SAGUARO is a detailed process code. Codes of this type are used for site characterization, site suitability, and detailed design review. 
- For a field-scale problem, SAGUARO must assume equilibrium between fracture and matrix. The only other option is direct gridding of fractures, but computer efficiency would then be too poor to permit field-scale simulations.

- SAGUARO is too detailed and its algorithms too inefficient for probabilistic analysis of the total system.

- SAGUARO does not have a three-dimensional capability.

- SAGUARO, when compared to TOUGH2, for example, has significant disadvantages and no apparent advantages.

- SANDIA is replacing SAGUARO with NORIA-SP.

- For the above reasons, it is recommended that SAGUARO not be considered further.

\section{References}

Birdsell, K.H., and B.J. Travis, 1991. TRACR3D: A Model of Flow and Transport in Porous Media, LA-11798-M, Los Alamos National Laboratory, Los Alamos, NM.

Bixler, N.E., 1985. NORIA - A Finite Element Computer Program for Analyzing Water, Vapor, Air, and Energy Transport in Porous Media, Sandia National Laboratories, SAND84-2057.

Cole, C.R., 1986. Evaluation and Status Report on HYDROCOIN at Midway (HYDROCOIN..An International Project for Studying Groundwater Hydrology Modelling Strategies), Pacific Northwest Laboratory, PNL-6087.

Eaton, R.R., D.K. Gartling, and D.E. Larson, 1983. SAGUARO - A Finite Element Computer Program for Partially Saturated Porous Flow Problems, Sandia National Laboratories, SAND82-2772.

Eaton, R.R. and M.J. Martinez, 1986. Cove Benchmark Calculations Using SAGUARO and FEMTRAN, Sandia National Laboratories, SAND85-0051.

Gartling, D.K., and C.E. Hickox, 1982. MARIAH - A Finite Element Computer Program for Incompressible Porous Flow Problems: Theoretical Background, Sandia National Laboratories, SAND79-1622.

Grundfelt, B., 1984. Proposal for a Test Problem for HYDROCOIN Level 1, Case 3, 0142 840515, KEMAKTA Consultants Co, Stockholm, Sweden.

Hayden, N.K., 1985. Benchmarking NNWSI Flow and Transpc . Codes: Cove 1 Results, Sandia National Laboratories, SAND84-0996. 
Martinez, M.J., 1985. FEMTRAN - A Finite Element Computer Program for Simulating Radionuclide Transport Through Porous Media, Sandia National Laboratories, SAND840747.

Martinez, M.J. and N.E. Bixler, 1984. Memo to Distribution, "DECODE--A Direct Data Transfer Routine for Using SAGUARO Mesh and Solution Data in FEMTRAN."

Narasimhan, T.N., and P.A. Witherspoon, 1976. "An Integrated Finite Difference Method for Analyzing Fluid Flow in Porous Media", Water Resour. Res., Vol. 12, No. 1, pp. 57-64, 1976.

Narasimhan, T.N., and P.A. Witherspoon, 1977. "Numerical Model for SaturatedUnsaturated Flow in Deformable Porous Media 1, Theory", Water Resour. Res., Vol. 13, No. 3, pp. 657-664, 1977.

Narasimhan, T.N., et al., 1978. "Numerical Model for Saturated-Unsaturated Flow in Deformable Porous Media 2, the Algorithm", Water Resour. Res., Vol. 13, No. 3, pp. 657-664, 1977.

Nitao, J.J., 1989. V-TOUGH - An Enhanced Version of the TOUGH code for the Thermal and Hydrologic Simulation of Large-Scale Problems in Nuclear Waste Isolation, UCD-21954, Lawrence Livermore National Laboratory, Livermore, CA.

Peaceman, D.W., 1977. Fundamentals of Numerical Reservoir Simulation, Elsevier Scientific Publishing Company, New York.

Pickens, J.F., R.W. Gillham, and D.R. Cameron, 1979. "Finite Element Analysis of the Transport of Water and Solutes in Tile-Drained Soils", J. Hydrology., 40, pp. 243-264.

Pruess, K., 1987. TOUGH User's Guide, NUREG/CR-4645, SAND86-07104, LBL-20700, Sandia National Laboratories, Albuquerque, NM.

Pruess, K., 1991. TOUGH2 - A General-Purpose Numerical Simulator for Multiphase Fluid and Heat Flow, LBL-29400, Lawrence Berkeley Laboratory, Berkeley, CA.

Travis, B.J., 1984. A Model of Flow and Transport in Porous/Fractured Media, LA-9667-MS, Los Alamos National Laboratory, Los Alamos, NM.

Travis, B.J., 1991. TRACR3D: A Model of Flow and Transport in Porous Media, Model Description and User's Manual, LA--11798-M, Los Alamos National Laboratory, Los Alamos, NM.

Updegraff, C.D., C.E. Lee, and D.P. Gallegos, 1991. DCM3D: A Dual-Continuum, Three Dimensional, Ground-Water Flow Code for Unsaturated, Fractured, Porous Media, NUREG/CR-5536, SAND90-7015, Sandia National Laboratories, Albuquerque, NM. 
Zyvoloski, G., Z. Dash, and S. Kelkar, 1992. FEHMN 1.0: Finite Element Heat and Mass Transfer Code, LA--12062-MS, Los Alamos National Laboratory, Los Alamos, NM. 


\section{A.14 TGIF}

1. Name of the Model

TGIF (Thermal Gradient Induced Flow)

2. General Program Information

2.1 Program size. TGIF (Ross et al., 1991) contains approximately 4,000 source statements.

\subsection{Programming language. FORTRAN 77}

2.3 Computer systems on which it operates. PC-286, PC-386, and PC-486

2.4 Compiler(s) used. RM Fortran and Lahey compilers

2.5 Location of code and availability. When fully documented, TGIF will be released to the public. At that time, one may obtain the code from Benjamin Ross, Disposal Safety Inc., 1660 L Street NW, Suite 314, Washington DC 20036

2.6 Brief description of model/code history. With DOE/Yucca Mountain funding from SNL (Sandia National Laboratories), Disposal Safety initiated development in 1987. A spread-sheet program was used at first. Then in 1988, TGIF was converted to fortran, code capabilities were generalized, and a conduction-only heat-transport module was added. Since then, a particle tracker has been added, and several application studies have been performed (Section 3.2), some supported by EPRI.

The conservation equation used by TGIF may be considered as an analog to the Richards equation. Starting from a general two-phase formulation and making simplifying assumptions about movement of the gas phase, one can derive a singlephase equation (Richards equation), which considers only the flow of liquid. Analogously, by making simplifying assumptions about movement of the liquid phase, one can also derive a single-phase equation (the TGIF governing equation), which considers only the gas phase. Ironically, the two-phase equations are highly nonlinear while the single-phase gas equation is only weakly nonlinear, thereby facilitating very efficient solution techniques for the latter.

So that it may consider the important questions of ${ }^{14} \mathrm{C}$ transport and buoyancy-driven latent-heat transport, TGIF models heat transport as well as gas flow.

\section{Status of Model}

3.1 Development (Is the model now undergoing significant development or modification? or continuing maintenance?). Significant development continues. Starting from a conduction-only formulation, the heat-transport model is being generalized to include 
a convection term characterizing the movement of latent heat from the repository (Ross, private communication). Previously, a sequential solution of gas flow and heat transport was sufficient. The latest change necessitates a fully coupled solution, which is now (January 1992) being debugged. To include a heat pipe in TGIF's capabilities, several different algorithms are currently under consideration.

3.2 Documentation. Ross et al. (1991) discuss both theory and applications and provide an initial version of a users manual. Sections on numerical implementation and data input have not yet been included. Lu et al. (1991) examines the effect on gas flow of a Paintbrush nonwelded unit, which has a relatively small air permeability. Sensitivities to the air permeability of this unit and to the repository temperature are considered. Ross (Shaw et al., 1991) conceptualizes the heat transfer processes and considers the effect which uncertainties in these processes could have on repository temperature. Ross (Shaw et al., 1991) also presents the results of his ${ }^{14} \mathrm{CO}_{2}$ traveltime calculations, which include the effect of isotopic exchange with aqueous-phase carbon. Finally, Amter et al. (1991) considers the effects of two atmospheric conditions (thermal lapse rate and humidity) upon gas flows in Yucca Mountain.

3.3 Status of verification and validation. Although informal tests have been perforned, no formal verification and validation have been performed. To rectify this situacion, a benchmark problem has been identified by Pruess and Ross, which will te run on both TOUGH2 (Pruess, 1991) and TGIF (Ross et al., 1991).

\subsection{Status of Quality Assurance (QA). TGIF is not under QA control.}

\section{Type of Model (Phenomena/Processes Modeled)}

TGIF simulates steady, two-dimensional, thermally-driven gas flows within Yucca Mountain. Various atmospheric effects can be accounted for in the boundary conditions, including the humidity and thermal lapse rate. Various underground effects can be accounted for in the flow and transport equations. These include the natural geothermal gradient, topography, a heated repository, buoyancy, ${ }^{14} \mathrm{C}$ transport, and inhomogeneities such as a nonwelded unit with a low gas permeability.

\section{Governing Equations}

In the TGIF conceptualization, several forces drive the movement of gas. Humidity levels of approximately 100 percent yield a rock gas which is generally lighter than atmospheric gas, causing buoyant uplift. Elevated repository temperatures enhance the effect. In addition, topographic relief results in a variation in surface temperatures. When coupled with a constant near-surface water-vapor level, this temperature variation yields a non-static surface pressure boundary. Modeled as internal boundary conditions, flow divides and the water table localize the effects these driving forces.

To characterize the interior of the system, TGIF employs three equations. The ideal gas law, expressed in terms of the dry-air component of the gas, is the constitutive relation. Darcy's Law, expressed in terms of the total pressure $P$ of dry air and water vapor, provides the 
equation of motion. A so-called volume balance for the dry air gives the conservation equation. In its formulation of a volume balance, the term "volume" refers to the volume of hypothetical packets, each containing a fixed number of moles of dry gas. Given that the term "mole" is a mass concept, it would appear that the conservation law could have been justifiably called a "mass balance". Though they are assumed to be temporal constants, both total pressure and temperature vary spatially. To maintain an assumed 100-percent humidity level as it flows through the system, the gas changes its composition by either evaporating liquid water or condensing water vapor. A source-sink term, formulated in terms of the relative volume change in the dry-air component, characterizes the effects of evaporation and condensation.

In contrast to its treatment of gas flcw, the current TGIF heat-transport model is simplistic. Ignoring the heat-pipe effect and the buoyant convection of latent heat, TGIF assumes that heat transport is dominated by conduction through the rock. As pointed out by Amter et al. (1991), this treatment of the heat-transport process is unlikely to be realistic, especially when the mountain is heated by a repository. It is being upgraded at the present time.

\section{Method of Solution}

Prior to the most current code modification, TGIF solved the gas-flow and heat-transport equations sequentially. In both cases, a lattice-centered, finite-difference discretization is employed. To obtain temperatures and freshwater heads, the code employs the iterative Gauss-Seidel algorithm with point successive-overrelaxation. After the current code modification is completed, TGIF will perform a fully coupled analysis of gas-flow and heattransport, which will include the convective transport of latent heat.

\section{Type of Input Parameters}

Although a specification of data input is unavailable at the present time, it is apparent that TGIF requires geometrical information describing both the shape of the system boundary and the gridding; hydrogeologic information such as thermal conductivity, heat capacity, porosity, liquid saturations, and gas permeabilities for both welded and nonwelded tuff units; and matrix solution information like the relaxation parameter, a convergence tolerance, and the maximum permitted number of iterations.

\section{Type of Output and User Options}

Although a specification of data output is also unavailable, it is apparent that TGIF output will contain temperature, gas-pressure, and gas-velocity fields, as well as particle travel paths and travel times.

\section{Model Interactions (emphasize needed processors)}

9.1 Does the model interface with any other models? TGIF represents a package of interfacing models. It includes gas-flow and heat-transport models. It also includes a particle tracker to determine gas and ${ }^{14} \mathrm{C}$ travel times along selected flow paths. 
9.2 Source code and type of information needed. Not applicable.

9.3 Receiving code and type of information provided. Not applicable.

9.4 Any pre- or postprocessing needed? The commercially available plotting package SURFER plots travel paths upon the stratigraphy of the system. 


\section{Model Application}

10.1 Usage within the Civilian Radioactive Waste Management System (CRWMS) program. Rock gas convects ${ }^{14} \mathrm{C}$ from the repository to the surface. With its buoyancy enhanced by repository heat, rock gas convects latent heat from the repository. This effect and the heat-pipe effect may dominate the heat-transport processes, yielding significantly cooler repository temperatures than those currently predicted by conduction alone. TGIF is the only model presently available in the Yucca Mountain Site Characterization Project (YMP) which can efficiently predict the transport of both buoyancy-driven latent-heat and ${ }^{14} \mathrm{C}$ radioactive gas.

Theoretically, TOUGH2 (Pruess, 1991) can characterize the convection of latent heat by both buoyant- and heat-pipe-driven processes. Practically, the mountain-scale gridding required for an accurate characterization of the buoyant transfers makes such a TOUGH2 calculation impossible at the present time. It is unclear whether one should modify TOUGH2 to include the TGIF simplifications as an option or, alternatively, whether one should modify TGIF to include a TOUGH2-like capability to calculate heat-pipe transfers. Ross (private communication) is pursuing the latter. However, it is clear that the YMP now has only a very primitive ability to predict repository temperatures and that a significant upgrade is called for.

10.2 Usage outside the program. Currently, there are no users of TGIF outside the office of Disposal Safety, and only the DOE and EPRI Yucca Mountain programs sponsor work using this code. Ross (private communication) points out, however, that acidmine drainage is controlled by oxygen transport into piles of mine waste, and he is pursuing funding for such applications.

\section{Codes With Similar or Same Capabilities}

11.1 Within the program. The YMP has funded the development of several multiphase flow codes. Theoretically, the multiphase codes are more capable than TGIF. Such codes include TOUGH2 (Pruess, 1991) at LBL (Lawrence Berkeley Laboratory), TRACR3D (Birdsell and Travis, 1991) and FEHM (Zyvoloski et al., 1992) at LANL (Los Alamos National Laboratory), MSTS at PNL (Pacific Northwest Laboratory), PORFLOW (Runchal and Sagar, 1991), and NORIA (Bixler, 1985) at SNL. Each code, like TGIF, has the capability to calculate buoyancy-driven flow. With exception to TRACR3D, which does not consider heat transport, the effect of repository heat on buoyancy can be assessed. Unlike TGIF, the multiphase codes, again with exception to TRACR3D, can include the heat-pipe process for convecting latent heat from the repository. However, the multiphase codes are limited by computational efficiency, leaving a gap in the computational capability of the project.

TGIF partially fills this gap (see Section 13). By focusing on rock-gas flow at 100percent humidity and at below-boiling temperatures, TGIF reduces a two-phase, highly nonlinear flow problem to an equivalent single-phase, weakly nonlinear problem. An understanding of relative time scales simplifies the problem to a pseudo-steady analysis. Transformation of the dependent variable to freshwater head further 
facilitates solution by removing a potentially troublesome subtraction error from the analysis.

11.2 Outside the program. After examining the literature, the developers of TGIF have found no competing codes outside the program (Ross, private communication). This review, however, has identified one researcher (R.W. Nelson), a current INTERA employee, who, in unpublished work on air curtains, has developed and applied such a code.

\section{Major Assumptions and Limitations}

- Barometric pressure changes are ignored. This is justified since the time scale for such changes (days to months) is much smaller than the time scale of interest in TGIF simulations (years to $10 \mathrm{~s}$ of years).

- The effect of wind on surface boundary pressures is ignored. Further research is needed to devise a way to model this effect.

- Thermodynamic equilibrium exists among air, water vapor, and water. This assumption is justified by the intimate contact between air and water in small pores in the subsurface of Yucca Mountain.

- Heat-convection processes may be ignored. Code upgrades are under way to eliminate this questionable assumption.

- Gas flow is a steady process. The data of Montazer et al. (1985) show that pressure throughout the mountain equilibrates on a time scale of weeks to months, which is much smaller than the time scale of interest. To accommodate transient thermal processes, current modifications will permit TGIF to consider a sequence of steady gas-pressure fields.

- Prior to the modifications currently in progress, heat transport was modeled as a steady process. When completed, they will allow repository temperatures to vary.

- Rock gas is saturated with water vapor (Tsang and Pruess, 1987).

- Rock gas behaves as an ideal gas. This approximation should cause very little inaccuracy.

- Molecular diffusion resulting from gradients in the partial pressure of the water vapor has a negligible effect on gas flow. Appendix A of Ross et al. (1991) argues that the diffusion-driven flow of gas is negligible compared with the temperature-driven flows included in the model.

- Liquid saturation levels within the unsaturated zone do not change as a function of time. Results of both field experiments and numerical simulations (Doughty and Pruess, 1990) indicate that this remains true at Yucca Mountain until temperatures 
approach the boiling point of water. This assumption appears questionable, particularly for the high-permeability Paintbrush nonwelded tuff during time periods immediately following a storm event.

- Unsaturated fractured tuff may be treated as an equivalent continuum. Appendix B of Ross et al. (1991) shows that gas diffusion into the rock matrix proceeds rapidly in comparison to flow in the fractures.

\section{Remarks/General Observations/Discussion}

It is interesting to speculate about the joint effects of convection and heat pipe on repository temperatures. Buscheck's calculations, as presented in the October 1991 meeting of the NWTRB, indicate that the repository heat pipe will lead to a net loss of water to the atmosphere. Presumably, mountain-scale convection cells would lead to a greater loss of water.

During dry periods, the water loss must be resupplied by slow downward infiltration from previous storm events and by capillary-driven upward movement from the water table. Ultimately, then, the effectiveness of both heat pipe and convection cells in cooling the repository depends upon an adequate flow of liquid water to the repository through the lowpermeability rock matrix of the welded tuff. The time scale of such flow is quite large, thousands of years, perhaps much longer. What then will be the net effect of the heat pipe and the buoyancy-driven convection cells? By depleting the water supply necessary. for latent-heat transfer, will they, in fact, cause a gradual increase in repository temperatures? Or, will decay of the heat source compensate for this depletion?

Lu et al. (1991) identify a sensitive relation between gas flow and fracture permeability of the Paintbrush nonwelded tuff. Their result suggests that rainstorm events may cause a surge in repository temperatures. Because of its large matrix permeability, the nonwelded unit preferentially imbibes water delivered to it via fractured media above. This is advantageous to repository performance since it tends to shield the repository from storm inflow. At the same time, however, high liquid saturations within the nonwelded unit may substantially reduce its fracture permeability for gas, thus weakening buoyancy-driven convection cells. Repository temperatures would rise, driving the repository heat pipe toward higher efficiency. But, matrix permeabilities within the nonwelded tuff control both the return liquid flow and the response time of the heat pipe. Thus, repository temperatures may surge immediately following a storm event due to inability of the heat pipe to "keep up" with rising temperatures.

The importance of repository temperatures to licensing is unclear. The geochemical consequences of elevated repository temperatures are also unclear. In any event, the M\&O and/or its associated contractors will undoubtedly be required to assess the thermal effects, together with their uncertainties. At present, however, we do not have the necessary modeling capabilities for such a task. A substantial improvement in the numerical capabilities of a detailed process code like TOUGH2 (Pruess, 1991) is required, together with some merging of TOUGH2 and TGIF capabilities. 


\section{Comparison to Other Models}

TGIF is the only single-phase gas-flow model in the YMP.

\section{Summary and Recommendations}

- TGIF simulates gas flow through Yucca Mountain. It also simulates the convective transport of ${ }^{14} \mathrm{C}$ radioactive gas and latent heat from the repository.

- In theory, multiphase flow and transport codes can also simulate gas flow and the convective transport of ${ }^{14} \mathrm{C}$ radioactive gas and latent heat from the repository. In practice, an excessive demand for computer resources on mountain-scale simulations makes this impossible.

- Most likely, TGIF can function in a statistical mode.

- Plans for a heat-pipe capability are now being developed which would make the only Yucca Mountain code capable of reliably predicting repository temperatures.

- As a relatively new code undergoing active development, TGIF is not sufficiently well documented to facilitate use of the code outside the offices of Disposal Safety.

- TGIF is not under QA control.

- In consideration of all of the above, it is recommended that the M\&O take steps to facilitate the development, verification-validation, and documentation of TGIF. These steps should include (1) obtaining and reviewing a listing of the most current version, (2) monitoring progress, and (3) developing a dependable source of future funding insofar as possible.

\section{References}

Amter, S., N. Lu, and B. Ross, 1991. Thermally driven gas flow beneath Yucca Mountain, Nevada, Paper presented at the December ASME Conference in Atlanta, GA.

Birdsell, K.H., and B.J. Travis, 1991. TRACR3D: A Model of Flow and Transport in Porous Media, LA-11798-M, Los Alamos National Laboratory, Los Alamos, NM.

Bixler, N.E., 1985. NORIA - A Finite Element Computer Program for Analyzing Water, Vapor, and Energy Transport in Porous Media, SAND84-2057, Sandia National Laboratories, Albuquerque, NM.

Doughty, C., and K. Pruess, 1990. A similarity solution for two-phase fluid and heat flow near high-level nuclear waste packages emplaced in porous media, Int J. Heat Mass Transfer, 33, 1205-1222. 
Lu, N., S. Amter, and B. Ross, 1991. Effect of a low-permeability layer on calculated gas flow at Yucca Mountain, Paper presented at the High Level Waste Conference at the April Conference in Las Vegas, NV.

Montazer, P., E.P. Weeks, F. Thamir, S.M. Yard, and P.B. Hofrichter, 1985. Monitoring the vadose zone in fractured tuff, Yucca Mountain, Nevada, in Proceedings of the NWWA Conference on Characterization and Monitoring of the Vadose (Unsaturated) Zone, Denver CO, November 19-21, pp. 439-469.

Pruess, K., 1991. TOUGH2 - A Cieneral-Purpose Numerical Simulator for Multiphase Fluid and Heat Flow, LBL-29400, Lawrence Berkeley Laboratory, Berkeley, CA.

Ross, B., S. Amter, and N. Lu, 1991. Numerical Studies of Rock-Gas Flow in Yucca Mountain, SAND91-7034, Sandia National Laboratories, Albuquerque, NM.

Runchal, A.K., and B. Sagar, 1991. PORFLOW: A Model for Fluid Flow, Heat, and Mass Transport in Multifluid, Multiphase Fractured or Porous Media, User's Manual - Version 2.34, ACRi/016/Rev. E, Analytical and Computational Research, Inc., West Los Angeles, CA.

Shaw, R.A., B. Ross, D.B. Bullen, M.J. Apted, R.K. McGuire, 1991. Performance Assessment: Effects of Thermal Loading, EPRI presentation to the October meeting of the Nuclear Waste Technical Review Board in Las Vegas, NV.

Tsang, Y.W., and K. Pruess, 1987. A study of thermally induced convection near a highlevel waste repository in partially saturated fractured tuff, Water Resour. Res. 23, 467-479.

Weeks, E.P., 1987. Effect of topography on gas flow in unsaturated fractured rock--concepts and observations, in Flow and Transport Through Unsaturated Fractured Rock, edited by D.D. Evans and T.J. Nicholson, Geophysical Monograph 42, American Geophysical Union, Washington, 1987, pp. 165-170.

Zyvoloski, G., Z. Dash, and S. Kelkar, 1992. FEHMN 1.0: Finite Element Heat and Mass Transfer Code, LA--12062-MS, Los Alamos National Laboratory, Los Alamos, NM. 


\section{A.15 TOSPAC}

1. Name of the Model

TOSPAC (Total System Performance Assessment Code)

\section{General Program Information}

2.1 Program size. TOSPAC (Dudley et al., 1988) has approximately 50,000 lines of source code, with an internal graphics package accounting for much its size.

2.2 Programming language. FORTRAN 77

2.3 Computer system on which it operates. Sun, VAX, Cray, and PC (386, or better).

2.4 Compiler(s) used. Standard compilers are used on each computer.

2.5 Location of code and availability. The code may be obtained from one of the authors, including Alan L. Dudley and John H. Gauthier of SPECTRA Research Institute or Michael L. Wilson of SNL (Sandia National Laboratories). As an on-site contract employee, Gauthier is physically located at SNL.

2.6 Brief description of model/code history. TOSPAC is used to estimate releases to the environment along ground-water pathways. It may be used in a stand-alone mode. In this case, it provides both steady and transient simulations of flow coupled with source-release and radionuclide-chain transport. In addition, the steady-flow module of TOSPAC may be combined with appropriate statistical and source modules to form the total systems model TSA (Total System Analyzer). As discussed by Wilson et al. (1991) and by Wilson (1992), TOSPAC can, within the TSA framework, compute two statistically based performance measures. These measures include the pre-emplacement ground-water travel time, as required by U.S. Nuclear Regulatory Commission (NRC) regulations, and the 10,000-year cumulative release to the accessible environment, as required by the Environmental Protection Agency (EPA) standard.

TOSPAC is a relatively new code. Dudley et al. (1988), a document devoted to theory and numerical implementation, is the first report. DOE's Yucca Mountain Site Characterization Project (YMP) funded model development, and, to date, all TOSPAC applications have focused on Yucca Mountain.

\section{Status of Model}

3.1 Development (Is the model now undergoing significant development or modification? or continuing maintenance?). Currently ongoing work consists of model testing and application. 
3.2 Documentation. Dudley et al. (1988) provides a readable and comprehensive description of theory and numerical implementation for flow and radionuclide transport. The physics-based discussion is excellent for several subjects. These subjects include stability issues associated with the numerical solution of the Richards equation, spatial and temporal gridding criteria, and fracture-matrix coupling.

Gauthier et al. (1992) provide a readable and comprehensive description of code structure, input, and output, with examples. The COVE2a benchmarking activity (Gauthier et al., 1992) also provides examples. Finally, with excellent commenting, the TOSPAC source code itself provides an excellent source of information.

\subsection{Status of verification and validation.}

No published component verification studies exist at present. Such studies would lend credibility to the technique for forcing convergence of the Richards equation solution and to the function used for fracture-matrix coupling, as well as to several other algorithms. There are, however, two general studies which evidence physically reasonable results.

\section{PACE-90 Analyses}

LANL (Los Alamos National Laboratory), LBL (Lawrence Berkeley Laboratory), and three SNL divisions participated in the PACE-90 study using six different flow codes and six different transport codes. Given a common data base and hydrogeologic characterization of the Yucca-Mountain Site, participants in the PACE-90 study determined the movement of radionuclides to the accessible environment. This exercise verified the ability of different researchers to independently conceptualize a complex site in a physically consistent manner. Although code implementations varied among the five participants, the study may be considered as a code-verification effort in a broad sense because of similarity of the results.

The TOSPAC flow simulations considered steady, partially saturated flow in four onedimensional columns. The columns used stratigraphies appropriate for wells G-1, G-4, UE-25a\#1 and H-1. Consisting of 17 distinct units, these stratigraphies extended from the top of the Topopah Spring Member to the water table. The TOSPAC transport considered only one column, the one appropriate for G-4.

The flow analysis assumed an equiviou single continuum for the fracture-matrix flow, while the transport analysis assumed a dual-permeability model. For each column, calculational mesh consisted of 1361 grid blocks. Grid-block thicknesses averaged $0.5 \mathrm{~m}$, with smaller thicknesses in the neighborhood of interfaces between geologic units. At the upper boundary, a net infiltration rate of $0.01 \mathrm{~mm} / \mathrm{yr}$ recharged the system, and, at the lower boundary, a pressure of zero fixed the water-table elevation.

The transport analysis considered four different radionuclides $\left({ }^{99} \mathrm{Tc},{ }^{129} \mathrm{I},{ }^{135} \mathrm{Cs}\right.$, and ${ }^{237} \mathrm{~Np}$ ) and two different source categories ("wet drip" and "moist continuous"). Six 
different time-dependent source-strength functions, calculated with the AREST code (Liebetrau et al., 1987), were provided to each participant in tabular form. All were incorporated into the TOSPAC analyses.

\section{COVE 2a Study}

LANL, LBL, PNL (Pacific Northwest Laboratories), and SNL participated in the COVE-2a study using several different codes. Although this study did not sufficiently control numerical errors to permit cross-comparison of CPU times, it is useful for code-to-code verification. Gautier et al. (1991) reports TOSPAC results, and Birdsell and Travis (1991a) report TRACR3D results. When fully reported, the COVE-2a study will also permit comparisons between TOSPAC, SUMO (Eslinger et al., 1990), and LLUVIA (Hopkins and Eaton, 1990), all of which are suitable for total system analyses.

The COVE-2a study focuses on an idealized one-dimensional stratigraphy consisting of $530.4 \mathrm{~m}$ and five fractured layers, the properties of which are taken from Yucca Mountain data. The problem definition memo (Prindle, 1986) specifies 12 isothermal one-dimensional problems, six steady and six unsteady cases. For the steady cases, a constant fluid flux is applied at the ground surface, and the steady-state system properties are reported as a function of depth. The solutions for the steady cases are then used as initial conditions for the unsteady cases.

To produce transient behavior, the applied flux is doubled at time zero and held at the higher rate. The transient system responses are followed as functions of depth and time. Each flow calculation is made for two stratigraphic configurations to test the sensitivity of the numerical solution techniques to sharp contacts between material layers with very different hydrologic characteristics. The configurations differ in the material type of the bottom unit; one assumes a zeolitized Calico Hills and the other a vitrified Calico Hills. The hydraulic conductivity of the latter $(2.7 \mathrm{E}-7 \mathrm{~m} / \mathrm{s})$ exceeds that of the former by four orders of magnitude.

\subsection{Status of Quality Assurance (QA). TOSPAC is under QA control at SNL.}

\section{Type of Model (Phenomena/Processes Modeled)}

TOSPAC considers three major processes. These processes include fluid flow, waste leaching, and radionuclide chain transport. To model the flow process, TOSPAC numerically solves the Richards equation to obtain one-dimensional vertical flow through multiple layers of saturated or partially saturated porous medium. To treat a fractured media, the code employs an equivalent continuum approximation. An update to the flow module reported by Dudley et al. (1988) allows TOSPAC to consider one-dimensional horizontal flow in a saturated fractured region. Here, again, an equivalent continuum, or single-porosity, model is employed. Both steady and unsteady flow regimes may be simulated. 
To model the waste leaching process, TOSPAC effers three options. One option calls for a tabular input function, perhaps one determised by the AREST code (Liebetrau, et al., 1987). A second option invokes a very conservative calculation. It assumes all water passing through the repository to be maximally contaminated, up to the solubility limit of each radionuclide in the repository. A third option accounts for the fact that only a fraction of the water passing through the waste contacts the waste. A number of factors limit contact between water and waste, including waste exposure area and the lifetime of the waste container. A recent version of the code considers other aspects of waste-water contact, including failure of cladding and waste pellets and the quick-release components of cesium, iodine, and carbon (Oversby and McCright, 1985).

To model radionuclide transport, TOSPAC invokes a relatively complete group of transport subprocesses, including advection, dispersion, retardation, radioactive decay, and radioactive production. A pseudo steady-state approximation partitions transport between fracture and matrix.

\section{Governing Equations}

For flow, TOSPAC employs the Richards equation, with rock properties suitably generalized for an equivalent continuum model of fracture-matrix flow. For rock properties, it uses what has become the standard for Yucca Mountain flow codes. This includes the van GenuchtenMualem form (Mualem, 1976) for hydraulic conductivity and the van Genuchten form (van Genuchten, 1978) for saturation, both expressed as functions of suction head. Consistent with its intended use for total-system analysis, TOSPAC considers only one dimension.

For radionuclide transport, TOSPAC solves the two partial differential equations appropriate for a dual-permeability model of a fracture-matrix system. The coupling contains two terms, one for advection and one for diffusion/dispersion. Rather than to characterize the latter in terms of its dependence on concentration gradient at the fracture-matrix interface, which is not possible in a dual-permeability conceptualization, TOSPAC approximates the diffusiondispersion term in terms of the difference between fracture and matrix concentrations. This may be identified as a pseudo steady-state approach.

In his analysis of interference tests, Moench (1984) considers both fully transient and pseudo steady-state conceptualizations. He concludes that the latter is appropriate for the relatively low-permeability skins that apparently cover the fracture-matrix interface for some of the saturated rock at the Nevada Test Site. However, one should realize that Moench's work applies only to the flow regime. It provides no assurance that a pseudo steady-state conceptualization is valid for transport, as assumed by TOSPAC.

\section{Method of Solution}

Generally speaking, one might characterize TOSPAC's numerical analysis as a standard implementation. For the flow analysis, finite differencing both spatial and temporal domains reduces the one-dimensional governing equation to a tri-diagonal set of algebraic equations. Mid-point spatial weighting defines the hydraulic conductivity at grid-block interfaces, and mid-point time weighting defines the time level at which tmasport terms are evaluated. To 
cope with the non-linearity introduced by the relative-permeability functions, TOSPAC uses an iterative procedure. For the first iteration, the difference equations are linearized by the Picard technique; thereafter, by the Newton-Raphson technique. For each iteration, the frequently used Thomas algorithm is activated to solve the difference equations.

TOSPAC does add a new "wrinkle" in solving the convergence problem associated with the Richards equation. In addition to the non-linearity introduced by the relative-permeability curves, Dudley et al. (1988, pp. 44-48) notes two other difficulties. One relates to the transition between boundary condition and characteristic solution and the other to rockproperty discontinuities at interfaces between differing rock types.

The "characteristic solution" is one for which Darcy velocity equals hydraulic conductivity. Dudley et al. (1988, pp. 44-48), note that, as elevation increases, pressure head tends toward the characteristic solution. Based on simple analytic solutions, the authors develop stability controls, which they employ, when necessary, to force convergence. With the same analytic solutions, the authors also develop gridding criteria. The authors indicate that deviations from flux conservation still occur at material interfaces and at nodes where the numerical solution first encounters the characteristic solution. With the TOSPAC stability controls and gridding criteria, these discontinuities can be kept to less than ten percent of the nominal value of flux.

For the transport analysis, finite differencing is applied to spatial and temporal domains of the one-dimensional governing equations for fracture and matrix continua. This yields a single penta-diagonal set of algebraic equations. Upstream spatial weighting defines concentration at grid-block interfaces. A time weighting factor of 0.6 , on a scale of zero (fully explicit) to one (fully implicit), identifies the time level at which transport terms are evaluated. In contrast to the flow equation, the transport equation used by TOSPAC is linear and does not require an iterative procedure. A generalization of the Thomas algorithm is used to solve the difference equacions.

\section{Type of Input Parameters}

Gauthier et al. (1992) provides a detailed discussion of code input and output. Here, the two topics are presented in a general manner. Partially saturated flow and transport models like TOSPAC require several different types of information pertaining to discretization and calculation control, to output control and to rock properties. For the latter, the TOSPAC input is similar to those of other codes. It includes values of porosity, saturated permeability, dispersivity, and sorption constant for each rock type. It also includes either parameters specifying functional relationships (van Genuchten, 1978 and Mualem, 1976) or tables specifying capillary pressure and relative permeability as functions of saturation for each rock type.

For its discretization and calculational-control requirements, TOSPAC input is rather unique compared to other codes in the YMP. Obviously, the developers have sought to minimize the amount of such input. Thus, to a great extent, spatial and temporal discretization, as well as calculational control specifications, are generated internally, leaving little to be specified directly by the user. 


\section{Type of Output and User Options}

Dependent variables consist of heads, saturations, Darcy fluxes, and waste concentrations. For a fractured medium, TOSPAC partitions saturations and Darcy fluxes between fractures and matrix using the equivalent-continuum approximation. Since the dependent variables are functions of space and time, tabular output is available at the end of each time step. However, such output can become voluminous, and TOSPAC provides the user with outputcontrol options.

TOSPAC performs mass-balance computations, and writes the results to output files. Such results provide source-sink information, cumulative mass crossing boundaries, and a massbalance performance measure to assure the user that the internal algorithms are mass conserving. In addition, control variables, like the number of Newton-Raphson iterations, also appear in the output.

\section{Model Interactions (emphasize needed processors)}

9.1 Does the model interface with any other models? When used for total systems analysis, TOSPAC becomes a part of the TSA code. When used in this mode, it is interfaced, by the TSA executive driver, with the Latin-hypercube sampling routines of Iman and Shortencarier (1984) and with support routines to determine performancemeasure values from TOSPAC results.

9.2 Source code and type of information needed. When incorporated in TSA, the parameter values are sampled from specified distributions to form an input parameter vector. Values of rock properties, source characteristics, and/or retardations may change as a result of the sampling. Using such values from the parameter vector, TOSPAC determines quantities such as Darcy velocity and radionuclide concentrations from which TSA support routines calculate performance-measure values.

9.3 Receiving code and type of information provided. See previous section.

9.4 Any pre- or postprocessing needed? Since all graphics are self-contained, TOSPAC does not require commercially available graphics packages.

\section{Model Application}

10.1 Usage within the Civilian Radioactive Waste Management System (CRWMS) program. For relatively simple conceptualizations suitable for a one-dimensional, nonisothermal implementation, TOSPAC may be used in a stand-alone mode. As a component of TSA, TOSPAC becomes a total systems model. For the undisturbed scenario, TOSPAC can then determine two performance measures established by the regulations. These measures, pre-emplacement ground-water travel time and 10,000year cumulative release, are both stochastically based.

10.2 Usage outside the program. TOSPAC is specially designed for a total systems analysis of an unsaturated repository. This severely restricts its usage. Nevertheless, 
in special circumstances, it may have application outside the YMP. Despite its one dimensionality, it might have limited application to near-surface contamination problems.

\section{Codes With Similar or Same Capabilities}

11.1 Within the program. SUMO from PNL (Pacific Northwest Laboratory) and SPARTAN, also from SNL, are currently operational. Each of these codes provides a stochastic simulation of the total system. Although LLUVIA (SNL) focuses on flow only, it has also been used for stochastic simulations.

11.2 Outside the program. The NRC has used NEFTRANS (Longsine et al., 1987) for both bedded salt and tuff programs, and EPRI (Electrical Power Research Institute) has a total systems code.

\section{Major Assumptions and Limitations}

- One-dimensional flow and transport pathways

- Isothermal flow

- Local hydrostatic equilibrium between fracture and matrix, i.e., an equivalentcontinuum conceptualization of flow

- Local pseudo steady-state transport between fracture and matrix

- Refined gridding appropriate for the centered and upstream differencing approximations used by the code

- Single-phase liquid flow

\section{Remarks/General Observations/Discussion.}

Applications of TOSPAC, SUMO (PNL) and LLUVIA (SNL) demonstrate that rigorous solution of simplified flow and transport equations are within the scope of statistical implementation. This provides hope that with hardware and software improvements, more general equations may also fall into the scope of statistical implementation. Since source submodels rely on relatively fast algorithms, they can be improved substantially with little increase in execution time. However, the simplified flow equations which now permit statistical calculations may be too simple for use in licensing.

Contrary to the steady-state assumption, storm events may contribute significantly, perhaps even dominantly, both to the pre-emplacement ground-water travel time and to the 10,000 year cumulative release. The presence of dominant flow channels, perhaps caused by fingering, or low-permeability fracture skins in nonwelded units lying above repository depths could invalidate the assumption of a continuous porous medium with isotropic porosity, as well. In addition, hydrothermal effects in the near field may seriously perturb 
the flow field, even causing flow vectors to point toward the repository for a significant period of time.

Rationalizing these effects with respect to the regulatory performance criteria should provide an interesting challenge. The challenge becomes even sharper when one compares the CPUtime requirements of the general flow and transport models with the efficiency demands of statistical simulations. Effects such as those described above, should they stand the test of further conceptualization studies, would place the future of TOSPAC in jeopardy given its restriction to nonisothermal, single-phase, and one-dimensional processes.

\section{Comparison to Other Models}

See Chapters 4,5 , and 6 of the main text.

\section{Summary and Recommendations}

- TOSPAC is a detailed process code which, in a steady-state mode, is used for total systems analyses.

- Attempting a compromise between model detail and computer efficiency, the developers have focused on the coding. They have looked carefully at the problem of nonlinear convergence in the solution of the flow equation.

- However, in their quest for computer efficiency, the developers have excluded key processes which are crucial to assessing the performance of Yucca Mountain. (This is a dilemma not only for the TOSPAC developers, but for the YMP as well.) Processes omitted include non-equilibrium fracture-matrix flow and heat-driven flow.

- TOSPAC is well written. Its organizational structure and the style of its commenting sets a standard which should be duplicated by future code development within the Project.

- TOSPAC is well documented. However, in its quest for completeness, the documentation tends to get somewhat wordy.

- TOSPAC is under QA control.

- In consideration of all of the above, it is recommended that TOSPAC be advanced to the testing phase. For one-dimensional tests based on the Richards equation, TOSPAC can be used as a benchmark in computer efficiency.

\section{References}

Birdsell, K.H., and B.J. Travis, 1991a. Results of the COVE2a Benchmarking Calculations Run with TRACR3D, LA-11513-MS, Los Alamos National Laboratory, Los Alamos, NM. 
Birdsell, K.H., and B.J. Travis, 1991b. TRACR3D: A Model of Flow and Transport in Porous Media, LA-11798-M, Los Alamos National Laboratory, Los Alamos, NM.

Dudley, A.L., R.R. Peters, J.H. Gauthier, M.L. Wilson, M.S. Tierney, E.A. Klavetter, 1988. Total System Performance Assessment Code (TOSPAC) Volume 1: Physical and Mathematical Bases, SAND85-0002, Sandia National Laboratories, Albuquerque, NM.

Eslinger, P.W., T.B. Miley, and D.W. Engel, 1990. SUMO-System Performance Assessment for a High-Level Nuclear Waste Repository: Mathematical Models, PNL-7581, Pacific Northwest Laboratory, Richland, WA.

Gauthier, J.H., N.B. Zieman, and W.B. Miller, 1991. TOSPAC Calculations in Support of the COVE 2A Benchmarking Activity, SAND85-2730, Sandia National Laboratories, Albuquerque, NM.

Gauthier, J.H., M.L. Wilson, R.R. Peters, A.L. Dudley, and L.H. Skinner, 1992. Total System Performance Assessment Code (TOSPAC) Volume 2: User's Guide, SAND85-0004, Sandia National Laboratories, Albuquerque, NM.

Hopkins, Polly and Roger R. Eaton, 1990. LLUVIA: A Program for One-Dimensional Steady-State Flow Through Partially Saturated Porous Media. Sandia National Laboratories, SAND88-0558.

Iman, R.L., and Shortencarier, M.J., 1984. A FORTRAN 77 Program and User's Guide for the Generation of Latin Hypercube and Random Samples for Use with Computer Models. Sandia National Laboratories, SAND83-2365.

Liebetrau, A.M., M.J. Apted, D.W. Engel, M.K. Altenhofen, D.M. Strachan, C.R. Reid, C.F. Windisch, R.L. Eridson, K.I. Johnson, 1987. The Analytical Repository Source Term (AREST) Model: Description and Documentation, PNL-6346, Pacific Northwest Laboratory, Battelle Memorial Institute, Hanford, WA.

Longsine, D.E., E.J. Bonano, C.P. Harlan, 1987. User's Manual for the NEFTRAN Computer Code, Sandia National Laboratories, SAND86-2405.

Moench, A.F., 1984. Double-Porosity Models for a Fissured Groundwater Reservoir With Fracture Skin, Water Resour. Res., 20(7), 831-846.

Mualem, Y., 1976. A New Model for Predicting the Hydraulic Conductivity of Unsaturated Porous Materials, Water Resour. Res., 12(3), 513-522.

Oversby, V.M., and R.D. McCright, 1985. "Laboratory Experiments Designed to Provide Limits on the Radionuclide Source Term for the NNWSI Project, Proceedings of the Workshop on the Source Term for Radionuclide Migration from High-Level Waste or Spent Fuel under Realistic Repository Conditions," eds. T.O. Hunter and A.B. Muller, SAND85-380, Sandia National Laboratory, Albuquerque, NM. 
Prindle, N.K., 1986. Benchmarking of Flow and Transport Codes, COVE2a-Yucca Mountain Hydrology, Sandia National Laboratories memorandum, YMP Accession No. NNA.890523.0140.

Sinnock, S., and Y.T. Lin, 1989. Preliminary Estimates of Groundwater Travel Time at Yucca Mountain, Radioactive Waste Management and the Nuclear Fuel Cycle, Vol. 13(1-4), pp. 121-145.

Updegraff, C.D., C.E. Lee, and D.P. Gallegos, 1991. DCM3D: A Dual-Continuum, Three Dimensional, Ground-Water Flow Code for Unsaturated, Fractured, Porous Media, NUREG/CR-5536, SAND90-7015, Sandia National Laboratories, Albuquerque, NM.

van Genuchten, R., 1978. Calculating the Unsaturated Hydraulic Conductivity with a New Closed Form Analytical Model, Water Resources Bulletin, Princeton University Press, Princeton, NJ.

Wilson, M.L., F.C. Lauffer, J.C. Cummings, and N.B. Zieman, 1991. Total-System Analyzer for performance assessment of Yucca Mountain, in High Level Radioactive Waste Management: Proceedings of the Second Annual International Conference, American Nuclear Society and American Society of Civil Engineers, Vol. 2, pp. 1734-1743 (NNA.920427.0051).

Wilson, M.L., 1992. Comparison of two conceptual models of flow using the TSA, in High Level Radioactive Waste Management: Proceedings of the 1992 International Conference, American Nuclear Society, Vol. 1, pp. 882-890 (NNA.920505.0061). 


\section{A.16 TOUGH, V-TOUGH, AND TOUGH2}

1. Name of the Models

TOUGH (Transport Of Unsaturated Ground Water and Heat), V-TOUGH, and TOUGH2

\section{General Program Information}

2.1 Program size. TOUGH, V-TOUGH, and TOUGH2 contain approximately 7,000 lines of source code.

\subsection{Programming language. FORTRAN 77}

2.3 Computer system on which it operates. Pruess (1987) reports the use of a CDC-7600 and a Cray XMP. Nitao (1989) reports the use of a Cray 2. At SNL (Sandia National Laboratories) TOUGH is operational on a Sun work station. Since there is a relatively large group of users, one would expect that TOUGH has been run on several other computers as well, including IBM PCs.

2.4 Compiler(s) used. A standard compiler may been used on each computer.

2.5 Location of code and availability. TOUGH, the parent of the TOUGH line of codes, and its enhancement TOUGH2 are being developed at Lawrence Berkeley Laboratory (LBL). They may be obtained from the Energy Science and Technology Software Center at Oak Ridge, Tennessee. V-TOUGH, a vectorized version of TOUGH, was developed by and may be obtained from Lawrence Livermore National Laboratory (LLNL).

2.6 Brief description of model/code history. Through its Office of Basic Energy Science and its Geothermal Technology Division, the U.S. Department of Energy (DOE) funded the initial development of TOUGH. Support for the documentation came from SNL and the U.S. Nuclear Regulatory Commission (NRC). TOUGH, a multi-dimensional numerical model, simulates nonisothermal, two-phase flow of water, vapor, air, and heat in porous and fractured media. It is a member of the MULKOM family of multi-phase, multi-component codes being developed at LBL.

Since its release in 1987, TOUGH has attracted significant interest in the scientific community. This is evidenced by its inclusion in a review by Updegraff (1989) with revisions by Moridis and Pruess (1992) and a review by Worgan et al. (1990). In addition, a relatively large group of users met at a TOUGH Workshop (September 13-14, 1990). At this meeting, participants from a variety of countries presented over 20 papers. In addition to nuclear-waste disposal, the fields of interest included geothermal reservoirs, hazardous-waste migration, and unsaturated-zone hydrology. 
To further expand TOUGH's capabilities, DOE's Yucca Mountain Site Characterization Project (YMP) has funded the development of TOUGH2 at LBL and the development of the vectorized version V-TOUGH at LLNL.

\section{Status of Model}

3.1 Development (Is the model now undergoing significant development or modification? or continuing maintenance?). Though structurally quite similar to TOUGH, TOUGH2 provides an "open" architecture to encourage future development of the code. Exploiting this facility, Oldenburg and Pruess (1992) have added a dispersion model, and Pruess (1991b) has added an equation-of-state module (EOS7) to simulate the miscible displacement of a brine and its etiects on the density and viscosity of the liquid phase. Other upgrades consider three-phase multi-component flow, porosity and permeability changes as a result of compositional changes, and precipitation and dissolution effects.

3.2 Documentation. User's guides for both TOUGH (Pruess, 1987) and TOUGH2 (Pruess, 1991a) are well written and understandable. Though brief, Nitao (1989, 1992) adequately supplements the TOUGH user's guide. He discusses V-TOUGH enhancements to TOUGH and the resulting changes to the TOUGH input.

3.3 Status of verification and validation. The TOUGH user's guide (Pruess, 1987) includes six example problems. Two of these are designed only to illustrate user options and areas of application of the code. Another, quite possibly, has been executed by other codes since it is recommended as a benchmark by an NRC-funded study (Ross et al., 1982). Three other problems may be classified as verification problems since they provide comparisons with known semi-analytical or numerical results. These problems are separately identified below:

Problem 2 - One-Dimensional Infiltration. An infiltration front enters a semiinfinite horizontal tube filled with a homogeneous soil. Air is not accounted for and is a passive spectator. This problem, one of the benchmarks adopted by Ross et al. (1982) compares the TOUGH solution with the semi-analytical results of Phillip (1955).

Problem 4 - Production from a Geothermal Well (One-Dimensional). A constant rate of production causes pressure drawdown within a geothermal reservoir. Though the reservoir initially contains a single-phase fluid, the pressure-drop at the wellbore causes vaporization, and a boiling front proceeds radially outward from the wellbore. This is a one-component, two-phase flow and heat-transport problem. TOUGH results are compared with the semi-analytical results of Garg (1978).

Problem 6 - One-Dimensional Heat Pipe. Heat entering one end of a porous tube causing counter-current flow of gaseous and liquid phases. TOUGH results are compared with the semi-analytical results of Udell and Fitch (1985). 
Updegraff (1989), in an NRC-funded study, evaluated TOUGH using code-to-code comparisons. All problems were run on the Cray XMP-24 at SNL (Sandia National Laboratories). Moridis and Pruess (1992) also considered these comparisons. Test problems used by these studies are briefly described below:

Problem 1.1 - One-Dimensional Infiltration. This problem, the same as Problem 2 of the TOUGH User's Guide, is described above. To simulate infiltration for 9,504 s, the Updegraff's analysis required $12.1 \mathrm{~s}$ of CPU time.

Problem 12 - One-Dimensional Heat Transport. Cold water is injected into a hot-water aquifer of thickness $100 \mathrm{~m}$. A production well, located $40 \mathrm{~m}$ away, pumps at a rate equal to the rate of injection. This problem, which considers both convection and thermal conduction, was originally solved analytically by Avdonin (1964). Ross et al. (1982) adopts it as a code benchmark. The TOUGH analysis of Updegraff required $967 \mathrm{~s}$ of CPU time to calculate the temperature profile $1.3 \mathrm{E} 5 \mathrm{~s}$ after initiation of the injection.

Problem 1.3 - One-Dimensional Radial Heat Transport. Except for its geometry, the radial heat problem is essentially the same as the above linear problem. Solved analytically by Avdonin (1964), it is also adopted as a benchmark by Ross et al. (1982). The TOUGH analysis of Updegraff successfully simulated the temperature profile at $1.5 \mathrm{E} 6 \mathrm{~s}$ using $2,000 \mathrm{~s}$ of CPU time.

Problem 1.4 - Production from a Geothermal Well (One-Dimensional). This problem, the same as Problem 4 of the TOUGH User's Guide, is described above. To simulate the production of hot water and steam from a radially symmetric reservoir for 1.0E6 s, the TOUGH analysis of Updegraff required $11.6 \mathrm{~s}$ of CPU time.

Problem 1.5 - One-Dimensional Heat Pipe. This problem, the same as Problem 6 of the TOUGH User's Guide, is described above. To simulate this problem, involving one-dimensional, two-phase, two-component flow and heat-transport for $876.6 \mathrm{~d}$ time period, the TOUGH analysis of Updegraff required $11.6 \mathrm{~s}$ of CPU time.

Problem 2.1 - Two-Dimensional Infiltration. In this problem, a 2-m-high by 6-m-long vertical slab of soil is recharged at a rate of $14.8 \mathrm{~cm} / \mathrm{hr}$. The recharge zone is located at the center of the top of the slab. Trenches bound the slab on both sides and each is filled with $0.65 \mathrm{~m}$ of water. A no-flow boundary lies across the bottom of the slab, and infiltration begins after an extended period of no flow through the top boundary. In Updegraff's analysis, TOUGH solved the first 6,300 s. After that, he found that time steps became sufficiently small that it was impractical to continue. In the analysis of Moridis and Pruess several problems relating to mobility weighting, gas-phase relative permeability, and spatial discretization were corrected. The TOUGH calculation was then carried forward to the desired simulation time of $28,800 \mathrm{~s}$. 
Problem 2.2 - Convection-Cell Experiment. Two concentric cylinders form cell of length $0.8384 \mathrm{~m}$ and outer radius $0.2191 \mathrm{~m}$. A heater of length $0.2516 \mathrm{~m}$ is placed within an inner cylinder of radius $0.0095 \mathrm{~m}$ such that its bottom lies $0.3982 \mathrm{~m}$ from the bottom of the cell. Except for the length occupied by the heater, insulation fills the inner cylinder. Insulation also covers the bottom and outer walls of the cell. Inside the cell, glass beads with an average diameter of $0.65 \mathrm{~mm}$ provide the porous medium. Initially the water at $21.5^{\circ} \mathrm{C}$ saturates this medium, maintaining hydrostatic equilibrium with a pressure of $200,000 \mathrm{~Pa}$ applied to the top surface. After the heater is turned on, the partially vaporized water forms a heat pipe transporting latent heat from the heater to the top surface, which is maintained at a temperature of $21.5^{\circ} \mathrm{C}$. Updegraff could not obtain satisfactory results using TOUGH. After examining Updegraff's input, Moridis and Pruess found problems relating to the radial grid, boundary conditions, and the density and specific heat of the medium. After correcting these problems, their TOUGH simulation yielded the desired results.

Problem 2.3 - Vaporizing-Flow Experiment. Initially, a saturated sandstone core of length $0.5969 \mathrm{~m}$ and cross-sectional area $2.027 \mathrm{E}-3 \mathrm{~m}^{2}$ is equilibrated with respect to temperature of $192.0^{\circ} \mathrm{C}$ on the left end, a temperature of $184.0^{\circ} \mathrm{C}$ on right end, and an external pressure of $1,840,965 \mathrm{~Pa}$. Placing the core in an oven fixes the side boundary of the core at $198.9^{\circ} \mathrm{C}$. At the same time, the side boundary is insulated to prevent liquid flow, the left end is insulated to prevent both liquid and energy flows, and the right end is insulated to prevent energy transport. A time-dependent pressure relation applied to the right end causes the pressure there to decline quadratically from an initial value of $1,840,965 \mathrm{~Pa}$. Updegraff could not obtain satisfactory results using TOUGH. After correcting several problems related to boundary conditions, Moridis and Pruess achieved satisfactory agreement with the experimental results and with previous simulations. Compared to work of other researchers, they also found their simulation to be efficient since it reached the desired simulation time with only 311 steps.

Doughty and Pruess (1992) present a similarity solution for a radial heat-pipe problem. With the assumption that gravitational effects are negligible, a radial geometry is employed. Given that the dimensions of the heat source are relatively small compared to the distances at which a solution is desired, a line source of zero radius is assumed. Given that there are no additional assumptions, the similarity solution provides an excellent test for nonlinear, two-phase, two-component flow. Using hydrothermal properties taken from Yucca Mountain properties and a realistic heat source rate, Doughty and Pruess $(1990,1992)$ define a problem to test the accuracy of both the similarity-solution method and TOUGH2. The space-time distributions of pressure, temperature, liquid saturation, and air mass fraction calculated by both methods are virtually identical.

3.4 Status of Quality Assurance (QA). TOUGH2 is under QA control at SNL. 


\section{Type of Model (Phenomena/Processes Modeled)}

Both TOUGH, V-TOUGH, and TOUGH2 are multi-dimensional (one-, two-, or threedimensional) numerical models for simulating the coupled transport of water, vapor, air and heat in anisotropic porous and fractured media. TOUGH takes into account the following physical processes:

- Fluid flow in both liquid and gas phases occurs under pressure, viscous, and gravity forces according to Darcy's law.

- Binary diffusion in the gas phase

- Capillarity between water and gas phases

- Dissolution of non-vaporizing gas component in water as represented by Henry's law

- Phase equilibrium between vapor and water as represented by steam tables (International Formulation Committee, 1967)

- Conduction of heat with thermal conductivity dependent on degree of saturation

- Convection of heat in both gas and water phases

- Latent-heat effects

- Both V-TOUGH and TOUGH account for vapor-pressure lowering

- Only V-TOUGH permits radiative heat transfer.

\section{Governing Equations}

It is important to note the internal structure of the TOUGH codes. This structure consists of two modules. One solves a generalized set of coupled equations. The other, the equation-of-state (EOS) module, and code input specify hydrothermal properties, including the number of components and phases. In general, this means that, to enhance physicalprocess capabilities, one adds an appropriate EOS module while leaving the coupledequations module unchanged.

Presently, the available equation-of-state modules permit TOUGH2 to solve up to three governing equations in as many as three dimensions. One governing equation treats mass conservation for the water component, which may be present in both water and gas phases. Another treats mass conservation for the non-condensing gas component (e.g., air), which is assumed to be present in the gas phase and, as a soluble constituent, in the water phase. The third, an energy-conservation equation, treats heat transport. Auxiliary equations enforce a total saturation of unity and total component mass fractions of unity in each phase. Henry's law characterizes the inter-phase equilibrium of the non-condensing gas component, 
while steam tables (International Formulation Committee, 1967) characterize the interphase equilibrium of the condensing gas component.

\section{Method of Solution}

The model employs the integrated finite-difference technique for space discretization, which allows considerable flexibility in specifying the problem geometry. Time discretization is accomplished by a fully implicit procedure, and the resulting set of nonlinear difference equations is linearized by the Newton-Raphson technique. Three algorithms critically affect the CPU time. They are: (1) automatic time stepping, (2) steam-table evaluations, and (3) linear-equation solution.

For TOUGH and TOUGH2, the time-stepping algorithm relates time-step magnifications and chops to the number of nonlinear iterations. For V-TOUGH, the time-stepping algorithm relates time-step size to the maximum desired change in the solution vector during one time step. To obtain steam-table properties such as mass density, specific internal energy, and saturation pressure, TOUGH and TOUGH2 evaluate relatively complex functional relationships. In contrast, V-TOUGH uses a linear interpolation algorithm which is vectorized for supercomputers such as the Cray, Convex, and Alliant computers.

Although a conjugate-gradient-type solver is now being implemented in TOUGH2, TOUGH and TOUGH2 now use the Harwell MA28 direct-solution algorithm (Duff, 1977). V-TOUGH does not offer the MA28 solver. Instead, it offers three different direct solvers, the vectorized versions of which provide superior performance on a supercomputer. For a typical nonisothermal, two-phase problem involving several thousand elements, Nitao (1989) reports a factor-of-20 improvement in CPU time.

\section{Type of Input Parameters}

The input of TOUGH, V-TOUGH, and TOUGH2 is organized into several data "blocks." Data needed in these blocks include:

TITLE Block: Problem title

\section{ROCKS Block}

- Material name (can be as many as 27 materials)

- Rock grain density

- Porosity

- Absolute permeabilities along three principal axes

- Formation heat conductivity under fully saturated conditions

- Rock grain specific heat

- Compressibility

- Expansivity

- Formation heat conductivity under desaturated conditions

- Tortuosity factor for binary diffusion

- Parameters for relative permeability functions 
- Parameters for capillary pressure function

\section{PARAM Block}

- Maximum number of iterations per time step

- Specify amount of printout

- Maximum number of time steps

- Maximum duration of simulation

- Strength parameter for diffusive vapor flux at standard conditions

- Parameter for temperature dependence of binary diffusion

- Starting time of simulation

- Time at which simulation should stop

- Length of time steps

- Upper limit for time step

- Magnitude of gravitational acceleration

- Factor by which time step is reduced in case of convergence failure, or other problems

- Scale factor to change size of the mesh

- Convergence criterion for relative and absolute error

- Pivoting parameter for linear equation solution

- Upstream weighting factor for mobilities and enthalpies at interfaces

- Weighting factor for increments in Newton/Raphson iteration

- Increment factor for numerically computing derivatives

TIMES Block

- Number of time provided on cards

- Total number of times desired for additional printout

- Maximum time step size after any of the prescribed tirnes have been reached

- Time increment for times with additional printout 
- List of times (in ascending order) at which printout is desired

ELEME Block

- Name of element

- Number of additional elements having same volume and belonging to same reservoir domain

- Element volume

- Increment between the code numbers of two successive elements

- Material identifier corresponding to one of the reservoir domains

\section{CONNE Block}

- Code name of first and second elements

- Number of additional connections in the sequence

- Increment of the code number of the first element between two successive connections (same for second element)

- Specify absolute permeability for the materials in elements

- Distance from center of first and second element, respectively, to their common interface

- Interface area

- Cosine of the angle between the gravitational acceleration vector and the line between the two elements

GENER Block

- Code name of the element containing the sink/source

- Code name of the sink/source

- Number of additional sinks/sources with the same injection/production rate

- Increment between the code numbers of two successive elements with identical sink/source

- Increment between the code numbers of two successive sinks/sources 
- Number of points in table of generation rate versus time

- Type of sink/source

- Constant generation rate

- Fixed specific enthalpy of the fluid for mass injection

- Thickness of layer

- Generation times and rates

- Specific enthalpy of produced or injected fluid

INCON Block

- Code name of element

- Number of additional elements with the same initial conditions

- Increment between the code numbers of two successive elements with identical initial conditions

- Porosity (void fraction)

- Pressure

- Temperature (single-phase points and two-phase points)

- Gas generation (two-phase points)

- Air mass fraction (single-phase points)

Data blocks permitted by V-TOUGH include:

DTSTP Block: Maximum changes in gas-phase pressure, gas saturation, temperature, and air mass fraction.

OPTN Block

- Newton-Raphson control parameters

- Vapor-pressure-lowering option

- Solver option 


\section{THIST Block}

- Variables to be saved in time-history files, e.g., sg (gas saturation), pc (capillary pressure), vl (liquid velocity), or qhe (conductive heat flow)

- Locations (either elements or connections) for which variable values are desired

- Times or time interval at which variable values are desired

Additionally, V-TOUGH input alters the CONNE data block to permit specification of radiative transfers between elements.

\section{Type of Output and User Options}

Standard output at specified time steps or simulation times consists of time-stepping and iteration information, and a complete element-by-element report of thermodynamic state variables (pressure, temperatures, saturations, and mass fractions). Additional optional output is available on mass and heat flow rates and velocities, and on changes in thermodynamic state variables during a time step. The above output can be printed either at convergence for each time step or after each iteration within the time step. Additional printout is available to meet various special needs. Users guides for TOUGH (Pruess, 1987), V-TOUGH (Nitao, 1992), and TOUGH2 (Pruess, 1991a) provide detailed information.

9. Model Interactions (emphasize needed processors)

9.1 Does the model interface with any other models? Yes, see below.

9.2 Source code and type of information needed. Not applicable.

9.3 Receiving code and type of information provided. There is no companion radionuclide-transport code. However, output could be processed to fit existing transport codes.

9.4 Any pre- or postprocessing needed? Postprocessing packages have been developed for Sun workstations to facilitate plotting capabilities (V-TOUGH version). Given the commercial availability of many excellent graphics packages and the wide-spread use of the TOUGH codes, several institutions have, no doubt, interfaced code output with several different graphics packages.

10. Model Application

10.1 Usage within the Civilian Radioactive Waste Management System (CRWMS) program. TOUGH, V-TOUGH, and TOUGH2 applications within the CRWMS program, e.g., Pruess et al. (1990a,b) and Buscheck and Nitao (1992), consider the near-field thermal and hydrological environment around a nuclear waste package. These calculations are needed for waste-package design and for radionuclide transport. Simulations of this 
type predict the relatively complex two-phase behavior of water as it interacts with the waste packages during the cool-down period following emplacement.

Potentially the TOUGH codes can be used to characterize many aspects of the physical system. They are constrained primarily by efficiency considerations. In addition to analysis of the near field, they potentially can characterize the following effects: the impact of gas flow and vaporization on water flow, the effect of fractures, the effect of matrix flow in nonwelded units on downward flow through fractures, the transport of radioactive gases to the accessible environment, the travel time required for dissolved radioactive species to reach the accessible environment. Some analyses can be performed now, while others must await software and hardware improvements.

10.2 Usage outside the program. Initially, TOUGH was developed for problems pertaining to geothermal reservoirs. TOUGH has since been applied in a variety of areas including uniaturated zone hydrology, environmental problems, and petroleumreservoir engineering, where TOUGH has been used in steam-flooded hydrocarbonreservoir problems. TOUGH has also been applied in other areas of waste disposal including Oberbauenstock in Switzerland, where it was used to simulate gas migration from a proposed underground repository for low- and intermediate-level waste. The widespread use of TOUGH was evidenced by the variety of fields represented in the papers contributed at the recent TOUGH Workshop.

\section{Codes With Similar or Same Capabilities}

11.1 Within the program. The YMP has funded the development of several codes with capabilities similar to those of TOUGH, V-TOUGH, and TOUGH2. These codes include NORIA (Bixler, 1985) at SNL, TRACR3D (Travis, 1984 and Birdsell and Travis, 1991) and FEHM (Zyvoloski et al., 1991) at LANL (Los Alamos National Laboratory), and PORFLOW (Runchal and Sagar, 1991) and MSTS(White and Nichols, 1992) at PNL (Pacific Northwest Laboratory). All these codes simulate multiphase flow. They differ in terms of spatial-discretization methods (finite difference vs finite element), linearization techniques (Picard vs Newton-Raphson), and linear-equations solvers (direct solution us conjugate-gradient gmres). They also differ in terms of the processes considered (heat transport, radionuclide transport, phase equilibrium or disequilibrium, Knudsen diffusion, thermo-diffusion).

11.2 Outside the program. In addition to the documentation of TOUGH, the NRC funded the development of DCM3D (Updegraff, 1991). Further, a number of codes have been developed within the petroleur industry. In terms of the processes considered, compositional models (Peaceman, 1977) provide a capability superior to TOUGH and V-TOUGH, but comparable to TOUGH2. Developed for use in the area of reservoir engineering, these codes are proprietary, and that constitutes a major impediment to their use in licensing. They include THERM (SSI-Intercomp, Inc.) and TETRAD (DYAD 88 Software, Inc.). Like TOUGH2, these codes consider multiple phases and components and are nonisothermal. TOUGH is restricted to two phases and two components. 


\section{Major Assumptions and Limitations}

- An iterative solver is not available. However, a new version of TOUGH2, soon to be released, will offer a conjugate-gradient-type solver. The large problems encountered in characterizing Yucca Mountain require an iterative solution capability. In contrast to the direct solver now used by TOUGH, V-TOUGH, and TOUGH2, interactive solvers require less core storage and less computer time. For problems containing a few thousand elements, or more, the savings can be quite significant.

- For problems larger than a few thousand elements, the V-TOUGH solvers, though vectorized, may not be competitive with a conjugate-gradient-type solver.

- A steady-state option is not available. Generally, running through a transient sequence to achieve steady state represents a costly and expenditure of computer time. Since most transient characterization runs assume steady-state initial conditions, this is a significant consideration. Pruess (private communication) cautions, however, that for a multiphase simulation, establishing gravity equilibrium is somewhat difficult. In addition, for Yucca Mountain simulations, the enormous difference in the various physical time cons:ants causes a sequence of pseudo steady states to evolve, thus obscuring the definition of steady state.

- The transport of radionuclide chains is not considered. A recently released equationof-state module (EOS7) provides general algorithms, including density and viscosity variations, for single miscible species. TOUGH2 documentation (Pruess, 1991a) also notes that higher-order differencing is being considered to facilitate efficient simulation of the convection-dominated problems. Thus, the transport capabilities of TOUGH2 are steadily improving.

- Air is treated as an ideal gas and additivity of parti : jressures (Dalton's Law) is assumed for air-vapor mixtures. In view of much larger uncertainties present at the site, this limitation represents a moot point at this time. Dalton's Law, which may be proved rigorously for an ideal gas, states that the total pressure of a mixture of gases equals the sum of the individual pressures each gas would exert if it alone occupied the entire container.

- The temperature dependence of Henry's constant is neglected due to the very small air solubility in water. This limitation also represents a moot point at this time, but it is easily correctable should the need arise. Henry's Law relates the concentration of dissolved gas in solution to the partial pressure of the same gas in an atmosphere in contact with the solution.

\section{Remarks/General Observations/Discussion}

In terms of the breadth of processes considered, TOUGH is a very comprehensive code. By opening the architecture of its predecessor, TOUGH 2 facilitates future enhancements. Possibly, computer and software advances during the lifetime of the YMP will be insufficient to permit the latter to operate in a stochastic environment. Undoubtedly,

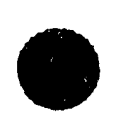


however, TOUGH2 and its future enhancements will play a strong role in characterizing near- and far-field flow of water and gas at the Yucca Mountain site.

To ensure its usefulness, the TOUGH codes will need improvements in computer efficiency. LLNL's V-TOUGH represents a step in the right direction. Nitao (1989) reports that approximately 80 percent of this version of TOUGH has been rewritten in order to improve efficiency. Even though it has been focused specifically on the Cray 2, much of this coding may prove useful for other machines as well. However, the demand for increased realism in Yucca Mountain simulations should push problem sizes beyond the level of several thousand elements. For such problems, conjugate-gradient-type solvers may prove superior to V-TOUGH's vectorized direct solvers in terms of both the CPU-time and computer memory requirements.

LBL will soon offer a version of TOUGH2 which uses a conjugate-gradient-type solver similar to that used by TRACR3D (Birdsell and Travis, 1991) and FEHM (Zyvoloski et al., 1991). Efforts by both LBL and LLNL provide a noteworthy beginning to an efficiencyimprovement program which should be continued, particularly with respect to solver improvements and implementation on massively parallel computers.

\section{Comparison to Other Models}

See Sections 4 and 5 of the main text.

\section{Summary and Recommendations}

- The TOUGH codes represent detain-process models which are useful for site characterization, site suitability, and detailed design review.

- They permit either equilibrium or disequilibrium between fracture and matrix. However, excessive computer-time requirements significantly restrict the scale of multi-dimensional applications.

- These codes may be used for some sensitivity analyses. However, excessive computer-time requirements make probabilistic total-system analyses impractical.

- They are well documented and widely used by the scientific community.

- Though all are cleanly coded, TOUGH2's open architecture is especially well suited for future enhancement.

- For this reason, TOUGH2 is selected for testing. Because of its extensive application to post-emplacement hydrothermal analyses, V-TOUGH may also be used.

\section{References}

Avdonin, N.A., 1964. Some Formulas for Calculating the Temperature Field of a Stratum Subject to Thermal Injection, Neft'i Gaz 3, 37-41. 
Birdsell, K.H., and B.J. Travis, 1991. TRACR3D: A Model of Flow and Transport in Porous Media, LA-11798-M, Los Alamos National Laboratory, Los Alamos, NM.

Bixler, N.E., 1985. NORIA - A Finite Element Computer Program for Analyzing Water, Vapor, and Energy Transport in Porous Media, SAND84-2057, Sandia National Laboratories, Albuquerque, NM.

Buscheck, T.A., and J.J. Nitao, 1992. The Impact of Thermal Loading on Repository Performance at Yucca Mountain, a paper presented at the 1992 International High Level Radioactive Waste Management Conference, April 12-16, 1992, UCRL-JC-109232, Lawrence Livermore National Laboratory, Livermore, CA.

Doughty, C., and K. Pruess, 1990. A Similarity Solution for Two-Phase Fluid and Heat Flow near High-Level Nuclear Waste Packages Emplaced in Porous Media, Int. J. Heat Mass Transfer, 33(6), 1205-1222.

Doughty, C., and K. Pruess, 1992. A Similarity Solution for Two-Phase Water, Air, and Heat Flow near a Linear Heat Source in a Porous Medium, Journal of Geophysical Research, Vol. 97, No. B2, 1821-1838.

Duff, I.S., 1977. A Set of FORTRAN Subroutines for Sparse Unsymmetric Linear Equations, AERE Harwell Report R8730.

Garg, S.K., 1978. Pressure Transient Analysis for Two-Phase (Liquid Water/Steam) Geothermal Reservoirs, paper SPE-7479, presented at 53rd Annual Fall Technical Conference and Exhibition of the SPE, Texas.

International Formulation Committee, 1967. A Formulation of the Thermodynamic Properties of Ordinary Water Substance, IFC Secretariat, Düsseldorf, Germany.

Moridis, G.J., and K. Pruess, 1992. TOUGH Simulations of Updegraff's Set of Fluid and Heat Flow Problems, LBL-32611, Lawrence Berkeley Laboratory, Berkeley, CA.

Nitao, J.J., 1989. V-TOUGH - An Enhanced Version of the TOUGH code for the Thermal and Hydrologic Simulation of Large-Scale Problems in Nuclear Waste Isolation, UCID21954, Lawrence Livermore National Laboratory, Livermore, CA.

Nitao, J.J., 1992. V-TOUGH Time-History Option, Memorandum, Accession Number NNA.900508.0040, UCID-21954, Lawrence Livermore National Laboratory, Livermore, CA.

Oldenburg, C.M., and K. Pruess, 1992. A Two-Dimensional Dispersion Module for the TOUGH2 Simulator, LBL-32505, Lawrence Berkeley Laboratory, Berkeley, CA.

Phillip, J.R., 1955. Numerical Solution of Equations of the Diffusive Type with Diffusivity Concentration Dependent, Transactions, Faraday Society 51, 885-892. 
Pruess, K., 1989. Modeling Studies of Multiphase Fluid and Heat Flow Processes in Nuclear Waste Isolation, Mat. Res. Soc. Symp. Proc. Vol. 127, 793-803, Materials Research Society Symposium, Berlin.

Pruess, K., 1987. TOUGH User's Guide, NUREG/CR-4645, SAND86-07104, LBL-20700, Sandia National Laboratories, Albuquerque, NM.

Pruess, K., 1991a. TOUGH2 - A General-Purpose Numerical Simulator for Multiphase Fluid and Heat Flow, LBL-29400, Lawrence Berkeley Laboratory, Berkeley, CA.

Pruess, K., 1991b. EOS7, An Equation-of-State Module for the TOUGH2 Simulator for Two-Phase Flow of Saline Water and Air, LBL-31114, Lawrence Berkeley Laboratory, Berkeley, CA.

Pruess, K., 1992. Brief Guide to the MINC Method for Modeling Flow and Transport in Fractured Media, LBL-32195, Lawrence Berkeley Laboratory, Berkeley, CA.

Pruess, K., and T.N. Narasimhan, 1985. A Practical Method of Modelling Fluid and Heat Flow in Fractured Porous Media, Society of Petroleum Engineers Journal, 25(1) 14-26, February 1985.

Pruess, K., Y.W. Tsang, and J.S.Y. Wang, 1985. Modelling of Strongly Driven Heat Flow in Partially Saturated Fractured Porous Media, Proceedings, IAH 17th International Congress on the Hydrogeology of Rocks of Low Permeability, Univ. of Arizona, 486-497.

Pruess, K., J.S.Y. Wang, and Y.W. Tsang, 1990a. On Thermohydrologic Conditions Near High-Level Nuclear Wastes Emplaced in Partially Saturated Fractured Tuff: 1. Simulation Studies With Explicit Consideration of Fracture Effects, Water Resour. Res., 26(6) 1235-1248.

Pruess, K., J.S.Y. Wang, and Y.W. Tsang, 1990b. On Thermohydrologic Conditions Near High-Level Nuclear Wastes Emplaced in Partially Saturated Fractured Tuff: 2. Effective Continuum Approximation, Water Resour. Res., 26(6) 1249-1261.

Ross, B., J.W. Mercer, S.D. Thomas, and G.H. Lester, 1982. Benchmark Problems for Repository Siting Models, NUREG/CR-3097, Geotrans, Inc., Reston, VA.

Runchal, A.K., and B. Sagar, 1991. PORFLOW: A Model for Fluid Flow, Heat, and Mass Transport in Multifluid, Multiphase Fractured or Porous Media, User's Manual - Version 2.34, ACRi/016/Rev. E, Analytical and Computational Research, Inc., West Los Angeles, CA.

Travis, B.J., 1984. A Model of Flow and Transport in Porous/Fractured Media, LA-9667-MS, Los Alamos National Laboratory, Los Alamos, NM. 
Udell, K.S., and J.S. Fitch, 1985. Heat and Mass Transfer in Capillary Porous Media Considering Evaporation. Condensable and Non-Condensable Gas Effects, presented at the 23rd ASME/AIChE National Heat Transfer Conference, Denver CO, 103-110, American Society of Mechanical Engineers, New York.

Updegraff, C.D., 1989. Comparison of Strongly Heat-Driven Flow Codes for Unsaturated Media, NUREG/CR-5367, SAND88-7145, Sandia National Laboratories, Albuquerque, NM.

White, M.D., and W.E. Nichols, 1992. Multiphase Subsurface Transport Simulator Theory Manual, Pacific Northwest Laboratory, Richland, WA.

Worgan, K.J., J. Pearson, and T. Nunez-McNally, 1990. A Review of Modelling of Gas Migration in Porous and Fractured Rock, Department of Environment, U.K., Commissioned Research on Radioactive Waste Management 1988/89, DOE Report No: DOE/RW/89/101.

Zyvoloski, G., Z. Dash, and S. Kelkar, 1991. FEHMN 1.0: Finite Element Heat and Mass Transfer Code, LA-12062-MS, Los Alamos Nationai Laboratory, Los Alamos, NM. 


\section{A.17 TRACR3D}

1. Name of the Model

TRACR3D

\section{General Program Information}

2.1 Program size. Approximately 10,000 lines of source code

\subsection{Programming language. FORTRAN 77}

2.3 Computer system on which it operates. Initially, TRACR3D was designed to run on CDC-7600. Then, the system was upgraded to the Cray X-MP at Los Alamos National Laboratory (LANL). TRACR3D has been installed on the Cray 1 computer at Sandia National Laboratories (SNL) (Prindle and Foster, 1987). In addition to SNL, TRACR3D has a group of users, and no doubt has been run on several other computers as well. According to the author (Travis, 1984), conversion should be relatively straightforward for any large-core system which supports words of 15 significant figures and several user-assigned logical units.

2.4 Compiler(s) used. TRACR3D uses the standard compiler on each machine.

2.5 Location of code and availability. The Quality Assurance (QA) section (EES-13) at LANL controls the release of the quality-controlled version TRACRN. An uncontrolled version of the code may be obtained from the author.

2.6 Brief description of modellcode history. TRACR3D (Birdsell and Travis, 1991), a multi-dimensional, two-phase flow and transport code, was developed by LANL. Initial development focused on the analysis of oil-shale reservoirs. Later modifications emphasized the flow and transport of radioactive tracers associated with the disposal of high-level radioactive waste.

\section{Status of Model}

3.1 Development (Is the model now undergoing significant development or modification? or continuing maintenance?) Development of TRACR3D is ongoing at LANL. Recent documentation (Birdsell and Travis, 1991) details many of the latest improvements. At the present time Travis (private communication) is examining the multi-grid technique, and his test cases suggest that this facility may reduce CPU time substantially. In view of the importance of code efficiency to the performance assessment of Yucca Mountain, the M\&O should follow Travis' multi-grid work carefully. Travis is not at present vectorizing TRACR3D coding.

3.2 Documentation. Documentation (Travis, 1984; Birdsell and Travis, 1991) is thorough and easily followed. 
3.3 Status of verification and validation. Travis (1991a) presents problems strictly to exemplify input-data construction. Although comparative results exist in many cases, they have not been assembled. This leaves three documents (Travis, 1984, Hayden, 1985, and Birdsell and Travis, 1991b) containing verification and validation problems. This seems a substantial amount of verification and validation for TRACR3D, and it is when compared to similar codes of the Yucca Mountain Site Characterization Project (YMP), TOUGH2 (Pruess, 1990) being the notable exception. However, the code changed substantially between 1985 and 1991 by the installation of a conjugategradient-type solver and the installation of new solution options for mass transport. Thus, for example, the computer times quoted by Hayden (1985) are no longer appropriate. Potentially, all the TRACR3D problems will be useful for the M\&O's testing program, and they are separately identified below.

\section{Travis (1984)}

- Problem A.1 - One-Dimensional Infiltration. An infiltration front enters a vertical column containing an initially partially saturated soil. Since air is assumed to be a passive spectator, the two-phase equations specialize to the Richards equation. TRACR3D results compare favorably with the numerical results of Hornung (1977).

- Problem A.2 - Two-Dimensional Saturated Flow. A pressure-controlled well injects water into one corner of an idealized rectangularly shaped reservoir. No-flow boundaries surround the reservoir. A second pressure-controlled well withdraws water from the opposite corner of the reservoir. The steady, twodimensional potential contours calculated by TRACR3D closely match the analytic results given by Bear (1972).

- Problem A.3 - Saturated Flow with Nonlinear Permeability. A steady, onedimensional flow passes through a horizontal soil column subject to constantpressure boundary conditions. Permeability is assumed to vary quadratically with pressure. The TRACR3D calculations show excellent agreement with analytic calculations.

- Problem B.1 - Advection-Dominated Transport. A constant-velocity flow field advects a stable tracer from a constant-concentration boundary into the interior of a one-dimensional column. The analysis assumed two different diffusivities. Both were small in comparison to the advection giving grid-block Peclet numbers of $\mathbf{5 2}$ and 5,200. For many finite-difference implementations, results become uninterpretable whenever Peclet numbers exceed a small multiple of two, typically four to six. For the indicated Peclet numbers, numerical results show remarkable agreement with the analytic results of van Genuchten (1976), indicating thereby the success of TRACR3D's high-Peclet-number algorithm.

- Problem B.2 - Transport of a Radioactive, Sorbing Tracer. A constant-velocity flow field advects a decaying tracer into a one-dimensional column. Sorption retards tracer movement in the column. After remaining constant for five

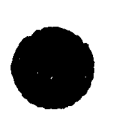


dimensionless time units, the tracer injection is removed, and the system is flushed with pure water having the same rate as the original injection. TRACR3D calculations agree with analytic calculations (van Genuchten, 1981).

- Problem B.3 - Non-equilibrium Sorption of a Diffusing Tracer. A sorbing tracer diffuses from a finite, well-stirred source, thereby causing a monotonically decreasing concentration within the source. The tracer diffuses into a soil column where it undergoes reversal, non-equilibrium sorption. A TRACR3D prediction of source concentrations agrees nicely with the analytic solution (Crank, 1957).

- Problem B.4 - Parallel Tracer Transport in Fracture and Adjacent Matrix. While advecting through a fracture, a tracer diffuses sideways into the adjacent rock matrix. In the porous matrix, the tracer encounters a slower, but non-negligible fluid flow moving parallel to the fracture. Sorption retards the tracer, further slowing its movement in the matrix. TRACR3D calculations at 75 years show reasonable agreement with analytic results (Nuttall and Ray, 1981).

Problem B.4 has implications for Yucca Mountain simulations. Travis (1984) uses a two-dimensional grid, and to properly characterize sideways diffusion uses a variable mesh within the rock matrix. This mesh grades from block sizes approaching the fracture width $(10 \mathrm{~mm})$ to much larger values $(100 \mathrm{~s}$ of $\mathrm{cm})$. Travis (1984) does not give a table of grid sizes in the sideways direction. Nevertheless, one can infer, based on the position of calculated points in Fig. 14, that a relatively large number of grid blocks has been used to adequately characterize the fracture-matrix exchange.

The implications may be significant. First, both for a partially saturated liquid during transient events and for a dissolved radionuclide, it is important to characterize the appropriate gradient at the fracture-matrix interface. This gradient controls flux into the matrix and, for non-equilibrium situations, controls the effective retention capacity of the matrix. Of course, predominantly dry conditions will favor flow and transport in the matrix alone. But simultaneous movement in fracture and matrix may be important for nonwelded units and for storm events.

Second, the gridding procedure used here, if generally applied, will degrade execution time sufficiently to make many field-scale Yucca Mountain problems impractical to simulate. Third and finally, this appears to be a code limitation both for TRACR3D (Travis, 1984) and for TOUGH2 (Pruess, 1990). The above arguments are meant to provide focus for both the component and the site-representative testing, and they emphasize the need for a more thorough conceptualization of the fracture-matrix interaction at Yucca Mountain.

- Problem B.5 - Transport of a Chain of Sorbing Tracers. A constant, onedimensional velocity transports a chain of tracers into a uniform porous material. This process continuously depletes the finite source inventory, and at 33,000 years completely exhausts the inventory. Thereafter, boundary concentrations are zero. Unequal half-lives transmute the members of this chain, and unequal retardations 
slow their movement. TRACR3D results at 50,000 years compare closely with the analytic solution (Pigford et al., 1980).

Several experiments that validate the TRACR3D code have been conducted:

- Problem C.1 - One-Dimensional Infiltration. A large caisson was sunk into one of the mesas in Los Alamos. At the bottom, six inches of gravel were overlaid with six inches of sand. The balance of the six-meter column was filled with crushed tuff. After complete saturation, the column was allowed to drain to equilibrium. This procedure established an initial condition. Then, a $13-\mathrm{cm}$ layer of water was added to the surface of the column, and saturations at various levels were monitored as a function of time. Perkins et al. (1985) describe the details of both the experiment and the simulation. In the latter, TRACR3D gave both initial and transient saturation profiles which agreed with experimental results to within experimental measurement errors.

- Problem C.2 - Non-equilibrium Sorption of a Diffusing Tracer. A well-stirred solution was placed in direct contact with a thin $(0.1 \mathrm{~cm})$ disk of tuff, thereby permitting ${ }^{90} \mathrm{Sr}$ to diffuse from the solution. Solution concentrations were monitored as a function of time for two days. Using coupled non-equilibrium sorption and diffusion models to characterize transport within the tuff wafer, TRACR3D yielded solution concentrations as a function of time. Simulated results compared well with experimental results.

- Problem C.3 - Transport of Tritium. At the Nevada Test Site, a radionuclide migration experiment was carried out over a period of several years. As a result of pumping, radionuclides migrated from the cavity created by an underground nuclear explosion, to a nearby well. The ground water was fully saturated. According to Travis (1984), the model employed only advection and diffusion mechanisms. Apparently, the approximately 12-year half life of tritium was thought to be sufficiently long that decay could be neglected. TRACR3D gave a breakthrough curve at the well, and the calculated tritium arrival time agreed with experimental results. Although the calculated peak height was greater than the observed value by slightly over 30 percent, and occurred somewhat earlier, the two were thought to agree to within experimental error.

\section{Hayden (1985)}

The YMP's COVE 1 study focuses on the tile-drainage problem, the geometry for which comes from Pickens et al. (1979). A tile of radius $0.05 \mathrm{~m}$ and depth $0.75 \mathrm{~m}$ drains an initially saturated soil slab measuring $1.5 \mathrm{~m}$ in depth and $5.0 \mathrm{~m}$ in length. Since only a symmetric half-system is considered, the tile is located along one boundary. The flow is two dimensional.

Pickens et al. (1979) considered only one case, with soil properties specified appropriately for a sandy soil. The COVE 1 study designates this case as COVE IN and extends the simulation over a 24-how period, during which the system approaches 
equilibrium. The COVE 1 study also considers two other cases, with soil properties specified appropriately for a nonwelded tuff. These cases, designated COVE $1 \mathrm{YMa}$ and COVE $1 \mathrm{YMb}$, extend the simulation time over thousands of years. The two cases differ only in terms of their boundary conditions.

The COVE study further extends the problem definition of Pickens et al. (1979) by considering transport. It assumes the presence of a nondecaying tracer, initially confined to the top $0.10 \mathrm{~m}$ of soil with constant concentration. COVE $1 \mathrm{~N}$ considers small longitudinal and transverse dispersivities were specified $\left(\alpha_{1}=2.0 \mathrm{~cm}\right.$ and $\alpha_{\mathrm{T}}=0.5 \mathrm{~cm}$ ), with no sorption and no diffusion. COVE 1YMa and COVE $1 \mathrm{YMb}$ consider both sorption $\left(k_{d}=230 \mathrm{ml} / \mathrm{g}\right)$ and molecular diffusion $\left(D=8.33 E-6 \mathrm{~cm}^{2} / \mathrm{s}\right)$, with no dispersion.

Most of the results of the COVE study are inconsequential insofar as the M\&O is concerned. Five sets of codes participated in the COVE 1 study, including TRACR3D (Birdsell and Travis, 1991), SAGUARO (Eaton et al., 1983) and TRUST (Narasimhan, 1975), all of which are being examined by the M\&O. After noting generally the similarity in the results obtained with these codes, the study, as reported by Hayden (1985), points out the relative accuracy of flow results in comparison to transport results. It also comments on the inability of finite-element codes to enforce a no-flow boundary and the effect this has on transport concentrations. The study also notes the presence of numerical dispersion in some of the results, an effect common to both finite-difference and finite-element codes which depends on mesh size. The study reassures finite-element users by noting that, for the relatively small fluxes present in the COVE-1 problems, the flux discontinuities at element boundaries introduce acceptably small discrepancies into the mass-transport calculations.

Table A-1 (Hayden, 1985) provides computer-run statistics. They show TRUST (Reisenauer et al., 1982 and Narasimhan, 1975) to be a very efficient code. For TRACR3D, they are inconsequential. Considering the CPU time per grid block per time step, TRACR3D run times are about the same as SAGUARO and Intera's proprietary code GWVIP. However, the reported TRACR3D times must be disregarded in view of a substantial upgrade in the TRACR3D solver. Rather than the Gauss-Seidel method used for the COVE 1 calculations, the code now uses the conjugate-gradient-type method. According to the author (Travis, private communication), the new solver should reduce CPU time by at least a factor of ten. Such a reduction would make TRACR3D run times approximately equal to those of the less comprehensive code TRUST.

\section{Birdsell and Travis (1991b)}

LANL, LBL (Lawrence Berkeley Laboratory), and SNL participated in the COVE-2a study using several different codes. At present, only TRACR3D results have been reported (Birdsell and Travis, 1991b). The study focuses on an idealized onedimensional stratigraphy consisting of $530.4 \mathrm{~m}$ and five fractured layers, the properties of which are taken from Yucca Mountain data. The problem definition memo (Prindle, 1986) specifies 12 isothermal one-dimensional problems, six steady and six 
unsteady cases. For the steady cases, a constant fluid flux is applied at the ground surface, and the steady-state system properties are reported as a function of depth. The solutions for the steady cases are then used as initial conditions for the unsteady cases.

To produce transient behavior, the applied flux is doubled at time zero and held at the higher rate. The transient system responses are followed as functions of depth and time. Each flow calculation is made for two stratigraphic configurations to test the sensitivity of the numerical solution techniques to sharp contacts between material layers with very different hydrologic characteristics. The configurations differ in the material type of the bottom unit; one uses the zeolitized Calico Hills (CHnz) and the other uses the vitrified Calico Hills (CHnv). The hydraulic conductivity of the latter (2.7E-7 m/s) exceeds that of the former by four orders of magnitude. Assuming that fracture and matrix are in local equilibrium, the calculations use the compositeporosity model of Peters and Klavetter (1988) to describe flow through a fractured rock mass.

A finite-difference mesh consisting of 362 grid blocks was applied to all twelve cases, with finer mesh placed at layer boundaries than in layer interiors. To check sensitivity to block size, grids consisting of 233,329 , and 521 blocks were also used. Differences, though small, appeared in the Darcy velocity and at layer boundaries. One expects this because of two reasons. First, the differentiation of pressure used to calculate the Darcy velocity lowers the order of accuracy of the Darcy velocity with respect to the calculated pressure. Second, sharply contrasting permeabilities at layer boundaries cause sharp discontinuities in the pressure gradient, an effect which is troublesome to capture with a numerical code. For the Newton-Raphson iteration on the nonlinear flow equations, TRACR3D applied an absolute convergence criterion of $0.1 \mathrm{~Pa}$ (approximately $1 \mathrm{E}-5 \mathrm{~m}$ ). Since liquid pressures ranged from $-150 \mathrm{~m}$ to zero, one would classify this as an extremely tight criterion, and one would expect relatively long run times.

One may refer to Birdsell and Travis (1991b) for detailed resuits from each of the twelve cases. Since efficiency is a prime concern, we note here only the CPU times for a Cray X-MP/48 computer: 0.5 to $3 \mathrm{~min}$ for the steady-state problems and 1.5 to $11 \mathrm{~min}$ for the unsteady flow problems. Although Birdsell and Travis (1991b) characterize these times as "very fast," they must be interpreted with caution. For these single-phase problems, TRACR3D solved only its liquid-flow equation. The gas-flow equation was not used. In addition, the COVE 2a problems did not exercise TRACR3D's conjugate-gradient-type solver, which will be used for more realistic calculations using more than one dimension.

3.4 Status of Quality Assurance (QA). TRACR3D is not under QA control. TRACRN, a sister code to TRACR3D with nearly identical capabilities, is currently being brought under QA control at LANL. The trget date for completion of this work, together with documentation, was scheduled for January 1992. 


\section{Type of Model (Phenomena/Processes Modeled)}

TRACR3D is a multi-dimensional (one-, two-, or three-dimensional) numerical model designed to simultaneously simulate isothermal liquid and gas flow and multi-component tracer transport in porous and fractured media. Features present in the code include:

- Fluid flow in both liquid and gas phases under pressure, viscous, and gravity forces according to Forschheimer's equation, a generalization of Darcy's law appropriate to Reynolds numbers less than 100

- Transient and steady-state solution options for the flow

- Capillarity between liquid and gas phases

- Transport of tracers by advection, dispersion, and diffusion in both liquid and gas phases

- Radioactive production and decay of tracer chains of arbitrary length

- Non-equilibrium sorption and desorption limited by degree of reversibility, adsorption limit, and solubility

- High-ordered finite-difference representation of advection capable of resolving sharp concentration fronts at high Peclet number.

- Discrete fractures including dead-ended fractures

- Matrix diffusion in directions both parallel and perpendicular to fracture.

\section{Governing Equations}

For partially saturated flow, TRACR3D solves two governing equations in as many as three dimensions. One governing equation treats mass conservation for the liquid phase, and another treats mass conservation for a non-condensing gas. For single-phase flow, the model solves only one such equation. The system is assumed to be isothermal, and neither vapor nor dissolved gas is considered. For Reynolds numbers between ten and 100, the Forschheimer equation provides a suitable generalization of Darcy's law. Such a formulation may be appropriate for fracture-transport simulations.

For tracer transport, the model solves one governing equation per radioactive component. The number of tracer components is limited only by computer time and space requirements. In contrast to the gas component, the TRACR3D partitions the tracer component between liquid and gas via Henry's law. The liquid and gaseous forms convect, diffuse, and disperse, and the mathematical models characterizing these processes are based on the conventionally used algorithms, with only a few exceptions. The exceptions consist of two coefficients. One scales the diffusion with an exponential term which strongly attenuates the diffusion within a given phase as the phase saturation becomes small. Another coefficient scales the 
dispersion according to the ratio of an intrinsic-length parameter to dispersivity. The intrinsic length could be specified as the correlation length of a heterogeneous permeability field, for example. Tracers may be chained via radioactive decay and production. In comparison to similar models, TRACR3D provides a large menu of sorption submodels, including equilibrium, non-equilibrium, reversible, and nonreversible options.

\section{Method of Solution}

TRACR3D uses finite-difference spatial discretization for both flow and transport. The flow solution employs a fully implicit finite-difference discretization in the temporal domain, obtaining thereby a coupled set of nonlinear difference equations. Application of the Newton-Raphson method linearizes the nonlinear equations and yields a set of linear equations with a nonsymmetric coefficient matrix - the Jacobian matrix.

For a given time step, TRACR3D assumes first that gas pressures change negligibly. This decouples the liquid and gas-flow equations, effectively reducing that for liquid flow to the Richards equation. After iterative solution for the liquid flow and with permeabilities updated using values of liquid saturation, the model performs an iterative solution for the gas flow. Variations in gas saturations, having been assumed to be negligibly small at the beginning of the gas-flow solution, are updated following gas-flow solution. Although such a solution will not be robust for systems with large and rapid changes in the gas phase, it should be adequate for nonisothermal calculations at Yucca Mountain.

TRACR3D offers a variety of techniques for solving the tracer-transport equations. Birdsell and Travis (1991) classify them as either "implicit" or "explicit". The implicit technique permits a variable amount of donor differencing. Like the algorithms employed for solution of the flow equations, the implicit technique yields a set of simultaneous solutions, which are solved by the incomplete-factorization method discussed below. With the explicit techniques, the accumulation term is not differenced but rather is expressed as a formal derivative. Fourth-order Runge Kutta is then used to integrate the resulting set of ordinary differential equations across each time step. Hindmarsh (1980) identifies this as the method of lines, a technique employed in the flow solution of DCM3D (Updegraff et al., 1991) and LLUVIA-II (Eaton and Hopkins, 1992).

For characterizing the convection term, explicit techniques use both high-order differencing and direct subtraction of the numerical dispersion. Among the Yucca-Mountain codes, these two features are unique to TRACR3D. Even though its theoretical limit is two, a standard second-order differencing of the advection term can consider grid-block Peclet numbers as high as about four. Thus, the results of Verification Problem 1 (Travis, 1984) are quite impressive. Calculated with TRACR3D's high-order finite differencing, these results shows excellent comparisons with analytic solutions for grid-block Peclet numbers of 52 and 5,200, approximately.

As discussed by Travis (1984), TRACR3D uses a discrete-fracture implementation in both flow and transport calculations. Here, the analyst is given several options through which fractures may be placed along selected grid faces with specified aperature and spacing. 
For solution of the linearized flow and for solution of the transport equations under the implicit-solution option, TRACR3D uses a generalized conjugate-gradient approach suitable for nonsymmetric matrices. Instead of complete factorization, as used by a direct solver, this approach uses incomplete factorization to precondition the Jacobian matrix. This minimizes core-storage requirements. Depending on the number of iterations and the size of the problem, it may also minimize CPU time. To minimize the number of iterations, TRACR3D uses the GMRES (Generalized Minimal Residual Equation Solver) procedure (Saad and Schultz, 1986).

\section{Type of Input Parameters}

Input into TRACR3D is accomplished through a single file (INPUT) using Fortran NAMELIST statements. The first line of the file contains the variables RESTART and CHANGE which determine if the current run is new or a continuation and whether changes will be allowed in the input list. The second line is reserved for the problem title. The remainder of the data is divided into the following groups:

Geometry Specification

- Type of coordinate system

- Number of dimensions

- Blocks of mesh zones having a specified time history

- Blocks having sources or sinks of mass

- Blocks with specified material types

- Internal no-flow planes

- Zoning in $\mathrm{x}$-direction

- Zoning in $y$-direction

- Vertical spacing

- Fracture-system specifiçtion (explicit, automatic, or random)

- Depending on chosen specification option, fracture parameters such as extension, width, and spacing. 


\section{Boundary Conditions}

- Boundary condition indicators for all boundaries

- Time-dependent of boundary conditions

- Initial concentrations of boundary cells (where appropriate)

- Duration of leach period (where appropriate).

Material, Fluid, and Tracer Properties

- Initial ambient air pressure

- Initial default air saturation

- Molecular diffusivity of tracers in host fluid

- Half lives (if radioactive)

- Molecular weight of tracers

- Initial velocity field

- Molecular weight of fluids

- Number of tracers

- Initial air-saturation distribution

- Initial pressure distribution

- Initial tracer-concentration distribution

- Viscosity of liquid component

- Viscosity of gas component

- Density of liquid

- Compressibility of liquid

- Temperature

- Source/sink tables

- Material property tables including saturated permeability, porosity, average particle size, matrix compressibility, irreducible water saturation, pore-size distribution index, bubbling pressure, bulk matrix density, and constrictivity coefficient 
- Tables for capillary pressure if analytical expression is not desired

- Tables for air and water relative permeabilities if analytical expression is not desired

- Initial values of adsorbed species

- Adsorption and desorption coefficients for cach tracer and each material type

- Maximum amount of tracer that can be adsorbed on each material type

- Solubility limit of each tracer in the presence of each material type.

Time Parameters

- Time-step size

- Initial time-step size

- Maximum allowed time step

- Postprocessing times

- Final and initial problem time

- Number of passes made in solution of transport equations

- Times at which time step will be set to a given value.

Flow Parameters

- Initially active cells

- Changes from initial pressure, air saturation, or concentration required to extend active mesh region

- Absolute tolerance for convergence of water-pressure solution

- Absolute tolerance for convergence of gas pressure and water pressure

- Over- or under-relaxation parameter

- Gravitational acceleration

- Flags indicating whether to include advective transport and whether to calculate dispersion tensor

- Type and number of phases

- Flags indicating whether flow is steady, whether permeabilities are pressure dependent, whether the Forschheimer term should be calculated, and whether one or more variables are spatially nonuniform 
- Minimum number of iterations for pressure solution

- Minimum number of iterations at which to freeze time step

- Maximum number of iterations allowed before time step is reduced

- Flags indicating presence and type of sorption and decay

- Sloping cells for which a horizontal component of gravity must be assigned.

There are also several input choices required of the user to determine the type of output that will be generated.

\section{Type of Output and User Options}

Several files containing various types of output are generated by TRACR3D. General information for printing is stored in the file OUTPUT. This file contains information about the problem setup, as generated from input data, along with some or all of the following parameters, depending on options chosen by the user:

For each time and cell specified,

- gas and water pressure

- gas saturation

- tracer fluid and solid concentrations.

For each layer of cells,

- time, cycle number, current time step

- cumulative air and water masses which have crossed specified boundaries of the problem

- boundary conditions and/or space coordinates of boundaries

- material number of each cell and whether active or inactive

- source-sink information

- cumulative gas and water production of specified cells. 
For each cycle or time step,

- number of iterations to solve the flow equations

- maximum difference in gas pressures for the last two iterations

- mass conservation ratio

- computing time for last step.

Output for postprocessing of various plots including time history plots, horizontal or vertical line plots, contour plots, and three-dimensional dot density or vector plots is stored in files labeled TAPE 7, 8, 9, and 10. The following variables can be plotted: gas or liquid phase velocity, pressure (both air and water), liquid saturation, tracer fluid and solid concentration, time-step size, and total gas mass flow, total liquid flow, and gas fraction across each boundary.

\section{Model Interactions (emphasize needed processors)}

9.1 Does the model interface with any other models? No.

9.2 Source code and type of information needed. Not applicable.

9.3 Receiving code and type of information provided. Not applicable.

9.4 Any pre- or postprocessing needed? Postprocessing programs are needed to produce the previously mentioned plots. Postprocessing programs are very machine-dependent and those available now can be used only on systems that have the DISSPLA graphics package (copies may be obtained from the author).

\section{Model Application}

10.1 Usage within the Civilian Radioactive Waste Management System (CRWMS) program. TRACR3D can be used to characterize some flow processes, providing that vapor movement and thermal processes may be neglected. The effect of matrix flow in nonwelded units on downward flow through fractures would likely fall within its purview. Potentially, TRACR3D could also be used to characterize the transport of radioactive gases. Here, however, its exclusion of nonisothermal processes may prove unreasonably restrictive.

TRACR3D should prove most useful in characterizing ground-water transport processes. It can make a non-stochastic determination of pre-emplacement groundwater travel time. The code has excellent capabilities both for characterizing sorption and reaction processes and for characterizing high Peclet-number transport velocities. The latter should mean that TRACR3D has superior computer efficiency in comparison to other transport simulators, an important consideration since computer efficiency can be a major limitation for 10,000-year transient simulations. In conjunction with a more capable flow simulator, the TRACR3D transport simulator 
should be capable of providing non-stochastic simulations of 10,000-year cumulative releases.

10.2 Usage outside the program. Originally, TRACR3D was developed for use in oil-shale analyses by the petroleum industry. Potentially, TRACR3D can be used to study chemical waste storage, soil water movement, and tests that define hydrocarbon (oil and gas) reservoir structure. Recently, following the review of a number of similar codes, Worgan et al. (1990) recommended that TRACR3D, TOUGH (Pruess, 1987), and two other codes for use in the United Kingdom's Nirex program. Like the U.S. program for high-level waste, this program focuses on deep burial of low and intermediate-level radioactive waste in engineered repositories.

\section{Codes With Similar or Same Capabilities}

11.1 Within the program. The YMP has funded the development of several codes with multiphase flow capabilities similar to those of TRACR3D. These codes include TOUGH2 at LBL, V-TOUGH (Nitao, 1989) at LLNL (Lawrence Livermore National Laboratory), NORIA (Bixler, 1985) at SNL, MSTS at PNL (Pacific Northwest Laboratory), and FEHM at LANL. All these codes simulate multiphase flow. They differ in terms of conceptualization options: dimensionality (two or three dimensions) and fracture characterization (equivalent continuum, dual permeability, dual porosity, or discrete fractures). They differ in terms of numerical solution: spatial-discretization (finite difference or finite element), linearization (Picard or Newton-Raphson), and linear-equations solver (direct solution, successive over-relaxation, method of lines, or conjugate gradient). The codes also differ in terms of physical processes (heat transport, vapor flow, and transport of radioactive contaminants in both gas and liquid phases.

The YMP has funded the development of several codes with transport capabilities similar to those of TRACR3D. These codes include general process codes like VS2DT (Healy, 1990 and Lappala et al., 1987) at USGS, and they include stand-alone transport codes like FEMTRAN (Martinez, 1985) and LLUVIA-S at SNL. They also include total-system codes with embedded transport routines, like SUMO (Eslinger et al., 1990) at PNL and TOSPAC (Dudley, et al., 1988) at SNL. In terms of conceptualization options and numerical solution, the codes differ in the same respects as the flow codes, with two important exceptions. In contrast to multiphase flow, the effects of non-linearity tend to be much less severe for transport, with transport and chemical-process parameters evidencing either independence or only a weak dependence on concentration. If it were not for the second item, this linearity would make the numerical simulation much more efficient. However, advection can be a much more dominant process for transport than for multiphase flow, and this tends to degrade computer efficiency.

11.2 Outside the program. In the YMP, the U.S. Nuclear Regulatory Commission (NRC) has funded the documentation of TOUGH and the development of DCM3D. The former has a general capability for treating multiphase flow while the capability of the latter is limited to that of a nonisothermal Richards-equation implementation. 
Further, several codes have been developed within the petroleum industry. In terms of the multiphase-flov processes considered, both black-oil and compositional models (Peaceman, 1977) provide a capability superior to TRACR3D. Developed for use in the area of reservoir engineering, these codes are proprietary, and that constitutes a major impediment to their use in licensing. Compositional models include THERM (SSI-Intercomp, Inc.) and TETRAD (DYAD 88 Software, Inc.). These codes consider more than two phases with generally unrestricted components. They are nonisothermal. TRACR3D has only two phases. Further, the liquid phase (component) is not permitted to vaporize into the gas phase, and, similarly, the gas phase (component) is not permitted to dissolve into the liquid phase.

Other federally funded projects have developed transport codes to characterize the movement of radionuclide chains. SWIFT II (Reeves et al., 1986), a saturated flow and transport code, provides one example. The NRC developed this code for their salt-repository project.

\section{Major Assumptions and Limitations}

- TRACR3D does not consider either heat transport or vapor movement. Current calculations indicate that these processes cause liquid movement toward the repository and vapor movement away from the repository. It is possible that these two effects will predominantly control the movement of radioactive gas and liquid components. This limitation affects the recommendations of Section 16.

- A steady-state option is not available. For large problems, running through a transient sequence to achieve steady state represents a costly and needless expenditure of computer time. Since most transient characterization runs assume steady-state initial conditions, this is a significant consideration. Since all detailed-process codes developed for the YMP have this defect, further development may be required.

- The gridding required to characterize the fracture-matrix exchange of mass or phasepressure changes may severely restrict the size of non-equilibrium field-scale simulations.

- An ideal gas is assumed. Uncertainties due to non-ideal behavior should be negligibly small.

- The liquid is assumed to be compressible under saturated conditions, but incompressible under unsaturated conditions. This is an acceptable assumption requiring no additional development.

- TRACR3D considers radionuclide concentrations to be small and thus includes only ordinary diffusion dependent on the concentration gradient. This is a standard assumption requiring no additional development. Bird et al. (1966, pp. 563 ff.) provide a general discussion of multicomponent diffusion. 
- The dispersion tensor is assumed to be dependent on fluid velocity only. Although the literature has questioned this assumption, no acceptable alternative has yet been offered. Thus, no additional development is required at this time.

\section{Remarks/General Observations/Discussion}

In terms of the basic physics of its multiphase flow code, TRACR3D is inferior to TOUGH2 and to FEHM. However, in its transport model, TRACR3D is superior to both these codes. TOUGH2 has no transport capability and, comparatively, FEHM's is quite limited. While TRACR3D's excellent geochemical model is matched only by VS2DT, its high Pecletnumber capability is unmatched by other transport codes within the YMP.

With their GMRES solvers, TRACR3D and FEHM now utilize computer resources more efficiently than TOUGH2. When released, however, LBL's most current version of TRACR3D will also offer a GMRES solver. In comparison to direct solvers, an iterative GMRES solver substantially decreases computer storage requirements, thereby permitting the solution of larger problems. The iterative solver can also decrease computer time requirements for such problems.

\section{Comparison to Other Models}

See Sections 4 and 5 of the main text.

\section{Summary and Recommendations}

- TRACR3D is a detailed process code. Its transport capability is useful for characterization of geochemical effects on transport and for non-stochastic determinations of the 10,000-year cumulative release. Its transport capability is also useful for characterization of the rapid fracture flows which may accompany storm events.

- An excessive demand for computer resources is the rule for Yucca Mountain process codes. Generally, the matrix-solution algorithm represents the dominant consumer of both computer time and computer space. TRACR3D employs a GMRES iterative routine for the matrix solution which is among the best currently available for multidimensional simulations of Yucca Mountain.

- TRACR3D is well documented. Though not as widely used as TOUGH, TRACR3D has good name recognition within the scientific community.

- Although the TRACR3D user's guide contains candidate test problems which may be used for cross-comparison of different numerical models, a comparison of TRACR3D to a similar code, such as TOUGH, has not been reported. Thus, a relative comparison of computer resource requirements is somewhat speculative at this point.

- In consideration of all of the above, it is recommended that the M\&O include TRACR3D in its component-testing program. 


\section{References}

Aziz, K., and A. Settari, 1979. Petroleum Reservoir Simulation, Elsevier Applied Science Publishers, New York.

Bird, R.B, W.E. Stewart, and E.N. Lightfoot, 1960. Transport Phenomena, John Wiley and Sons, New York.

Birdsell, K.H., and B.J. Travis, 1991a. TRACR3D: A Model of Flow and Transport in Porous Media, LA-11798-M, Los Alamos National Laboratory, Los Alamos, NM.

Birdsell, K.H., and B.J. Travis, 1991b. Results of the COVE2a Benchmarking Calculations Run with TRACR3D, LA-11513-MS, Los Alamos National Laboratory, Los Alamos, NM.

Bixler, N.E., 1985. NORIA - A Finite Element Computer Program for Analyzing Water, Vapor, and Energy Transport in Porous Media, SAND84-2057, Sandia National Laboratories, Albuquerque, NM.

Brooks, R.H., and A.T. Corey, 1964. Hydraulic Properties of Porous Media, Hydrology Papers, Colorado State University, Fort Collins, CO.

Dudley, A.L., R.R. Peters, J.H. Gauthier, M.L. Wilson, M.S. Tiemey, and E.A. Klavetter, 1988. Total System Performance Assessment Code (TOSPAC) Volume 1: Physical and Mathematical Bases, SAND85-0002, Sandia National Laboratories, Albuquerque, NM.

Eaton, R.R., D.K. Gartling, and D.E. Larson, 1983. SAGUARO - A Finite Element Computer Program for Partially Saturated Porous Flow Problems, Sandia National Laboratories, SAND82-2772.

Eaton, R.R., and P.L. Hopkins, 1992. LLUVIA-II: A Prograin for Two-Dimensional Transient Flow Through Partially Saturated Porous Media. SAND91-2146, Sandia National Laboratories, Albuquerque NM.

Eslinger, P.W., T.B. Miley, and D.W. Engel, 1990. SUMO-System Performance Assessment for a High-Level Nuclear Waste Repository: Mathematical Models, PNL-7581, Pacific Northwest Laboratory, Richland, WA.

Hayden, N.K., 1985. Benchmarking NNWSI Flow and Transport Codes: COVE 1 Results, SAND84-0996, Sandia National Laboratories, Albuquerque, NM.

Healy, R.W., 1990. Simulation of Solute Transport in Variably Saturated Porous Media With Supplemental Information on Modifications to the U.S. Geological Survey's Computer Program VS2D, Water-Resources Investigations Report 90-4025, U.S. Geological Survey, Denver, CO.

Hindmarsh, A.C, 1980. ODE Solvers for Use with the Method of Lines, UCRL-85293, Lawrence Livermore Laboratory, Livermore, CA. 
Lappala, E.G., R.W. Healy, and E.P. Weeks, 1987. Documentation of Computer Program VS2D to Solve the Equations of Fluid Flow in Variably Saturated Porous Media, WaterResources Investigations Report 83-4099, U.S. Geological Survey, Denver, CO.

Martinez, M.J., 1985. FEMTRAN - A Finite Element Computer Program for Simulating Radionuclide Transport Through Porous Media, Sandia National Laboratories, SAND840747.

Narasimhan, T.N., 1975. A Unified Numerical Model for Saturated-Unsaturated Groundwater Flow, Ph.D dissertation, University of California, Berkeley, CA.

Nitao, J.J., 1989. V-TOUGH - An Enhanced Version of the TOUGH code for the Thermal and Hydrologic Simulation of Large-Scale Problems in Nuclear Waste Isolation, UCID-21954, Lawrence Livermore National Laboratory, Livermore, CA.

Peaceman, D.W., 1977. Fundamentals of Numerical Reservoir Simulation, Elsevier Scientific Publishing Company, New York.

Perkins, B.A., and B.J. Travis. Soil Water Flow Under Saturated/Unsaturated Conditions Validation of the TRACR3D Code in Three Experiments, Los Alamo National Laboratory, Los Alamos, NM.

Pickens, J.F., et al., 1979. Finite Element Analysis of the Transport of Water and Solutes in Tile-Drained Soils, Journal of Hydrology, 40, pp. 243-264.

Prindle, N.K., 1986. Benchmarking of Flow and Transport Codes, COVE2a-Yucca Mountain Hydrology, Sandia National Laboratories memorandum, YMP Accession No. NNA.890523.0140.

Prindle, N.K., and J. Foster, 1987. Sandia Implementation of the TRACR3D Flow and Transport Code, SAND85-0008, Sandia National Laboratories, Albuquerque, NM.

Pruess, K., 1990. TOUGH2 - A General-Purpose Numerical Simulator for Multiphase Fluid and Heat Flow, LBL-29400, Lawrence Berkeley Laboratory, Berkeley, CA.

Reeves, M., D.S. Ward, N.D. Johns, and R.M. Cranwell, 1986. Theory and Implementation for SWIFT II, The Sandia Waste-Isolation Flow and Transport Model for Fractured Media, Release 4.84, NUREG/CR-3328, U.S. Nuclear Regulatory Commission, Washington DC, and SAND83-1159, Sandia National Laboratories, Albuquerque, NM.

Reisenauer, A.E., K.T. Key, T.N. Narasimhan, and R.W. Nelson, 1982. TRUST: A Computer Program for Variably Saturated Flow in Multidimensional, Deformable Media, NUREG/CR-2360, U.S. Nuclear Regulatory Commission, Washington DC, and PNL3975, Pacific Northwest Laboratory, Richland WA.

Travis, B.J., 1984. TRACR3D: A Model of Flow and Transport in Porous/Fractured Media, LA-9667-MS, Los Alamos National Laboratory, Los Alamos, NM. 
Updegraff, C.D., C.E. Lee, and D.P. Gallegos, 1991. DCM3D: A Dual-Continuum, Three Dimensional, Ground-Water Flow Code for Unsaturated, Fractured, Porous Media, NUREG/CR-5536, SAND90-7015, Sandia National Laboratories, Albuquerque, NM.

Worgan, K.J., J. Pearson, and T. Nunez-McNally, 1990. A Review of Modelling of Gas Migration in Porous and Fractured Rock, Department of Environment, U.K., Commissioned Research on Radioactive Waste Management 1988/89, DOE Report No: DOE/RW/89/101. 


\section{A.18 VS2DT}

1. Name of the Model

VS2DT

2. General Program Information

2.1 Program size. VS2DT (Lappala et al., 1987 and Healy, 1990) contains approximately 4,000 source statements.

\subsection{Programming language. ANSI FORTRAN77}

2.3 Computer system on which it operates. Sun, Prime, PC-386, and PC-486

2.4 Compiler(s) used. Standard compilers.

2.5 Location of code and availability. VS2DT may be obtained from the U.S. Department of Interior, Geological Survey, Box 25046, Mail Stop 421, Denver Federal Center, Denver, CO 80225.

2.6 Brief description of modellcode history. VS2DT was developed in order to make a Richards-equation-based flow and transport model developed by the U.S. Geological Survey (USGS) available to the general public.

\section{Status of Model}

3.1 Development (Is the model now undergoing significant development or modification? or continuing maintenance?). No.

3.2 Documentation. Lappala et al. (1987) provides a readable discussion of theory and data input for flow analyses. Healy (1990) provides a supplementary discussion of theory and data input for transport analyses.

3.3 Status of verification and validation. Lappala et al. (1987) present five verification and validation problems for the flow module.

Problem 1: A horizontal, one-dimensional column has a constant hydraulic diffusivity function $\left(D=0.3118 \mathrm{~cm}^{2} / \mathrm{min}\right)$. Initially, the total head $(\mathrm{H}=0)$ is constant throughout the length $(\mathrm{L}=8.0 \mathrm{~cm})$ of the column. Two Dirichlet boundary conditions $(\mathrm{H}=0$ and $\mathrm{H}=3 \mathrm{~m})$ control recharge and discharge from the system. For a uniform grid spacing $(0.5 \mathrm{~cm})$, the VS2DT analysis gave head values which, for an elapsed time of five minutes, compared favorably with analytic calculations. The latter employ a relation taken from Carslaw and Jaegar (1959). 
Problem 2: An infinite, nonleaky aquifer with an initial head value $\mathrm{H}=100 \mathrm{~m}$ and a constant hydraulic diffusivity function $\left(D=1,157 \mathrm{~m}^{2} / \mathrm{min}\right)$. Penetrating the entire thickness $(b=10 \mathrm{~m})$, a well withdraws fluid at a constant rate $\left(q=13.369 \mathrm{~m}^{3} / \mathrm{min}\right)$. Using a one-dimensional radial coordinate system, the VS2DT analysis employed variable time steps and variable grid spacings. The analysis gave head values which, at a radial distance of $3.94 \mathrm{~m}$, compared favorably with the analytical solution of Theis (1935).

Problem 3: Surface evaporation, arising from a large negative head, causes a capillary-driven upward flow of moisture from the water table. Assuming an infinitely negative capillary head $h$ at the ground surface and a Haverkamp-type relation $K_{1}=\left[1+(h / A)^{b}\right]^{-1}$ (Haverkamp et al., 1977) between capiliary head and relative conductivity permits one to obtain the steady evaporation rate analytically (Ripple et al., 1972). Both analytic and numeric calculations assume a saturated conductivity $\mathrm{K}=0.10 \mathrm{~m} /$ day, a water-table depth $\mathrm{L}=100 \mathrm{~m}$ below the ground surface, and relative-permeability parameters $A=-0.10 \mathrm{~m}$ and $B=3$, corresponding to a medium sand. VS2DT results vary depending on grid spacing, weighting scheme, and the finite values used to approximate the effect of an infinitely negative capillary head used as a boundary condition in the analytic solution. However, using a geometric mean weighting with relatively small grid spacing at the ground surface yielded a value for the evaporation rate which is identical to that obtained with the analytic solution.

Problem 4: A vertical column of sand has a length $\mathrm{L}=0.70 \mathrm{~m}$ and an initial capillary head and a lower boundary condition $h=-0.615 \mathrm{~m}$. Infiltration into the top surface at a rate $0.1369 \mathrm{~m}$ causes a front to develop within the column. Here, VS2DT results are obtained using upstream, arithmetic-mean, and geometric-mean weighting. In each case, numerical results compared favorably to the experimental results of Haverkamp et al. (1977), particularly at larger times.

Problem 5: In an experiment reported by Duke (1973) and by Hedstrom et al. (1971), water infiltrates through the surface of a flume at a constant rate $(0.1035 \mathrm{~m} / \mathrm{d})$, then seeps from its sides. Impermeable along its bottom, the flume measures $12.2 \mathrm{~m}$ in length and $1.22 \mathrm{~m}$ in height. The packed Poudre sond, which fills the flume, may be characterized by the Brooks-Corey relations for effective saturation $s_{0}$ and relative hydraulic conductivity $K_{T}$. They are: $s_{6}=\left(h_{b} / h\right)^{\lambda}$ for $h<h_{b}$, $s_{c}=1.0$ for $h \geq h_{b}, K_{q}=\left(h / h_{b}\right)^{-2.3 \lambda}$ for $h<h_{b}$, and $K_{q}=1.0$ for $h \geq h_{b}$. This analysis validates VS2DT by comparing its results with those obtained by experiment and with those obtained by an earlier analysis (Davis and Neuman, 1983). Both analyses use the same values of the hydraulic parameters: porosity $\theta_{3}=0.348$, airentry head $h_{b}=-0.19 \mathrm{~m}$, pore-size distribution index $\lambda=1.6$, and saturated conductivity $\mathrm{K}=5.564 \mathrm{~m} / \mathrm{d}$. The VS2DT grid, which covered a symmetric half section of the flume, consisted of 42-by-23 array with 1344 nodes. This grid was variable in both directions, being fine near the soil surface and near the seepage face. The VS2D analysis reached steady state after 136 time steps or 5.89 days, and the calculated steady-state position of the free-water surface agreed with that determined by experiment. Similarly, the steady-state head profile at the outlet 
boundary calculated by VS2DT agreed with that determined by Davis and Neuman (1983). Healy (1990) presents five verification and validation problems for the transport module.

Problem 1: From a fully penetrating injection well injecting at a constant rate, fluid of concentration $\mathrm{C}=1$ enters a fully saturated confined aquifer having an initial concentration $\mathrm{C}=0$. Although several analytic solutions characterize the radial spreading of the concentration, the one by Hsieh (1986) is chosen here for comparison with VS2DT. To determine flow, both analytic and numeric analyses assume injection rate $Q=225 \mathrm{~m}^{3} / \mathrm{h}$, porosity $\theta_{3}=0.20$, well radius $r_{w}=0.05 \mathrm{~m}$, and aquifer thickness $b=10 \mathrm{~m}$. To determine transport, both analyses assume a longitudinal dispersivity $\alpha_{\mathrm{L}}=10 \mathrm{~m}$. Although the problem requires consideration of the radial direction only, VS2DT uses a two-dimensional r-z grid consisting of three rows and 188 columns. Radial grid spacing varies from $0.05 \mathrm{~m}$ near the well to $5 \mathrm{~m}$, with the total radius of the simulated region extending out to $847 \mathrm{~m}$. The temporal grid, which varies upward from an initial time step of $1 \times 10^{-7} \mathrm{~h}$, consisted of 1,043 time steps covering a total time of 2,000 h. The chosen numerical algorithm uses centered differencing in both spatial and temporal domains. Results obtained with VS2DT consisted of four concentration profiles corresponding to four different times. They were nearly identical to those obtained with the analytical solution of Hsieh (1986).

Problem 2: Water moves through a fully saturated $160-\mathrm{m}$ column of soil with an interstitial velocity of $27.778 \mathrm{~m} / \mathrm{s}$. Initially, the concentration within the column is zero. At time equal to zero, fluid of unit concentration began to flow into the column, and this continued for 7,200 s. In addition to convection, dispersion $\left(\alpha_{1}=10 \mathrm{~m}\right)$ and molecular diffusion $\left(D_{m}=1 \times 10^{-10} \mathrm{~m}^{2} / \mathrm{s}\right)$ controlled the movement of the concentration front within the column. Forty-three nodes were used to grid the spatial domain, and 86 time steps were used to grid the temporal domain. Many authors, including Ogata and Banks (1961), give the analytic solution to this problem. At 7,200 s, VS2DT results closely matched analytic results.

Problem 3: Water moves through a partially saturated $125-\mathrm{cm}$ soil column. For $2.8 \mathrm{~h}$, the water carries a dissolved solute (209 milliequivalents per liter) into the initially solute-free soil. After that, the infiltrating water is solute free. This problem is based on a field experiment performed by Warrick, Biggar, and Nielsen (1971) and has been simulated by van Genuchten (1982) and others. The initial moisture-content distribution varies across the length of the column, and infiltration is effected by means of a constant head $(h=-14.495 \mathrm{~cm})$ at one end of the column. Having been chosen to best represent experimental results, the nonlinear hydraulic properties do not conform to the relations of Brooks and Corey (1964), Haverkamp et al. (1977), or van Genuchten (1980). A constant nodal spacing of $2.5 \mathrm{~cm}$ and a constant time step of $0.048 \mathrm{~h}$ were used to grid the spatial and temporal domains, and several differencing algorithms were used. At two and nine hours, the VS2DT evidenced excellent agreement with those of van Genuchten (1982) for a completely centered differencing algorithm. Using a backward-in-time and centered-in-space algorithm degraded the agreement only 
slightly. Using a completely backward differencing algorithm, however, noticeably degrades the agreement. When compared to those of van Genuchten (1982), the results obtained with VS2DT show more smearing and decreased peak concentration.

Problem 4: Water and a decaying solute enter the top $4 \mathrm{~cm}$ of one side (the left side) of a soil slab and move two dimensionally toward the opposite side (the right side). The slab measures $10 \mathrm{~cm}$ on a side by $15 \mathrm{~cm}$ in length, and impermeable boundaries line its top, bottom, and the lower $6 \mathrm{~cm}$ of the left side of the slab. Variable-head $(h=z-4)$ and constant-concentration $(c=1)$ conditions control water and solute inflow into the slab, while constant-head $(\mathrm{h}=-90 \mathrm{~cm})$ and advective-flow $(\mathrm{dc} / \mathrm{dx}=0)$ conditions control outflow from the slab. Initially, the solute-free slab has a uniform head $(\mathrm{h}=-90 \mathrm{~cm})$ distributed throughout its interior. Relative conductivity $\left(K_{\mathrm{T}}=3.33 \theta-0.5\right)$ and moisture content $(\theta=0.45+0.003 \mathrm{~h})$ depend linearly on water content and pressure head, respectively. Other flow parameters include saturated conductivity $(K=1 \mathrm{~cm} / \mathrm{d})$ and porosity $\left(\theta_{\mathrm{s}}=0.45\right)$. Transport parameters include dispersivities $\left(\alpha_{1}=1 \mathrm{~cm}, \alpha_{\mathrm{T}}=0\right)$, molecular diffusivity $\left(D_{m}=0.01 \mathrm{~cm}^{2} / \mathrm{d}\right)$, and decay constant $\left(\lambda=0.001 \mathrm{~d}^{-1}\right)$.

After designing this problem, Huyakorn et al. (1985) solved it using a finite element model. Employing a uniform grid spacing $(\Delta x=\Delta z=1 \mathrm{~cm})$, the VS2DT simulation gave results showed reasonable agreement with those of Huyakorn. However, the VS2DT finite-difference concentration profiles at the surface $(z=0)$ for times of 0.165 and $0.508 \mathrm{~d}$ tended to lead the finite element profiles. Gridblock averaging within a finite-difference model tends to advance concentration profiles slightly beyond those of a finite-element model, particularly for a relatively coarse grid such as the one used for this problem.

Problem 5: Water flows through a column at a steady interstitial velocity $v=0.1 \mathrm{~cm} / \mathrm{s}$. Initially, the column is solute free. For a time period $0 \leq t \leq 160 \mathrm{~s}$, the inflowing water carries a solute of concentration $c_{o}$, after which the column is flushed with solute-free water. Within the column, the solute disperses (dispersivity $\alpha_{1}=1.0 \mathrm{~cm}$ ), decays (decay constant $\lambda=0$ or $\lambda=0.01 \mathrm{~s}^{-1}$ ), and sorbs (distribution coefficient $K_{d}=0$ or $\left.K_{d}=0.3 \mathrm{~cm}^{3} / \mathrm{gm}\right)$ onto a soil of porosity $\left(\theta_{s}=0.37\right.$ ) and bulk density $\left(\rho_{b}=1.587 \mathrm{gm} / \mathrm{cm}^{3}\right)$. The object is to calculate the concentration breakthrough curve at an observation point located at a distance $z=8 \mathrm{~cm}$ from the inlet. Bear (1972, p. 630) gives the analytic solution for this problem, assuming a column of infinite length. Assuming the column to be long $(\mathrm{L}=35 \mathrm{~cm})$ relative to the distance from inlet to observation point, the VS2DT numeric solution captures the essence of an infinite column. For the three $\left(\lambda, K_{d}\right)$ combinations considered $\left[\left(0,0.3 \mathrm{~cm}^{3} / \mathrm{gm}\right),\left(0.01 \mathrm{~s}^{-1}, 0\right)\right.$, and $\left.\left(0.01 \mathrm{~s}^{-1}, 0.3 \mathrm{~cm}^{3} / \mathrm{gm}\right)\right]$, VS2DT results compared very well with the analytic solution of Bear (1972) at all times considered ( $0 \leq t \leq 480 \mathrm{~s})$.

\subsection{Status of Quality Assurance (QA). VS2DT is under QA control.}




\section{Type of Model (Phenomena/Processes Modeled)}

VS2DT simulates two major processes in either rectangular $(x-y$ or $x-z)$ or cylindrical $(r-z)$ geometries. For flow, the code numerically solves the Richards equation in one or two dimensions. For transport, VS2DT solves a partial differential equation characterizing the following processes: advection, dispersion, diffusion, radioactive decay, sorption, and ion exchange.

\section{Governing Equations}

For solution of the Richards equation, the VS2DT flow model offers four options for specifying either the specific moisture capacity or the relative permeability. These options are: (1) the Brooks-Corey (1964) equation, (2) the relation of Haverkamp et al. (1977), (3) the equation of van Genuchten (1980), or (4) tabular input.

The VS2DT transport model employs the advection-dispersion equation. Although the radioactive production process is not considered, an unusually large variety of sorption and ion-exchange options is offered. Frequently, codes offer only a linear-isotherm $\left(\mathbf{k}_{\mathbf{d}}\right)$ option. In addition, VS2DT allows the analyst to select either the Freundlich or the Langmuir nonlinear isotherms, or to select a general ion-exchange formulation. The latter permits the competition of two types of ions for a limited number of sorption sites.

\section{Method of Solution}

VS2DT uses a block-centered, finite-difference method to discretize the governing equations. In its application to the Richards equation, this method necessitates the use of intercell averaging, or weighting, to determine a value for intercell conductance. This quantity depends not only on the value of unsaturated conductivity at the interface of neighboring cells but also on interface area and block-center separation distance. The value of intercell conductance is important since it enters the convection term of the unsaturated flow equation and therefore affects numerical dispersion and stability of the solution. Many modelers simply use a harmonic average. The authors of VS2DT, however, treat this issue very carefully. Referring to the work of Appel (1976) and Havercamp and Vauclin (1979), the authors offer a choice of averaging methods (upstream weighting and arithmetic, geometric, and harmonic averaging), and they provide some guidance on the use of each method (Lappala, 1987, pp. 29,30).

The issue of intercell averaging, or weighting, also arises in the transport equation. Here the block-centered, finite-difference method necessitates the use of such a procedure to obtain the intercell value of the dependent variable (concentration c). Because the transport equation is only weakly nonlinear, VS2DT offers but two choices, namely backward-in-space weighting (upstream weighting) or centered-in-space weighting (arithmetic averaging). Offering these two options is standard practice for most transport codes.

Nonlinear sorption and ion-exchange algorithms can cause the transport equation to be nonlinear, like the flow equation. For linearization, most Yucca Mountain codes employ the Newton-Raphson method. Some employ the Picard method. VS2DT is unique in that it 
employs a hybrid algorithm, i.e., a blend of both. To maintain symmetry in the flow equation, the Newton-Raphson method is applied only to the accumulation (time-derivative) term. For consistency, the Newton-Raphson method is also applied only to the accumulation term of the transport equation. For the transport (spatial-derivative) terms, the Picard sequential updating method is used. This iterative procedure yields matrix equations, which are solved using the strongly implicit procedure of Stone (1968).

One may compare the hybrid implementation with the fully Newton-Raphson implementation. For the hybrid case, the bandwidth is a factor-of-two smaller. Certainly, the core-storage requirement is less for the hybrid case, with the savings amounting to less than a factor of two. However, relative computer-time requirements are very problemdependent and difficult to assess. If the number of iterations is the same, the hybrid flow analysis is faster by as much as a factor of four. However, for most nonlinear problems, the hybrid analysis requires more iterations than the Newton-Raphson analysis, and the issue becomes one of time saved per iteration versus time lost due to an increased number of iterations. The net computer-time advantage can go either way, depending on the problem.

\section{Type of Input Parameters}

Data are read by VS2DT mainly as free-formatted or list-directed input. Data input entries are listed by line in Healy (1990) and are grouped according to the subroutine through which the data is read.

Line Group A read by subroutine VSEXEC: Group A specifies problem description, gridding, and several logical variables controlling not only the calculation but also the primary variables to be printed.

Line Group B read by subroutine VSREAD: Group B specifies the iterative solution including closure criteria, relaxation parameter, weighting options, and number of iterations per time step. The group also provides material properties, flow properties, and transport properties. These properties include values of the hydraulic conductivities, porosities, moisture contents, pressure heads, adsorption isotherms, and ion-exchange coefficients. They also specify evaporation and evapotranspiration rates and time periods during which they operate.

Line Group C read by subroutine VSTMER: Group C specifies time-dependent input by dividing the total simulation time into recharge groups. For each group, the input specifies time stepping and time-dependent recharge. Logical variables control not only the application but also the printing of time-dependent boundary conditions.

\section{Type of Output and User Options}

VS2DT output includes an echo of all input data, initial conditions, and boundary conditions. Pressure heads, total heads, moisture contents, and/or saturations are output at all time steps or at specified times depending on user selections. These data may be printed for all nodes at each time step or only at selected observation points for each time step. Mass balance information is optional at each time step, but mass balance and the pressure head profile is 
output at the end of the simulation. Output also includes the time step number, elapsed simulation time, and maximum head change for each iteration.

9. Model Interactions (emphasize needed processors)

9.1 Does the model interface with any other models? Yes, see below.

9.2 Source code and type of information needed. Not applicable.

9.3 Receiving code and type of information provided. Not applicable.

9.4 Any pre- or postprocessing needed? The plotting packages TELLAGRAF and SURF2 are used to provide time histories and coutour plots.

10. Model Application

10.1 Usage within the Civilian Radioactive Waste Management System (CRWMS) program. VS2DT is used primarily for design of laboratory and field experiments. However, under appropriate approximations, VS2DT could be used by performance assessment to analyze flow and transport for the undisturbed case. Such approximations would include isothermal flow, a rather severe but often-used approximation for Yucca Mountain analyses, and two dimensionality.

10.2 Usage outside the program. Potentially, VS2DT could be used in a variety of wastemanagement areas, including hazardous waste and low-level nuclear waste. However, the availability of many other codes with similar capabilities may limit its use.

\section{Codes With Similar or Same Capabilities}

11.1 Within the program. The Yucca Mountain Site Characterization Project (YMP) has funded the development of other flow and transport codes with capabilities which are either similar to or greater than those of VS2DT. To characterize variably saturated flow, LLUVIA-2 and TOSPAC (Dudley et al., 1988) from SNL (Sandia National Laboratories), SUMO (Eslinger et al., 1990) from PNL (Pacific Northwest Laboratory), and TRUST (Reisenauer et al., 1982 and Narasimhan, 1975) from both PNL and LBL, solve the single-phase Richards equation, as does VS2DT. TOUGH2 (Pruess, 1991) at LBL (Lawrence Berkeley Laboratory), TRACR3D (Birdsell and Travis, 1991) and FEHM (Zyvoloski et al., 1992) at LANL (Los Alamos National Laboratory), MSTS at PNL, PORFLOW (Runchal and Sagar, 1991), and NORIA (Bixler, 1985) at SNL solve general multiphase equations which include the Richards equation as a special case. Each code, like VS2DT, has a transport capability, through either built-in or stand-alone transport modules.

11.2 Outside the program. With its YMP, the U.S. Nuclear Regulatory Commission (NRC) has funded the documentation of TOUGH (Pruess, 1987), a multiphase solver, and the development of DCM3D (Updegraff et al., 1991), a single-phase solver. Other government funded efforts have yielded FEMWATER (Yeh and Ward, 1980), 
UNSAT2 (Davis and Neuman, 1983) and VAM2D (Huyakom et al., 1989). Each of these codes, like VS2DT, has a transport capability, through either built-in or standalone transport modules.

\section{Major Assumptions and Limitations}

- Thermal effects are not considered. Such effects may be quite significant for Yucca Mountain.

- Vapor flow is not considered. The effect of vapor flow may also be quite significant for Yucca Mountain.

- A high-order differencing option is not available for the convection term. The effect of this assumption will depend upon the extent to which liquid flow can penetrate the heat envelope surrounding the repository.

- A dual-continuum option is not available. Without substantial modification, fracturematrix disequilibrium cannot be accounted for in field-scale simulations.

- Radioactive chaining is not considered.

- Only two spatial dimensions are considered. This will be sufficient for many applications. However, some applications will undoubtedly require three dimensions.

\section{Remarks/General Observations/Discussion}

As indicated by Section 11, VS2DT's general performance capabilities duplicate those of many codes. To characterize a variably saturated flow domain, some solve the Richards equation. Others solve multiphase equations, thereby including the performance capability of VS2DT as a special case. Most have either built-in or stand-alone transport modules. The dominance of nonisothermal flow at Yucca Mountain may dictate a rather limited role for codes based on the Richards equation.

Nevertheless, VS2DT has some unique design characteristics which should be considered. It considers the issue of conductance averaging more carefully than other Yucca-Mountain codes. Further, in terms of the number of sorption and ion-exchange options offered, it apparently is second only to TRACR3D (Birdsell and Travis, 1991). VS2DT is the only Yucca-Mountain code using the strongly implicit method (Stone, 1968) for matrix solution. This technique may offer some computational advantage for Yucca-Mountain simulations.

Although the hybrid linearization method may also offer some computational advantages in special situations, VS2DT should not be considered a candidate for general implementation in Yucca Mountain codes. The frequently used equivalent-continuum approximation yields soil-property curves which are highly nonlinear. This non-linearity is particularly severe for water-content values corresponding to the transition from fracture to matrix-dominated flow. If infiltration rates are sufficiently large that they trigger such transitions, the hybrid method may not converge. 


\section{Comparison to Other Models}

See Chapters 4, 5, and 6 of the main text.

\section{Summary and Recommendations}

Although VS2DT has too many limitations to be considered a candidate for general implementation, its hybrid linearization method should be tested. If the general level of non-linearity is only moderate, it may be desirable to transfer it to other Yucca Mountain models. Fortunately, the USGS has supplied us with a source code.

\section{References}

Appel, C.A., 1976. A Note on Computing Finite Difference Interblock Transmissivities, Water Resources Research, vol. 12, no. 3, pp. 561-563.

Bear, Jacob, 1972. Dynamics of Fluids in Porous Media, New York, American Elsevier Publishing Co., 764 pp.

Birdsell, K.H., and B.J. Travis, 1991. TRACR3D: A Model of Flow and Transport in Porous Media, LA-11798-M, Los Alamos National Laboratory, Los Alamos, NM.

Bixler, N.E., 1985. NORIA - A Finite Element Computer Program for Analyzing Water, Vapor, Air, and Energy Transport in Porous Media, Sandia National Laboratories, SAND84-2057, Albuquerque, NM.

Carslaw, H.S., and J.C. Jaeger, 1959. Conduction of Heat in Solids: Oxford, England, Oxford University Press, 510 p.

Davis, L.A., and S.P. Neuman, 1983. Documentation and Users Guide--UNSAT2-Variably Saturated Flow Model, U.S. Nuclear Regulatory Commission, NUREG/CR-3390, 200 p.

Dudley, A.L., R.R. Peters, J.H. Gauthier, M.L. Wilson, M.S. Tierney, E.A. Klavetter, 1988. Total System Performance Assessment Code (TOSPAC) Volume 1: Physical and Mathematical Bases, SAND85-0002, Sandia National Laboratories, Albuquerque, NM.

Duguid, J.O., and M. Reeves, Material Transport Through Porous Media: A Finite Element Galerkin Model, ORNL 4928, Oak Ridge National Laboratory, Oak Ridge, TN.

Duke, H.R., 1973. Drainage Design Based Upon Aeration, Fort Collins, Colorado State University Hydrology Paper 61, 59 p.

Dykhuizen, R.C., 1987. "Transport of Solutes Through Unsaturated Fractured Media", Water Resour. Res., vol. 21, no. 12, pp. 1531-1539. 
Eslinger, P.W., T.B. Miley, and D.W. Engel, 1990. SUMO-System Performance Assessment for a High-Level Nuclear Waste Repository: Mathematical Models, PNL-7581, Pacific Northwest Laboratory, Richland, WA.

Haverkamp, R., and M. Vauclin, 1977. A Note on Estimating Finite Difference Interblock Hydraulic Conductivity Values for Transient Unsaturated Flow Problems, Water Resources Research, vol. 15, no. 1, pp. 285-294.

Haverkamp, R., M. Vauclin, J. Tovina, P.J. Wierenga, and G. Vachaud, 1977 . A Comparison of Numerical Simulation Models for One-Dimensional Infiltration, Soil Science Society of America Proceedings, vol. 41, pp. 285-294.

Healy, R.W., 1990. Simulation of Solute Transport in Variably Saturated Porous Media With Supplemental Information on Modifications to the U.S. Geological Survey's Computer Program VS2D, Water-Resources Investigations Report 90-4025, U.S. Geological Survey, Denver, CO.

Hedstrom, W.E., A.T. Corey, and H.R. Duke, 1971. Models for Subsurface Drainage, Colorado State University Hydrology Paper 48, 56 pp.

Hsieh, P.A., 1986. A New Formula for the Analytical Solution of the Radial Dispersion Problem, Water Resources Res., vol. 22, no. 11, pp. 1,597-1,605.

Huyakorn, P.S., J.B. Kool, and J.B. Robertson, 1989. VAM2D - Variably Saturated Analysis Model in Two Dimensions, NUREG/CR-5352, HGL-8901, U.S. Nuclear Regulatory Commission, Washington, DC (1989).

Huyakorn, P.S., J.W. Mercer, and D.S. Ward, 1985. Finite Element Matrix and Mass Balance Computational Schemes for Transport in Variably Saturated Porous Media, Water Resources Res., vol. 21, no. 3, pp. 346-358.

Lappala, E.G., R.W. Healy, and E.P. Weeks, 1987. Documentation of Computer Program VS2D to Solve the Equations of Fluid Flow in Variably Saturated Porous Media, WaterResources Investigations Report 83-4099, U.S. Geological Survey, Denver, CO.

Narasimhan, T.N., 1975. A Unified Numerical Model for Saturated-Unsaturated Groundwater Flow, Ph.D dissertation, University of California, Berkeley, CA.

Ogata, A., and R.B. Banks, 1961. A Solution of the Differential Equation of Longitudinal Dispersion in Porous Media, U.S. Geological Survey Professional Paper 411-A, 7 pp.

Pruess, K., 1987. TOUGH User's Guide, NUREG/CR-4645, SAND86-07104, LBL-20700, Sandia National Laboratories, Albuquerque, NM.

Pruess, K., 1991. TOUGH2 - A General-Purpose Numerical Simulator for Multiphase Fluid and Heat Flow, LBL-29400, Lawrence Berkeley Laboratory, Berkeley, CA. 
Reisenauer, A.E., K.T. Key, T.N. Narasimhan, and R.W. Nelson, 1982. TRUST: A Computer Program for Variably Saturated Flow in Multidimensional, Deformable Media, NUREG/CR-2360, U.S. Nuclear Regulatory Commission, Washington, DC, and PNL3975, Pacific Northwest Laboratory, Richland, WA.

Ripple, C.D., J. Rubin, and T.E.A. van Hylckama, 1972. Estimating Steady-State Evaporation Rates From Bare Soils Under Conditions of High Water Table, U.S. Geological Survey Water Supply Paper 2019-A, 39 pp.

Runchal, A.K., and B. Sagar, 1991. PORFLOW: A Model for Fluid Flow, Heat, and Mass Transport in Multifluid, Multiphase Fractured or Porous Media, User's Manual - Version 2.34, ACRi/016/Rev. E, Analytical and Computational Research, Inc., West Los Angeles, CA.

Sinnock, S., and Y.T. Lin, 1989. Preliminary Estimates of Groundwater Travel Time at Yucca Mountain, Radioactive Waste Management and the Nuclear Fuel Cycle, vol. 13(1-4), pp. 121-145.

Stone, H.L., 1968. Iterative Solution of Implicit Approximations of Multidimensional Partial Differential Equations, SIAM Journal of Numerical Analysis. vol. 5, pp. 530-558.

Theis, C.V., 1935. The Relation Between the Lowering of the Piezometric Surface and the Rate and Duration of Discharge of a Well Using Groundwater Storage, Transactions of the American Geophysics Union, part 2, pp. 519-524.

Updegraff, C.D., C.E. Lee, and D.P. Gallegos, 1991. DCM3D: A Dual-Continuum, Three Dimensional, Ground-Water Flow Code for Unsaturated, Fractured, Porous Media, NUREG/CR-5536, SAND90-7015, Sandia National Laboratories, Albuquerque, NM.

van Genuchten, M.Th., 1980. A Closed-Form Equation for Predicting the Hydraulic Conductivity of Unsaturated Soils, Soil Science Society of America Proceedings, vol. 44, no. 5, pp. 892-898.

van Genuchten, M.Th., 1982. A Comparison of Numerical Solutions of the OneDimensional Unsaturated-Saturated Flow and Mass Transport Equations, Advances in Water Resources, vol. 5, no. 1, pp. 47-55.

Warrick, A.W., J.W. Biggar, and D.R. Nielsen, 1971. Simultaneous Solute and Water Transfer for an Unsaturated Soil, Water Resources Res. vol. 7, no. 5, pp. 1216-1225.

Updegraff, C.D., 1989. Comparison of Strongly Heat-Driven Flow Codes for Unsaturated Media, NUREG/CR-5367, SAND88-7145, Sandia National Laboratories, Albuquerque, NM.

Yeh, G.T., and D.S. Ward, 1980. FEMWATER: A Finite-Element Model of Water Flow Through Saturated-Unsaturated Porous Media, ORNL-5567, Oak Ridge National Laboratory, Oak Ridge, TN. 
Zyvoloski, G., Z. Dash, and S. Kelkar, 1992. FEHMN 1.0: Finite Element Heat and Mass Transfer Code, LA--12062-MS, Los Alamos National Laboratory, Los Alamos, NM. 


\section{APPENDIX B}

\section{DESCRIPTION OF TEST PROBLEMS}




\section{DESCRIPTION OF TEST PROBLEMS}

Appendix B discusses the four problems chosen for model testing. They may be briefly characterized as follows:

- Jornada Trench - two and three-dimensional, isothermal, unsaturated flow of water in a dry, heterogeneous soil;

- COVE2a - one-dimensional, isothermal, unsaturated flow of water in a homogeneous column of Yucca Mountain tuff;

- Pre-Emplacement Vapor Diffusion - one-dimensional, nonisothermal movement of water, vapor, and air in an undisturbed column of Yucca Mountain tuff; and

- Repository Heat Pipe - two-dimensional, nonisothermal movement of water, vapor, and air, as influenced by the presence of repository heat.

For each problem, the following sections discuss the physical setting and provide thermohydrologic data, as required. They also define the spatial grid used for all implementations.

\section{B.1 Jornada Trench}

Originally developed as a conceptual model for an infiltration experiment conducted near Las Cruces, New Mexico (Smyth et al., 1989), this test problem focuses on two- and threedimensional unsaturated flow into a relatively dry, heterogeneous soil. It does not use Yucca Mountain hydraulic properties. Nevertheless, this represents an obvious choice for the evaluation of flow codes used by the Yucca Mountain Site Characterization Project (YMP). YMP codes have already been applied to this problem. Magnuson et al. (1990) considered a group of codes, including PORFLOW and TRACR3D, for possible use at Idaho National Engineering Laboratory (INEL). McCord, Eaton, and Martinez (private communication) considered LLUVIA-II, NORIA-SP, VS2DT and several other codes as part of their work on two separate projects, one of which was the YMP. These researchers have kindly supplied us with input data sets, thus allowing us to focus on consistency in space and time integration and on convergence criteria. Of the two cases defined for this problem, Case A, with more moist initial conditions, is relatively easy to solve. Case B, with dryer initial conditions, provides a rather severe test of a code's ability to handle strong non-linearities, an ability which is essential for Yucca Mountain flow codes.

Conceptualization. Figure B-1, a cross-sectional view of the physical system, shows four zones. Table B-1 defines the soil parameters for each region. For Case A, initial conditions are specified by a uniform pressure head of $-734 \mathrm{~cm}$ and, for Case B, by a uniform pressure head of $-10,000 \mathrm{~cm}$. Except for a portion of the top boundary, no-flow conditions are specified for all boundaries.

For block-centered finite-difference implementations, a uniform infiltration rate of $2.04 \mathrm{~cm} /$ day is applied across the region $0 \leq \mathrm{x} \leq 220 \mathrm{~cm}$. For finite-element and point-distributed finitedifference implementations (FEHM and LLUVIA-I, respectively), a uniform rate of $2.00 \mathrm{~cm} /$ day 


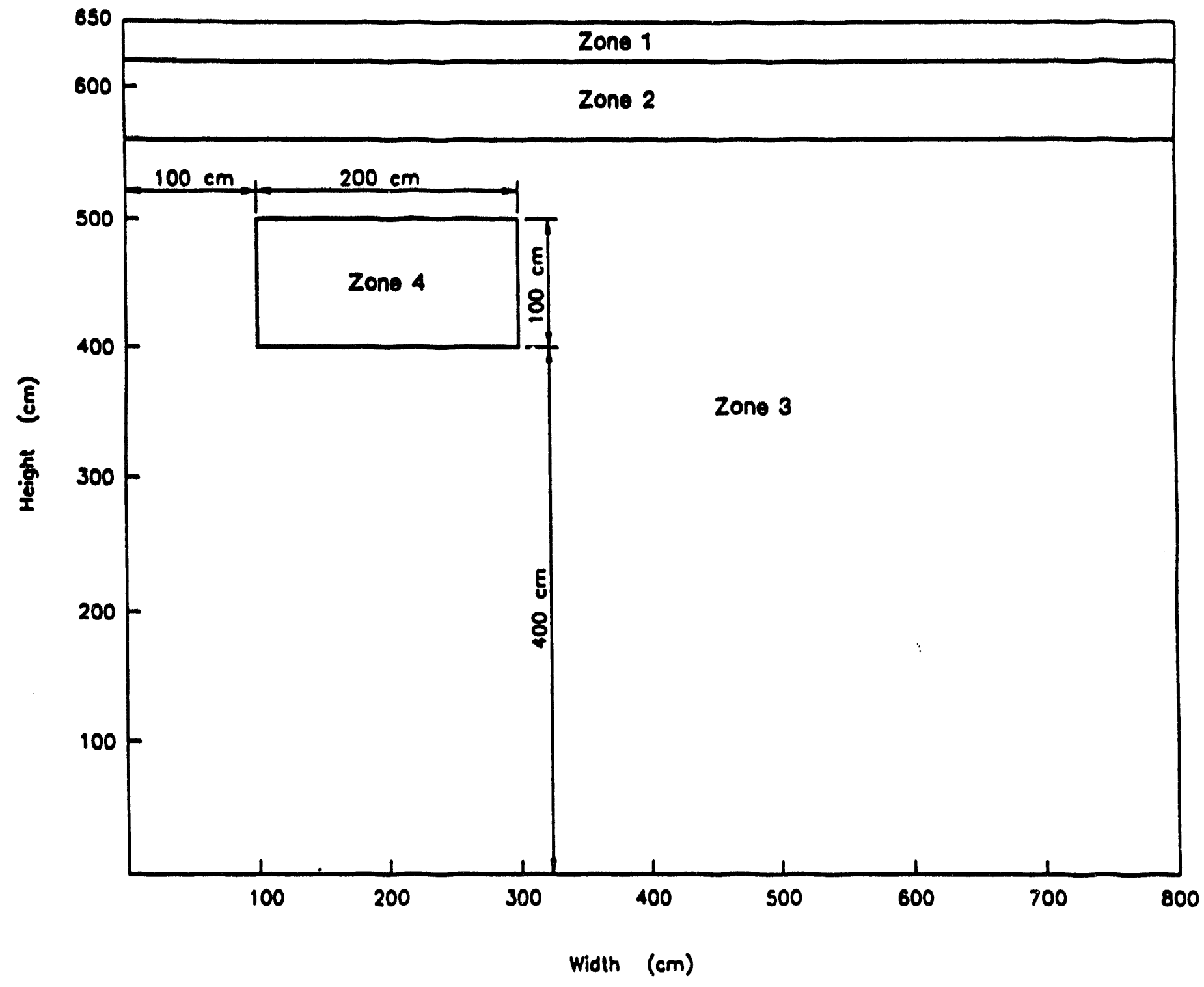

Figure B-1. Two-Dimensional Crose-Sectional View for the Jomada-Trench Problem 
TABLE B-1. Hydraulic Properties for the Jornada-Trench Problem

\begin{tabular}{|c|c|c|c|c|c|c|}
\hline \multirow[b]{2}{*}{ ZONE } & \multirow[b]{2}{*}{ POROSITY } & \multirow[b]{2}{*}{$\begin{array}{l}\text { SATURATED } \\
\text { CONDUCTIVITY } \\
\text { (cm/d) }\end{array}$} & \multirow[b]{2}{*}{$\begin{array}{l}\text { RESIDUAL } \\
\text { SATURATION }\end{array}$} & \multicolumn{3}{|c|}{ VAN GENUCHTEN PARAMETERS } \\
\hline & & & & $\underset{\left(\mathrm{cm}^{-1}\right)}{\alpha}$ & B & $\lambda=1-\frac{1}{\beta}$ \\
\hline 1 & 0.368 & 790.9 & 0.277 & 0.0334 & 1.982 & 0.4955 \\
\hline 2 & 0.351 & 469.9 & 0.281 & 0.0363 & 1.632 & 0.3873 \\
\hline 3 & 0.325 & 415.0 & 0.264 & 0.0345 & 1.573 & 0.3643 \\
\hline 4 & 0.325 & 4150.0 & 0.264 & 0.0345 & 1.573 & 0.3643 \\
\hline
\end{tabular}


is applied across the region $0 \leq x \leq 225 \mathrm{~cm}$. Assuming a system width of $200 \mathrm{~cm}$, the threedimensional analyses further define the source to lie in the region $0 \leq \mathrm{y} \leq 100 \mathrm{~cm}$.

Discretization. In the two-dimensional analyses, the spatial grid consists of 53 increments in the horizontal (x) direction and 44 increments in the vertical (z) direction. This yields 2,332 and 2,430 nodes, respectively, for codes using block-centered finite differences and either pointdistributed finite differences or finite elements. In the three-dimensional analyses, the grid is augmented by ten equally spaced increments in the horizontal $(y)$ direction. This yields 23,320 for models using a block-centered grid and 26,730 nodes for models using either point-distributed or finite-element grids. Table B-2 defines both two (x-z) and three (x-y-z) dimensional grids. Figure B-2 displays the three-dimensional grid.

\section{B.2 COVE2a}

Sponsored by the YMP, the COVE2a benchmarking activity considered a total of 12 different one-dimensional cases involving unsaturated flow. Here again, the fact that data sets have already been prepared (e.g., Birdsell and Travis, 1991 and Dudley, et al., 1988) allows us to focus on consistency in spatial and temporal discretization and on convergence criteria. Such consistency, which was not considered by the benchmarking activity, is essential for detailed code-to-code comparisons.

Conceptualization. Though identical in stratigraphy (Figure B-3), the 12 cases differ both in the assumed hydraulic properties of the Calico Hills unit $(\mathrm{CHn})$ and in the assumed infiltration rate. The COVE2a problerı definition memo (Prindle, 1986) provides two sets of hydraulic properties for the $\mathrm{CHn}$ unit, one corresponding to a vitrified tuff and the other to a zeolitized tuff. We have arbitrarily chosen a case pertaining to a zeolitized Calico Hills. Table B-3 defines the hydraulic properties for each geologic unit.

The problem definition memo also calls for steady analysis at a given infiltration followed by transient analysis at twice the given rate, with the latter using the result of the former as an initial condition. The rates are specified as $0.1,0.5$, and $4.0 \mathrm{~mm} / \mathrm{yr}$ for the steady and $0.2,1.0$, and $8.0 \mathrm{~mm} / \mathrm{y}$ for the transient analyses. We have chosen the smallest rates, i.e., 0.1 and $0.2 \mathrm{~mm} / \mathrm{y}$, respectively, for steady and transient analyses. Some codes have a direct steady-state solution capability; others do not. To establish most directly the relationship of computer time and internal algorithms, the problem focuses on results of the transient analysis.

Discretization. Table B-4 defines the one-dimensional spatial grid. Taken from the work of Birdsell and Travis (1991b), it consists of 362 increments in the vertical (z) direction. The grid refines near boundaries and unit interfaces and coarsens in unit interiors. For a block-centered finite-difference implementation, the number of nodes equals the number of increments. For point-distributed finite-difference and finite-element implementations, the number of nodes exceeds the number of increments by one.

\section{B.3 Pre-Emplacement Vapor Diffusion}

Taken from the work of Tsang and Pruess (1990), this problem considers the nonisothermal flow of gas and liquid phases within Yucca Mountain under pre-emplacement conditions. The 


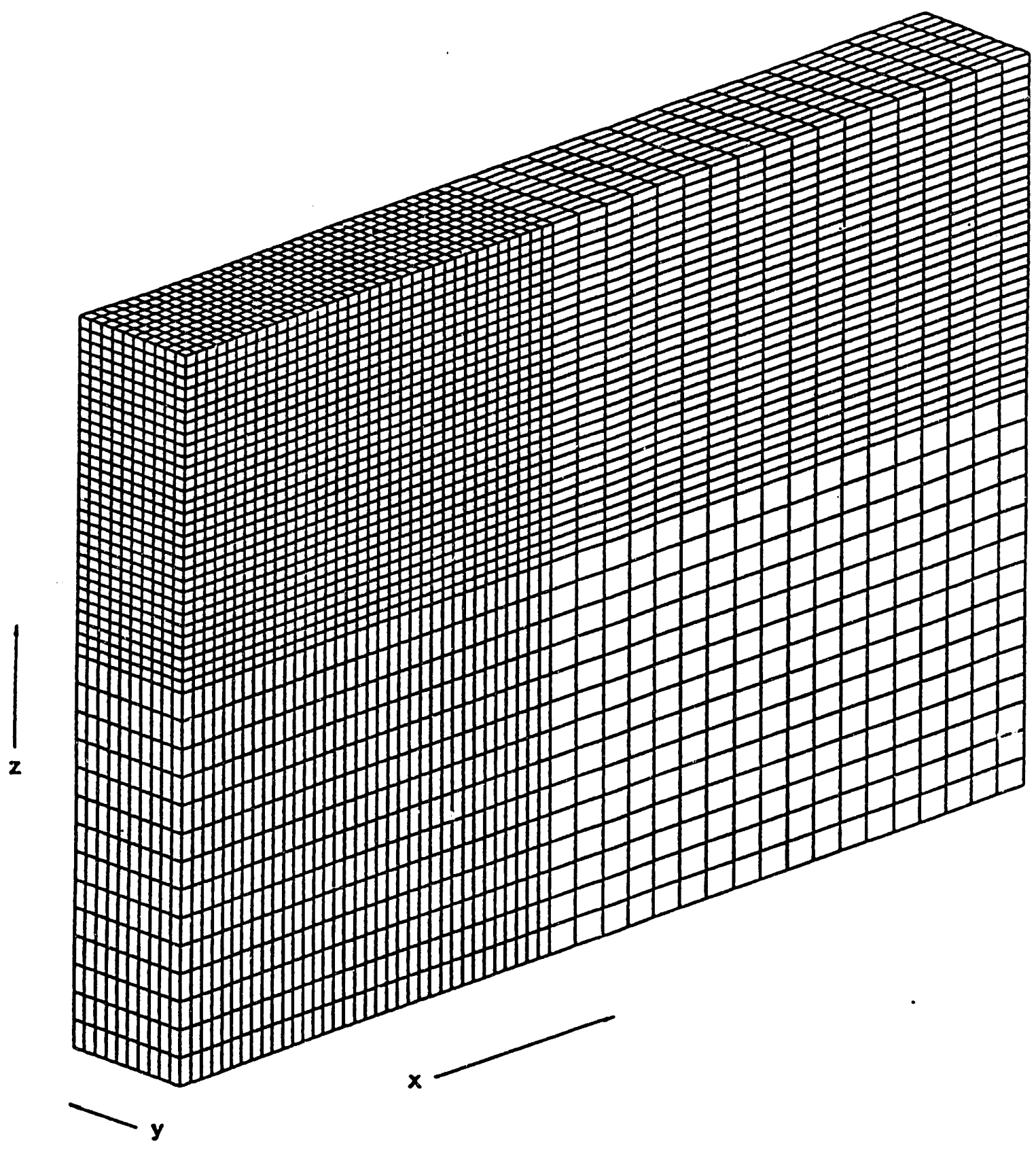

Figure B-2 Three-Dimensional View for the Jomada-Trench Problem with Discretization. 
TABLE B-2. Discretization of Jornada-Trench Problem ${ }^{(a, b)}$

\begin{tabular}{|c|c|c|c|c|c|}
\hline \multicolumn{2}{|c|}{ Horizontal (x) } & \multicolumn{2}{|c|}{ Horizontal (y) } & \multicolumn{2}{c|}{ Vertical (z) } \\
\hline $\begin{array}{c}\text { Interval } \\
(\mathrm{cm})\end{array}$ & $\begin{array}{c}\text { Discretization } \\
(\mathrm{cm})\end{array}$ & $\begin{array}{c}\text { Interval } \\
(\mathrm{cm})\end{array}$ & $\begin{array}{c}\text { Discretization } \\
(\mathrm{cm})\end{array}$ & $\begin{array}{c}\text { Interval } \\
(\mathrm{cm})\end{array}$ & $\begin{array}{c}\text { Discretization } \\
(\mathrm{cm})\end{array}$ \\
\hline $0-350$ & 10 & $0-200$ & 10 & $0-350$ & 25 \\
\hline $350-800$ & 25 & NA & NA & $350-650$ & 10 \\
\hline
\end{tabular}

(a) Figures B-1 and B-2 identify the origin of the coordinate system.

(b) NA - Not Applicable 


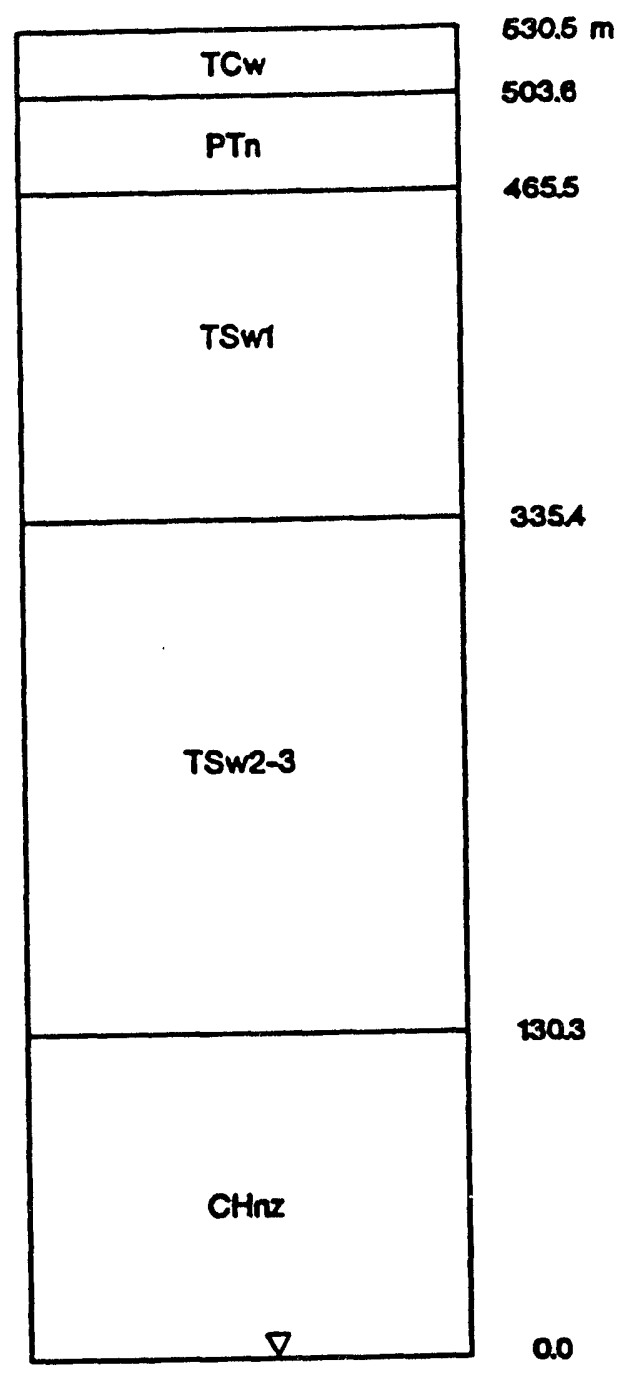

Floure B-3. Stratlgraphy for the COVE2a Study. 
TABLE B-3. Hydraulic Properties for the COVE2a Problem

\begin{tabular}{|c|c|c|c|c|c|c|c|}
\hline \multirow[b]{2}{*}{ UNIT } & \multirow[b]{2}{*}{ POROSITY } & \multirow{2}{*}{$\begin{array}{c}\text { HYDRAULIC } \\
\text { CONDUCTIVITY } \\
(\mathrm{m} / \mathrm{s})\end{array}$} & \multirow{2}{*}{$\begin{array}{c}\text { BULK MATRIX } \\
\text { CONDUCTIVITY } \\
(\mathrm{m} / \mathrm{s})\end{array}$} & \multirow{2}{*}{$\begin{array}{l}\text { RESIDUAL } \\
\text { SATURATION }\end{array}$} & \multicolumn{3}{|c|}{ VAN GENUCHTEN PARAMETERS } \\
\hline & & & & & $\begin{array}{c}\alpha \\
\left(m^{-1}\right)\end{array}$ & $\boldsymbol{\beta}$ & $\lambda=1-\frac{1}{\beta}$ \\
\hline TCw & 0.08 & $9.7 e-12$ & $9.7 e-12$ & 0.002 & $\begin{array}{c}0.821 e- \\
02\end{array}$ & 1.558 & 0.3582 \\
\hline PTn & 0.40 & $3.9 e-07$ & $3.9 e-07$ & 0.100 & $1.50 e-02$ & 6.872 & 0.8545 \\
\hline TSw1 & 0.11 & $1.9 e-11$ & $1.9 e \cdot 11$ & 0.08 & $\begin{array}{c}0.567 e- \\
02\end{array}$ & 1.798 & 0.4438 \\
\hline $\begin{array}{l}\text { TSw2- } \\
3\end{array}$ & 0.11 & $1.9 e-11$ & $1.9 e-11$ & 0.08 & $\begin{array}{c}0.567 e- \\
02\end{array}$ & 1.798 & 0.4438 \\
\hline $\mathrm{CHnz}$ & 0.28 & $2.0 e-11$ & $2.00-11$ & 0.11 & $\begin{array}{c}0.308 e- \\
02\end{array}$ & 1.602 & 0.3758 \\
\hline \multirow[b]{2}{*}{ UNIT } & \multirow[b]{2}{*}{$\begin{array}{l}\text { FRACTURE } \\
\text { POROSITY }\end{array}$} & \multirow[b]{2}{*}{$\begin{array}{c}\text { FRACTURE } \\
\text { CONDUCTIVITY } \\
(\mathrm{m} / \mathrm{s})\end{array}$} & \multirow{2}{*}{$\begin{array}{c}\text { BULK } \\
\text { FRACTURE } \\
\text { CONDUCTIVITY } \\
(\mathrm{m} / \mathrm{s})\end{array}$} & \multirow[b]{2}{*}{$\begin{array}{l}\text { RESIDUAL } \\
\text { SATURATION }\end{array}$} & \multicolumn{3}{|c|}{ VAN GENUCHTEN PARAMETERS } \\
\hline & & & & & $\begin{array}{c}\alpha \\
\left(m^{-1}\right)\end{array}$ & $\beta$ & $\lambda=1-\frac{1}{\beta}$ \\
\hline TCw & $14 . e-5$ & $3.8 e-5$ & $5.3 e-9$ & 0.0395 & 1.2851 & 4.23 & 0.764 \\
\hline PTn & $2.7 e \cdot 5$ & $61 . e-9$ & $16 . e-9$ & 0.0395 & 1.2851 & 4.23 & 0.764 \\
\hline TSw1 & $4.1 e-5$ & $2.2 e-5$ & $0.9 e-9$ & 0.0395 & 1.2851 & 4.23 & 0.764 \\
\hline $\begin{array}{l}\text { TSw2- } \\
3 \\
\end{array}$ & $18 . e-5$ & $1.7 e-5$ & $3.1 e-9$ & 0.0395 & 1.2851 & 4.23 & 0.764 \\
\hline $\mathrm{CHnz}$ & $4.6 e-5$ & $20 . e-5$ & $9.2 e-9$ & 0.0395 & 1.2851 & 4.23 & 0.764 \\
\hline
\end{tabular}


TABLE B-4. Discretization of the COVE2a Problem

\begin{tabular}{|c|c|c|}
\hline UNIT & $\begin{array}{l}\text { NUMBER OF } \\
\text { GRID BLOCKS }\end{array}$ & $\begin{array}{l}\text { DISCRETIZATION } \\
(\mathrm{m})\end{array}$ \\
\hline TCW & 41 & $\begin{array}{l}4^{*} 0.2,4^{*} 0.4,3^{*} 0.6,3^{*} 0.8,1.13,1.14,1.13,1.0,1.2,4^{*} 1.5 \\
2^{*} 1.0,0.6,3^{*} 0.8,0.6,4^{*} 0.2,0.2,2^{*} 0.3,2^{*} 0.2,0.1,0.2\end{array}$ \\
\hline PTn & 62 & $\begin{array}{l}0.2,3^{*} 0.1,0.2,2^{*} 0.15,0.2,0.25,0.3,4^{*} 0.3875,0.6,0.63 \\
0.64,0.63,4^{*} 0.8,4^{*} 1.05,0.8,9^{*} 1.0,3^{*} 1.2,2^{*} 0.825,0.7 \\
5^{*} 0.75,2^{*} 0.6,2^{*} 0.55,2^{*} 0.4,0.35,2^{*} 0.3,0.35,5^{*} 0.2\end{array}$ \\
\hline TSW, & 75 & $\begin{array}{l}0.2,2^{*} 0.1,0.2,0.3,2^{*} 0.4,0.6,0.4,2^{*} 1.0,3^{*} 1.6,2.0,3.0 \\
2.0,2.58,2.59,2.58,35^{*} 2.5,2.75,2.0,2.2,3^{*} 1.5,2^{*} 0.95 \\
2^{*} 0.8,2^{*} 0.65,2^{*} 0.4,2^{*} 0.3,3^{*} 0.2,0.1\end{array}$ \\
\hline $\mathrm{TSW}_{2-3}$ & 109 & $\begin{array}{l}0.1,2^{*} 0.2,2^{*} 0.35,2^{*} 0.45,2^{*} 0.6,2^{*} 0.8,2^{*} 1.0,4^{*} 1.5,3^{*} 2.0 \\
2^{*} 2.625,31^{*} 2.5,2.25,3^{*} 3.0,2^{*} 2.0,2.42,2.41,2.42,23^{*} 2.5, \\
2.75,2.0,5^{*} 1.68,2^{* 1} 1.2,2^{*} 1.0,2^{*} 0.8,4^{*} 0.6,0.4,2^{*} 0.35 \\
4^{*} 2.0\end{array}$ \\
\hline $\mathrm{CHnz}$ & 75 & $\begin{array}{l}2^{*} 0,0.3,2^{*} 0.2,0.4,0.5,0.6,3^{*} 0.8,0.6,4^{*} 1.0,1.4,5^{*} 1.66 \\
2.0,6 * 3.0,2.0,6^{*} 3.0,2.0,6^{*} 3.0,2.0,6^{*} 3.0,2.0,3^{*} 2.5,3.0 \\
4^{*} 1.95,1.4,3^{*} 1.3,4^{*} 0.8,0.40,2^{*} 0.35,0.2,0.3,3^{*} 0.2\end{array}$ \\
\hline
\end{tabular}

(a) Notation such as $4^{*} 0.2$ indicates four grid cells, each with a thickness of $0.2 \mathrm{~m}$. 
problem rather intricately couples several processes and conditions. A reduced vapor pressure (humidity) at the surface creates a vapor compositional gradient, thereby causing an upward diffusion of vapor. In response to the temperature gradient, vapor pressure generally increases with depth. This, too, causes an upward diffusion of vapor.

Condensation, which occurs whenever the vapor pressures exceed the saturated value, limits the amount of upward vapor diffusion. It also changes liquid-phase saturations, thereby setting up a flow of liquid. The vapor-pressure-lowering effect reduces the maximum vapor pressure below its saturated value in relation to the capillary pressure. This further complicates the interrelation of gas and liquid phases.

Conceptualization. Figure B-4 presents the Yucca Mountain stratigraphy used by this problem. It is a one-dimensional vertical column, $600 \mathrm{~m}$ in height and stretching from water table to ground surface. As shown, the column divides into four hydrologic units with the Calico Hills unit located at the bottom. This unit is overlain by Topopah Spring, Paintbrush, and Tiva Canyon units. Figure B-5 presents the boundary conditions used to characterize water table and atmosphere. The humidity condition given there assumes that surface capillary pressures keep soil-gas humidities at the 50-percent level.

Table B-5 gives some of the thermo-hydrologic properties for welded (Topopah Spring and Tiva Canyon) and nonwelded (Calico Hills and Paintbrush) units. Relative-permeability and capillarypressure data derive from the work of Klavetter and Peters (1986) and Peters et al. (1984). Table B-6 lists van Genuchten parameter values which these authors obtained from laboratory tests. For the sparsely fractured nonwelded units, van Genuchten hydraulic-property functions based on the CHNV GU3-15 sample are applied without modification. For the intensely fractured welded units, van Genuchten hydraulic-property functions based on the TSW G4-6 sample are modified to yield composite hydraulic-property functions which account for the presence of both matrix and fractures.

Within a porous media the vapor-air diffusivity is proportional both to the diffusivity in free air $\mathrm{D}_{\mathrm{va}}{ }^{\circ}$ and to a temperature ratio $\left(T / T_{0}\right)^{\theta}$ raised to the power $\theta$. Here $\mathrm{T}$ is the absolute temperature and $T_{0}=273.15 \mathrm{~K}$ is the reference temperature. Following Tsang and Pruess (1990), parameter values $D_{v a}{ }^{\circ}=2.14 \times 10^{-5} \mathrm{~m}^{2} / \mathrm{s}$ and $\theta=2.334$ are specified. The vapor-air diffusivity is also proportional to a factor $\beta$. For vapor, the value $\beta=1$ is specified. For air, quantity $\beta$ is defined by the relation $\beta=\tau \phi S_{g}$ where $S_{g}$ is the gas saturation and $\phi$ is the porosity. For the highly fractured welded tuff, $\tau=1$ is specified, and for the sparsely fractured nonwelded tuff, $\tau=0.25$ is specified. For this problem the air diffusion does not equal the vapor diffusion.

Discretization. Table B-7 defines the one-dimensional spatial grid. It consists of 34 increments in the vertical $(z)$ direction. The grid refines near boundaries and unit interfaces and coarsens in unit interiors. For a block-centered finite-difference implementation, the number of nodes equals the number of increments. For a finite-element implementation, the number of nodes exceeds the number of increments by one. 


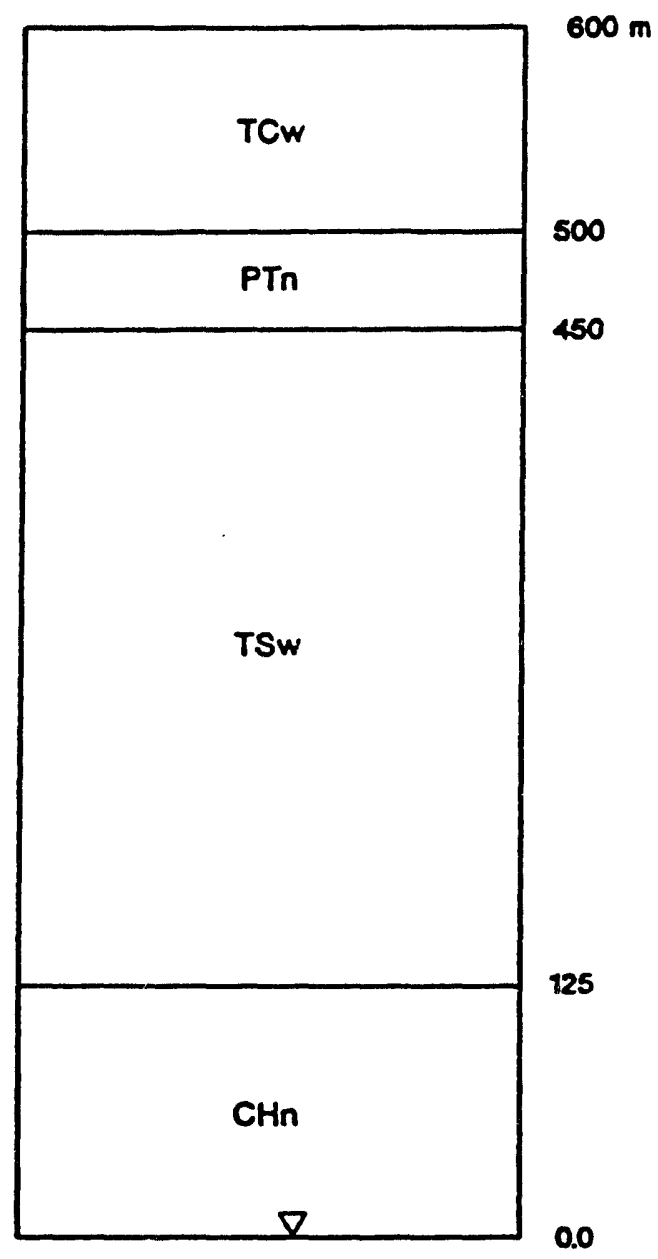

Figure B-4. Stratigraphy for the Pre-Emplacement Vapor-Diffusion Problem. 
(066L ssand pUe bues $\perp$ wOJ! pal!!pow)

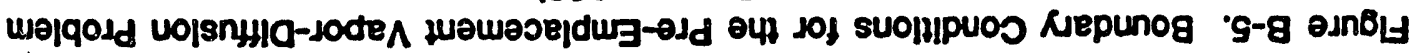

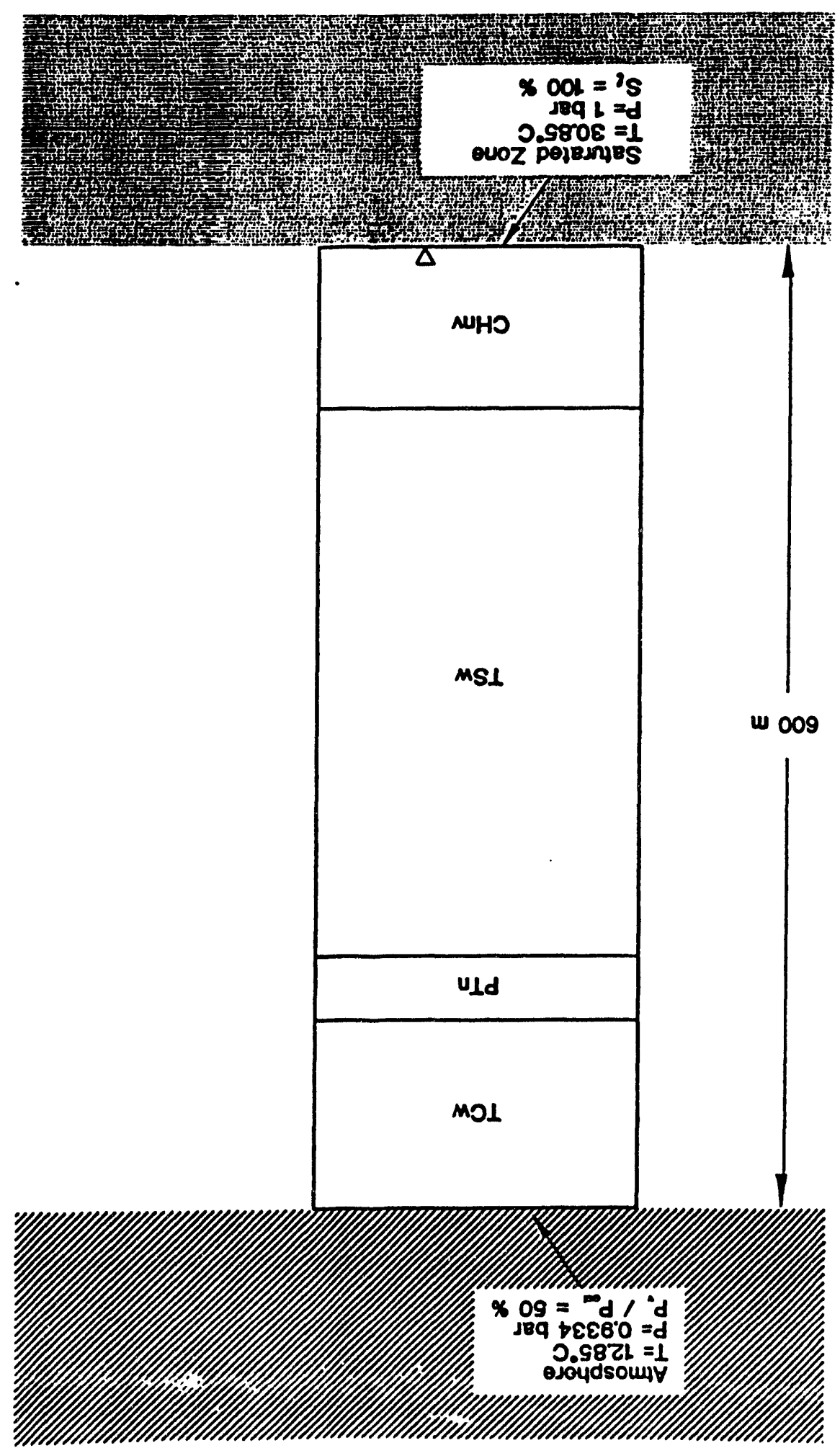


TABLE B-5. Material Properties for the Pre-Emplacement Vapor-Diffusion Problem ${ }^{(\boldsymbol{)})}$

\begin{tabular}{|l|c|c|}
\hline & WELDED UNITS & NONWELDED UNITS \\
\hline Rock grain density & $2,480 \mathrm{~kg} / \mathrm{m}^{3}$ & $2,300 \mathrm{~kg} / \mathrm{m}^{3}$ \\
\hline Rock specific heat & $840 \mathrm{~J} / \mathrm{kg} / \mathrm{C}$ & $840 \mathrm{~J} / \mathrm{kg} / \mathrm{C}$ \\
\hline Matrix permeability & $1.9 \times 10^{-18} \mathrm{~m}^{2}$ & $1.8 \times 10^{-14} \mathrm{~m}^{2}$ \\
\hline Fracture permeability & $1.8 \times 10^{-14} \mathrm{~m}^{2}$ & $\mathrm{NA}$ \\
\hline $\begin{array}{l}\text { Dry formation heat } \\
\text { conductivity } \mathrm{K}_{\text {dry }}\end{array}$ & $1.90 \mathrm{~W} / \mathrm{m} / \mathrm{C}$ & $1.02 \mathrm{~W} / \mathrm{m} / \mathrm{C}$ \\
\hline $\begin{array}{l}\text { Fully saturated formation } \\
\text { heat conductivity } \mathrm{K}_{\text {wot }}\end{array}$ & $2.34 \mathrm{~W} / \mathrm{m} / \mathrm{C}$ & $1.35 \mathrm{~W} / \mathrm{m} / \mathrm{C}$ \\
\hline & & \\
\hline $\begin{array}{l}\text { Total (effective) porosity } \\
\text { Fracture porosity }\end{array}$ & 0.1 & 0.4 \\
\hline
\end{tabular}

(a) NA - Not applicable

(b) At liquid saturation $S$, heat conductivity is $K(S)=K_{d r y}+S\left(K_{\text {wet }}-K_{d r y}\right)$. 
TABLE B-6. Hydraulic Properties for the Pre-Emplacement Vapor-Diffusion Problem

\begin{tabular}{|c|c|c|c|c|c|}
\hline \multirow[b]{2}{*}{ SAMPLE } & \multirow[b]{2}{*}{ REFERENCE } & \multirow[b]{2}{*}{$\begin{array}{l}\text { RESIDUAL } \\
\text { SATURATION }\end{array}$} & \multicolumn{3}{|c|}{ VAN GENUCHTEN PARAMETERS } \\
\hline & & & $\underset{\left(m^{-1}\right)}{\alpha}$ & $\beta$ & $\lambda=1-\frac{1}{\beta}$ \\
\hline PTn GU3-7 & (a) & 0.100 & 0.0150 & 6.872 & 0.8545 \\
\hline PTn GU4-2 & (b) & 0.040 & 0.0305 & 1.22 & 0.1803 \\
\hline TSw G4-6 & (a) & 0.080 & 0.00567 & 1.798 & 0.4438 \\
\hline CHnv GU3-14 & (a) & 0.041 & 0.0160 & 3.872 & 0.7417 \\
\hline CHnv GU3-15 & (b) & 0.085 & 0.0440 & 1.496 & 0.3316 \\
\hline TSw Fracture & (a) & 0.040 & 1.285 & 4.23 & 0.7637 \\
\hline
\end{tabular}

(a) Klavetter and Peters (1986)

(b) Peters et al. (1984) 
TABLE B-7. Discretization of the Pre-Emplacement Vapor Diffusion Problems

\begin{tabular}{|c|c|c|}
\hline UNIT & $\begin{array}{c}\text { NUMBER OF } \\
\text { GRID BLOCKS }\end{array}$ & $\begin{array}{c}\text { DISCRETIZATION } \\
(\mathrm{m})\end{array}$ \\
\hline TCW & 7 & $5,10,20,30,20,10,5$ \\
\hline PTn & 5 & $5,10,20,10,5$ \\
\hline TSw & 14 & $5,10,20,30,6 * 32.5,30,20$, \\
& & 10,5 \\
& & $5,10,20,2 * 27.5,20,10,5$ \\
\hline CHnz & 8 & \\
\hline & & \\
\hline
\end{tabular}

(a) Notation such as 6*32.5 indicates six grid cells, each with a thickness of $32.5 \mathrm{~m}$. 


\section{B.4 Repository Heat Pipe}

Based on the work of Buscheck and Nitao (1992) and Buscheck (private communication), this problem considers the hydrothermal effects of a Yucca Mountain repository. Initially, it is assumed, thermal conduction dominates, and a geothermal temperature distribution pervades the entire system. Relatively soon after the emplacement of a hypothetical 559-acre repository, however, the assumed value for the areal power density $(114 \mathrm{kw} /$ acre $)$ causes thermal stratification within the system. When repository temperatures reach boiling $\left(96^{\circ} \mathrm{C}\right)$, a heat-pipe zone develops in and around the repository, with a condensation front forming at its outermost edge. Here, the convection of latent heat (water vapor) keeps temperatures near the boiling point.

In time, as water depletes, an inner conduction zone displaces the heat-pipe to a region surrounding the repository. Within this inner zone, temperatures rise above the boiling point.

Conceptualization. At a depth of $568.1 \mathrm{~m}$ below ground surface, the water table lies only $225 \mathrm{~m}$ below the hypothetical repository. Evaporation from the water table contributes to the water balance. In time, when elevated temperatures reach this zone, these contributions may become significant. The problem conceptualization therefore includes a 1,000-m saturated zone.

The repository is approximated as a 4.6-m disk of radius $848.5 \mathrm{~m}$ located at a depth of $343.1 \mathrm{~m}$ below ground surface. The outer radius of the model $(15,000 \mathrm{~m})$ is sufficiently removed from the repository that boundary variables differ insignificantly from their initial undisturbed values. Figure B-6 characterizes stratigraphy. Assuming an equivalent-continuum characterization of the fracture flow and transport processes, Tables B-8 and B-9 provide hydraulic and hermal properties.

Discretization. Table B-10 divides the system into 82 layers and 30 columns, a total of 2,460 active cells. In the chosen cylindrical coordinate system, the 30 columns comprise an inner cylinder of radius $150 \mathrm{~m}$ surrounded by 29 cylindrical shells, the outer of which has a thickness of $4,500 \mathrm{~m}$. In addition, inactive boundary cells surround the active cells on all sides. Table B-10 indicates that, for the repository, two layers and ten columns divide the repository into 20 cells. Figure B-7 provides the volume-specific, repository heat source in watts $/ \mathrm{m}^{3}$. Some codes, notably the TOUGH codes, require that this source be multiplied by cell volumes, so that a source term may be separately specified in watts for each repository block.

Initial-Boundary Conditions. In prescribing conditions for the atmosphere and deep saturated zone, Figure B-6 fixes the values of dependent variables within the inactive top and bottom boundary cells. In addition to their use in the two-dimensional simulation, these boundary conditions are also used by an auxiliary one-dimensional, steady-state simulation. Figure B-8 presents the steady-state results, which include the effects of vapor-pressure lowering. They provide initial variable values for active cells within the discretized system. Assuming nonisothermal, two-phase flow, they define pressure, liquid saturation, and temperature as functions of depth. Above the water table, this pressure represents gas pressure. Below the water table, it becomes liquid pressure. There, the liquid saturation profile is supplemented with a profile showing liquid-phase mass fraction of air as a function of depth. In addition to the initial conditions they provide, the results shown in Figure B-8 also fix values of the dependent variables within the inactive side boundary cells. 


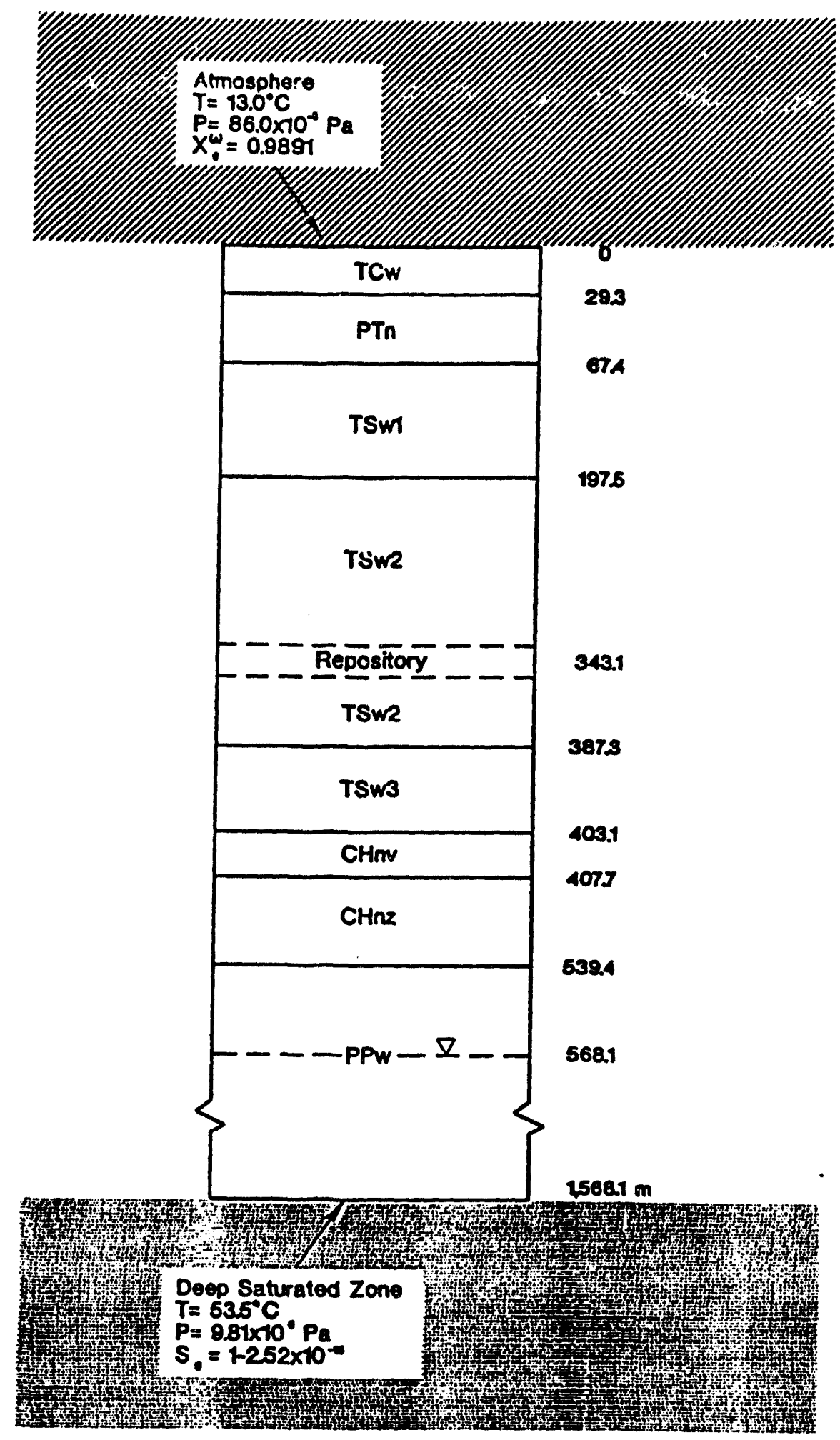

Floure B-6. Stratlgraphy for the Repository Heat-Plpe Problem. 
TABLE B-8. Hydraulic Properties for the Repository Heat-Pipe Problem

\begin{tabular}{|c|c|c|c|c|c|}
\hline \multirow{2}{*}{ UNIT } & \multirow{2}{*}{ POROSITY } & \multirow{2}{*}{$\begin{array}{c}\text { ABSOLUTE } \\
\text { PERMEABILITY } \\
\left(\mathrm{m}^{2}\right)\end{array}$} & \multirow{2}{*}{$\begin{array}{l}\text { RESIDUAL } \\
\text { SATURATION }\end{array}$} & \multicolumn{2}{|c|}{$\begin{array}{l}\text { VAN GENUCHTEN } \\
\text { PARAMETERS }\end{array}$} \\
\hline & & & & $\begin{array}{c}\alpha \\
\left(\mathrm{Pa}^{-1}\right)\end{array}$ & $\beta$ \\
\hline \multicolumn{6}{|l|}{ Matrix } \\
\hline $\mathrm{TCW}$ & 0.08 & $9.700-19$ & 0.002 & $0.840 \theta-6$ & 1.558 \\
\hline PTn & 0.40 & $3.90 \theta-14$ & 0.100 & $1.530 \theta-6$ & 6.873 \\
\hline TSw1 & 0.11 & $1.90 e-18$ & 0.08 & $0.580 e-6$ & 1.798 \\
\hline TSw2 & 0.11 & $1.90 e-18$ & 0.08 & $0.5800-6$ & 1.798 \\
\hline Repository & 0.11 & $1.900-18$ & 0.08 & $0.580 \theta-6$ & 1.798 \\
\hline TSw3 & 0.07 & $1.500-19$ & 0.08 & $0.451 \mathrm{e}-6$ & 2.058 \\
\hline CHnv & 0.46 & $2.700-19$ & 0.041 & $1.640 \theta-6$ & 3.872 \\
\hline $\mathrm{CHnz}$ & 0.28 & $2.00 \theta-18$ & 0.11 & $0.315 e-6$ & 1.602 \\
\hline PPw & 0.24 & $4.500-16$ & 0.066 & $1.440 \theta-6$ & 2.639 \\
\hline \multicolumn{6}{|l|}{ Fractures } \\
\hline All Units & $3.330-4$ & $8.33 r-10$ & 0.0395 & $1.315 \theta-3$ & 4.230 \\
\hline
\end{tabular}



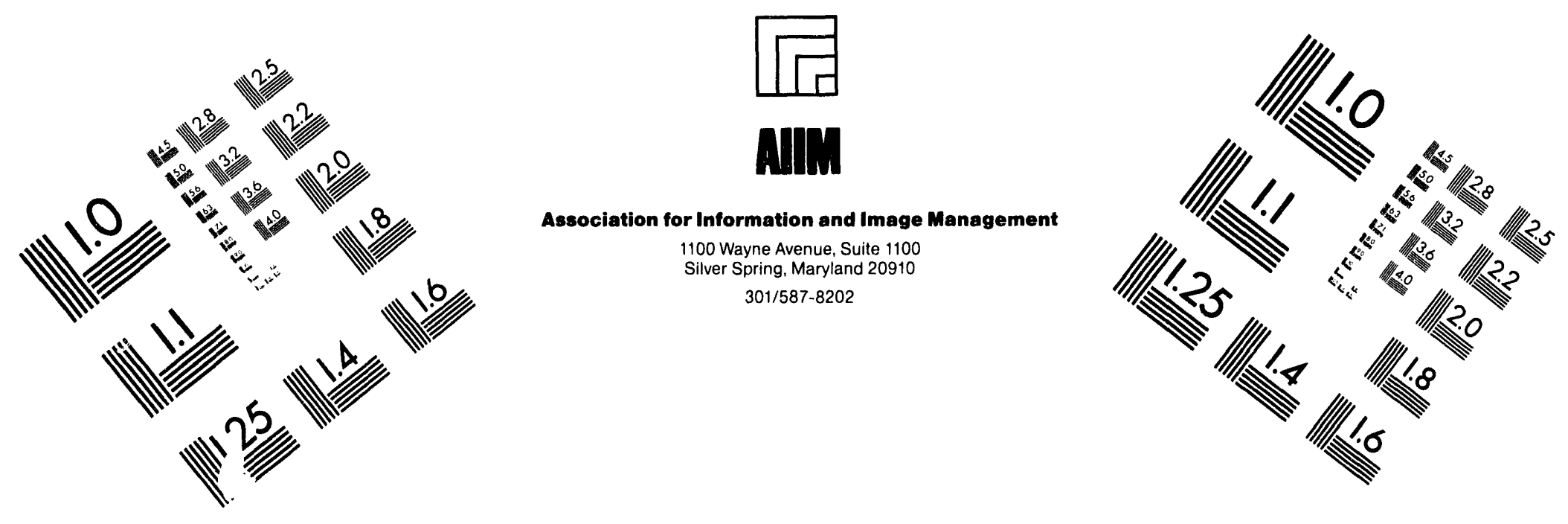

\section{Centimeter}

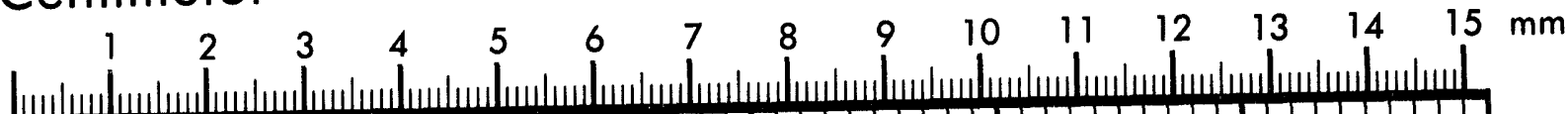

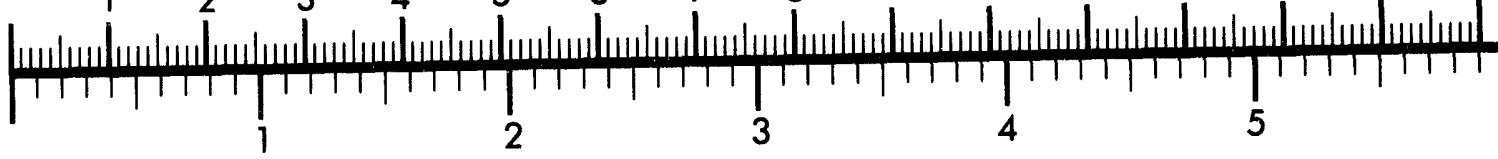
Inches
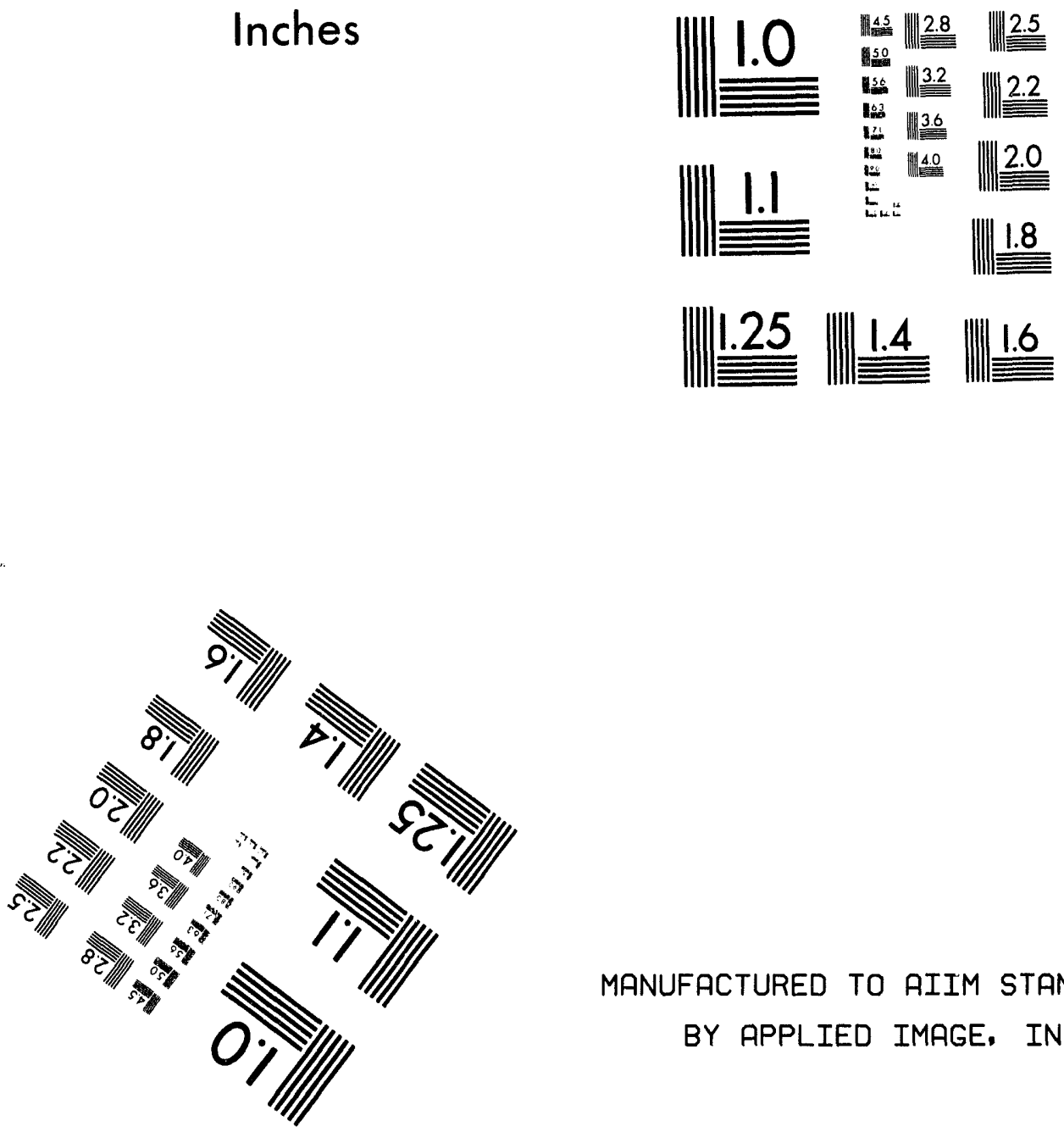

MANUFACTURED TO AIIM STANDARDS BY APPLIED IMAGE, INC.

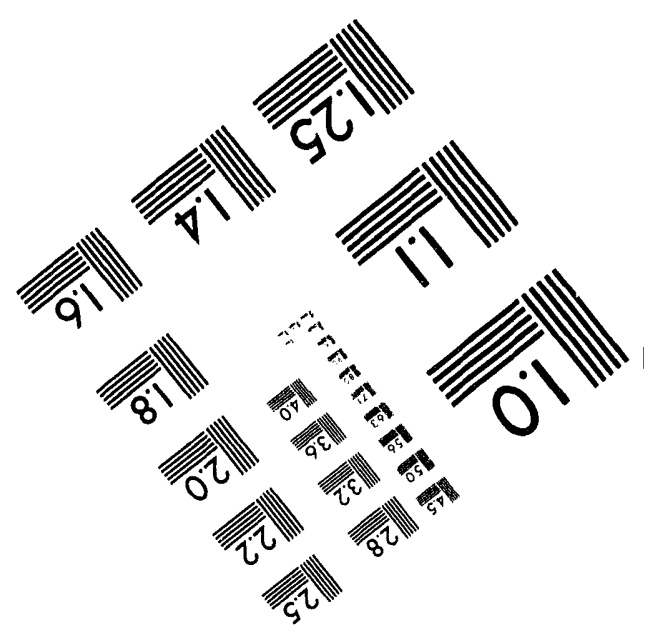



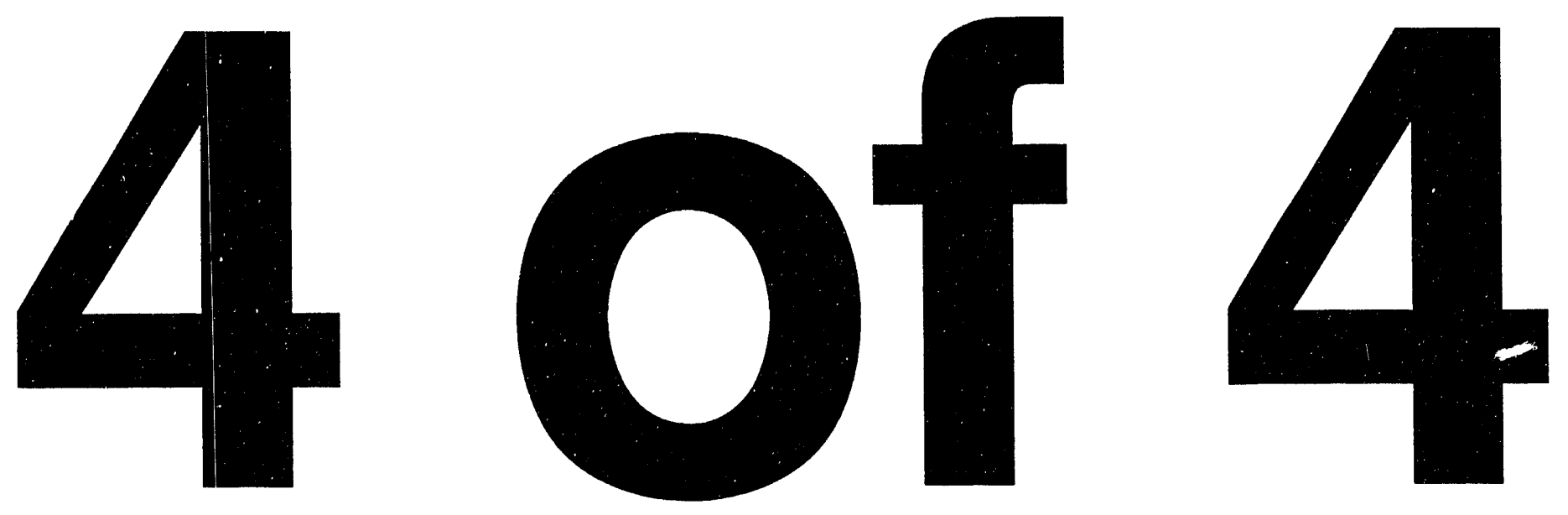
TABLE B-9. Thermal Properties for the Repository Heat-Pipe Problem

\begin{tabular}{|c|c|c|c|c|c|}
\hline \multirow[t]{2}{*}{ UNIT } & \multirow{2}{*}{$\begin{array}{c}\text { GRAIN } \\
\text { DENSITY } \\
\left(\mathrm{kg} / \mathrm{m}^{3}\right)\end{array}$} & \multirow{2}{*}{$\begin{array}{c}\text { SPECIFIC } \\
\text { HEAT } \\
(\mathrm{J} / \mathrm{kg} / \mathrm{C})\end{array}$} & \multirow[t]{2}{*}{ TORTUOSITY } & \multicolumn{2}{|c|}{$\begin{array}{l}\text { FORMATION HEAT } \\
\text { CONDUCTIVITY }\end{array}$} \\
\hline & & & & $\begin{array}{c}\text { Dry } \\
(W / m / C)\end{array}$ & $\begin{array}{c}\text { Wet } \\
(W / m / C)\end{array}$ \\
\hline TCw & 2,580 & 728 & 0.2 & 1.60 & 1.69 \\
\hline PTn & 2,580 & 422 & 0.2 & 0.61 & 0.85 \\
\hline TSw1 & 2,580 & 766 & 0.2 & 1.55 & 1.65 \\
\hline TSw2 & 2,580 & 840 & 0.2 & 2.10 & 2.10 \\
\hline Repository & 2,580 & 840 & 0.2 & 2.10 & 2.10 \\
\hline TSw3 & 2,580 & 948 & 0.2 & 1.26 & 1.28 \\
\hline CHnv & 2,580 & 488 & 0.2 & 0.84 & 1.20 \\
\hline $\mathrm{CHnz}$ & 2,580 & 526 & 0.2 & 0.56 & 1.42 \\
\hline PPW & 2,580 & 639 & 0.2 & 1.35 & 2.00 \\
\hline
\end{tabular}




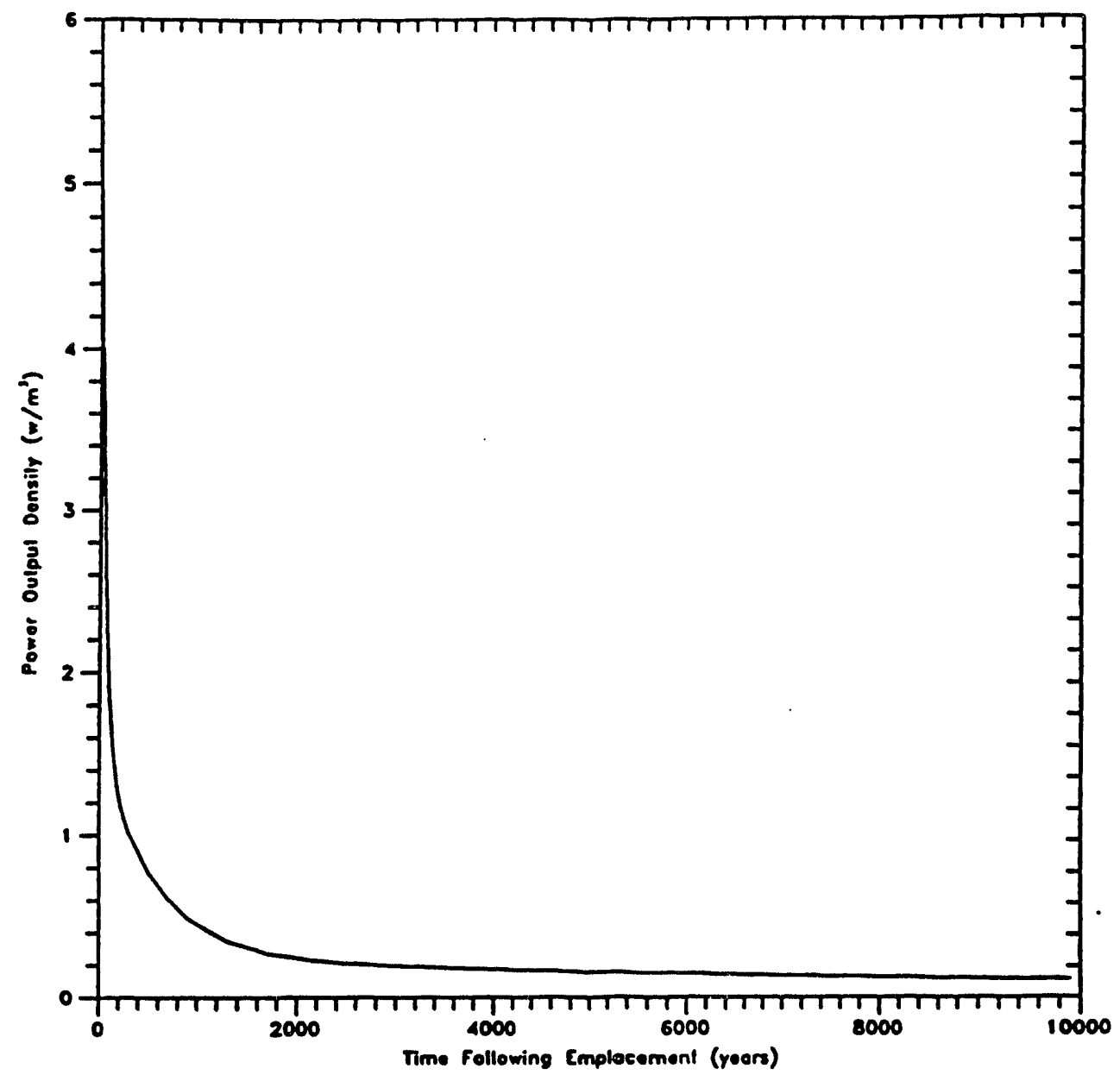

Figure B-7. Heat Source for Repository Heat-Pipe Problem 

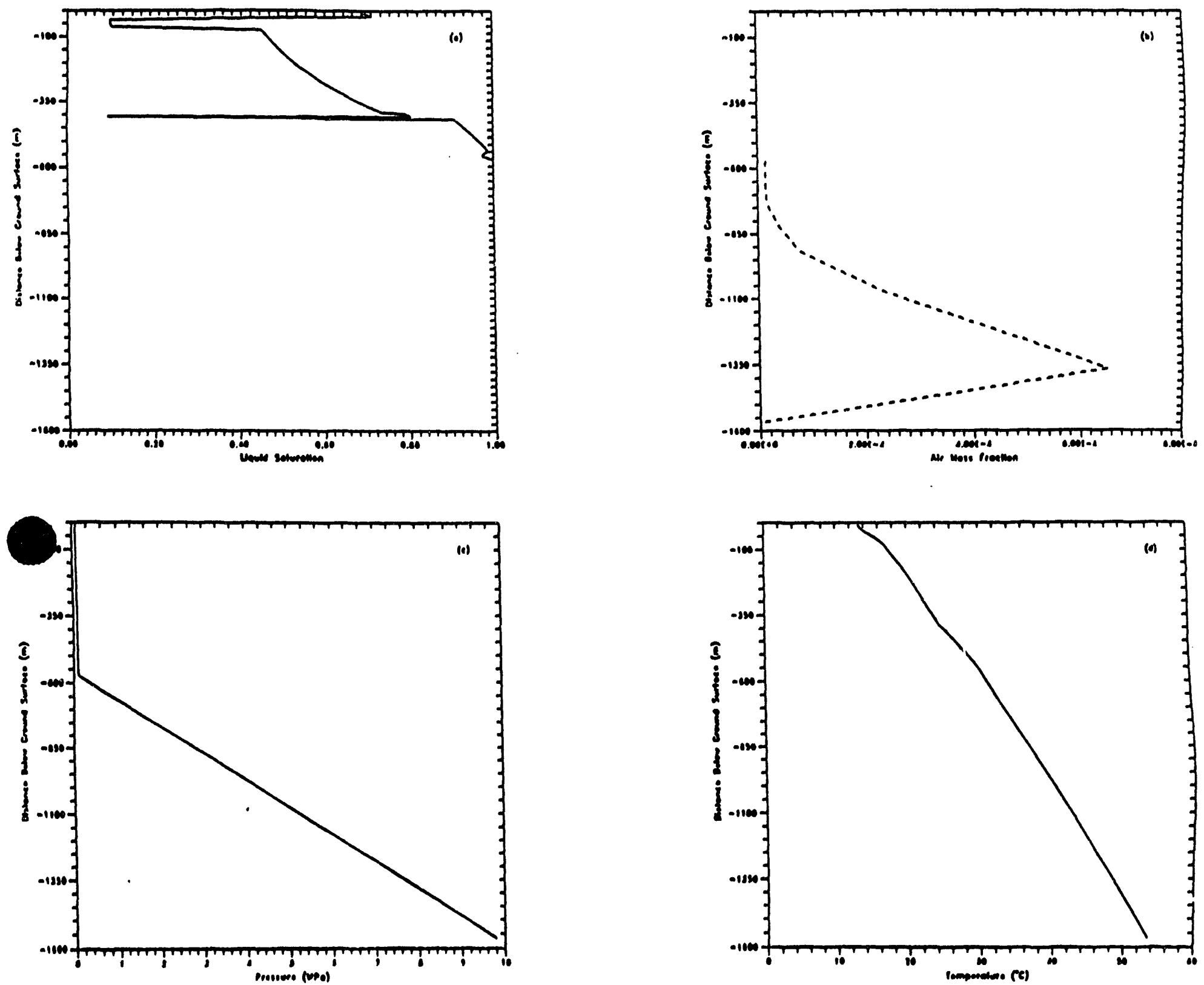

Flgure 8-8. Steady-State, Pre-Emplacement Proliles - Inilial Boundary Condillons for the Repository Heat-Pipe Problem. 
TABLE B-10. Discretization of the Repository Heat-Pipe Problem

\begin{tabular}{|c|c|c|c|c|}
\hline DIMENSION & UNIT & SUBUNIT & NUMBER & $\begin{array}{l}\text { DISCRETIZATION } \\
(\mathrm{m})\end{array}$ \\
\hline \multirow{11}{*}{ Vertical } & $\mathrm{TC}_{\mathrm{w}}$ & & 2 & $7.5,7.15$ \\
\hline & $\mathrm{PT}_{\mathrm{n}}$ & & 3 & $13.0,13.0,12.1$ \\
\hline & $\mathrm{TS}_{\mathrm{w} 1}$ & & 7 & $15.1,15.0,5^{*} 20.0$ \\
\hline & \multirow[t]{3}{*}{$T S_{w 2}$} & & 23 & $\begin{array}{l}15.3,2^{*} 15.0,3^{*} 10.0,8.0, \\
7.0,2^{*} 6.0,5.0,3^{*} 4.0,6 * 3.0, \\
3^{*} 2.0\end{array}$ \\
\hline & & $\begin{array}{l}\text { Repository } \\
\text { Horizon }\end{array}$ & 2 & $2 * 2.3$ \\
\hline & & & 13 & $3^{*} 2.0,6 * 3.0,3^{*} 4.0,5.9$ \\
\hline & $T S_{w s}$ & & 3 & $5.8,2 * 5.0$ \\
\hline & $\mathrm{CH}_{\mathrm{nv}}$ & & 2 & $2 * 2.3$ \\
\hline & $\mathrm{CH}_{\mathrm{nz}}$ & & 13 & $\begin{array}{l}5.0,3 * 6.0,6.7,4 * 8.0,10.0 \\
3 * 20.0\end{array}$ \\
\hline & \multirow[t]{2}{*}{$\mathrm{PP}_{\mathrm{w}}$} & & 2 & $20.0,8.7$ \\
\hline & & $\begin{array}{l}\text { Saturated } \\
\text { Zone }\end{array}$ & 12 & $\begin{array}{l}2.0,4.0,8.0,16.0,30.0 \\
40.0,2^{*} 50.0,2^{*} 100,200 \\
400\end{array}$ \\
\hline \multirow[b]{2}{*}{ Radial } & & $\begin{array}{l}\text { Repository } \\
\text { Columns }\end{array}$ & 10 & $\begin{array}{l}150,120,100,98.5,90.0 \\
80.0,70.0,60.0,50.0,30.0\end{array}$ \\
\hline & & & 20 & $\begin{array}{l}30.0,50.0,60.0,70.0,80.0, \\
90.0,100,120,150,200 \\
250,300,400,600,651.6, \\
800,1200,1800,2700, \\
4500\end{array}$ \\
\hline
\end{tabular}

(a) Notation such as $5^{*} 20.0$ indicates five cells, each with a thickness of $20.0 \mathrm{~m}$. 
(Square-bracketed numbers preceding names indicate number of copies to be sent.)

[1] D. A. Dreyfus (RW-1)

Director

Office of Civilian Radioactive Waste Management

U.S. Department of Energy

1000 Independence Avenue, S.W

Washington, DC 20585

[1] L. H. Barrett (RW-2)

Acting Deputy Director

Office of Civilian Radioactive Waste Management

U.S. Department of Energy

1000 Independence Avenue, S.W.

Washington, DC 20585

[1] J. D. Saltzman (RW-4)

Office of Strategic Planning \& International Programs

Office of Civilian Radioactive Waste Management

U.S. Department of Energy

1000 Independence Avenue, S.W.

Washington, DC 20585

[1] J. D. Saltzman (RW-5)

Office of External Relations

Office of Civilian Radioactive Waste Management

U.S. Department of Energy

1000 Independence Avenue, S.W.

Washington, DC 20585

[1] S. Rousso (RW-10)

Office of Program and Resources Management

Office of Civilian Radioactive Waste Management

U.S. Department of Energy

1000 Independence Avenue, S.W.

Washington, DC 20585

[1] J. C. Bresee (RW-10)

Office of Civilian Radioactive Waste Management

U.S. Department of Energy

1000 Independence Avenue, S.W.

Washington, DC 20585 
[1] R. M. Nelson (RW-20)

Office of Geologic Disposal

Office of Civilian Radioactive Waste Management

U.S. Department of Energy

1000 Independence Avenue, S.W.

Washington, DC 20585

[1] S. J. Brocoum (RW-22)

Analysis and Verification Division

Office of Civilian Radioactive Waste Management

U.S. Department of Energy

1000 Independence Avenue, S.W.

Washington, DC 20585

[1] D. Shelor (RW-30)

Office of Systems and Compliance

Office of Civilian Radioactive Waste Management

U.S. Department of Energy

1000 Independence Avenue, S.W.

Washington, DC 20585

[1] J. Roberts (RW-33)

Director, Regulatory Compliance Division

Office of Civilian Radioactive Waste Management

U.S. Department of Energy

1000 Independence Avenue, S.W.

Washington, DC 20585

[1] G. J. Parker (RW-332)

Regulatory Policy and Requirements Branch

Office of Civilian Radioactive Waste Management

U.S. Department of Energy

1000 Independence Avenue, S.W.

Washington, DC 20585

[1] R. A. Milner (RW-40)

Office of Storage and Transportation

Office of Civilian Radioactive Waste Management

U.S. Department of Energy

1000 Independence Avenue, S.W.

Washington, DC 20585 
(Square-bracketed numbers preceding names

indicate number of copies to be sent.)

[1] S. Rousso (RW-50)

Office of Contract Business Management

Office of Civilian Radioactive Waste Management

U.S. Department of Energy

1000 Independence Avenue, S.W.

Washington, DC 20585

[1] T. Wood (RW-52)

Director, M\&O Management Division

Office of Civilian Radioactive Waste Management

U.S. Department of Energy

1000 Independence Avenue, S.W.

Washington, DC 20585

[4] Victoria F. Reich

Librarian

Nuclear Waste Technical Review Board

1100 Wilson Blvd., Suite 910

Arlington, VA 22209

[1] Dr. C.A.W. Di Bella

Nuclear Waste Technical Review Board

1100 Wilson Blvd., Suite 910

Arlington, VA 22209

[5] R. M. Nelson, Jr

Acting Project Manager

Yucca Mountain Site Characterization Project Office

U.S. Department of Energy

P. O. Box 98608--MS 523

Las Vegas, NV 89193-8608

[1] C. Kouts (RW-4)

Office of Strategic Planning and International Programs

Office of Civilian Radioactive Waste Management

U.S. Department of Energy

1000 Independence Avenue, S.W.

Washington, DC 20585

[1] A. Benson (RW-5)

Office of External Relations

Office of Civilian Radioactive Waste Management

U.S. Department of Energy

1000 Independence Avenue, S.W.

Washington, DC 20585 
(Square-bracketed numbers preceding names

indicate number of copies to be sent.)

[1] L. M. Smith (RW-20)

Office of Geologic Disposal

Office of Civilian Radioactive Waste Management

U.S. Department of Energy

1000 Independence Avenue, S.W.

Washington, DC 20585

[1] J. R. Dyer

Director Regulatory Site Evaluation Division

Yucca Mountain Site Characterization Project Office

U.S. Department of Energy

P.O. Box 98608--MS 523

Las Vegas, NV 89193-8608

[1] J. M. Boak

Chief - Technical Analysis

Yucca Mountain Site Characterization Project Office

U.S. Department of Energy

P.O. Box 98608--MS 523

Las Vegas, NV 89193-8608

[1] S. B. Jones

Acting Director - Regulatory \& Site Evaluation Division

Yucca Mountain Site Characterization Project Office

U.S. Department of Energy

P.O. Box 98608--MS 523

Las Vegas, NV 89193-8608

[1] A. M. Simmons

Technical Analysis Branch

Yucca Mountain Site Characterization Project Office

U.S. Department of Energy

P.O. Box 98608--MS 523

Las Vegas, NV 89193-8608

[1] C. M. Newbury

Technical Analysis Branch

Yucca Mountain Site Characterization Project Office

U.S. Department of Energy

P.O. Box 98608--MS 523

Las Vegas, NV 89193-8608 
(Square-bracketed numbers preceding names indicate number of copies to be sent.)

[1] E. T. Smistad

Technical Analysis Branch

Yucca Mountain Site Characterization Project Office

U.S. Department of Energy

P.O. Box 98608--MS 523

Las Vegas, NV 89193-8608

[1] George Lindenberg

Technical Analysis Branch

Yucca Mountain Site Characterization Project Office

U.S. Department of Energy

P.O. Box 98608--MS 523

Las Vegas, NV 89193-8608

[1] C. L. West

Director, Office of External Affairs

DOE Nevada Operations Office, Nevada

U.S. Department of Energy

P.O. Box 98518

Las Vegas, NV 89193-8518

[8] Technical Information Officer

DOE Nevada Operations Office

U.S. Department of Energy

P.O. Box 98518

Las Vegas, NV 89193-8518

[1] P. K. Fitzsimmons

Technical Advisor

Office of Assistant Manager for Environmental Safety and Health

U.S. DOE/Nevada Operations Office

P.O. Box 98518

Las Vegas, NV 89193-8518

[1] D. R. Elle

Director

Environmental Protection Division

DOE Nevada Operations Office

U.S. Department of Energy

P.O. Box 98518

Las Vegas, NV 89193-8518 
[1] Repository Licensing \& Quality Assurance Project Directorate

Division of Waste Management

U.S. Nuclear Regulatory Commission

Washington, DC 20555

[1] Senior Project Manager for Y.jcca Mountain Repository Project Branch

Division of Waste Managem/nt

U.S. Nuclear Regulatory Commission

Washington, DC 20555

[1] NRC Document Control Desk

Division of Waste Management

U.S. Nuclear Regulatory Commission

Washington, DC 20555

[1] Dick Coddell

U.S. Nuclear Regulatory Commission

Washington, DC 20555

[1] Philip S. Justus

NRC Site Representative

301 E. Stewart Ave., Room 203

Las Vegas, NV 89101

[1] E. P. Binnall

Field Systems Group Leader

Lawrence Berkeley Laboratory

Building 50B/4235

Berkeley, CA 94720

[1] G. S. Bodvarsson

Lawrence Berkeley Laboratory

1 Cyclotron Road

Berkeley, CA 94720

[1] Karston Pruess

Lawrence Berkeley Laboratory

1 Cyclotron Road

Berkeley, CA 94720

[1] Joe Wang

Lawrence Berkeley Laboratory

1 Cyclotron Road

Berkeley, CA 94720 
[1] Yvonne W. Tsang

Lawrence Berkeley Laboratory

1 Cyclotron Road

Berkeley, CA 94720

[1] Chin-Fu Tsang

Lawrence Berkeley Laboratory

1 Cyclotron Road

Berkeley, CA 94720

[1] Bob Zimmerman

Lawrence Berkeley Laboratory

1 Cyclotron Road

Berkeley, CA 94720

[1] Center for Nuclear Waste Regulatory Analyses

6220 Culebra Road, Drawer 28510

San Antonio, TX 78284

[3] W. L. Clarke

Technical Project Officer for YMP

Lawrence Livermore National Laboratory

Attn: YMP/LRC - P.O. Box 5514

Livermore, CA 94551

[1] J. A. Blink

Deputy Project Leader

Lawrence Livermore National Laboratory

101 Convention Center Drive, Suite 820, MS 527

Las Vegas, NV 89109

[1] T. A. Buscheck

Lawrence Livermore National Laboratory

Attn: YMP/LRC - P.O. Box 5514

Livermore, CA 94551

[1] Dwayne Chesnut

Lawrence Livermore National Laboratory

Attn: YMP/LRC - P.O. Box 5514

Livermore, CA 94551

[1] John Nitao

Lawrence Livermore National Laboratory

Attn: YMP/LRC - P.O. Box 5514

Livermore, CA 94551 
[1] W. G. Halsey

Lawrence Livermore National Laboratory

Attn: YiAP/LRC - P.O. Box 5514

Livermore, CA 94551

[4] J. A. Canepa

Technical Project Officer for YMP

Los Alamos National Laboratory

P.O. Box 2663 - EES-13, Mail Stop J521

Los Alamos, NM 87545

[1] K. H. Birdsell

Los Alamos National Laboratory

P.O. Box 1663 - EES-13, Mail Stop J521

Los Alamos, NM 87545

[1] H. N. Kalia

Project Leader for ESF Test Coordination

Los Alamos National Laboratory

101 Convention Center Drive, Suite 820, Mail Stop 527

Las Vegas, NV 89101

[1] N. Z. Elkins

Deputy Technical Project Officer

Los Alamos National Laboratory

101 Convention Center Drive, Suite 820,Mail Stop 527

Las Vegas, NV 89101

[1] Carl Gable

Los Alamos National Laboratory

P.O. Box 1663, EES-13, Mail Stop J521

Los Alamos, NM 87545

[1] Brian J. Travis

Los Alamos National Laboratory

P.O. Box 1663, Mail Stop F665

Los Alamos, NM 87545

[1] George Zyvoloski

Los Alamos National Laboratory

P.O. Box 1663, Mail Stop F665

Los Alamos, NM 87545 
(Square-bracketed numbers preceding names

indicate number of copies to be sent.)

[2] L. E. Shephard

Technical Project Officer for YMP

Sandia National Laboratories

Organization 6310 - P.O. Box 5800

Albuquerque, NM 87185

[1] George Barr

Sandia National Laboratories

Organization 6310 - P.O. Box 5800

Albuquerque, NM 87185

[1] Roger R. Eaton

Sandia National Laboratories

P.O. Box 5800, MS 827

Albuquerque, NM 87185-0827

[1] Cliff Ho

Sandia National Laboratories

P.O. Box 5800, MS 827

Albuquerque, NM 87185-0827

[1] Mario J. Martinez

Sandia National Laboratories

P.O. Box 5800, MS 827

Albuquerque, NM 87185-0827

[1] James T. McCord

Sandia National Laboratories

P.O. Box 5800, MS 1350

Albuquerque, NM 87185-1350

[1] W. G. Perkins

Sandia National Laboratories

P.O. Box 5800, MS 1350

Albuquerque, NM 87185-1350

[1] E. E. Ryder

Sandia National Laboratories

Organization 6310 - P.O. Box 5800

Albuquerque, NM 87185

[1] M. L. Wilson

Sandia National Laboratories

Organization 6310 - P.O. Box 5800

Albuquerque, NM 87185 
[1] L. Anna

U.S. Geological Survey

P.O. Box 25046 - Denver Federal Center

Lakwood, CO 80225

[1] M. Chornack

U.S. Geological Survey

P.O. Box 25046 - Denver Federal Center

Lakwood, CO 80225

[1] J. F Devine

Assistant Director for Engineering Geology

U.S. Geological Survey

106 National Center - 12201 Sunrise Valley Drive

Reston, VA 22092

[1] D. Gillies

U.S. Geological Survey

P.O. Box 25046 - Denver Federal Center

Lakwood, CO 80225

[1] L. R Hayes

Technical Project Officer

U.S. Geological Survey

P.O. Box 25046 - Denver Federal Center

Lakwood, CO 80225

[1] R. W. Healy

U.S. Geological Survey

P.O. Box 25046, Denver Federal Center MS 413

Lakewood, CO 80225

[1] Edward Kwicklis

U.S. Geological Survey

P.O. Box 25046, Denver Federal Center MS 421

Lakewood, CO 80225

[1] V. R. Schneider

Asst. Chief Hydrologist

Office of Program Coordination \& Technical Support

U.S. Geological Survey

12201 Sunrise Valley Drive--MS 414

Reston, VA 22092 
(Square-bracketed numbers preceding names indicate number of copies to be sent.)

[1] J. S. Stuckless

Geologic Division Coordinator

Yucca Mountain Project

U.S. Geological Survey

P.O. Box 25046--MS 913

Lakewood, CO 80225

[1] D. H. Appel

Chief

Hydrologic Investigations Progic:?

U.S. Geological Survey

P.O. Box 25046--MS 421

Denver, CO 80225

[1] E. J. Helley

Branch of Western Regional Geology

U.S. Geological Survey

345 Middlefield Road--MS 427

Menlo Park, CA 94025

[1] R. W. Craig

Chief

Nevada Operations Office

U.S. Geological Survey

101 Convention Center Drive, Suite 860, MS 509

Las Vegas, NV 89109

[1] Dwight Hoxie

U.S. Geological Survey

101 Convention Center Drive, Suite 860, MS 509

Las Vegas, NV 89109

[1] D. Zesiger

U.S. Geological Survey

101 Convention Center Drive, Suite 860, MS 509

Las Vegas, NV 89109

[1] G. L. Ducret

Associate Chief

Yucca Mountain Project Division

U.S. Geological Survey

P.O. Box 25046 - 421 Federal Center

Denver, CO 80225 
[1] A. L. Flint

U.S. Geological Survey

P.O. Box 327--MS 721

Mercury, NV 89023

[1] D. A. Beck

Water Resources Division

U.S. Geological Survey

6770 So. Paradise Road

Las Vegas, NV 89119

[1] P. A. Glancy

U.S. Geological Survey

Federal Building, Room 224

Carson City, NV 89701

[1] Sherman S. C. Wu

Branch of Astrogeology

U.S. Geological Survey

2255 N. Gemini Dr.

Flagstaff, AZ 86001

[1] J. H. Sass

Branch of Tectonophysics

U.S. Geological Survey

2255 N. Gemini Dr.

Flagstaff, AZ 86001

[1] DeWayne Campbell

Technical Project Officer for YMP

U.S. Bureau of Reclamation

P.O. Box 25007 -Code D-3790

Denver, CO 80225

[1] J. M. LaMonaca

Records Specialist

U.S. Geological Survey

421 Federal Center - P.O. Box 25046

Lakewood, CO 80225

[1] W. R. Keefer

U.S. Geological Survey

913 Federal Center - P.O. Box 25046

Denver, CO 80225 
(Square-bracketed numbers preceding names indicate number of copies to be sent.)

[1] M. D. Voegele

Technical Project Officer for YMP

Science Applications International Corp

101 Convention Center Dr., Suite 407

Las Vegas, NV 89109

[2] L. D. Foust

Nevada Site Manager

TRW Environmental Safety Systems

101 Convention Center Drive--MS 423

Las Vegas, NV 89109

[1] C. E. Ezra

YMP Support Office Manager

EG\&G Energy Measurements, Inc

MS V-02

P.O. Box 1912

Las Vegas, NV 89125

[1] Swen O. Magnuson

EG\&G

Box 1625

Idaho Falls, ID 83415

[1] E. L. Snow

Program Manager

Roy F. Weston, Inc

955 L'Enfant Plaza, S.W.

Washington, DC 20024

[1] Technical Information Center

Roy F. Weston, Inc

955 L'Enfant Plaza, S.W.

Washington, DC 20024

[1] D. Hedges

Vice President

Quality Assurance

Roy F. Weston, Inc

4425 Spring Mountain Road, Suite 300

Las Vegas, Nevada 89102 
(Square-bracketed numbers preceding names indicate number of copies to be sent.)

[1] D. L. Fraser

General Manager

Reynolds Electrical \& Engineering Co., Inc

P.O. Box 98521 - MS 555

Las Vegas, NV 89193-8521

[1] R. F. Pritchett

Technical Project Officer for YMP

Reynolds Electrical \& Engineering Co., Inc

P.O. Box 98521- MS 408

Las Vegas, NV 89193-8521

[1] B. W. Colston

President/General Minager

Las Vegas Branch

Raytheon Services Nevada

P.O. Box 95487 - MS 416

Las Vegas, NV 89193-5487

[1] R. L. Bullock

Technical Project Officer for YMP

Raytheon Services Nevada

101 Convention Center Dr. - MS 403

Las Vegas, NV 89109

[1] Paul Eslinger

Pacific Northwest Laboratories

P.O. Box 999

Richland, WA 99352

[1] D. W. Engel

Pacific Northwest Laboratories

P. O. Box 999

Richland, WA 99352

[1] Mark White

Pacific Northwest Laboratories

P. O. Box 999

Richland, WA 99352 
[1] A. T. Tamura

Science and Technology Division

Office of Scientific and Technical Information

U.S. Department of Energy

P.O. Box 62

Oak Ridge, TN 37831

[1] Carlos G. Bell, Jr.

Professor of Civil Engineering

Civil and Mechanical Engineering Dept

University of Nevada, Las Vegas

4505 So. Maryland Parkway

Las Vegas, NV 89154

[1] P. J. Weeden

Acting Director

Nuclear Radiation Assessment Division

Environmental Monitoring Systems Laboratory

U.S. Environmental Protection Agency

P.O. Box 93478

Las Vegas, NV 89193-3478

[1] ONWI Library

Office of Nuclear Waste Isolation

Battelle Columbus Laboratory

505 King Ave.

Columbus, $\mathrm{OH} 43201$

[1] T. Hay

Executive Assistant

Office of the Governor

State of Nevada

Capitol Complex

Carson City, NV 89710

[3] R. R. Loux

Executive Director

Agency for Nuclear Projects

State of Nevada

Evergreen Center, Suite 252

1802 N. Carson St.

Carson City, NV 89710 
[1] C. H. Johnson

Technical Program Manager

Agency for Nuclear Projects

State of Nevada

Evergreen Center, Suite 252

1802 N. Carson St.

Carson City, NV 89710

[1] John Fordham

Water Re:sources Center

Desert Research Institute

P.O. Box 60220

Reno, NV 89506

[1] David Rhode

Desert Research Institute

P.O. Box 60220

Reno, NV 89506

[1] Eric Anderson

Mountain West Research-Southwest, Inc

2901 N. Central Ave., \#1000

Phoenix, AZ 85012-2730

[1] The Honorable Cyril Schank

Chairman

Churchill County Board of Commissioners

190 W. First St.

Fallon, NV 89406

[1] Dennis A Bechtel

Coordinator

Nuclear Waste Division

Clark County Department of Comprehensive Planning

301 E. Clark Ave., Suite 570

Las Vegas, NV 89101

[1] Juanita D. Hoffman

Nuclear Waste Repository Oversight Program

Esmeralda County

P.O. Box 490

Goldfield, NV 89013 
(Square-bracketed numbers preceding names indicate number of copies to be sent.)

[1] Eureka County Board of Commissioners

Yucca Mountain Information Office

P.O. Box 714

Eureka, NV 89316

[1] Brad R Mettam

Yucca Mountain Repository Assessment Office

Inyo County

P.O. Drawer L

Independence, CA 93526

[1] Lander County Board of Commissioners

315 South Humboldt St.

Battle Mountain, NV 89820

[1] Jason Pitts

Nuclear Waste Project Office

Lincoln County

P.O. Box 90

Pioche, NV 89043

[1] Judy Foremaster

Nuclear Waste Project Office

City of Caliente

P.O. Box 158

Caliente, NV 89008

[1] Vernon E. Poe

Office of Nuclear Projects

Mineral County

P.O. Box 1600

Hawthome, NV 89415

[1] Les W. Bradshaw

Program Manager

Nuclear Waste Repository Project Office

Nye County

P.O. Box 2389

Pahrump, NV 89041

[1] William Offutt

Manager

Nye County

P.O. Box 153

Tonopah, NV 89049 
(Square-bracketed numbers preceding names indicate number of copies to be sent.)

[1] Phihip. A. Niedzielski-Eichner

Nuclear Waste Repository Project Office

Nye County

P.O. Box 221274

Chantilly, VA 22022-1274

[1] Florindo Mariani

Coordinator

White Pine County

P.O. Box. 135

Ely, NV 89301

[1] Glenn Van Roekel

Director of Community Development

City of Caliente

P.O. Box 158

Caliente, NV 89008

[1] Ray Williams, Jr.

P.O. Box 10

Austin, NV 89310

[1] Charles Thistlethwaite, AICP

Associate Planner

Planning Department

Inyo County

Drawer L

Independence, CA 93526

[1] Nye County District Attorney

P.O. Box 593

Tonopah, NV 89049

[1] Economic Development Department

City of Las Vegas

400 E. Stewart Ave.

Las Vegas, NV 89101

[1] Community Planning and Development

City of North Las Vegas

P.O. Box 4086

North Las Vegas, NV 89030 
[1] Community Development and Planning

City of Boulder City

P.O. Box 61350

Boulder City, NV 89006

[1] Commission of the European Communities

200 Rue de la Loi

B-1049 Brussells, BELGIUM

[2] M.J. Dorsey

Librarian

YMP Research and Study Center

Reynolds Electrical \& Engineering Co., Inc

P.O. Box 98521--MS 407

Las Vegas, NV 89193-8521

[1] Amy Anderson

Argonne National Laboratory

9700 So. Cass Ave.--Building 362

Argonne, IL 60439

[1] Steve Bradhurst

P.O. Box 1510

Reno, NV 89505

[1] Michael L. Baughman

35 Clark Road

Fiskdale, MA 01518

[1] Dr. Moses Karakouzian

1751 E. Reno, \#125

Las Vegas, NV 89119

[1] John F. Ahearne

Sigma Xi

The Scientific Research Society

99 Alexander Drive, P.O. Box 13975

Research Triangle Park, NC 27709

[1] Jean M. Bahr

Department of Geology and Geophysics

University of Winsconsin-Madison

1215 West Dayton Street--Weeks Hall

Madison, WI 53706 
(Square-bracketed numbers preceding names

indicate number of copies to be sent.)

[1] R. Darryl Banks

World Resources Institute

1700 New York Avenue, N. W.

Washington, DC 20006

[1] Robert J. Budnitz

Future Resources Associates

2000 Center Street, Suite 418

Berkeley, CA 94704

[1] Sol Burstein

7475 North Crossway Road

Milwaukee, WI 53217

[1] Melvin W Carter

4621 Ellisbury Drive

Atlanta, GA 30338

[1] Charles Fairhurst

Department of Civil and Mineral Engineering

University of Minnesota

Minniapolis, MN 55455

[1] Charles McCombie

NAGRA

Hardstrasse 73, CH-5430

Wettingen, Switzerland

[1] P. Zuidema

NAGRA

Hardstrasse 73, CH-5430

Wettingen, Switzerland

[1] M. Thury

NAGRA

Hardstrasse 73, $\mathrm{CH}-5430$

Wettingen, Switzerland

[1] S. Vomvoris

NAGRA

Hardstrasse 73, CH-5430

Wettingen, Switzerland 
(Square-bracketed numbers preceding names indicate number of copies to be sent.)

[1] Fred M. Phillips

Geoscience Department

New Mexico Institute of

Mining \& Technology

Socorro, NM 87801

[1] Thomas H. Pigford

College of Engineering

Department of Nuclear Engineering

University of California Berkeley

Berkeley, CA 94720

[1] Arthur C. Uptoe

1424 Seville Road

Santa Fe, NM 87501

[1] Chris Whipple

ICF Kaiser Engineers

Environment Group

1800 Harrison Street, 7th Floor

Oakland, CA 94612-3430

[1] Gilbert F. White

Institute of Behavioral Science

University of Colorado

Campus Box 482

Boulder, CO 80309-0482

[1] Susan D. Wiltshire

J. K. Associates

P.O. Box 2219

Hamilton, MA 01982

[1] Les W. Bradshaw

Program Manager

Nuclear Waste Repository Program

Nye County

P. O. Box 1767

Tonopah, NV 89049 
(Square-bracketed numbers preceding names

indicate number of copies to be sent.)

[1] J. William Gunter

Director

Criteria \& Standards Division

Office of Radiation a.:d Indoor Air

U. S. Environmental Protection Agency

401 M. Street, S. W.

Washington, DC 20460

[1] Margaret Federline

Chief, Hydrology and Systems Performance Branch

U. W. Nuclear Regulatory Commission

High-Level Waste Management Division

11555 Rockville Pike

Rockville, MD 20552

[1] Mark Ankeny

Daniel B. Stephens Associates

6020 Academy NE, Suite 100

Alburquerque, NM 87109

[1] W. S. Dershowitz

Golder Associates Inc.

4104 148th Avenue NE

Redmond, WA 98052

[1] P. Wallmann

Golder Associates Inc.

4104 148th Avenue NE

Redmond, WA 98052

[1] P. LaPoint

Golder Associates Inc.

4.04 148th Avenue NE

Redmond, WA 98052

[1] T. Doe

Golder Associates Inc.

4104 148th Avenue NE

Redmond, :VA 98052

[1] Barry W. Dial

Golder Associates Inc.

1451 Harbor Bay Pkwy, Suite 1000

Alameda, CA 94501 
(Square-bracketed numbers preceding names indicate number of copies to be sent.)

[1] Wesley C. Patrick

Center for Nuclear Waste Regulatory Analyses

6220 Culebra Road

San Antonio, TX 78238-5116

[1] Lynn B. Reid

Department of Civil Engineering

Massachutetts Institute of Technology

Bldg. 48, Rm. 212

Cambridge, MA 02139

[1] Benjamin Ross

Disposal Safety Inc.

1211 Connecticut Avenue, Suite 610

Washington, DC 20036

[1] Patrick Domenico

Geology Department

Texas A\&M University

College Station, TX 77843

[1] Allan Freeze

3755 Nico Wynd Dr.

White Rock, British Columbia

V4A 5Z4 Canada

[1] Lin Gelhar

Department of Civil Engineering

Massachusetts Institute of Technology

Rm 48-329

Cambridge, MA 02139

[1] Dr. S. O. Durrant

Chairman

Civil Engineering Dept.

Brigham Young University

368 Clyde Bldg.

Provo, Utah 84602

[1] Dr. Wayne Downs

Brigham Young University

368 Clyde Blig.

Provo, Utah 84602 
[1] Dr. N. L. Jones

G.M.S. Project Director

Brigham Young University

368 Clyde Bldg.

Provo, Utah 84602

[1] Casey Miller

Dept. of Environmental

Science \& Engineering

114 Rosenau Hall CB 7400

Chapel Hill, NC 27599-7400

[1] Solomo Neuman

Dept. of Hydrology \& Water Resources

University of Arizona

Tucson, Arizona 85721

[1] Stavros Papadopulos

Papadopulos and Associates

8216 Scotch Bend Way

Potomic, MD 20854

[1] George Pinder

Dean

College of Engineering \& Math

University of Vermont

101 Voley Building

Burlington, VT 05405

[1] John B. Robertson

Hydrogeolic, Inc.

503 Carlisle Dr., Suite 250

Herndon, VA 22070

[1] Frank Schwartz

Geological Sciences Dept.

Ohio State University

1090 Carmack Rd. - 183 Scott Hall

Columbus, $\mathrm{OH} 42210$

[1] William Walton

Rural Route 5 - Box 131

Mahomet, IL 61853 
(Square-bracketed numbers preceding names indicate number of copies to be sent.)

[1] Marty Altenhofen

Waste Management Consultant

2000 Logston Blvd.

Richland, WA 99352

[25] Noreen A. Baker

INTERA, Inc.

Management and Operating Contractor

6850 Austin Center Blvd, Suite 300

Austin, TX 78731

[1] T. F. Dale

Performance Assessment

Civilian Radioactive Waste Management System

Management and Operating Contractor

6850 Austin Center Blvd

Austin, TX 78731

[1] J. A. McNeish

Performance Assessment

Civilian Radioactive Waste Management System

Management and Operating Contractor

14900 Landmark blvd., Suite 365

Dallas, TX 75240

[1] Suresh Pahwa

Performance Assessment

Civilian Radioactive Waste Management System

Management and Operating Contractor

6850 Austin Center Blvd

Austin, TX 78731

[25] Mark Reeves

Performance Assessment

Civilian Radioactive Waste Management System

Management and Operating Contractor

6850 Austin Center Blvd

Austin, TX 78731

[25] J. O. Duguid

Performance Assessment

Civilian Radioactive Waste Management System

Management and Operating Contractor

2650 Park Tower Drive, Suite 800

Vienna, VA 22180 
DISTRIBUTION LIST--April 4, 1994

(Square-bracketed numbers preceding names

indicate number of copies to be sent.)

[1] J. O. Cowles

Chief Engineer

Civilian Radioactive Waste Management System

Management and Operating Contractor

2650 Park Tower Drive, Suite 800

Vienna, VA 22180

[1] D. F. Fenster

Requirements and Licensing

Civilian Radioactive Waste Management System

Management and Operating Contractor

2650 Park Tower Drive, Suite 800

Vienna, VA 22180

[1] R. W. Godman

Assistant General Manager, Operations

Civilian Radioactive Waste Management System

Management and Operating Contractor

2650 Park Tower Drive, Suite 800

Vienna, VA 22180

[1] A. B. Greenberg

Senior Staff

Civilian Radioactive Waste Management System

Management and Operating Contractor

2650 Park Tower Drive, Suite 800

Vienna, VA 22180

[1] C. A. Heath

Senior Staff

Civilian Radioactive Waste Management System

Management and Operating Contractor

2650 Park Tower Drive, Suite 800

Vienna, VA 22180

[1] A.S. Kubo

Assistant General Manager, Systems

Civilian Radioactive Waste Management System

Management and Operating Contractor

2650 Park Tower Drive, Suite 800

Vienna, VA 22180 
(Square-bracketed numbers preceding names indicate number of copies to be sent.)

[1] J. R. Levine

Communications

Civilian Radioactive Waste Management System

Management and Operating Contractor

2650 Park Tower Drive, Suite 800

Vienna, VA 22180

[1] J. J. Miller

Systems Engineering

Civilian Radioactive Waste Management System

Management and Operating Contractor

2650 Park Tower Drive, Suite 800

Vienna, VA 22180

[1] L. D. Ramspott

Senior Staff

Civilian Radioactive Waste Management System

Management and Operating Contractor

2650 Park Tower Drive, Suite 800

Vienna, VA 22180

[1] L. D. Rickertsen

Senior Staff

Civilian Radioactive Waste Management System

Management and Operating Contractor

2650 Park Tower Drive, Suite 800

Vienna, VA 22180

[1] Frank Ridolphi

Strategic Planning

Civilian Radioactive Waste Management System

Management and Operating Contractor

2650 Park Tower Drive, Suite 800

Vienna, VA 22180

[1] R. L. Robertson

General Manager

Civilian Radioactive Waste Management System

Management and Operating Contractor

2650 Park Tower Drive, Suite 800

Vienna, VA 22180 
DISTRIBUTION LIST--April 4, 1994

(Square-bracketed numbers preceding names

indicate number of copies to be sent.)

[1] S. S. Sareen

Senior Staff

Civilian Radioactive Waste Management System

Management and Operating Contractor

2650 Park Tower Drive, Suite 800

Vienna, VA 22180

[1] E. C. Taylor

Chiê Scientist

Civilian Radioactive Waste Management System

Management and Operating Contractor

2650 Park Tower Drive, Suite 800

Vienna, VA 22180

[1] Albin Brandstetter

Performance Assessment

Civilian Radioactive Waste Management System

Management and Operating Contractor

101 Convention Center Drive, Suite P110

Las Vegas, Nevada 89109-2006

[1] E. R. Brandstetter

Performance Assessment

Civilian Radioactive Waste Management System

Management and Operating Contractor

101 Convention Center Drive, Suite P110

Las Vegas, Nevada 89109-2006

[1] T. C. Geer

Systems Engineering

Civilian Radioactive Waste Management System

Management and Operating Contractor

101 Convention Center Drive, Suite P110

Las Vegas, Nevada 89109-2006

[1] J. E. Houseworth

Performance Assessment

Civilian Radioactive Waste Management System

Management and Operating Contractor

101 Convention Center Drive, Suite P110

Las Vegas, Nevada 89109-2006 
(Square-bracketed numbers preceding names indicate number of copies to be sent.)

[1] Suresh Lingineni

Performance Assessment

Civilian Radioactive Waste Management System

Management and Operating Contractor

101 Convention Center Drive, Suite P110

Las Vegas, Nevada 89109-2006

[1] M. A. Lugo

Regulatory and Licensing

Civilian Radioactive Waste Management System

Management and Operating Contractor

101 Convention Center Drive, Suite P110

Las Vegas, Nevada 89109-2006

[1] E. B. Mann

Performance Assessment

Civilian Radioactive Waste Management System

Management and Operating Contractor

101 Convention Center Drive, Suite P110

Las Vegas, Nevada 89109-2006

[1] Richard Memory

Systems Analysis

Civilian Radioactive Waste Management System

Management and Operating Contractor

101 Convention Center Drive, Suite P110

Las Vegas, Nevada 89109-2006

[1] Srikanta Mishra

Performance Assessment

Civilian Radioactive Waste Management System

Management and Operating Contractor

101 Convention Center Drive, Suite P110

Las Vegas, Nevada 89109-2006

[1] R. W. Nelson

Performance Assessment

Civilian Radioactive Waste Management System

Management and Operating Contractor

101 Convention Center Drive, Suite P110

Las Vegas, Nevada 89109-2006 
(Square-bracketed numbers preceding names indicate number of copies to be sent.)

[1] S. P. Nesbit

Regulatory and Licensing

Civilian Radioactive Waste Management System

Management and Operating Contractor

101 Convention Center Drive, Suite P110

Las Vegas, Nevada 89109-2006

[1] E. K. Paleologos

Performance Assessment

Civilian Radioactive Waste Management System

Management and Operating Contractor

101 Convention Center Drive, Suite P110

Las Vegas, Nevada 89109-2006

[1] M. W. Pendleton

Technical Evaluation

Civilian Radioactive Waste Management System

Management and Operating Contractor

101 Convention Center Drive, Suite P110

Las Vegas, Nevada 89109-2006

[1] R. D. Rogers

Technical Evaluation

Civilian Radioactive Waste Management System

Management and Operating Contractor

101 Convention Center Drive, Suite P110

Las Vegas, Nevada 89109-2006

[1] D. C. Sassani

Performance Assessment

Civilian Radioactive Waste Management System

Management and Operating Contractor

101 Convention Center Drive, Suite P110

Las Vegas, Nevada 89109-2006

[1] S. F. Saterlie

Systems Analysis

Civilian Radioactive Waste Management System

Management and Operating Contractor

101 Convention Center Drive, Suite P110

Las Vegas, Nevada 89109-2006 
DISTRIBUTION LIST--April 4, 1994

31 of 32

(Square-bracketed numbers preceding names indicate number of copies to be sent.)

[1] Scott Sinnock

Senior Staff

Civilian Radioactive Waste Management System

Management and Operating Contractor

101 Convention Center Drive, Suite P110

Las Vegas, Nevada 89109-2006

[1] A. J. Smith

Performance Assessment

Civilian Radioactive Waste Management System

Management and Operating Contractor

101 Convention Center Drive, Suite P110

Las Vegas, Nevada 89109-2006

[1] R. K. St. Clair

Regulatory Management and Integration

Civilian Radioactive Waste Management System

Management and Operating Contractor

101 Convention Center Drive, Suite P110

Las Vegas, Nevada 89109-2006

[1] David Stahl

Waste Package Design

Civilian Radioactive Waste Management System

Management and Operating Contractor

101 Convention Center Drive, Suite P110

Las Vegas, Nevada 89109-2006

[1] C. T. Statton

Site Characterization

Civilian Radioactive Waste Management System

Management and Operating Contractor

101 Convention Center Drive, Suite P110

Las Vegas, Nevada 89109-2006

[1] B. H. Thompson

Systems Analysis

Civilian Radioactive Waste Management System

Management and Operating Contractor

101 Convention Center Drive, Suite P110

Las Vegas, Nevada 89109-2006 
DISTRIBUTION LIST--April 4, 1994

32 of 32

(Square-bracketed numbers preceding names

indicate number of copies to be sent.)

[1] F. C. Tsai

Performance Assessment

Civilian Radioactive Waste Management System

Management and Operating Contractor

101 Convention Center Drive, Suite P110

Las Vegas, Nevada 89109-2006

[1] A. E. Van Luik

Performance Assessment Management \& Integration

Civilian Radioactive Waste Management System

Management and Operating Contractor

101 Convention Center Drive, Suite P110

Las Vegas, Nevada 89109-2006

[1] R. G. Vawter

Deputy for Management and Integration

Civilian Radioactive Waste Management System

Management and Operating Contractor

101 Convention Center Drive, Suite P110

Las Vegas, Nevada 89109-2006

[1] E. M. Weaver

Regulatory Management and Integration

Civilian Radioactive Waste Management System

Management and Operating Contractor

101 Convention Center Drive, Suite P110

Las Vegas, Nevada 89109-2006

[1] J. L. Younker

Regulatory and Technical Evaluation

Civilian Radioactive Waste Management System

Management and Operating Contractor

101 Convention Center Drive, Suite P110

Las Vegas, Nevada 89109-2006 

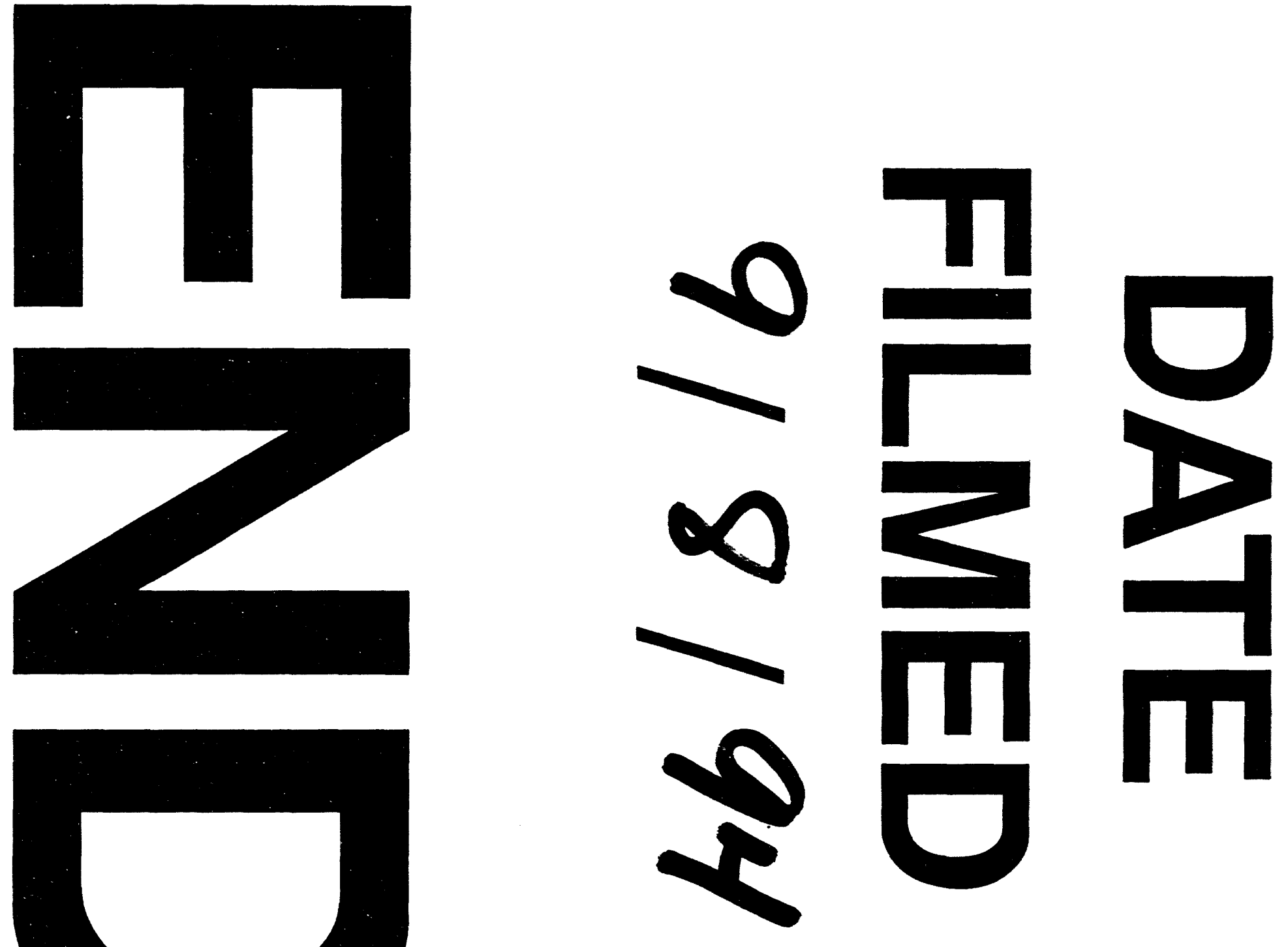
